\title{
A collaborative approach to tailored whole-school health promotion : the schoolBeat study
}

Citation for published version (APA):

Leurs, M. T. W. (2008). A collaborative approach to tailored whole-school health promotion : the schoolBeat study. [Doctoral Thesis, Maastricht University]. Universiteit Maastricht. https://doi.org/10.26481/dis.20080516ml

Document status and date:

Published: 01/01/2008

DOI:

10.26481/dis.20080516ml

Document Version:

Publisher's PDF, also known as Version of record

\section{Please check the document version of this publication:}

- A submitted manuscript is the version of the article upon submission and before peer-review. There can be important differences between the submitted version and the official published version of record. People interested in the research are advised to contact the author for the final version of the publication, or visit the DOI to the publisher's website.

- The final author version and the galley proof are versions of the publication after peer review.

- The final published version features the final layout of the paper including the volume, issue and page numbers.

Link to publication

\footnotetext{
General rights rights.

- You may freely distribute the URL identifying the publication in the public portal. please follow below link for the End User Agreement:

www.umlib.nl/taverne-license

Take down policy

If you believe that this document breaches copyright please contact us at:

repository@maastrichtuniversity.nl

providing details and we will investigate your claim.
}

Copyright and moral rights for the publications made accessible in the public portal are retained by the authors and/or other copyright owners and it is a condition of accessing publications that users recognise and abide by the legal requirements associated with these

- Users may download and print one copy of any publication from the public portal for the purpose of private study or research.

- You may not further distribute the material or use it for any profit-making activity or commercial gain

If the publication is distributed under the terms of Article $25 \mathrm{fa}$ of the Dutch Copyright Act, indicated by the "Taverne" license above, 
A collaborative approach to tailored whole-school health promotion

- the schoolBeat study - 


\section{$\varepsilon_{3}^{3}$}

(C) Mariken Leurs, Maastricht/Amersfoort 2008

Design \& lay-out Nora Oosting \& Leo Zander, Maastricht

Printed by PrintPartners Ipskamp, Enschede

ISBN 978-90-808752-4-I

All rights reserved. Illustrations and brief excerpts of this publication may be used for scientific, educational and practical purposes provided that the source is acknowledged.

The studies described in this thesis were financially supported by the Netherlands Organisation for Health Research and Development (ZonMw - Healthy Living grant 4010.0003) with additional support from the OGZ Foundation for the application of the schoolBeat checklist (grant p342).

Support by GGD ZuidLimburg and University Maastricht (GVO and BEOZ) is gratefully acknowledged.

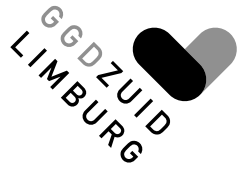

Universiteit Maastricht 


\section{A collaborative approach to tailored whole-school health promotion}

- the schoolBeat study -

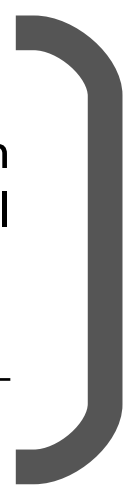

PROEFSCHRIFT

ter verkrijging van de graad van doctor aan de Universiteit Maastricht, op gezag van de Rector Magnificus, Prof.Mr. G.P.M.F. Mols, volgens het besluit van het College van Decanen, in het openbaar te verdedigen op vrijdag 16 mei 2008 om 14.00 uur

door

Martina Theodora Wilhelmina Leurs 
Promotoren

Prof.dr. N.K. de Vries

Prof.dr. H.P. Schaalma

Co-promotor

Mevr. dr. I.M. Mur-Veeman

\section{Beoordelingscommissie}

Prof.dr. C. Spreeuwenberg, voorzitter

Mevr. dr. P. van Assema

Mevr. prof.dr. M.C.H. Donker (Erasmus MC Rotterdam)

Prof.dr. G.J. Kok

Prof.dr. S.A. Reijneveld (Universitair Medisch Centrum Groningen) 
A tribute to $\stackrel{\dagger}{\text { Anja }}$

Maurice

Arda

Colleagues former GGD ZZL 



\section{CONTENTS}

Chapter 1 Introduction in school health promotion ..................................................... 9

Chapter 2 The tailored schoolBeat-approach:

new concepts for health promotion in schools

Chapter 3 Development of a collaborative model to improve

school health promotion

Chapter 4 Integrated shared care offers opportunities to strengthen

whole-school health

Chapter 5 Focus points for school health promotion improvements in primary schools

Chapter 6 Development of the schoolBeat quality checklist for healthy school interventions

Chapter 7 Comprehensive quality assessment of healthy school interventions

Chapter 8 DIagnosis of Sustainable Collaboration in health promotion: a case study......

Chapter 9 The schoolBeat-strategy put into practice

Chapter 10 General discussion

References

Summary.

Samenvatting

Thank you

Curriculum Vitae 164

Appendix A. The Quick Scan Shared Care in Whole-School Health 2002 and 2005 168

B. The schoolBeat checklist 2.0 174 



\section{CHAPTER I}

\section{Introduction in school health promotion}

The central theme of this thesis is school health promotion. This introduction provides a historical perspective of school health focusing on the emergence of school health promotion in the Netherlands in general and in the Maastricht-Mergelland region specifically. Attention will be paid to the evidence base for comprehensive school health promotion and its limitations. Additionally, the goals of the schoolBeat study and the methods used will be outlined shortly. A concise reading guide to the main chapters closes the introduction.

\section{HISTORY OF SCHOOL HEALTH PROMOTION}

School health promotion has its roots in Roman times with their organized quest for physical strength - Citius, Altius, Fortius. The interest in school hygiene, a more modern predecessor of school health promotion, has its origins in the 19th century with the growing interest in public health in general. This was associated with rising interest in children's health in general (Kerkhoff \& Wagenaar-Fisher, 2005). In the Netherlands, the first rules pertaining to the hygiene of pupils and classrooms were included in the Education Act of 1806 (Gorissen, 2001). In 1868 the first doctors were asked to provide regular health screenings of primary school children in the Netherlands (Wafelbakker, 1983). Requirements regarding the school environment date from 1872 when pupils and teachers could be removed from school if they could not provide proof of proper vaccination and from 1883 with the formulations of norms for the minimum level of space per pupil (Dijkstra, 2004). About the same 
time, holiday colonies for 'weak city children' were introduced in the Netherlands (Kerkhoff $\&$ Wagenaar-Fisher, 2005). This was followed with the appointment of the first school doctors to schools in Zaandam and Arnhem in 1904, just a few years after the implementation of the Dutch Compulsory Education Act. Compared to other European countries, this was rather late. Sweden appointed its first school doctor in 1863, followed by Belgium in 1874 and France in 1883 (Dijkstra, 2004). The Netherlands appointed their first school nurse in 1914 in Amsterdam (Schuil et al., 1987). In 1928 school dental health services were introduced in Rotterdam, but did not become common practice in the Netherlands until the 1950s (Tjalsma-Smit, 2007). During the German occupation of the Netherlands during World War II, it became compulsory for municipalities to organize a school medical service. In the early 1980s, over a hundred such services existed in the Netherlands, of which 42 were linked to a municipal or district public health service (Wafelbakker, 1983).

Discussions about the need to expand the tasks of school medical services/youth health care services with health education date from the 1970s when an increasing number of health education projects and materials became available to schools (Pijpers, 1990). Health promotors recognized the school as an access point to address young people and as a setting for health promotion. Internationally, promoting the health of children through schools has been an important goal of WHO, UNESCO and UNICEF since the 1950s. This includes the WHO Expert Committee on School Health Services in 1950, the WHO Expert Committee on School Health Services in 1954 and the joint WHO/UNESCO Expert Committee on Teacher Preparation for Health Education in 1959 (WHO, 1996). Towards the end of the 1970s, a multidisciplinary working group in the Netherlands was asked for advice on the consequences of health education in Dutch primary schools for youth health care (Pijpers, 1999). The working group advised the Dutch Youth Health Care Association to distinguish three main tasks in youth health care:

- individual behavior change strategies by providing information and motivation;

- behavior change strategies targeting specific groups of pupils using agogic methods; and

- behavior change strategies targeting the school as a system in which pupils function on a daily basis (Van der Meeren, 1981).

With the introduction of the Collective Prevention Act (WCPV) in the Netherlands in 1990, youth health care services started realizing that supporting the development of school health policies was one of their tasks as well. Primary schools were already obliged by the Primary Education Act to promote healthy behaviour among pupils since 1985. This required schools to develop a School Health Policy with or without the assistance of public health services or other organizations. By then, the concept of health promotion had replaced the idea of health education, with the Declaration of Alma Ata and the Ottawa Charter (WHO, 1986) playing important roles in this regard. In 1991, the European Commission, the Council of Europe and the WHO Regional Office for Europe launched the European Network for Health Promoting Schools (ENHPS) as a tripartite activity, embracing a community approach to school health (Barnekow et al., 2006; Nutbeam, 1992). The Netherlands joined the ENHPS a few years after its launch. In this period, a new 'building block' for coordinated school 
health promotion appeared with the introduction of WCPV-based youth risk behavior surveys. These surveys yielded regional and school health profiles, followed by group profiles for pupils in some regions (Butte, 2005; De Munter, 1998; Goldschmeding \& Van de LooijJansen, 2003). Youth monitoring is not limited to WCPV-based monitoring as shown for example by the Zeeland youth monitor coordinated by SCOOP - the Zeeland instituut for welfare, care and culture (De Kraker, 2004; Smit \& Braat, 2006).

Tailoring at the individual (pupil) level has a relatively long history in school health promotion. For example, personal sport advice from the school doctor was introduced in 1974, more than three decades ago (Schuil et al., 1987). The personal touch to the advice was primarily based on the presence of physical limitations as diagnosed by the school doctor. Today, this early interpretation of tailoring is no longer state-of-the-art as it does not take into account those personal preferences and experiences (Brug et al., 1998; Dijkstra, 2005). Internet now offers refined options for lifestyle tailoring in schools. E-MOVO, initiated in 2002, is the first large-scale web-based strategy incorporating individual tailoring in compulsory youth monitoring in the Netherlands (De Nooijer et al., 2006).

The Safe School Campaign by the Dutch Ministry of Education in 1995 provided extra effort put into the prevention of risk-behavior among pupils (Prior, 1998). Schools and their teachers were urged to enhance the social commitment of pupils to school and to address differences among pupils in an appropriate manner. Important elements in the Safe School Campaign were prevention of risk-behaviour in the area of substance abuse and bullying. The three pillars of the Safe School Campaign - promotion of social commitment, adequate response to calamities and creating a safe environment - are very similar to the pillars of school health policy as described by the Dutch Institute for Health Promotion and Disease Prevention in the same period (Paulussen et al., 1998). An intervention like 'Healthy School and Drugs' has been welcomed in both approaches (Cuijpers et al., 2002; Fillekes-Brand \& Bron, 2000). The Safe School Campaign introduced new partners to school health promotion such as the local police and the youth welfare organizations (Doorduijn et al., 2002; Prior, 1998).

Towards the end of the $20^{\text {th }}$ century, Paulussen defined school health policies in the Netherlands as a compilation of health education, pupil care and the school environment (Paulussen et al., 1998). He described the school environment as a combination of the physical school building and playground, the psychosocial climate, services provided to the school and participation of stakeholders other than pupils and staff. This implies a settings approach focusing on whole school change, with the development of general competencies gaining interest above addressing health-related behaviours, and extending beyond the accumulation of single health-related behavior interventions (Guldbrandsson \& Bremberg, 2006; Rowling, 2002).

To achieve this broader approach to school health Pijpers (1999) advocated School Health Policies to be carried out in a structured and planned manner. This implies that a school tailors its health promotion activities to its own needs and capacity by: 
- explicitly formulating objectives;

- setting out its arrangements in a school work plan;

- evaluating on a systematic basis the health of his students;

- evaluating the physical environment and the school climate systematically;

- evaluating health promotion activities systematically; and

- giving priority to health promotion.

As Pijpers did not find many schools that could be qualified as having a school health policy, he recommended the development of a uniform, widely acceptable operational framework describing as accurately as possible what School Health Policy is in daily school practice. The absence of such a framework has impeded research and development in this area. At the end of the $20^{\text {th }}$ century, school health promotion and preventive youth care in the Netherlands were fragmented, supply driven and rarely focusing on the specific needs of schools and its populations. Participation of students in school health policy was non-existing. Hardly any relevant health promotion material was available for special needs schools. Schools were overwhelmed with well-intended projects and campaigns developed by zealous institutions or commercial parties. This combined with the restructioring of the education sector over the last decades, made schools become tired and irritated about the ongoing bombardment with health promotion activities. Moreover, health promotion activities are rarely included in the regular education curriculum. Schools were, and still are, largely free in their efforts regarding school health promotion. Support organizations compete for the attention of schools to incorporate their activities and projects. In contrast, individual pupil care is much more regulated in the Netherlands and is often giving priority by schools over preventive or health promoting measures. This is no surprise as a disruptive pupil is a major hinderance for the educational group process in class. Therefore, the disruptive pupil will be dealt with primarily, while little energy is left for the prevention of disruptive or unhealthy behavior in the rest of the class.

This thesis describes the development and introduction of an integrated approach to school healtjh promotion, including general preventive activities and individual pupil care, coordinated between the different organizations involved (e.g. schools, health services, police, welfare agencies and mental health services). With the introduction of this schoolBeat-approach, the schoolBeat-partners in Maastricht-Mergelland (including Maastricht University and NIGZ) have provided the Netherlands with an alternative comprehensive strategy to wholeschool health promotion (Leurs et al., 2006). The introduction of the Dutch schoolBeat-ideas to the national and international healthy school community was staged at the second conference of the European Network for Health Promoting Schools, titled 'Education and Health in partnership' in 2002 (Leurs, Jansen et al., 2005). Translated in 2005 into the Dutch Healthy School Method (Buijs, 2005), the schoolBeat approach is set to become a uniform and widely accepted healthy school framework in the Netherlands. 
Ist century Roman interest in physical strength and well-being

$18^{\text {th }}$ century rising interest in children's health

$19^{\text {th }}$ century rising interest and regulations regarding school hygiene

$20^{\text {th }}$ century Dutch developments in youth health care \& school health promotion

This includes:

1901 Introduction of the Compulsory Education Act

1904 first school doctors appointed in Zaandam and Arnhem

1914 first school nurse appointed in Amsterdam

1928 introduction school dental health services in Rotterdam-Spangen

1942 Compulsory medical supervision for all schools in the Netherlands

1950 WHO expert committee on School Health Services

1978 Declaration of Alma Ata

1986 Ottowa Charter stresses comprehensive health promotion

1986 The Netherlands starts with collaborative health education in primary education

1989 Introduction of the Youth Support Act in the Netherlands

1990 Introduction Collective Prevention Act in the Netherlands

1990 Implementation project school health policy in primary education

1992 Initiation European Network for Health Promoting Schools (ENHPS)

1994 The Netherlands joins the ENHPS

1994 First review of the effectiveness of health education and health promotion in schools

1995 Start Safe School Campaign

1997 First regular large-scale youth risk behavior monitors at regional level

1999 Introduction of the Prevention Act regarding sexual abuse and intimidation in schools

Followed in the $21^{\text {st }}$ century by:

2002 Introduction of the schoolBeat ideas

2003 E-MOVO in the Dutch provinces Gelderland \& Overijssel

2005 National introduction of the schoolBeat-based Dutch Healthy School Method

2007 Establishment of the RIVM/Workplace Healthy School

\section{THE EVIDENCE BASE OF SCHOOL HEALTH PROMOTION}

The evidence base of comprehensive tailored school health promotion is still very limited. It comprises primarily single-intervention studies, with only very few using a design resembling a randomized controlled trial. Nonetheless, several authors have addressed the evidence base of school health promotion, reporting some promising indications of effectiveness on healthy behavior and on school performance (Lister-Sharp et al., 1999; Peters \& Paulussen, 1994; St.Leger \& Nutbeam, 1999; Stewart-Brown, 2006; Weare \& Markham, 2005). For example, there is considerable evidence for a positive association between regular physical activities and 
academic performance (Aarnio et al., 2002; St.Leger \& Nutbeam, 1999) and between schoolbreakfast programs to improved attendance rates and decreased tardiness (Taras, 2005). St.Leger and Nutbeam conclude, based on published studies, that "quality school health programs address all or a combination of:

- the curriculum: formally taught classroom based programs;

- the environment: geographical, psychosocial, physical and organizational elements of the school and its local community;

- health services: the medical, dental, counseling and guidance services within a school;

- partnerships: formal and informal partnerships which exist between the school, parents, health sector and local community; and

- school policies: rules, regulations, accepted practices which contribute to maximizing the health of students" [(St.Leger \& Nutbeam, 1999) p. 112].

By advocating the inclusion of at least a combination of the components mentioned above, the authors stress the need for a comprehensive approach to school health promotion. This implies a mixture of health promotion interventions tailored to the needs and the capacity of the school, as also promoted by Pijpers (Pijpers, 1999), supported and realized in a collaborative manner with partners within and outside the school.

Others have looked into the requirements for successful implementation of such comprehensive school health promotion (Deschesnes et al., 2003; Greenberg, 2004). This is an important issue as healthy school interventions are highly likely to fail when the implementation is poor (Mukoma \& Flisher, 2004). Partnership, one of the themes in this thesis, seems to be a key issue in this process (Costongs \& Springett, 1997; St.Leger, 1998; St.Leger, 2004). It incorporates partnerships within the school between staff, pupils and parents and partnerships of schools with support organizations and the wider community (Deschesnes et al., 2003). Successful school interventions with a major partnership component are nearly always resource intensive if not planned correctly and if not based on structures and tasks already in place (Leurs, Schaalma et al., 2005; St.Leger \& Nutbeam, 1999). As tailored and comprehensive health promotion in schools is not yet common practice, support structures for the systematic planning of comprehensive school health are needed to support effective and efficient implementation.

Furthermore, one should take into account that schools are limited in time and space (St.Leger, 2004; Taras, 2005). Many interests and values compete for attention in schools, both within the educational program and its environment. Even when restricted to health issues, schools cannot deal with all health claims. Also, development and implementation take time: it may take several years in any one school to implement all the unique components of a comprehensive healthy school initiative (Lister-Sharp et al., 1999). As a result, schools tend to focus on those issues causing political concern using light, visible but limited and often ineffective strategies (Tones, 2005). Therefore, it is no surprise that the effectiveness and sustainability of school health interventions are influenced by the extent to which they support the primary business of schools: providing education (St.Leger \& Nutbeam, 1999). 
Or, as stated by Taras, "knowledge that obesity and overweight may have detrimental ramifications on current academic performance may tip the balance on how administrators decide on these issues" [(Taras, 2005) p.292]. The involvement of parents and peers seems to support the effectiveness of school health interventions as well, for parents this includes a reciprocal relationship with teachers instead of a one-side support-providing role teachers are likely to assign to parents (Deschesnes et al., 2003; Lister-Sharp et al., 1999). The need for financial incentives for schools to initiate comprehensive school health promotion is subject to some debate as it may be useful only if it does not hinder sustainability in a later phase too much (Lister-Sharp et al., 1999; Mukoma \& Flisher, 2004). In school health promotion, collaboration with stakeholders from the schools is essential as they are best informed about the limitations and opportunities schools provide for health promotion (Barnekow et al., 2006).

Health promoting schools are more than schools implementing one or more school health interventions: health-promoting schools integrate health promotion into the whole context of the school and explores how the school can reach out to the community to facilitate healthpromoting processes (Barnekow et al., 2006). According to the European Network for Health Promoting Schools, "the basic values of the health-promoting schools approach include students' participation, the concepts of empowerment and actions competence, the settings approach and health policies" [(Barnekow et al., 2006) p.27]. Especially the first value - students' participation has gained international interest over recent years (Jensen \& Simovska, 2005).

Even though the preceeding paragraphs may seem promising, the health promoting schools approach is not a magic bullit to resolve unhealthy behavior of youth, with health garanteed. Or - as argued by St.Leger - "it is salutary to remind ourselves that schools are only one component and probably quite small in their influence in altering a person's health status. Other factors are genetics, peer influences, family modeling and expectations and media influences" [(St.Leger, 2004) p.408]. Generally, factors such as genetics and the influence of media are beyond the level of influence at local and regional level. On the other hand, schools are basically the only setting through which all school-age youth can be reached with limited resources, albeit with limited effectiveness so far. Considering that young people receive over 10 years of formal education to equip them for their future, a one week project or three month intervention to improve healthy behaviors has limited or no impact. Therefore St.Leger does advocate "to use the school as an ongoing setting where health is created, supportive environments are built, partnerships are made and many skills are learned" [(St.Leger, 2004) p.408]. This constitutes a true partnership-challenge for schools and support-organizations. And a challenge for researchers to study schools as systems where the interaction of interventions and other actions may create an effect greater than the sum of their individual effects, justifying the comprehensive health promotion work done in schools (Dooris, 2006; Konu \& Lintonen, 2006). 


\section{ORIGINS OF THE SCHOOLBEAT STUDY}

The roots of the schoolBeat study date back to the early 1990s when the former GGD Zuidelijk Zuid-Limburg [Maastricht Public Health Institute] initiated Hartslag Limburg (Ruland et al., 2006; Steenbakkers et al., 2005). This is a successful community-intervention approach incorporating an intervention mix in neighborhoods, the practices of general practitioners and the cardiology outpatient clinic of the university hospital (Schuit et al., 2006). In Hartslag Limburg, only a limited number of activities and interventions targeted youth. Parallel to this multi-strategy approach, the Mental Health Services in Limburg developed a project proposal in the area of the healthy school and psychosocial health (Albertz \& Ruiter, 1999). Maastricht University acted as the research partner in both initiatives. Like several other initiatives towards regional collaboration in public health at the time, the last proposal did not receive funding.

Two factors drove the Maastricht Public Health Institute in their quest for a new collaborative youth strategy. Schools called for a stop to the increasing number of health promotion projects that were 'dropped' in schools. Also there was a desire to incorporate more health promotion for youth in regular youth health care. When the partners in the Maastricht public mental health scene (such as youth care, youth welfare, drug-abuse prevention and public mental health) joined forces with Maastricht University and NIGZ, a grant proposal for tailored school health promotion was submitted and accepted by ZonMw in 2001. In the spring of 2002, a project manager / researcher (the author of this thesis) was contracted and the development of schoolBeat and accompanying studies commenced.

\section{PROBLEM STATEMENT}

The status of school health promotion in the Netherlands at the beginning of the $21^{\text {st }}$ century was one of fragmentation, uncoordination, supply-driven and relatively low priority. Support organisations were competing for the attention of schools, collaboration was minimal. Schools became irritated with the bombardment of healthy projects, activities and materials. Local governments were responsible for public health and health promotion, but not for the school curricula. Schools were part of school associations organisated at regional level, and were mainly interested in relating to municipalities for good housing. Interest in effectiveness of healthy school interventions at the side of schools was absent. This all lead to the following problem statement for this thesis:

Can a fragmented, uncoordinated, supply driven support of school health promotion be transformed into a comprehensive, collaborative and demand oriented approach to effective whole-school health promotion? 


\section{OBJECTIVES AND METHODS OF THE SCHOOLBEAT STUDY}

This thesis aims to explore the status of intersectoral school health promotion in the Maastricht-Mergelland region in the Netherlands, and to introduce and evaluate a set of innovations and reinventions intended to support the realization of effective and efficient intersectoral school health promotion.

At the start of the study, the aim was to clarify the desired outcomes of the schoolBeat project and current impediments in school health promotion in the Netherlands. Therefore, the schoolBeat study has taken an action research approach with the research methods following the steps taken in project development, wherever possible. In the initial phases of the project, the focus was on exploring and clarifying the central issues of the study by reviewing literature regarding school health promotion and quality of interventions, consulting experts and hosting consensus-meetings with prevention professionals and school staff (Leurs et al., 2002; Leurs, Jansen et al., 2005; Peters \& Keijsers, 2002). The first four chapters of this thesis reflect the results of this iterative and explorative phase.

Based on the impediments observed (such as a lack of insight into the evidence of school health interventions, a lack of a shared frame of reference among partners in school health promotion and a lack of a comprehensive assessment tool for collaborative processes in intersectoral school health promotion), new instruments and frameworks were developed. These served the primary process of tailored school health promotion or its evaluation, with the evaluation tools providing feedback for the primary process as well. Two of these innovative developments are outlined in more detail in this thesis: the schoolBeat-checklist for quality assessment of healthy school interventions (chapters 6 and 7) and the DIagnosis of Sustainable Collaboration model (chapter 8). Collaborative processes play an important role throughout the whole schoolBeat-study and are key assets of the schoolBeat-methodology. Descriptions of other schoolBeat innovations and reinventions such as the Quick Scan Shared Care in Whole-School Health, the schoolBeat Priority Workshop for secondary education and the Healthy School Model, are summarized in chapter 9 to provide for a comprehensive understanding of the entire schoolBeat-strategy. Chapter 9 is an adaption of the schoolBeatmanual (Leurs et al., 2006).

\section{OUTLINE OF THE THESIS}

The thesis comprises of a set of articles. As a result, several introductory paragraphs regarding whole-school health promotion in general and the schoolBeat approach in particular are to some extent repeated a number of times. With repetition being one of the critical factors of successful communication, this has not been edited. As a reading guide, a short overview of the chapters is provided: 
In Chapter 2, new concepts for health promotion in schools developed as part of the collaborative schoolBeat approach and studied by the schoolBeat study are introduced.

In Chapter 3, a regional collaboration model for tailored and coordinated school health promotion is delineated, showing the desired change from a fragmented, supply-oriented approach to a coordinated demand-oriented approach in whole-school health and introducing the principle of workload-sharing among health promotion partners.

In Chapter 4, school health promotion is linked to individual pupil care in schools and more specialized settings via a shared care continuum, offering opportunities to strengthen wholeschool health.

In Chapter 5, focus points for the introduction of coordinated and effective whole-school health promotion are looked for in primary schools in the Maastricht region, with some interesting recommendations as a result.

In Chapter 6, the intersectoral development of the schoolBeat-checklist is described. This is a quality checklist for healthy schools interventions incorporating criteria perceived as quality aspects by the health sector and/or by the education sector.

In Chapter 7, the application protocol of the schoolBeat-checklist results is discussed based on the results of the first nation-wide application of the checklist by health and education professionals and final adaptations of the checklist.

In Chapter 8, the Diagnosis of Sustainable Collaboration (DISC) model is introduced. Its added value and applicability to intersectoral collaborative processes is illustrated with a study of the developing schoolBeat alliance.

In Chapter 9, the practical aspects of the schoolBeat strategy are outlined and reflected upon, primarily based on the experiences of the users when they were put into practice in the Maastricht region.

In Chapter 10, a reflection on the results of conducted studies and achievements is presented. The discussion closes with recommendations for future research and development in the area of tailored whole-school health promotion.

The thesis is completed with summaries in English and Dutch, acknowledgements, curriculum vitae and a list of publications by the author of this thesis. 


\section{The tailored schoolbeat-approach:} new concepts for health promotion in schools

Published as:

Leurs MTW, Jansen MWJ, Schaalma HP, Mur-Veeman IM, De Vries NK (2005).

The Tailored Schoolbeat-Approach: New Concepts for Health Promotion in Schools in the Netherlands. In: Clift S, Jensen BB (eds.). The Health Promoting School: International Advances in Theory, Evaluation and Practice. Copenhagen: Danish University of Education Press, 87-105. 
The first developments in school health promotion in many European and English-speaking countries date from early $20^{\text {th }}$ century. Developments in the area of school-wide health promotion are now widespread, especially in the English-speaking countries (Goffin et al., 2004; Kolbe, 1986; Marshall et al., 2000; Rogers et al., 1998). However, the inclusion of comprehensive health promotion in school policies remains a challenge as education and not health is the core business of schools (St.Leger \& Nutbeam, 2000).

As a member of the European Network for Health Promoting Schools since the mid 1990s, the Netherlands developed a national action plan on school health promotion over a number of years. This plan focuses on the three 'historical' domains: classroom health instruction, school health services and a healthy school environment (Buijs et al., 2002). Results so far are limited: school health promotion and preventive youth care in the Netherlands are fragmented, supply-driven, primarily focused on individual pupil care and address the specific needs of a school and its population rarely directly (Paulussen, 2002; Pijpers, 1999; Van Veen et al., 1998). As is the case in other countries, few health promoting school (HPS) interventions have been evaluated and even fewer have proven to be effective (Cuijpers et al., 2002; Schaalma et al., 1996; Van Lier et al., 2002). This is changing with recent increases in the number and breath of evidence-based school-based prevention programs and effectiveness research becoming a central focus of research activity in this area (Greenberg, 2004). Hence, it came as no surprise that the effectiveness of specific HPS-interventions was marked as the number 1 priority of the international HPS-research agenda at the 18th World Conference on Health Promotion and Health Education in Melbourne in 2004 (Leurs, 2004).

Recently, a bottom-up approach for school health promotion was initiated in the Netherlands. This article describes this bottom-up approach, dubbed 'schoolBeat' ['schoolSlag' in Dutch]. The approach has a strong focus on the establishment and monitoring of sustainable intersectoral collaborative support for comprehensive school health promotion. This is one of the keystrategies advocated recently by Deschesnes and colleagues to enhance broad implementation of comprehensive approaches to school health (Deschesnes et al., 2003). Additionally, schoolBeat aims to develop and introduce a specific tailored approach to comprehensive school health promotion, involving - in first instance - school staff, pupils and parents. The coalition-partners take responsibility for disseminating congruent messages into the surrounding community. Hence, a multifaceted approach to multiple determinants will be created. As this is a complex HPS initiative, its evaluation will be challenging (Stewart-Brown, 2001). This article includes a description of a new model for evaluating the collaborative aspects of our approach - the DISC-model - as part of this evaluation process. 


\section{THE SCHOOLBEAT APPROACH}

The development of schoolBeat commenced in 2001 when five regional health-promoting agencies joined forces in the south of the Netherlands. The five key-players came from the areas of addiction, mental health, public health, youth care and social welfare. With the recruitment of a project manager and researcher, financed by a national four-year grant, the project advanced in Spring 2002.

In ten years, schoolBeat aims to reduce risk behaviours among youth (4-19 years) in the Maastricht region. The projects midterm objectives (2005) focus on establishing sustainable collaboration among schools, health promoting agencies and local authorities. The number and quality of tailored health promotion activities should also be increased in this period. In order to pursue these objectives a systematic plan of coordinated support for tailored school health promotion policy was developed. The plan is based on the principles of intervention mapping (Bartholomew et al., 2001) and tailored to the possibilities and pitfalls of the educational system and the health system in the Netherlands. Forms of action research were used in combination with literature reviews and expert consultations (Leurs et al., 2002; Peters, 2001; Peters \& Keijsers, 2002). However, programs cannot be developed based on expertise and authority alone. It requires full participation of all stakeholders (Wallerstein et al., 2002). Hence, the development of schoolBeat includes participation of stakeholders from the health, welfare and education sectors. This is a common type of collaboration in school health promotion (Goffin et al., 2004; Jones et al., 2002; Lee et al., 2003; St.Leger \& Nutbeam, 2000).

As part of the process, new concepts were introduced in the area of (1) participation of the entire school population in HPS, (2) quality assessment of HPS- interventions, (3) workload sharing among regional support organizations, (4) linking school health promotion to individual pupil care and (5) diagnoses of the development of sustainable collaboration using the newly developed DISC-model (Buijs et al., 2004; Leurs, Mur-Veeman et al., 2003; Leurs, Schaalma et al., 2005; Peters et al., 2004). An in-depth description of each specific innovation is beyond the scope of this general introductory article.

SchoolBeat-study I, accompanying the development-phase of schoolBeat, spans the first four years of development, preliminary implementation and adjustments of the approach, primarily using action research.

Before describing the steps of the schoolBeat approach, including the introduction of new concepts where appropriate, the main planning-principles of 'Intervention Mapping' will be outlined. These principles are widely applicable to health promoting school developments.

\section{Intervention Mapping Principles}

A sound Intervention Mapping process provides program planners "with a framework for effective decision making at each step in intervention planning, implementation and evaluation" 
(Bartholomew et al., 2001), with interventions being defined as a "planned combination of theoretical methods delivered through a series of strategies organized into a program". The specific focus of Intervention Mapping is the evidence- and theory-based development of health education and promotion using a socio-ecological approach to health. This is in line with the holistic approaches to school health promotion, popular since the mid-eighties (Allensworth \& Kolbe, 1987; St.Leger, 1999). Basically, both paradigms focus on the wide picture of interrelationships among individuals with their personal characteristics and their environments. Intervention Mapping identifies the most effective points and accompanying strategies for interventions in this complex picture and eliminates the use of an ineffective trial-and-error approach. It is a comprehensive and pragmatic step-by-step approach to the development, implementation and evaluation of health education and promotion interventions. A form of needs assessment precedes the Intervention Mapping steps. Intervention Mapping starts with (1) a specification of evidence-based program objectives regarding behaviour and environmental conditions. This is followed by (2) the selection of intervention methods and strategies with a sound theoretical base and (3) program design, pre-test and production. Additionally, (4) adoption and implementation plans are developed integrally with a focus on sustainability. This all should be supported by (5) an evaluation plan (Bartholomew et al., 2001). This evaluation is not only meant to judge the planned intervention on effectiveness, but also to facilitate understanding of all stakeholders (Judd et al., 2001). Overall, Intervention Mapping is an iterative process. New insights gained along the way, will adjust choices made in previous or future steps resulting in an adjusted, more effective program. As a planning model, Intervention Mapping builds strongly on previous models by Green and colleagues (Green \& Kreuter, 1999; Green \& Lewis, 1986).

To engage successfully in Intervention Mapping, insights are required into the needs and capacities of the intended target group (individuals and communities) and into the current state-of-play in health education and promotion evidence and theories (Bartholomew et al., 2001). As far as school health promotion is concerned, it is important to take into account differing objectives of the health promotion agencies (i.e. health) and schools (i.e. education) prior to engaging in any intervention mapping process regarding HPS-interventions (St.Leger \& Nutbeam, 1999). Or, as stated by Green and Kreuter [(Green \& Kreuter, 1999) p392]: "Experiences around the world have taught planners this lesson: failure to acknowledge and address the perceptions and feelings held by administrators, teachers and parents, however difficult those sentiments may be to quantify, can stop the best-designed, well-intended program dead in its tracks."

Therefore, it is important to be aware of the existing evidence regarding the potential positive impact of school health promotion on school curricula and knowledge of pupils (Lister-Sharp et al., 1999; St.Leger \& Nutbeam, 1999).

The schoolBeat approach is based on the Intervention Mapping steps described. This will be illustrated by outlining the approach using the Intervention Mapping steps described in the next section. 


\section{The schoolBeat-steps towards a Healthy School}

The systematic schoolBeat approach includes coordinated support of schools during - what is defined from the perspective of schools - the 'schoolBeat-steps towards a Healthy School'. This support takes in the form of account managers (mostly health promotion professionals) with advisory tasks on behalf of the collaboration. They are called 'schoolBeat-advisors'. This concept implies workload sharing among the collaboration partners in attracting and supporting schools. It requires regular consultation between the schoolBeat-advisors as well as educating the advisors regarding the schoolBeat-approach and the fields of expertise of the different collaborating partners. This is done to pro-actively deal with possible difficulties due to a lack of understanding among the partners of how sectors work and function as suggested by the findings of school health promotion programs with a major partnership component (St. Leger \& Nutbeam, 1999).

The first two steps in the schoolBeat-approach are the prerequisites for the application of intervention mapping principles from step 3 onwards. Hence, the 'schoolBeat-steps towards a Healthy School' come down to a specification of the intervention mapping principles to the school setting, extended with two 'preparation' steps. Regarding schoolBeat, it should be noted that the 'schoolBeat-steps towards a Healthy School' focus on the school-based process, without taking full account of the back-office structure and activities of the collaborating partners supporting this process. The schoolBeat-steps can be described as follows:

\section{I) Determining the health needs of the school}

The health needs of a school cannot be based on available epidemiological data regarding the health status of students alone (Bartholomew et al., 2001; Rissel \& Bracht, 1999). In the Netherlands, and possibly elsewhere as well, there is a tendency among regional public health institutes to do just this, as this data is relatively easy available. However, it is important to also include data on the educational performances of students, registration of absence due to illness among students and staff sick leave, issues coming up in staff and parent meetings regarding school health policies and information on the current status of the school's organization, housing and activities with a possible impact on school health (Nutbeam et al., 1989). A schoolBeat advisor is available to assist schools in clarifying and interpreting these types of information. It is preferable that at least one partner-organization has the capability, expertise and personnel to compile school health profiles for each school within the HPS-scheme. It is important to stress that this information is compiled with the school instead of for the school, as the most important source and data interpreter needs to be the school itself. It was found to be extremely important that the major stakeholders in a school recognize themselves in the data provided and that they be able to complete the picture with internal data sources and interpretations. By the major stakeholders we mean school administrators, prevention and care coordinators, teaching staff, students (especially in secondary schools) and parents. Involvement in this needs assessment process, which continues in the next step, by stakeholders is likely to increase awareness, create "ownership" of the program and build commitment (Rissel \& Bracht, 1999). 
In many of our schools this step included the installation of a school health promotion team with representatives of the major target groups in schools. This could be a new team or an extension of an existing school team, for example a working group on the prevention of substance abuse in school. This school-based health promotion team (some schools refer to this team as the 'schoolBeat-team') is related to the school care team in order to maximize opportunities regarding an integrated approach to school health, based on an extended comprehensive view on shared care (Leurs, 2003b). It links health promotion to other schoolbased interventions. According to St.Leger and Nutbeam (St.Leger \& Nutbeam, 2000) and Greenberg (Greenberg, 2004), this link is one of the priorities in school health promotion that needs to be pursued in the coming decade.

\section{2) Setting health promotion priorities}

Based on the information described in step one, a school can determine its school-health priorities, including health promotion. Schools are advised to limit their priorities to around six or eight items and to have them recognized by the school board.

As described in step one, participation of students, staff (educational as well as support staff) and parents can be achieved by organizing a school health team. In practice, this means a school care team and a school health promotion team as two separate but linked entities. As the introduction of specific teams limits the level of active participation to a restricted number of stakeholders, other participation strategies for the selection of health promotion priorities are welcome.

While working with schools, the knowledge of school-based stakeholders regarding the activities their own school undertakes in the area of health promotion and the information upon which choices are based were found to be limited. This was supported by previous findings of Marshall and colleagues (Marshall et al., 2000). Hence, we were not surprised at the limited support for school health promotion. To raise support for school health promotion and increase general knowledge on the possible choices and current actions in school health promotion, a healthy school priority-workshop was adopted. Originally, this workshop was developed for staff and parents of primary schools (Boerma \& Hegger, 2001). To be applicable to students, parents and staff in secondary education the workshop needed adjustments. Based on expert consultation, explorative research among the three target groups (i.e. students, staff and parents) and pilots in different settings (i.e. classroom setting, parent evenings, mixed meetings of staff and parents and mixed meetings of students, staff and parents) an adjusted workshop was developed specifically for secondary education schools (Buijs et al., 2004). This adjusted workshop differentiates the priorities based on the components of the Comprehensive School Health Program (Kolbe, 1986; Marx \& Wooley, 1998). After conducting the schoolBeat-workshop, stakeholders reported an increase in internal support for school health-promotion activities and an increase in knowledge regarding school health promotion among workshop participants. They perceived the results of the workshop as being relevant for tailoring school health promotion to the demands of their own school population. Joint actions have not yet been reported. However, one should take into account that these findings are preliminary and might be biased, as they are not based on rigorous research. 


\section{3) Assessing the important and changeable determinants}

Even though the Intervention Mapping protocol includes the setting of health promotion priorities and the selection of important and changeable determinants in step one (Bartholomew et al., 2001), we separated these two aspects in distinct steps. This is done to emphasize the importance of a clear analysis of the situation instead of implementing projects that seem to address the health promotion priorities set too quickly, without further analysing whether these projects focus on the most important and changeable determinants of the priorities set. This step is very much a task for the experts of the support organizations in their role as school health advisors. For example, when a school sets a priority regarding the promotion of safe sex among students, the advisor looks for the different determinants of safe sex among adolescents. This may be knowledge regarding the risks of acquiring sexually transmitted diseases or getting pregnant. Other determinants are skills of students to acquire condoms and the availability of condoms in 'safe' places for students like school toilets. Based on this analysis, the advisor will look at the importance of the different determinants with regards to expected effects on the set priority. Additionally, the level of changeability of this determinant will be assessed in order to provide schools with realistic advice.

\section{4) Compiling the school health plan}

The fourth schoolBeat-step corresponds with step two in Intervention Mapping: 'selecting theory-based intervention methods and practical strategies' and compiling them into a wholeschool plan. Evidence-based interventions are rare, so the choice for 'theory based' is a logical one. However, little has yet been reported on the theoretical basis of most school health interventions. In this respect, the Dutch situation seems common worldwide. This led to the development an instrument for assessing the quality of school health promotion interventions (Peters et al., 2004). It is assumed that the use of a specific quality check based on quality criteria from the health promotion and education domains would improve overall quality of a comprehensive school health promotion plan in terms of the effectiveness and adaptability within the school of selected prevention programs. The schoolBeat quality-instrument is based on consultations of experts from both fields (health and education) and a review of other possibly relevant quality indicators (Ader et al., 2001; Cameron et al., 2001; Molleman et al., 2003; Vandenbroucke et al., 1995). Table 2.1 presents the nine criteria on the checklist (see also Appendix B, page 174). Each criterion is operationalized by a set of items, differing between two and ten items per criteria. Scoring is done per item on a three-point scale. 
Table 2.I Criteria of the SchoolBeat quality-checklist 1.0

I. Effectiveness proven

2. Well planned

3. Efficiency for support organization

4. Efficiency for school

5. Meeting educational needs

6. Participation

7. Environmental awareness

8. Quality of support

9. Ethical principles

In order to structure the program and activity choices, the American Coordinated School Health Program (Marx \& Wooley, 1998) was adapted to the Dutch situation. Proposals for changes were based on the health and education structure and priorities in the Netherlands and sanctioned by the managers of the collaborating schoolBeat partner-organizations. This process yielded a slightly adjusted 'Healthy School Model' (Leurs, 2003b), as illustrated in Figure 2.1.

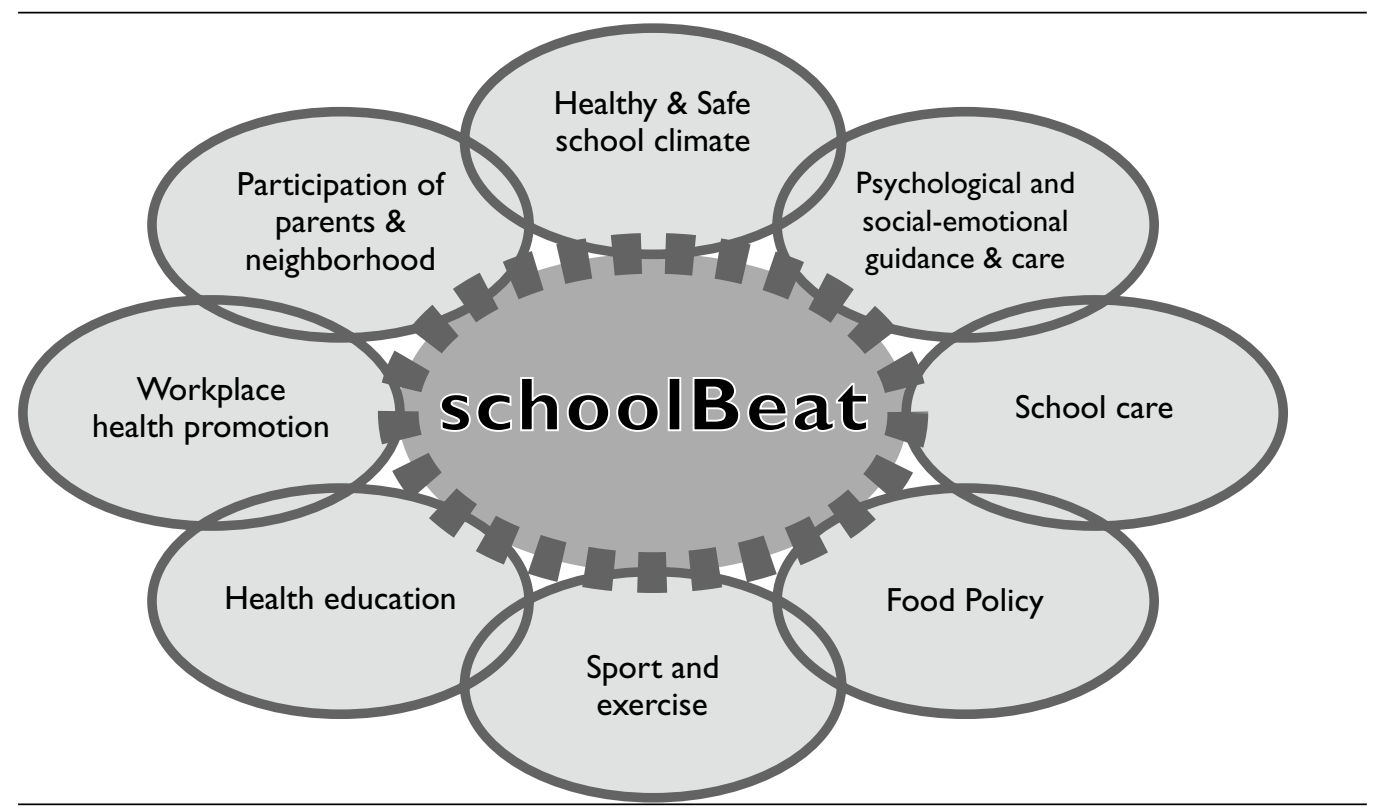

Figure 2.I The schoolBeat-interpretation of the Healthy School Model (adapted from (Marx \& Wooley, 1998) 
To assist schools, we use a matrix with the different target groups (i.e. students/classes, teachers, parents) on one axis and the selected health priorities on the other (see table 9.2, page 120). Filling in the different cells, it became clear that secondary schools focus mainly on interventions targeting healthy student behaviour in the first three curriculum years. This was an eyeopener for schools, because they did not yet have a clear view of their overall input in school health. It became a challenge for the schools to fill in the cells for the other target groups. Schools decide themselves what to do. It appears that they have several relatively simple and often sound ideas on how to achieve progress in some of the areas. Support organizations come in with additional advice on effective approaches and solutions that suit the implementation possibilities of schools.

\section{5) Realizing the school health plan}

As with the other steps, the adoption, implementation and sustainability of the school health plan is the responsibility of the school itself. Health promoters may play a supportive role, where necessary and desired by the school. Schools have a long tradition in developing annual and long-term school plans. A school health plan should be very much an extension of this school plan. Where possible, it should be included in the school plan as an integral part of school policy. Thus, linking school health promotion once again with other school-based activities as stressed by St.Leger and Nutbeam (St.Leger \& Nutbeam, 2000). This step contains a lot of useful information that health promotion agencies - regional and national - may be able to learn from schools. Their support ought to be adjusted accordingly. This may strengthen the expertise and skills already present in schools and fill existing 'gaps' that appear. This fifth schoolBeat-step coincides with the fourth Intervention Mapping planning phase (planning program adoption, implementation and sustainability). Special attention needs to be paid to the commitment of all stakeholders in the realization of the plan, not only in the planning phase but also in the implementation phase. Those involved in the planning phase must be informed about progress and possible outcomes. If possible, they should be able to experience certain aspects of the entire school health-promotion plan themselves.

\section{6) School-based evaluation}

Evaluation is an element of the schoolBeat-methodology which needs to be considered right from the very start as evaluation not only deals with the effects on health and behaviour, but also with the process of school health promotion. Specifically, in the first years of introducing and implementing a systematic tailored whole-school approach, it is the process evaluation, which needs attention. When taking an action-research approach, the newly gained insights may be used directly to adjust processes, where needed. Anchors for effect evaluation in later years should not be forgotten. Attitudes, knowledge and satisfaction regarding the new approach, especially of school staff and administration, are important indicators to take into account. They are the main gateway to the wider school population: students, other teaching and support staff and parents. To limit the research burden on schools we ensured that instruments used for needs assessment purposes can be used for evaluation purposes as well. Support organizations with tasks in the area of epidemiology can assist schools in this area as well. 
The two latter schoolBeat-steps have not yet been described in detail as we do not yet have the necessary field-experience with the implementation of these steps. In future publications this omission will be rectified.

\section{EVALUATION}

The evaluation of the schoolBeat-approach - the schoolBeat-collaboration and its account mangers and the school-based schoolBeat-steps - focuses on the extent to which coordinated and tailored school health promotion is realized in the Netherlands in 2010 and the results it yields in terms of the levels of healthy behaviour and healthy schools. This includes research into the collaborative aspects of this comprehensive working procedure, which has much in common with the apparent increasing worldwide interest in productive partnerships (Greenberg, 2004; Peters, 2001; Pratt et al., 1998; Walker, 2000).

In order to monitor and evaluate the collaboration process and to be able to adjust procedures where required, we have developed a research model for 'DIagnosis of Sustainable Collaboration' (DISC) (Leurs, Mur-Veeman et al., 2003). By doing so, we went beyond the more traditional evaluation models used in health promotion focussing primarily on the implementation and effects of single intervention programs. The DISC-model is based on the WIZ-model used for coordination and integration of health services and reviews into networking, collaboration and implementation in the area of health promotion (Mur-Veeman \& Van Raak, 1994; Ravensbergen, 2003; Ruland et al., 2003; Van Raak et al., 2003). The DISCmodel focuses on the interaction between the project management and the perceptions, intentions and actions of the collaborating partners together (the project-support group), the project organization and factors in the wider context (Figure 2.2). The DISC-model links the collaborative approach directly to the real-life context in which the approach develops, making it appropriate for case study designs (Yin, 1994).

Process evaluation of the schoolBeat-approach using the DISC-model is done by means of a survey among stakeholders from the collaborating partners (schools, municipalities and health promotion organisations) followed by in-depth interviews. The survey was piloted in a nearby region using the regional youth prevention network as a test case. Preliminary results indicate that especially municipalities and schools perceive schoolBeat as a new intervention, not differentiating it from interventions like substance-abuse prevention programs for schools and bullying preventions plans. They do not seem to perceive schoolBeat as an advanced working procedure aimed at improving the match between interventions and the needs of a school. Additionally, local authorities fear the costs of schoolBeat following the development phase, which is financed by a national grant, as the coordinating costs are no longer covered. However, right from the outset of the schoolBeat-development municipalities have made clear that the working method to be developed should not add costs to current investments in 


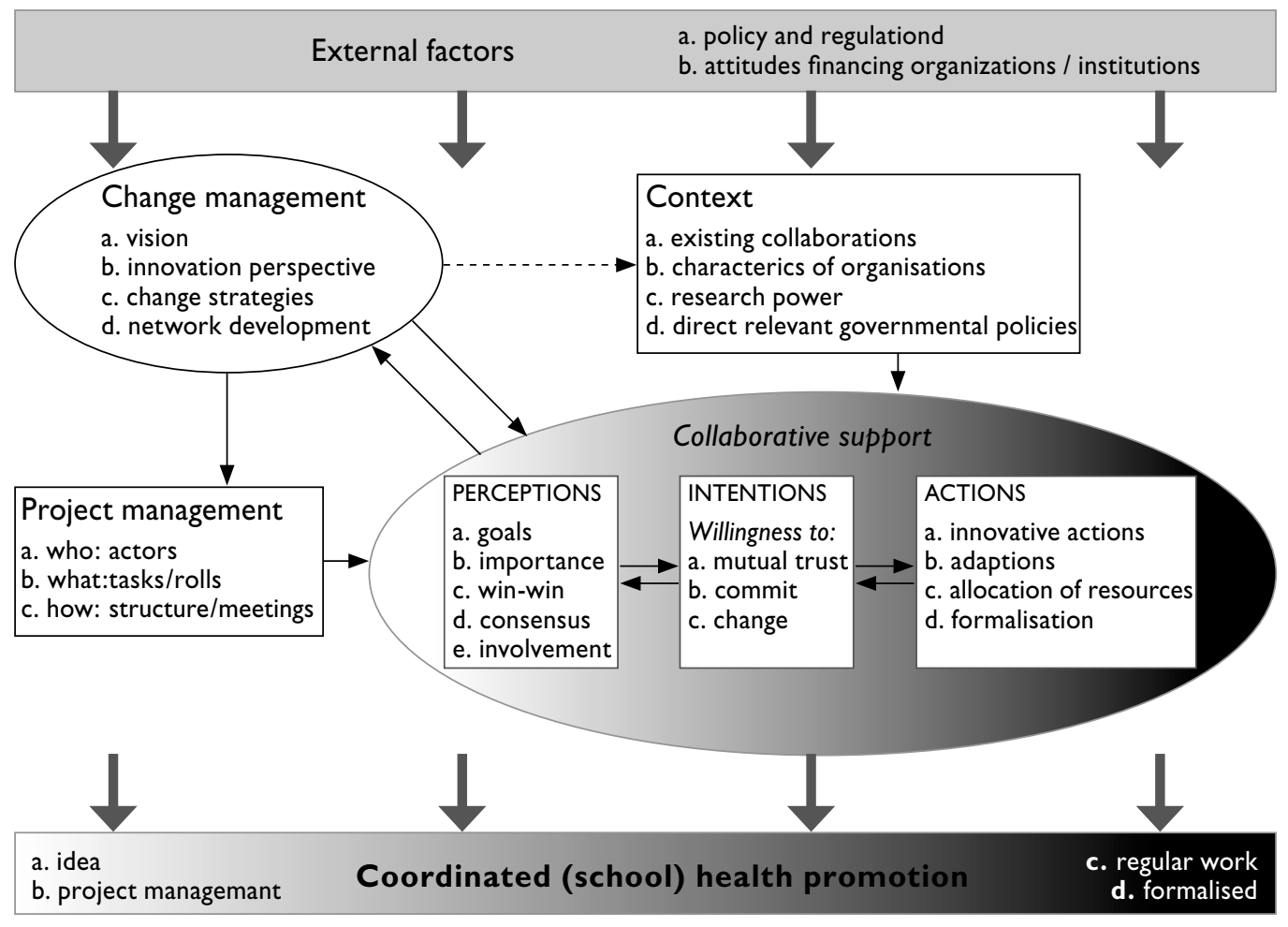

Figure 2.2 Diagnosis of Sustainable Collaboration (DISC) model

health promotion. Although, the collaborating partners have developed the project with this in mind, municipalities do not seem convinced. The outcomes call for additional and more focussed communication. Within the schoolBeat project-management structure, this will be a challenge for the schoolBeat communication group to address.

At the national policy level in the Netherlands there is a focus on investing in young people in order to reduce inequalities in health and to increase safety levels in society. It is a challenge for all health promotion professionals to profit from this - in DISC terms - 'external factor' on behalf of the health promoting schools

The DISC-model only serves as a diagnosis-tool. Actions to be taken to improve the diagnosed situation have to be decided on collaboratively. For example, "the Partnership Analysis Tool: for partners in health promotion" (McLeod, 2003) may be used to support the decision process when progress is needed at the level of the initial health promotion partners. In this initial phase, it should be decided on within the project management structure. This eval- 
uation and adaptation process ought to involve the key-stakeholders in meaningful ways. This fits the contemporary community-evaluation principles as formulated by Goodman (Goodman, 1998). In due time the project management structure it to be phased out, once the schoolBeat method has been adopted as part the regular working procedure of health promoting agencies and schools. It should be replaced by a sustainable network-structure or integrated in an already existing collaboration. These issues require communication efforts of the collaborating partners, supported by the schoolBeat coordinator. Studies on applications of this model should indicate the added value of the model as a diagnosis instrument for health-promotion collaborations, if present. Hence, it is also possible that the model itself will need to be adjusted and will 'change colour' as well.

\section{CONCLUDING REMARKS}

The schoolBeat-approach is made up of six - relatively easy to apply - steps as part of a coordinated support of tailored school health promotion. Field experience with these steps is still limited. From other studies, it is widely accepted that general community programs take may years to produce results (Goodman, 1998). Hence, little can be said about its proven effectiveness as yet.

During the initial development of the schoolBeat approach some shortcomings were identified, which were addressed as well. As some of the introduced new concepts in school health promotion deal with one or more of the priority areas for enhancing the effectiveness of school health promotion, it seems worthwhile to take a long-term perspective with this approach. In the meantime, some of these new concepts have been lifted from the regional level to the national level to facilitate long-term regional implementation. For example, application of the schoolBeat quality-checklist to nationally available school-based health promotion programs does not fit fully with the set tasks of regional health promotion agencies. On the other hand, application of the checklist and making assessment results publicly available does fit with tasks set by the National Government for National Health Promotion Institutes to support regional and local health promotion.

Based on theoretical planning, formative research and preliminary fieldwork, we have high expectations of the added value of the 'schoolBeat quality-checklist' and the 'DISC-model' in the field of school health promotion. The use of the quality checklist and the diagnosis-model in other countries and cultures is welcomed in order to gain a wide spectrum of field experiences and insights into possible points for improvement. 


\section{Development of a collaborative model} to improve school health promotion

Published as:

Leurs MTW, Schaalma HP, Jansen MWJ, Mur-Veeman IM, St.Leger LH, De Vries NK (2005). Development of a collaborative model to improve school health promotion in the Netherlands. Health Promotion International, 20(3), 296-305. 
The last 20 years have seen major changes in the development of approaches to school health promotion and health education. During the 1980s a comprehensive school health approach with eight components was developed in the US (Allensworth \& Kolbe, 1987; Kolbe, 1986). One of the 'new' components that received special attention was linking schools with communities (Allensworth, 1987). In the early 1990s, this was followed by the introduction of the health promoting schools concept in Europe, marked by the installation of the European Network of Health Promoting Schools in 1992 (St.Leger, 1999; Stewart Burgher et al., 1999). After working with a health education curriculum focus for many decades, these developments led to a more organizational and structural approach to school health, including attention for collaborations with external agencies. Today, this holistic approach has been adopted in many countries, on most continents (Lee et al., 2003; Rogers et al., 1998; Rowling, 1996).

Currently, an increasing appreciation of the core-business of schools is evident in the area of school health promotion [e.g. (Jones et al., 2002; Lee et al., 2003; Stewart-Brown, 2001)]. St.Leger and Nutbeam (St.Leger \& Nutbeam, 2000) introduced five essential priorities in school health promotion and education to be pursued in the next decade. They highlighted the number one priority as "finding effective ways to link the health curriculum with other school-based interventions", since the effectiveness and sustainability of school health intervention depends on this link (St.Leger \& Nutbeam, 1999). Hence, as a school's core business involves the education and social development of students, health agencies can assist schools by supporting a more holistic and integrated approach to school health that seeks to improve educational outcomes for students.

Internationally, a growing - but still limited - number of studies have demonstrated that school health promotion can lead to positive, cost-effective change, improving the potential of students to benefit fully from schooling as a result of having a positive health status at the same time (Durlak \& Wells, 1997; Gosin et al., 2003; Lister-Sharp et al., 1999; Nadar et al., 1999; St.Leger, 1999; Stewart-Brown, 2001). Studies have indicated that an integrated school approach, especially with long-term implementation of prevention programs, is likely to be more effective than short-term classroom-based prevention programs (St. Leger \& Nutbeam, 1999; St.Leger, 1999; Wells et al., 2003). However, the application of whole-school approaches to health promotion is still limited (Paulussen \& Wiefferink, 2002; Vandenbroucke \& Stevens, 2003; Young, 2002).

This article focuses on the development of a collaborative model for needs-based wholeschool health in the Netherlands. The model is developed as part of the schoolBeat-approach to coordinated intersectoral needs-based school health promotion in the Maastricht-region (in the South of the Netherlands). The limitations and challenges in coordinated school health promotion in the Netherlands will be described first. 


\section{EDUCATION AND SCHOOL HEALTH IN THE NETHERLANDS}

The Netherlands has a system of compulsory education for children and youth between 5 and 16 years of age, and partial compulsory education up to the age of 18, making schools an ideal setting for establishing health promotion activities targeting young people. However, schools in the Netherlands are limited in their ability to implement such programs due to a lack of finances and shortages in human resources. Expenditure per student relative to GDP per capita is among the lowest in the OECD (Schleicher et al., 2003). This is compounded by shortages in teaching staff, particularly in schools with a high percentage of immigrant students, schools for children with special needs, and lower general education (Kervezee, 2003). These shortages are likely to occur in many OECD countries in the years to come when older teachers retire and not enough younger people join the profession (Schleicher et al., 2003). At the same time, schools and health promotion agencies in the Netherlands, like their counterparts abroad, have to deal with increasing levels of health-risk behaviors, including the growing incidence of obesity among young people, mental health issues and the ever present issue of drug management (Dietz, 2001; Hirasing et al., 2001; Van Oers, 2002).

School health promotion and preventive youth care in the Netherlands are fragmented and rarely do they directly address the specific needs of a school and its population (Paulussen, 2002; Pijpers, 1999). The 'National Action Program on School Health Policy', that was launched in the Netherlands in 2002, still focuses on the three 'historical' domains: classroom health instruction, school health services, and a healthy school environment (Buijs et al., 2002). School health in the Netherlands is very much supply driven with a strong focus on the child-centered nature of much service delivery (Van Veen et al., 1998). To date, a limited number of school health promotion interventions in the Netherlands have been evaluated. Of those evaluated, only few have proven to be effective in reducing risk behavior among young people (Cuijpers et al., 2002; Schaalma et al., 1996; Van Lier et al., 2002).

\section{Policy issues regarding whole-school health}

In the Netherlands responsibilities in education and health promotion have been increasingly decentralized from the national government to the provinces, and, in particular, to local municipalities. Schools, or rather school boards, have been given more autonomy in the allocation of human and other resources to achieve their aims (Geelen et al., 1998). The underlying principle is that local/regional coordination of schools, local institutions and municipalities is a key factor to achieve national objectives with regard to comprehensive youth policy (Doorduijn et al., 2002; Gilsing, 1999; Van Veen \& Day, 1998). This, however, is difficult to achieve because of consistencies in policies and practices of service providers, the child-centered nature of many services, and the non-utilization of school-based stakeholders, including students (Gilsing, 1999; Van Veen \& Day, 1998). Accordingly, collaboration between health promotion and individual student-care support organizations is limited (Doorduijn et al., 2002). 
By 2004, the national government expected all municipalities in the Netherlands to have a regional care structure focusing on integrated care for individual students with health and social problems. This student care support structure usually consists of a school-based care team with the school physician/nurse, school social worker, and the school care-coordinator as its core members. The physician, nurse and social worker are mainly employed by external support agencies. As care and health promotion are closely linked, this mandatory care structure is likely to benefit integrated school health promotion as well. The importance of this intersectoral approach to health problems has been underlined many times (Bartholomew et al., 2001; De Leeuw, 1989; Merzel \& D'Afflitti, 2003), and continues to be a major aim of youth policy in the Netherlands (Gilsing, 1999; Van der Spek, 2003).

Relevant to an intersectoral approach are the following groups:

- regional public health institutes providing preventive youth health care (including screening, vaccination, and health promotion);

- welfare organizations providing youth welfare services to schools and communities;

- safety providers, such as the local police, offering classroom-based programs on safety and risk behavior;

- school counselors assisting schools in identifying students with learning problems, and providing appropriate in-service training to school staff;

- local youth care bureaus responsible for diagnosing students' problems related to social and mental well-being, and organizing follow-up;

- health promotion organizations directly providing interventions to schools free of charge or at reduced prices, sometimes with a direct link with a mass media campaign; and

- workplace health promotion agencies focusing on reintegration of sick employees, and on the compliance of employers to national workplace health laws.

All these organizations deal with several policy areas, the most important being education, welfare, health and youth. In terms of school health promotion, they address schools directly with their prevention support on offer. Not all service providers play a role in the mandatory care structure mentioned above, as not all deal directly with the problems of individual youth. These all seem to be limiting factors of tailored school health promotion in the Netherlands. Figure 3.1 is a diagrammatic representation of the current health promotion and youth care situation in Dutch schools.

Additional limiting factors to a needs-based whole-school approach to health promotion in the Netherlands are the absence of a nationally accepted comprehensive youth health survey, and a quality standard specifically for school health promotion interventions, such as the school health quality label used in Belgium (Maes et al., 2001). Knowledge of school health promotion policies and programs within schools in the Netherlands is also still limited (Paulussen, 2002). Furthermore, it seems that schools adopt those interventions with the best PR-campaign rather than programs that best meet their needs. Schools and health promotion organizations in other regions have confirmed these observations. For example, presentation of the aggregated results at school level from a youth risk behavior survey (De Munter, 


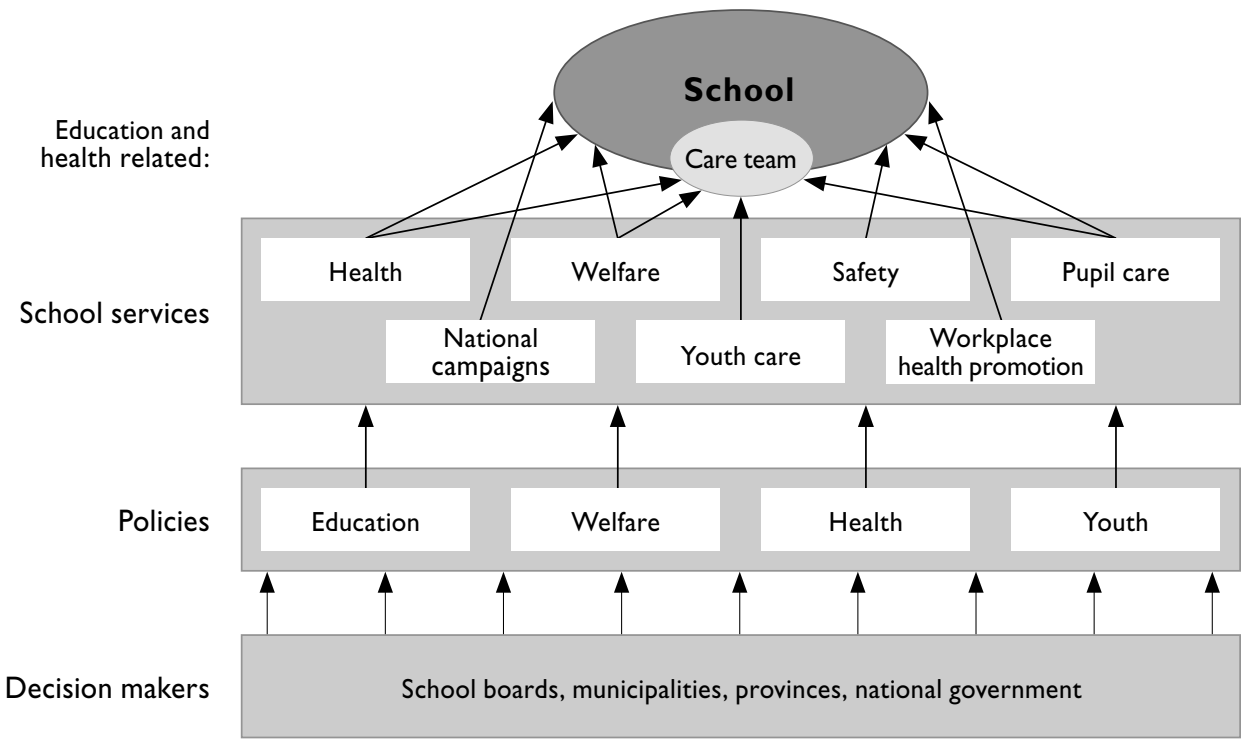

Figure 3.I Current organizational structure of school health in the Netherlands.

1998) yielded no noticeable effect on the choices of schools regarding health promotion. The previously mentioned practices are at odds with a coordinated and needs-based approach to whole-school health.

\section{A NEEDS-BASED SCHOOL HEALTH PROMOTION MODEL}

This article now explores the development of a coordinated and needs-based model of school health promotion. This approach is named schoolBeat. Based on the described situation, in 2001 five regional health promoting agencies in the Maastricht-region decided to jointly focus their efforts on improving the support structure and capacity needed to enhance needs-based school health promotion. These five agencies came from the areas of addiction, mental health, public health, youth care and social welfare. They wanted to collaboratively address risk and health behavior among children aged 4-19 more effectively. This willingness to collaborate was partly due to previous successful experiences with a collaborative approach to community health promotion: Hartslag Limburg (Ronda, 2003).

The criteria for formative evaluation for problem identification, as formulated by Green and Lewis, were applied during the developmental process: broad gathering of data, litera- 


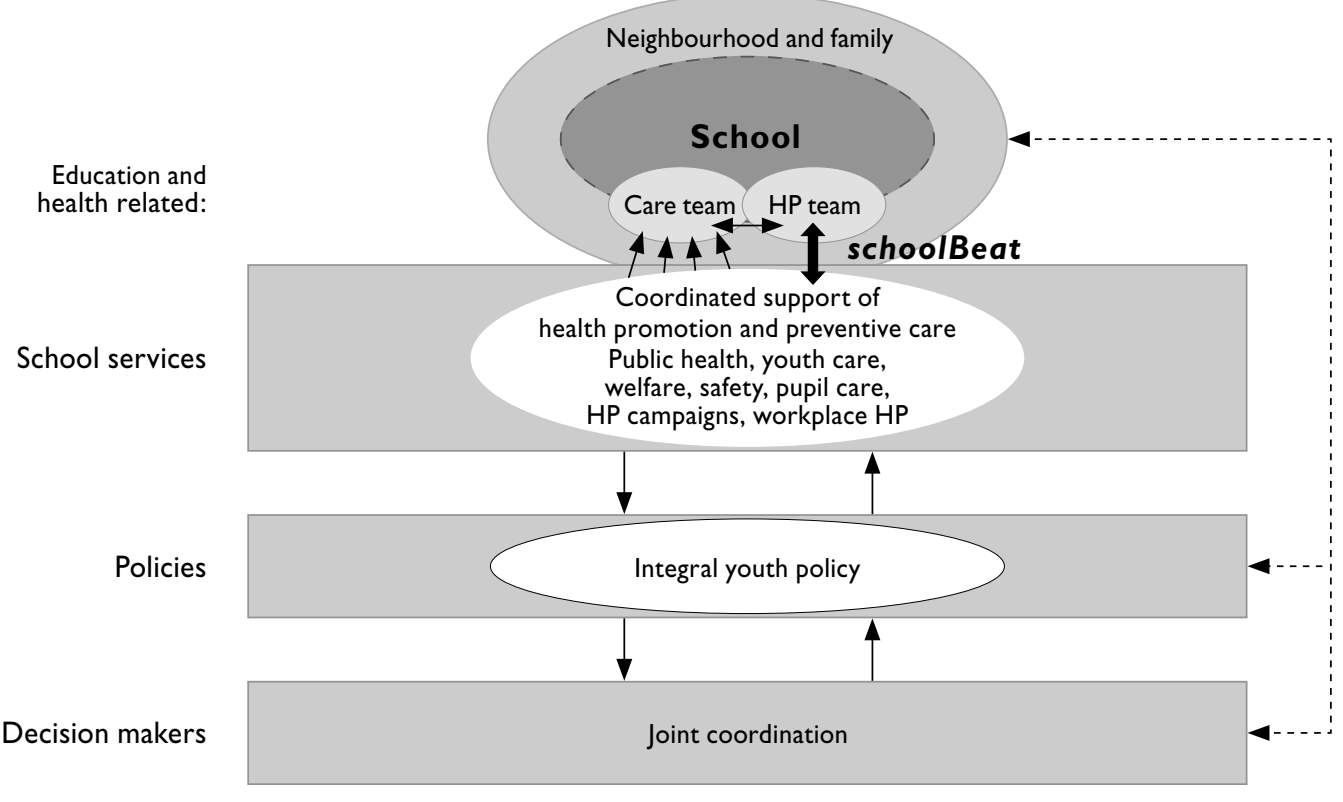

Figure 3.2 Desired organizational school-health support structure

ture review, stakeholder interviews and consultation with experts (Green \& Lewis, 1986). A national organization for health promotion and disease prevention (NIGZ) provided information on opportunities and experiences with coordinated school health promotion, from the Netherlands and abroad. Maastricht University agreed to provide scientific guidance in developing the schoolBeat evaluation design. Marx and Wooley's guide to coordinated school health programs was used as a starting point for developing a tailored whole-school approach (Marx \& Wooley, 1998). Several meetings were held with school principals in primary education and care coordinators in secondary education. This yielded valuable information on the dilemmas schools face in deciding how to implement school health promotion. Moreover, this process shaped a model of the desired organizational school health support structure, which is illustrated in Figure 3.2.

The core of any approach is that the core of any approach, including schoolBeat, should be a health promotion team (HP-team) of school-based stakeholders in order to improve ownership and to enable effective tailoring to the needs of the school (see also:(Marx \& Wooley, 1998; McLeroy et al., 2003). This team should include representatives of school staff, parents, and students, and be assisted by a prevention worker from the collaborating health promoting agencies. The HP-team should be linked to the school care team as the care professionals may signal problem areas and prevention opportunities in these areas. This element of needs 
assessment is in addition to epidemiological school health data, and data on school policies and regulations influencing school health. Another reason for linking the care team and the HP-team were the remarks of the school principals highlighting the need for more support in the area of individual student care rather than the area of collective health promotion. It became apparent that if commitment of school management is wanted, there is a need to clearly establish such a link with individual student care, and indicate the preventive aspects of school health promotion towards individual students.

To enhance school commitment, the leader of the HP-team should be someone from the school, preferably a school administrator. Additionally, to strengthen the link with the school care team, it is advisable to have the school care coordinator be a member of the HP-team and the care team. Other more supportive agencies are also represented in the school care team because of the specific expertise needed to discuss individual student problems. This results in additional links between the school care team and the school health promotion team at the services level within the limits of existing privacy laws.

\section{Workload-sharing among support organizations}

The number of primary (90) and secondary (18) schools in the Maastricht-region, with their 35,000 students, was regarded as too large for any single health promotion organization to provide tailored support in the area of school health promotion. This limitation led to the decision to share tailoring tasks, and to include them in the regular health promotion advisory work of the partners. This meant working with one advisor per school. The advisory tasks are thus spread among the health promotion agencies and do not require additional funding. At the same time, the prevention workers fulfilling these tasks have to improve their overall knowledge of integrated school health promotion in order to be able to represent the expertise areas of the other key groups in the school-based health promotion teams. Hence, this professional - the advisor - need not be employed by the regional public institute, as is the case in many approaches to coordinated school health promotion in other countries (McDonald, 2002; Somers \& Vandenbroucke, 2001). In schoolBeat, advisors are employed by a drug prevention agency, a mental health organization and a welfare organization adjacent to the public health institute. The task of the advisor is to guide the school health promotion teams through a sequence of coordinated steps from needs assessment, planning and implementation to evaluation and reassessing priorities.

In order to further decrease the pressure on schools from various health promotion agencies seeking to have their projects adopted, it was decided to develop a comprehensive overview of possible activities and projects to be included in comprehensive school health promotion plans. School services should be coordinated and presented as one integrated service to schools. Based on literature (e.g., (Allensworth, 1987; Andis et al., 2002; St.Leger \& Nutbeam, 1999), and the needs of school staff expressed during our consultation rounds, the link with the neighborhood and family was included in the design of a model for wholeschool health promotion. 
Consultation with stakeholders in the policy domain revealed a perceived inability to make full use of existing opportunities. This was claimed to be primarily due to fragmented policy development as opposed to integral policy development. The stakeholders indicated that the development of integral youth policy at the governmental level would be a desirable prerequisite to enhance comprehensive school health promotion. It was necessary to include this in the model of the desired organizational school health structure to encourage policy makers to take up this challenge favoring the youth within their region. The same is true for the joint coordination at the decision makers level, favored by most experts that we consulted.

\section{The schoolBeat approach}

The model developed for a tailored whole-school health approach forms the basis of the schoolBeat project. This project aims to reduce health risk behaviors in young people (4-19 years) in the Maastricht region over a period of ten years. The project's mid-term objectives (2005) focus on establishing long-term sustainable collaboration among schools, parents, students, communities, health promoting agencies, and local authorities and increasing the number and quality of tailored school health-promotion activities. This means:

- empowering schools through the development of systematic needs-based and comprehensive school health promotion;

- incorporating relevant existing activities and collaborations wherever possible;

- matching demand and supply in the area of school health promotion according to a Dutch adaptation of the American Healthy School Model (Kolbe, 1986), including workplace health promotion and family/environment participation, these being new components of integrated school health promotion in the Netherlands - this may be referred to as tailoring at the school health policy level;

- tailoring specific activities to the needs of teachers, parents and students if no direct match between demand and supply exists;

- combining general school health promotion with health screening and care for students with health problems; and

- reducing the burden on schools of being independently approached by various health promoting agencies to adopt specific projects or for research purposes.

The schoolBeat approach can best be described as a complex community intervention as it includes different types of collaborating partners and consists of several interventions targeting different groups at different times in the school setting. A 4-year project-grant of 0.6 million euros (approximately USD 1.0 million) includes financing for project development, coordination, evaluation, and limited implementation funds for participating schools. Implementation of the services provided is covered within the regular budget and staffing of the collaborating regional health promotion and welfare organizations. 


\section{EVALUATION}

Evaluation of multifaceted and broad health promotion interventions like the schoolBeat approach by focusing on behavioral and subjective health outcomes alone does not do justice to the health promotion principles of empowerment and partnerships (WHO, 1986). Therefore data from different sources - including a control region - will be compiled and combined to examine:

- the schoolBeat collaboration;

- quality improvement in school health-promotion design and implementation practices;

- empowerment of staff (health promotion and education); and

- whole-school health as measured in health risk behaviors and health perceptions among students.

In order to monitor and evaluate the schoolBeat-partnerships, and to be able to adjust collaboration procedures where required, a model for 'DIagnosis of Sustainable Collaboration' (DISC) was developed (Leurs, Mur-Veeman et al., 2003). This was based on earlier models used for coordination and integration of health services (Mur-Veeman \& Van Raak, 1994; Van Raak et al., 2003). The DISC-model focuses on 1) the interaction between the project management and the collaboration; 2) the perceptions, intentions and actions of the collaborating partners; 3) the project organization; and 4) factors in the wider context, such as national legislation. Applying this model is expected to yield insight into the development of the collaboration among school support agencies, schools, and local governments in relation to coordinated, needs-based school health promotion. The DISC-model links the collaborative approach directly to the real-life context in which the approach develops, making it appropriate for case study designs (Yin, 1994).

To evaluate quality improvement and effects on school-based health promotion, the schoolBeat study focuses on the number and quality of school health interventions using a specifically developed schoolBeat quality checklist (Peters et al., 2004), and data on implemented prevention programs in schools. Additionally, the effects on the school health promotion organizational structure will be examined by tracking effect indicators of successful coordinated school health promotion schemes, such as the existence of a HP-team, the use of school health data, active links to the community, the inclusion of all eight components of the school health model in school health policies and the level of satisfaction of school staff with the organization and support of school health promotion within their school.

Impact evaluation on health risk behavior and subjective health outcomes among adolescents is included in the study. However, a long-term perspective is needed to enable results in this area to become visible, especially since a single behavioral target for all schools is absent. Base-line data on health risk behavior is collected in 2001 and used in discussions with schools for planning school health promotion. Follow-up measurements are scheduled for 2005, 2009 and 2013. 
The schoolBeat research design includes qualitative and quantitative evidence and draws on the work of Campbell and colleagues regarding complex interventions (Campbell et al., 2000).

\section{Emerging evaluation issues}

To date, the following issues in evaluating a collaborative needs-based whole-school approach to health promotion have been identified:

- As schoolBeat is being developed using action research, the evaluation measurements are part of the developmental process, and in most cases also part of the schoolBeat working procedure. This double focus limits the research burden on both support organizations and schools.

- With a national schoolBeat-masterclass and other schoolBeat-presentations and publications, some diffusion of schoolBeat-elements into other regions, including the control region, is likely to occur.

- Measurements may be part of the intervention, and therefore not always suitable for baseline measurements in the control region. To overcome this dilemma, a second control region is considered where no base-line measurements have been made.

- As Nutbeam stated earlier (Nutbeam, 2003a), research is more likely to inform policy and thereby promote sustainability when it takes into account the experiences of practitioners in delivering programs, and of the public - the schools, their staff, students and parents who are being targeted.

- In the health, welfare and educational domain different terminology regarding health promotion is being used. For example, the word 'prevention' is interpreted by many schools as a service provided by school welfare workers to individual students with problems, whereas public health agencies define 'prevention' as the prevention of diseases at a later age. This calls for a shared frame of reference for school health or - staying closer to the perspective of schools - a shared frame of reference for levels of student care that is also reflected in evaluation research.

- Governmental policies and laws may undermine or increase specific effects of a wholeschool approach to health promotion and its needs-based support. Governmental policy developments should therefore be well monitored and described regarding changes in the education or health sector.

- The schoolBeat project entails an iterative cycle of research and action involving considerable interaction between participating support organizations, schools and research staff. The researcher draws conclusions from the data collected, as do the partner organizations that may use the data to enhance further development of the approach. The way data is reported to the collaborating partners may influence the interpretation and direction of decision-making. For this reason, it is advisable to facilitate a close link between the researcher and project team (Campbell, 1969, 1984; Ellenbroek \& Reijmerink, 2003). Due to financial constraints, however, the schoolBeat partners had to make one person responsible for both project management and evaluation, possibly reducing the objectivity of the researcher. To limit negative effects, a scientific advisory board was installed to complement a national advisory board and a local project group. 


\section{FUTURE PERSPECTIVES}

In its first 18 months, the introduction of schoolBeat in secondary schools has been successful in establishing comprehensive collaboration in tailored school health promotion, thereby spreading the workload among partners. Education and health professionals together created a mutually acceptable frame of reference when combining school health promotion with individual student care. The main challenge now is to keep the momentum going in secondary schools and to find a suitable way to start in primary schools, which have fewer staff with special tasks in the area of health promotion and individual student care.

From an international perspective, it is the collaboration, the task sharing between public health, welfare, mental health, addiction and youth care organizations (as outlined in figure 2), and the mutually accepted frame of reference which make the schoolBeat approach unique. With the first results regarding the diagnosis of the development of sustainable collaboration using the DISC-model (Leurs, Mur-Veeman et al., 2003) on their way, we intend to delineate our diagnoses model in the near future. Additionally, the development and application of a school health promotion quality instrument - the schoolBeat-checklist - could be beneficial to others who wish to improve the quality of school health promotion in their countries.

To support implementation of the schoolBeat approach in the Netherlands, two national master classes were held in 2004 in addition to publications in national journals and presentations at national meetings. To date, there has been considerable interest in, and appreciation for, the schoolBeat development from both education and public health professionals, including the ministries of health and education, in the Netherlands. 


\section{Integrated shared care offers opportunities \\ to strengthen whole school health}

Published in Dutch as:

Leurs MTW, Mur-Veeman IM, Schaalma HP, Feron FJM, De Vries NK (2005).

Integrale ketenzorg biedt mogelijkheden om de zorgkracht in het onderwijs te versterken. Tijdschrift Jeugdgezondheidszorg, 37(4), 7I-76. 
In education there is a growing trend in collective health promotion and prevention on the one hand, and individual student care on the other. Together they form a care structure in education. In the Maastricht region, and together with the education sector itself, this structure has been defined in six levels of care and given the name 'integrated health care'. The structure starts at the basic level, which encompasses the entire school, and continues to the level of the class and sub-groups in a class through to the level of individual student assistance via external organisations. In this innovative approach to care in education, youth health care plays a strengthening and supporting role. This involves identifying the care needs of a school and improving the care structure in a school. The central aim in this process is encouraging the healthy development of students.

In the Netherlands, school health policy and individual student care has gone through important change in certain sectors/areas. Current school health policy is highly fragmented, being characterised by ad hoc activities and supply driven (Paulussen, 2002). However, more and more schools and other organisations are working together, based on their involvement with the same children (Bosdriesz \& Berkenbosch, 2003). At the same time, school health policy is being broadened in line with the so-called Healthy School approach (Buijs et al., 2002). No longer is the focus only on health education in the classroom. So-called school-wide strategies are implemented for the school as a whole and for high-risk sub-groups, as are strategies focused on changing the behaviour of individuals. Current policy in the Netherlands aims to keep students in regular schools for as long as possible, this necessitated a broadening in the area of individual student care; in this case a broadening of care facilities being put in place to address concerns at the level of sub-groups and entire classes (Leurs, 2003b). This development in the care structure in education has been occurring independent from existing initiatives in the area of collective health promotion and prevention.

The schoolBeat approach links collective school health policy, including monitoring, with individual student care, an approach that can be used as a blueprint for policy in general in this sector (Kleijnen \& Leurs, 2003).

It is important to note that we recognise that care for children is primarily the task of parents: they are after all responsible for a healthy upbringing, including an upbringing in terms of values and norms. The responsibility of education in this regard is an important element of this (Donkers, 2003). A second comment in this regard is that the primary task of schools is providing good education and not wide-scale health promotion (Green \& Kreuter, 1999; St.Leger, 2004). After all, schools are assessed based on the education results and not health results. The concept of the child as the focal point of education and not the knowledge that has to be transferred to the child, appears to be becoming more the norm at various schools.

In this article, we describe the schoolSlag-approach in which the link between collective school health policy and student care is set in the form of 'integrated shared care' within the education care continuum. This approach offers many opportunities for other education collaborations and support organisations such as youth health care, welfare work and youth care. 
In order to illustrate this, we have used the term 'care power' in relation to the 'care needs' of the school in this article.

\section{CONTINUITY OF CARE}

The 'integrated shared care', such as that operating in education in the Maastricht region, should be seen as a continuum, in which various levels of care are distinguished. The level structure starts at the level of collective health promotion and prevention focussed on the entire school population (students and personnel). The smallest level in the structure, after going through various levels, met special facilities/provisions for students with major problems that mean they cannot function in regular education - even with extra specific support. By working together on integrated shared care, the partners aim to optimally meet the care needs of education. Initially, the main focus of these networks is the collective and achieving a broadening of the prevailing views in education with regard to the care continuum. In many care structures and policy developments in education, early identification of individual problems among students is the first level of care. Many problems can be prevented with a collaborative and collective approach. Unfortunately, the possibility of realising this is too often not recognised - although certainly not always.

\section{Care levels}

Integrated health care has been defined into six levels of care. This box contains a brief description of each level has been described in order to assist with the understanding of this article.

The six care levels are:

- Level 0 - Health promotion and prevention at the school level (students, staff and parents) which includes physical aspects of the school (the building - including the presence and form of facilities such as a canteen and sporting or recreational facilities), policy (norms and rules) also known as 'the care shell'. Youth Health Care (JGZ) workers can at this level play an advisory and informing roles;

- Level 1 - Group level health promotion and prevention (the class), this could include health education, skill development, sport $\&$ recreation, but also regular contact with Youth Health Care (JGZ) or regular medical check-ups for all children at certain ages; 
- Level 2 - Extra care at the group level in regular schools (sub-groups). This is meant for children in high-risk groups where unhealthy development and learning difficulties can be a problem, but can also be for an entire class. For example, a class with social problems associated with extreme forms of teasing. Such programmes are put in place by the school in the form of a group plan and which could encompass effective instruction, efficient class management and systematic treatment of problems and group discussions. Expertise from youth health care organisations can provide assistance to school personnel staff, depending on the nature of the problem and how it is to be approached;

- Level 3 - Support at school level from internal experts (individual). At this level, the student receives extra support outside the group (individual oo in small groups), at their own school. While the support comes from someone attached to the school, the school doctor or nurse can be asked for further advice with regard to the best form of support;

- Level 4 - Calling on external and internal expertise, including ambulant support. If the extra support within regular education does not produce the desired results, the school requests further examination and advice from external organisations. The school doctor is then called on where it is necessary to refer a student to further medical care;

- Level 5 - Permanent or temporary placing of students into special education (SBO), external school care facilities (such as an Orthopedagogical Didactic Centre) or Regional Expert Centre (REC). In special education (SBO/REC) and Centres for student care/OPDC (secondary education) individual programmes are developed, tailored to the specific learning and/or behavioural problems which encompasses special methods and instruction principles. These facilities offer most forms of specialisation at the schoolexternal level. At this level, second and third line organisations are involved in the area of diagnostics, support and treatment.

Each level of care includes the previous level(s). That means that if support or assistance is provided at level 3, this includes care at the previous two levels as well. This care structure is based on the care that students receive and the 'system' which this care is part of. Because of the importance of offering an integrated and ongoing care structure, it is also vital that school care partners - such as youth health care, social workers and youth support - be aware of the structure of this system. Knowing others involved in the care structure and using the same terminology can greatly enhance communication that is beneficial to the care for students and personnel.

\section{Care requirements determines needs}

The care requirements of a school comprises those care needs of students and personnel that have been identified, and the care needs in a school such as a system and buildings. 
In order to identify accurately a school's care requirements, a school can use the following sources of information and instruments such as:

- Discussions in the pupil care advisory team (or a similar care structure depending on the possibilities at a school and existing arrangements in the region). This involves discussing an individual case and developing a specific plan for that individual pupil. In addition, youth health care workers can also be asked to look into the prevalence of certain problems, and where a problems has a high frequency to look into the reasons why this is the case. The involvement of youth health care workers in the care advisory teams exists in the Netherlands where such specific arrangements have been made with the relevant local authority;

- Observations of at-school personnel. These people see students every day and, from the perspective of their pedagogic and didactic expertise and skills also have ideas and suggestions for achieving improvement;

- Using a care scan such as the 'Quick Scan Shared Care in Whole-School Health', in which the knowledge, skills and activities with regard to student care and collective prevention of teachers and mentors are identified (Kleijnen et al., 2003);

- Student monitoring system and education results waaruit the school-wide development in relation to the core tasks of education blijkt. Good educational results are closely related to the healthy development of children. If there are problems in education achievements, the risk of unhealthy developments rises and attention is required;

- Questions from teachers or support personnel about certain students or groups of students and about new developments in the area of integrated care. These questions might also have been put to youth health care workers and in turn be put to the care advisory team by them;

- School health profile based on student questionnaires. In the Maastricht region, we are able to use information collected at primary schools as part of the periodical medical examination and a verbal questionnaire. At secondary schools there is also information available from the periodical consultation with the school nurse and a 4-jaarlijkse risk behaviour monitor, both performed in second and fourth years of secondary school. This is complemented with surveys of teachers/school staff. Most of this information can be provided by youth health care agencies at the school level;

- Finally, the 'schoolBeat priority workshop' can be used. This is a participatory method in which parents, personnel and students are involved in determining priorities with regard to healthy school (Buijs et al., 2004). In terms of the youth health care tasks in the area of collective health promotion, these workshops can be developed and administered by for example youth nurses or health promotion workers. In running these workshops in the past, youth health care workers have seen that the involvement of parents, personnel and in some cases students can be important because these groups have a good understanding of the care structure in a given school. Sometimes this leads to surprisingly simple and cheap solutions that produce the desired results. 


\section{'Care power' turns words into action}

'Care power' is in reality 'the care at various levels that is actually customised to specific needs'. Implementing such activities is primarily the responsibility of the school. The school is supported by its own education collaboration structure, such as the VOVSO (Organisation that supports schools for special education in the Netherlands) and similar organisations for primary education. Schools are highly appreciative of the specific expertise of youth health care, whether it be for individual student care or collective prevention. In addition, schools are dependant on the legislative requirements of their supporting organisations, such as legislation on collective health care prevention (in Dutch: WCPV) in the Netherlands, and the extent to which government, local or otherwise, facilitates the implementation of such programmes.

The effectiveness and practicality of the available care power determines a school's ability to meet its own care needs. This is partly a budgetary situation: what does a school have to pay for itself and what does the government finance, and is this enough to meet these requirements? To this end we are referring to the use professionals and available methods and strategies. In the area of school health, there are countless projects for which the effectiveness has not been proven, or projects that are only effective in combination with other activities relevant to the same theme. For example, a one-off project focused on highlighting smoking and its damaging health effects will have little or no long-term effect. This is true of both students and personnel. Research into the effectiveness of this integrated approach shows that it is really only worthwhile when it is smoking is part of a broader range of initiatives. This could include developing social skills, changing the social norm so that not smoking is seen as "cool", discussing smoking as part of the periodical consultation with the school medical officer, eliminating examples of teachers that smoke, and organising school activities associated with this theme at the same time or shortly after national anti-smoking campaigns.

A school integrated care plan describes school activities and measures that will be undertaken. A pedagogic, didactic and social-emotional development environment is defined, in which the various levels of the integrated care structure are described. This school care plan obviously depends on the care power available and the extent to which it can meet a school's care requirements. The care consultation structure required for implementation of the plan is described in the plan. This makes it clear to youth health care workers what they can and cannot expect from a school in the area of integrated health care.

\section{SCHOOLBEAT}

The broad vision of integrated health care in the Maastricht region is reflected in the collaborative development of a coordinated and demand-driven approach to whole-school health promotion and prevention: the schoolBeat-approach (Leurs, Schaalma et al., 2005). Supporting 
organisations in the area of addiction (Mondriaan Zorggroep), public health (GGD Zuidelijk Zuid-Limburg), mental health care (RIAGG Maastricht), welfare (Trajekt) and youth care have been working on developing this approach together with education, Maastricht University and the National Institute for Health promotion and Prevention (NIGZ) since 2002. In this regard, care at the school-wide level in the context of its surroundings was an important element in this process. For each school there was a schoolBeat advisor (a health promotion or prevention worker from one of the partner organisations) functioning as the coordinator of this process. At the South Limburg Regional Public Health institute, the youth health care worker performed this role. At other regional public health institutes, for example in the Dutch provinces 'Zeeland' and 'Brabant', the youth medical officer filled this advisory role. As part of the schoolBeat approach, organisations try and protect schools from countless so-called advisors and a continuous flow of mailings about projects and materials. Digital news bulletins on behalve of the schoolBeat-collaborative and an annual regional overview of prevention possibilities in education were created to achieve just this. This regional overview is an extension of the national annual inventory produced by the National Institute for Health promotion and Prevention. In Flanders (Belgium), there is a similar inventory of materials and programmes for healthy schools under the name INVENT and it is produced by the Education Office of the Flemish Institute for Health promotion (Maes et al., 2001).

Because some project descriptions say little about effectiveness or quality, the schoolBeatchecklist $^{\Theta}$ has been developed (Peters et al., 2004).This enables health promoting programmes for schools to be tested in terms of quality. In addition to effectiveness, the checklist also looks at education orientation (is the programme suited to the school or class setting, does it appeal to students, does it require a lot of preparation time, etc), and efficiency for the school and supporting organisations. In 2004 the schoolBeat checklist was applied to 29 available projects in the Netherlands (Leurs, Schaalma et al., 2007). The first quality assessments are reported on the web site of the Healthy School National Support Agency. The criteria used in the checklist go further than the no longer in use Flemish quality table for health promotion.

The translated and adjusted American 'Healthy School Model' (Marx \& Wooley, 1998) forms the basis of the systematic approach to improving prioritising in the school setting (see Figure 4.1) (Leurs, 2005). This model is based on a 'multi-strategy approach': for each priority multiple strategies to grade effect. We now know from various studies that the one-off provision of information has little effect if it is not combined with for example parent involvement, skills training, school policy and care policy (Maes \& Lievens, 2003; St.Leger \& Nutbeam, 1999; Verdurmen et al., 2003; Veugelders \& Fitzgerald, 2005). 


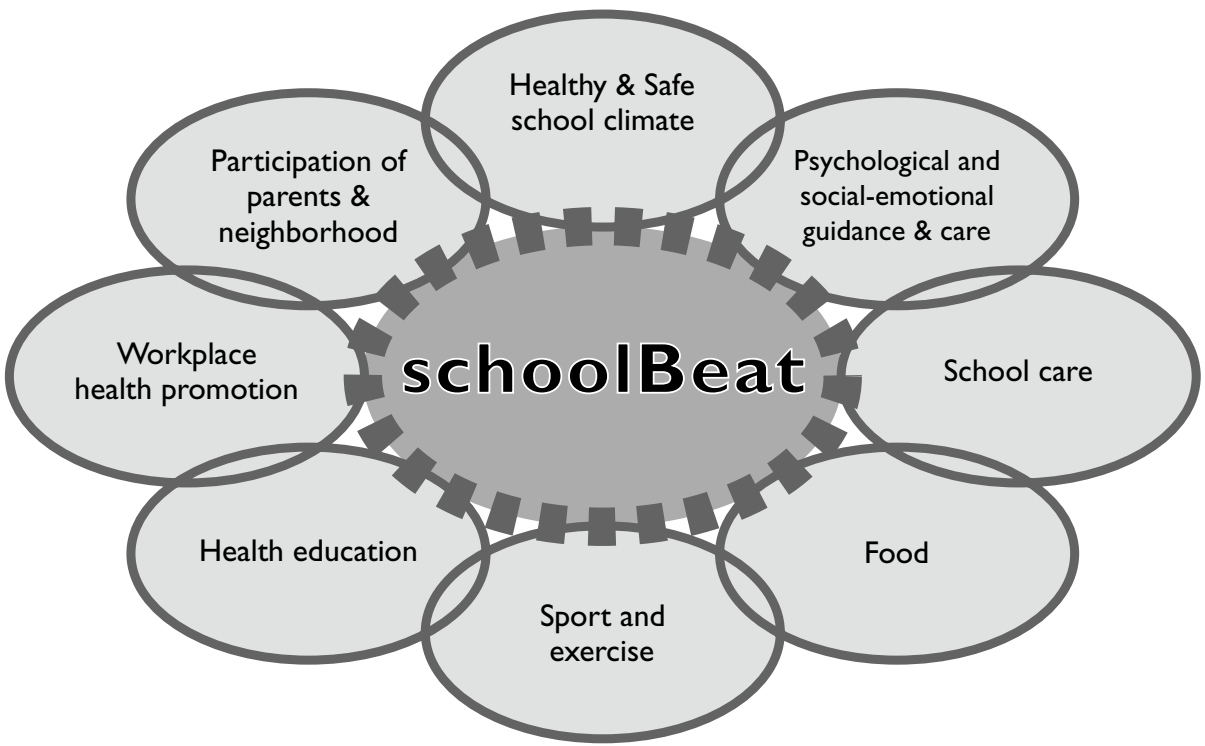

Figure 4.I The Dutch Healthy School Model, based on the American 'Healthy School Model' (Leurs \& De Vries, 2005)

The motto here is "prevention is better than cure". A truism that, partly due to the increase in individual care plans, it can be concluded too often is ignored. Individual care plans generally have a higher priority than for a school than considering and putting in place collective health promotion and prevention. This is understandable given that a single student is capable of disrupting the education process for an entire class. Acute care is often not just necessary for the student, but also for the system that he or she is part of. One of the strategies to bring improve the balance between these two aspects of care, this article describes the link between the collective and the individual in terms of the vision of integrated shared care. Projects aimed at collective health promotion and prevention are part of the activities that fall under levels 0,1 and also part of level 2. At level 0, school policy and the structure of a school are excellent target areas for achieving change that can influence the entire school when it comes to the health development of children and the welbevinden of school personnel. In the battle against obesity, at this level it is possible to consider exercise possibilities, traktatieregels and the products offered for sale in the canteen and automatic food dispensers (Van Gorp \& Mooij, 2004). It is also possible to look into ways the school can stimulate students to have breakfast before coming to school. This is also beneficial to schools because a good breakfast improves school performances (De Ronne, 2004).

Including the entire school as a level in the care continuum ensures that it is considered in a school strategic plan and the associated school care plan. What is the school planning to do 
in the coming year to encourage the healthy development of the entire student population? In doing this, care levels 1 and 2 also play a role in the planning and realisation. In this way, it is possible to work on the healthy weight of students at the class level through project weeks, lesson series and popular forms of exercise in PE classes or group participation in sporting events. Students that have been identified by youth health care workers with a real or threatening weight problem can be advised to participate in specific, after-school activities suited to them. Every region appears to have now developed its own version of this approach. In South Limburg there are a number projects for groups of children/young adults with weight problems, namely 'SmartKids', "RealFit' and 'Pleasure in Exercise'. Identifying candidates for these sportive projects is partly the responsibility/ask of youth health care.

Organisations and schools in the Netherlands that want to introduce whole-school customised health promotion and prevention can call on the services of the Healthy School national support agency (www.gezondeschool.nl). The associated website is also accessible to organisations and schools in Flanders.

\section{INTERNATIONAL AND NATIONAL DEVELOPMENTS}

Nationally and internationally, there have been developments in which all these different form of care are better coordinated and that schools no longer have an ad hoc secries of programmes or activities. It is becoming increasingly the case that care organisations examine what is necessary to achieve a healthy and safe (and in some cases broader) school (Leurs, 2004; Maes et al., 2001; St.Leger, 2004). In the context of this integrated approach the school is the key location where young people can be reached: and so the care structure has the school as its central point.

This requires a high degree of coordination and cooperation, in areas including:

- Integrated student care in primary and secondary education - youth health care - youth assistance / school social work - health improvement \& prevention (schoolBeat / Safe School)

- Coordination of goals in the area of prevention and cure;

- Continuity of integrated student care at the school, group and individual levels;

- Continuity of health promotion, prevention \& care focused on school, home and surroundings via regional collaborations / LOGO's (local health think tanks in Flanders - Belgium);

- Overview of preventive possibilities put together by providers.

Developing the competencies of education professionals who function in the classroom on a daily basis in an important challenge (St.Leger, 2004). Youth health care has, based on its own expertise, a specific role in this regard. This includes together with schools and other 
partners identifying the knowledge and level of competence of teachers, providing advice on improvement possibilities and where desirable and possible conducting training sessions for education professionals.

\section{FINALLY}

The classification into 'levels of care' as described in this article, serves as the basis for current and future developments in integrated care, preferably in combination with the principles of the Healthy School. Whether it concerns 'implementing care activities', 'cooperation', 'professionalisation' or 'future policy', the levels of care serve as concrete definitions for schools, youth health care and other partner organisations. The step-by-step plan that is part of the demand-driven schoolBeat approach provides a usable and concrete set of definitions for organisations and schools. 
Focus points for school health promotion improvements in primary schools

Published as:

Leurs MTW, Bessems K, Schaalma HP, De Vries H (2007). Focus points for school health promotion improvements in Dutch primary schools. Health Education Research, 22(I), 58-69. 
Overweight and obesity among children is rising rapidly in developed countries (Dietz, 2001; Kautiainen et al., 2002; Lazarus et al., 2000). Smoking rates, binge drinking and the practice of unsafe sex among adolescents are additional reasons why we have to strengthen our investment in health promotion targeting youth in order to provide them with the best developmental opportunities towards healthy adulthood (Grunbaum et al., 2004; Van Oers, 2002).

Schools can play an important role in the promotion of children's physical and mental health (Hornby \& Atkinson, 2003; St.Leger \& Nutbeam, 1999; Wells et al., 2003). As health promotion is a planned activity, an analysis of the current school situation and a needs assessment is necessary before a whole-school approach to health promotion can be designed (Kok et al., 2004; Leurs, Schaalma et al., 2005; St.Leger \& Nutbeam, 2000). These needs of a school are determined by the needs of its population: pupils, staff and - preferably - parents. The needs are based on health status and healthy behavior of the school population as well as the school climate and current school health policy and action taken. In schools, professional capacity is an important resource that is controlled by the school. This includes personal competence of teaching staff and motivational factors influencing them to do so. It implies an analysis of teachers' preferences for teaching health promotion, a topic that is mostly not addressed extensively, but is the goal of this paper. Moreover, effective health interventions may be developed, but if they do not take into account the motivational factors and barriers of school staff to implement these interventions, their impact is likely to be limited (St.Leger $\&$ Nutbeam, 2000; Steckler et al., 2002). Hence, it is important to investigate which characteristics are likely to exert the greatest influence on the performance of health promotion in class (whether mediated by individual perceptions or not) and which are the most open to change.

The goal of this study is therefore to analyze the decision-making process that leads a teacher to address health promotion at school. In primary schools, this ranges from education in healthy eating, dental care and physical exercise to the prevention of smoking and social skills training. In the Netherlands three health promotion issues are considered to be basic elements in school health promotion in primary schools: sports and physical exercise, social skills development (including the prevention of bullying) and personal care (Görts \& Jonker, 2001).

Insights into teacher decision making with regard to health promotion in the classroom is deduced from the current study via the motivational factors, attitude, social influence, selfefficacy and perceived barriers, possibly all influencing the inclusion of health-promotion issues in schools (Bandura, 1986; De Vries \& Mudde, 1998; De Vries et al., 2003; Fishbein \& Ajzen, 1975). 


\section{METHOD}

\section{Sample}

Data for the analyses reported here are from a survey conducted anonymously in the Maastricht-region in the Netherlands, towards the end of the 2002-2003 school year. Eligible for participation in the study were primary school teachers employed by one of the 84 schools for primary education in this region. This included four schools for special education. Teachers had to be teaching Grades 6, 7 and/or 8 (last three years of primary education).

Of the 352 primary school teachers approached 180 (51.1\%) completed and returned the survey. Inclusion criteria were teaching upper school classes for a minimum of 0.4 full time equivalent and having filled in at least $50 \%$ of the survey questions. Based upon these criteria three surveys were excluded from further analyses. Respondents represented 78 of 84 eligible schools (92.9\%). School size varied between 56 and 593 pupils (mean: 248.4; SD 133.3).

Reasons cited for not participating in the survey were time constraints (particularly with the end-of-year quickly approaching), lack of experience with health education and lack of interest in the survey-topic.

\section{Procedure}

A questionnaire was used focusing on the motivational factors of 'teacher-based health promotion', general health promotion needs-assessment, teaching support materials and knowledge regarding a new whole-school approach to health promotion in the region. As this article focuses on the motivational factors of behavior change regarding teacher-based health promotion, only the scales and items used to measure these factors will be outlined here.

As teachers tend to think about health in terms of topics and curricula (St.Leger, 1998), teacher-based health promotion was measured using a seven-point scale, assessing whether they had addressed one or more of the following health promotion issues in the previous year: sport \& exercise, personal care (including hygiene), healthy eating, substance abuse (smoking, alcohol and drugs), sexuality \& relations, mental health and social skills (including bullying prevention). This was dichotomized into teachers reporting addressing a minimum of three health issues per annum, being at least one per term on average, and teachers who fail to reach the minimum set of three health issues according to their own report. Three is considered the minimum number of school health promotion issues in the Netherlands (Görts \& Jonker, 2001).

Attitude towards teacher-based health promotion was measured using an attitude-scale of 14 items on a five-point scale. Cronbach's alpha of the attitude-scale was 0.61. Using principal component analysis (rotation method: Oblimin with Kaiser Normalization), an advantagescale consisting of 8 items $(\alpha=0.82)$ and a disadvantage-scale of 6 items $(\alpha=0.59)$ was extracted. 
Social influence regarding teacher-based health promotion was measured using three scales: modeling, social norm and social support, all reflecting subjective social norm (De Vries et al., 1995). A five-point scale was used. Modeling was measured in relation to colleagues with one item ('Colleagues address health education in class'). Perceived social norm was measured with 9 items, starting with 'The following persons / organizations find it important that I address health issues in class' $(\alpha=0.88)$. Principal Components Analysis of the social norm scale indicated three subscales of the social norm construct. The first scale of three items focused on the social norm of the school-staff: school management, colleagues and the school care coordinator $(\alpha=0.85)$. The other scales included two items each. These can be referred to as the client-norm: parents and pupils (Pearson $=0.66, \mathrm{p}<0.01$ ); and the external-norm: public health and welfare organizations, the inspector of education and the municipality $(\alpha=0.82)$. Principal components analysis of the social support scale revealed the same subscales as with social norm. The first scale of three items focused on the social support of school-staff ( $\alpha=0.87$ ), with the latter two scales focusing on the client-norm (Pearson $=0.66$, $\mathrm{p}<0.01)$ and the external-norm $(\alpha=0.86)$.

Self-efficacy towards teacher-based health promotion was measured with seven items ( $\alpha=0.79$ ). Based on principal components analysis two subscales were deducted. The first scale focused on circumstances related self-efficacy and includes five items $(\alpha=0.82)$. The second scale focused on so-called educational-routine related self-efficacy, consisting of two items (Pearson $=0.48$ ).

The perception of barriers towards classroom health promotion was measured with a yes/no question, followed by a list of possible barriers for those who perceived barriers. A sum-score of perceived barriers was computed. This yielded a single barrier-variable with integers as an outcome, ranging from 0 to a maximum of 14 barriers.

To increase response rates, the survey was recommended by the head of the youth health care department of the regional Public Health Institute Maastricht and by the coordinator of an organization responsible for cooperation between schools for regular and special education. This coordinator is a school principal of one of the special education schools in Maastricht. School physicians were asked to encourage school managers and eligible teachers to participate in the survey. Shortly after the survey-deadline, teachers of schools without or with only one respondent received a reminder letter from the head of the youth health care department again stressing the importance of participation in the study.

\section{Statistical analyses}

Whole sample means and standard deviations were calculated for the study variables. This was followed by the calculation of average scores of the scales. For the context characteristics, correlations with behavior were calculated using Pearson Correlation. For the motivation-scales (attitudes, social influence and self-efficacy) and variables t-tests were conducted distinguishing between teachers who addressed two or fewer health issues in the current year versus those who addressed three or more. 
The relationship of the motivational factors attitude, social influence and self-efficacy with teacher-based health promotion was tested via logistic stepwise regression. In the logistic regression, variables were entered in two blocks. First the context characteristics were entered, followed by the motivational-constructs (including barriers) in the second block. In this analysis gender was treated as a nominal variable and grade level as an ordinal variable.

\section{RESULTS}

\section{Participation and context characteristics}

Of the 180 respondents $54.3 \%$ were female (average age $=38.6$; SD 11.7), and $45.7 \%$ male (average age $=46.1 ; \mathrm{SD}$ 10.3). As less than $25 \%$ of teachers in Dutch primary education is male, this gender group is over-represented in this sample. The average age of respondents was 41.9 years (SD 11.7), with a significant difference between the sexes $(t=4.59, \mathrm{df}=172.1$, $\mathrm{p}<0.001)$, comparable to the average ages of teaching staff in the Netherland.

Respondents all taught at least one of the grades 6,7 or $8 ; 31.1 \%$ of the respondents taught a combination group of two or three grades. A slight majority of respondents (51.4\%) worked at a school in an urban area; 48,6\% worked in rural areas.

\section{Health promotion behavior}

The number of health promotion issues addressed by respondents ranged between 1 and 7 during the previous twelve months (mean: 4.03; SD: 1.51). Of the respondents $46.2 \%$ addressed at least the three topics considered to be the basic elements of school health promotion in the Netherlands. In total, $19 \%$ of the respondents failed to address any of the three basic health topics in the previous year. Overall, $80,7 \%$ of teachers reported having addressed a minimum of any three health-promotion issues in the previous year. Figure 5.1 illustrates the popularity of the different health issues among upper primary school teachers.

Of the context variables, the variables gender and grade level correlated significantly with the number of health issues addressed in the previous annum. Males reported on average 4.29 issues (SD 1.49) and females reported 3.81 issues (SD 1.50). Grade six, seven and eight teachers reported respectively 3.29 (SD 1.40), 3.98 (SD 1.30) and 4.93 (SD 1.24) issues addressed. No significant correlation was found between gender and grade level.

\section{Attitudes}

Two groups were compared on their attitudes towards teaching health promotion, comparing teachers addressing fewer than three health issues per year versus those who addressed three 


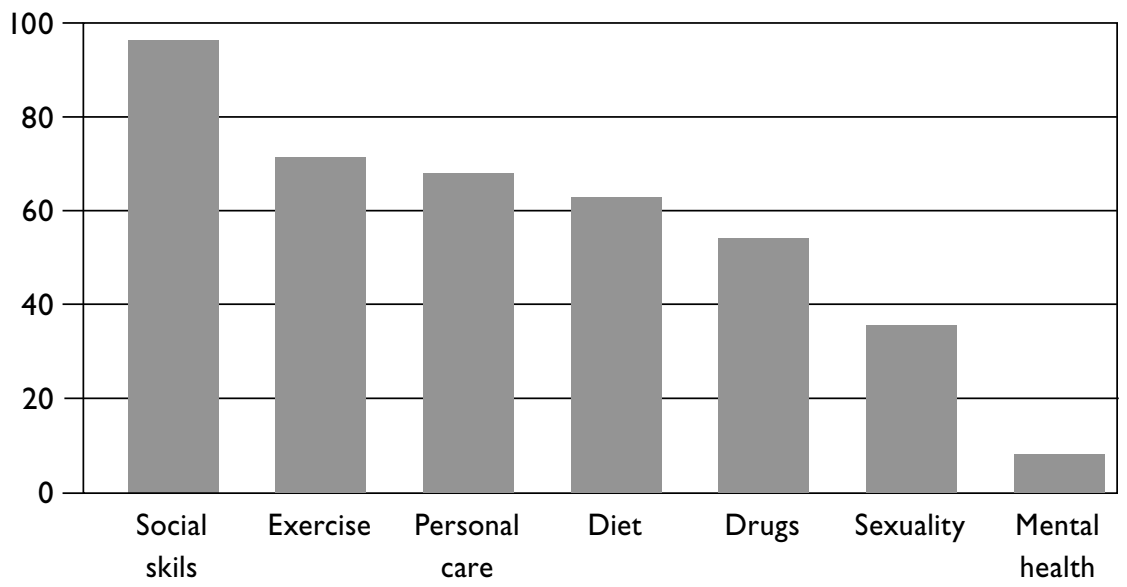

Figure 5.I Percentage of primary school teachers addressing different health issues

or more health issues. Table 5.1 shows that teachers that taught three or more health issues were significantly more positive than their colleagues about the fact that teaching health education would result in positive outcomes such as personal enjoyment, personal satisfaction and a positive commitment of the school towards pupil health. Furthermore, teachers that taught up to two health themes saw significantly more disadvantages, especially regret of not being able to perform 'regular' teaching tasks and going beyond perceived normal teacher responsibilities when addressing health themes in class.

\section{Social influence}

Of the main social influence constructs, only the modeling construct indicated a significant difference between teachers having addressed three or more health issues in the previous year versus those that did not as shown in table II. Those who perceived more modeling by colleagues, were more likely to have addressed three health issues or more. As part of the overall constructs regarding social norm and social support, the staff social-norm scale and the staff social-support scale revealed a significant difference between these groups. In both scales especially the social influence perceptions regarding school administration and the pupil care coordinator can be held responsible, with social influence of colleagues indicating a significant difference as part of the social-support scale too. Perceived social-support by pupils indicated a significant difference between the two groups as well. The pupil and parent social support scale indicated a trend $(\mathrm{p}<0.1)$ towards significance. This means that when teachers perceive more support, particularly from pupils, for engaging in health promotion, they tend to be more likely to have addressed three health issues or more in the previous year, as opposed to those who did not perceive much support from their pupils. 
Table 5.I Averages scores ( $\pm S D$ ) of the attitude scales and individual attitude-items for respondents addressing limited health education issues ( 2 or fewer) compared with those teaching average or more issues ( 3 or more). $(n=176)$

Measured construct

( -2 totally disagree to +2 totally agree)

Attitudes towards health promotion (HP) in the classroom

Perceived advantages-scale

When I address health themes in my own class
a) I do something good for my pupils
b) I contribute to school health promotion
c) I enjoy it
d) parents will be pleased with it
e) pupils will be more aware of the risks involved with certain unhealthy behaviors.
f) I do something which will satisfy myself
g) This will have an impact on the health of my pupils
h) I perceive a positive commitment of the school towards health and well-being of the pupils

\section{Perceived disadvantages-scale}

When I address health themes in my own class
a) It costs me much time
b) Pupils will feel uncomfortable
c) I go beyond the responsibility of a teacher
d) I have to familiarize myself with teaching methodology which I find difficult to per- form
e) pupils will start worrying unnecessarily about their health .
f) I will regret not being able to perform 'regu- lar' teaching tasks

Group I

(2 issues or fewer)

Mean SD

0.41

0.38

0.56

0.97

1.50

I.4I

0.66

0.70

0.85

0.74

0.91

0.71

I. 18

0.76

0.68

0.84

0.50

0.96

0.78

0.95

$-1.55$

0.76

$-0.33$

0.86

1.16

0.69

$-2.87^{* *}$

$-0.33$

0.66

$-0.65$

0.57

$2.28^{* * *}$

\subsection{5}

$-0.82$

1.05

0.32

1.02

I.20

$-0.32$

I.06

$-1.14$

0.96

$1.70^{\circ}$

1.27

$-0.91$

1.09

$2.47^{*}$

$-0.50$

1.02

$-0.76$

1.08

$-0.79$

0.97

$-0.93$

0.85

0.81

$-0.12$

1.07
$-0.47$

I. 15 
Table 5.2 Averages scores ( \pm SD) of Social Influence scales and social influence items for respondents addressing limited health education issues (2 or fewer) compared with those teaching average or more issues (3 or more). $(n=176)$

Measured construct

(-2 totally disagree to +2 totally agree)

HP modeling by colleagues

Perceived social norm towards teacher-based HP

- Staff social norm-scale (a,b, c)

- Pupil and parent social norm-scale $(d, e)$

- External social norm-scale (f, $g, h, i)$

The following persons / organizations value my input regarding class health promotion:
a) School administration
b) Colleagues
c) Pupil care coordinator
d) Parents
e) Pupils
f) Inspector of education
g) Regional public health institute
h) Regional welfare organization
i) The municipality

Perceived social support for classroom HP

- Staff social support-scale $(a, b, c)$

- Pupil and parent social support-scale (d,e)

- External social support-scale (f, g, h, i)

The following persons / organizations encourage me to conduct health promotion activities in class:
a) School administration
b) Colleagues
c) Pupil care coordinator
d) Parents
e) Pupils
f) Inspector of education
g) Regional public health institute
h) Regional welfare organization
i) The municipality

Group I

(2 issues or fewer)

$\overline{\text { Mean }} \frac{\text { SD }}{0.62} \frac{.82}{0.62}$

0.82

0.63

0.76

0.99

0.85

0.71

0.32

0.79

0.74

0.94

1.38

0.85

0.76

0.45

0.34

0.29

0.62

0.44

0.38

0.21

0.32

0.26

0.91

0.62

0.44

0.50

0.57
0.69
0.65
0.67

0.82
0.72
0.98
0.68
0.75
0.82
0.82
0.93
0.89

0.56
0.59
0.59
0.71

1.02

0.61

$-1.77^{\circ}$

0.99

0.75

$-2.55^{*}$

0.80

0.74

$-0.25$

I. 16

0.71

$-1.26$

1.24

0.79

$-2.55^{*}$

0.93

0.81

$-1.49$

0.79

0.95

$-2.55^{*}$

0.89

0.79

$-0.68$

0.70

0.84

0.20

1.06

0.89

$-0.73$

1.58

0.76

$-1.33$

I.16

0.91

$-1.77^{\circ}$

0.82

0.94

$-0.33$

0.61

0.53

$-1.55$

0.73

0.71

$-3.29 * *$

0.52

0.66

$-1.84^{\circ}$

0.58

0.60

0.32

${ }^{\circ} p<0.1 ; * p<0.05 ; * * p<0.01$

$\begin{array}{llll}0.75 & 0.87 & 0.83 & -2.76^{* *} \\ 0.74 & 0.70 & 0.75 & -2.25^{*} \\ 0.54 & 0.61 & 0.80 & -3.57^{* *} \\ 0.64 & 0.45 & 0.67 & -1.00 \\ 0.67 & 0.59 & 0.77 & -2.49 * \\ 0.87 & 1.04 & 0.79 & -0.80 \\ 0.89 & 0.56 & 0.75 & 0.33 \\ 0.71 & 0.37 & 0.69 & 0.51 \\ 0.75 & 0.33 & 0.69 & 1.26\end{array}$


Table 5.3 Averages scores ( \pm SD) of Self-Efficacy scales and Self-Efficacy items for respondents having addressed limited health education issues (2 or fewer) compared with those having taught three or more issues. $(n=176)$

Measured construct

( 2 totally disagree to +2 totally agree)

Self-Efficacy scale

- Circumstances-related SE scale (a, b, c, d, e)

- Educational-routine related SE scale (f, g)

I am able to conduct health promotion activities in class...

a) when colleagues and administration disagree with its importance

b) when pupils find the themes difficult

c) when the overall work-load is high

d) when I lack supporting materials

e) when I find the themes difficult

f) when themes arise in class unexpectedly

g) during the daily routine of teaching
Group I

( 2 issues or fewer)

\begin{tabular}{|c|c|}
\hline Mean & SD \\
\hline 0.07 & 0.65 \\
\hline-0.19 & 0.84 \\
\hline $0.7 \mid$ & 0.80 \\
\hline
\end{tabular}

Group 2

(3 issues or more) $\quad t$

\begin{tabular}{lllll}
\hline Mean & & SD & & \multicolumn{1}{c}{ values } \\
\cline { 5 - 6 } 0.37 & & 0.17 & & $-2.39 *$ \\
0.15 & & 0.82 & & $-2.15^{*}$ \\
0.93 & & 0.88 & & -1.37
\end{tabular}

${ }^{\circ} p<0.1 ; * p<0.05$

\section{Self-Efficacy}

The Self-Efficacy (SE) scale indicated a significant difference between teachers who had addressed fewer than three health issues in the previous year versus those who addressed three or more issues. Teachers who addressed three or more health issues are more likely to report a higher level of confidence in their own skills to address health issues in class than those who addressed fewer than three health issues. This can mainly be accounted for by the circumstance-related SE-scale. On average, teachers in the group having addressed three or more issues in the previous year had more confidence in their own skills than the teachers failing to address a minimum of three issues, that they were able to conduct health promotion activities in class when they perceived the themes as being difficult. The educational-routine related SE-scale did not indicate a significant difference between the two groups. Although other scales and items do not reveal a significant difference between the groups, they are illustrative of a possible direction of influence.

\section{Barriers}

Teachers who reported having addressed three or more health issues in the previous twelve months perceived 1.64 barriers on average $(S D=1.60)$. Teachers who reported having 
addressed fewer issues perceived 2.29 barriers on average (SD.2.04). Analyses of variance showed a significant difference between these two groups $(t=2.95, \mathrm{p}<0.01)$. Taking a closer look at the individual barriers, Pearson correlations revealed negative relationships between the behavior variable and the barriers lack of knowledge / information (Pearson correlation = $-0.19, \mathrm{p}<0.01$ ) and lack of consensus within school regarding the importance of health promotion (Pearson correlation $=-0.12 ; \mathrm{p}=0.01$ ). This indicates that teachers are more likely to address a minimum of three health issues when they do not perceive a lack of knowledge nor a lack of consensus with school regarding the importance of health promotion.

Overall, $80.4 \%$ of teachers reported that the limited time available in class is an obstacle to engaging in school health promotion properly. A lack of suitable materials was perceived as a barrier by $70.5 \%$ of all teachers. The third most often perceived barrier was lack of time beyond the regular teaching schedule ( $43.8 \%$ of all teachers). Additionally, lack of financial resources, lack of knowledge and lack of proper insight into the overall health status of the pupils were perceived as barriers by $25.0 \%, 20.5 \%$ and $17.9 \%$ of the respondents respectively. Besides a lack of knowledge, none of these often-perceived barriers were significantly linked with the behavior barrier used in this study.

\section{Correlations}

Within the attitude construct, advantages was found to correlate significantly with parent/ pupil norm $(r=.47)$ and with external norm $(r=.45)$, both from the social influence construct. Within the social influence construct, modeling correlated significantly with staff social norm $(r=.53)$ and staff social support $(r=.47)$. Staff social norm correlated significantly with parent/pupil norm $(\mathrm{r}=.55)$; with external norm $(\mathrm{r}=.59)$; and with staff social support $(\mathrm{r}=.52)$ as well. Additionally, the external norm was found to correlate significantly with parent/pupil norm $(r=.55)$ and with external support $(r=.51)$ also. Staff social support correlated significantly with parent/pupil support $(\mathrm{r}=.51)$ and with external support $(\mathrm{r}=.58)$. The latter correlated significantly wit parent pupil support $(\mathrm{r}=.50)$ too. Table 5.4 presents the correlations between all constructs and their significance.

\section{Logistic Regression Analyses}

A sequential logistic regression analysis was performed to assess membership prediction of the group addressing 3 or more health issues versus the group addressing fewer issues, first on the basic demographic predictors (context variables) and then after the addition of attitude, social norm and self-efficacy predictors. To avoid multicollinearity as much as possible only variables and subscales were entered in this logistic regression with a significant or nearsignificant t-value with regards to the behavior variable. Of the demographic variables gender and grade level met this entry-criterion. Of the motivational variables, advantages, disadvantages, modeling by colleagues, staff norm, staff support, pupil \& parent support, circumstances-related $S E$ and barriers met this criterion and were entered in the analysis. 


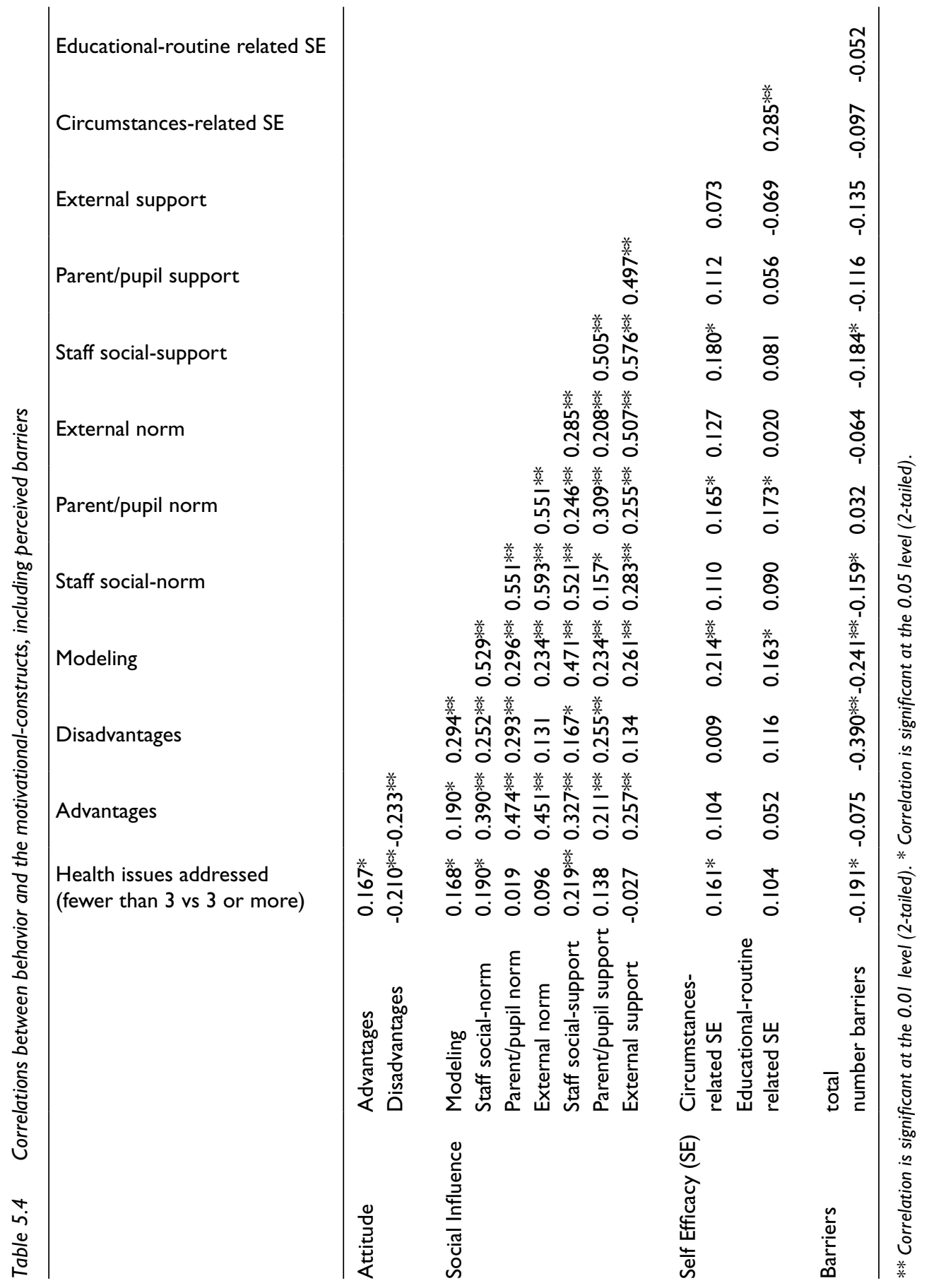


Table 5.5 Results of the logistic regression analysis of variables that showed a significant difference between the group teachers who had addressed a minimum of three health issues in the previous year versus those that did not.

\begin{tabular}{|c|c|c|c|c|c|c|}
\hline & \multicolumn{3}{|c|}{$\begin{array}{c}\text { Step I: } \\
\text { background-variables }\end{array}$} & \multicolumn{3}{|c|}{$\begin{array}{c}\text { Step 2: } \\
\text { ASE-variables }\end{array}$} \\
\hline & OR & $P=$ & $95 \% \mathrm{Cl}$ & OR & $P=$ & $95 \% \mathrm{Cl}$ \\
\hline Gender $(0=$ male; $I=$ female $)$ & 2.43 & .052 & $0.99-5.96$ & 2.51 & .067 & $0.94-6.73$ \\
\hline Grade level & 3.65 & .000 & $1.98-6.73$ & 4.82 & .000 & $2.30-10.09$ \\
\hline A: Disadvantages & & & & 1.25 & .006 & $1.07-1.46$ \\
\hline S: Staff Support & & & & 1.56 & .005 & $1.14-2.14$ \\
\hline E: Circumstances-related to SE & & & & 1.10 & .079 & $0.99-1.25$ \\
\hline
\end{tabular}

When only demographic factors were taken into account, teaching 3 or more health issues was positively related with teaching in higher grades and indicated a tendency towards being male. When the motivational factors were included, the significant effect of grade level persisted. Perceiving disadvantages reduced the likelihood of addressing a minimum of three health issues. Staff support increased the likelihood of addressing a minimum of three health issues in the previous year. Nagelkerke's R square for the two models was 0.23 and 0.43 respectively. The results of the regression analysis are presented in Table 5.5.

\section{DISCUSSION}

This study analyzed the determinants of teachers' decisions for teaching health promotion. We found teachers addressing three or more health issues per year could be differentiated from those who addressed fewer based on gender, grade level, perceived disadvantages, circumstances related to self-efficacy and especially staff support. The importance of school staff, especially school administration, for school health promotion practice was demonstrated in earlier studies. Cullen and others (Cullen et al., 1999) found teachers more supportive of change when supported by the school principal. Additionally, an Australian study by St.Leger (St.Leger, 1998) indicated that 'resources', 'staff' and the 'curriculum' were the most perceived enhancers of the health promoting school concept among teachers. Our study added the importance of support by pupil care coordinators. This is not necessarily someone who is part of the school administration. The importance of pupil care coordinators is understandable since they deal with pupil care at a more individual level within Dutch schools. 
The opinions of students and immediate colleagues were reported to be most influential in the decisions of Dutch teachers to provide an education program on organ donation and registration (Reubsaet et al., 2004). Earlier research already indicated that secondary school teachers in the Netherlands are more motivated by students' responses than by expected outcomes (Paulussen et al., 1995). This confirms the finding that pupil support may be positively linked to the likelihood that teachers engage more in school health promotion. It fits with the so-called Dutch Polder-model, characterized by attaining solutions through a process of dialogue and compromises. Following also the Ottawa Charter (WHO, 1986) advocating participation and empowerment, the influence of pupils may be another promising entry point for exploring school health promotion improvements.

In the St.Leger study (St.Leger, 1998) staff was named among the top three perceived inhibitors of the accomplishment of a health promoting school. Unlike in the current study, this perception was not related to the actual input in school health promotion. We found the perceived barriers 'a lack of knowledge' and 'a lack of consensus in schools with regard to the importance of health promotion' significantly linked to addressing less than three health promotion issues in the previous year or not. For both these barriers a link with staff seems likely as staff is responsible for additional training and expertise development (do they welcome knowledge from outside the education sector?). This could also boast their confidence in their own skills regarding the handling of themes perceived as being difficult. In the end, the staff members themselves are responsible for the level of consensus reached regarding school health promotion within their school. Support organizations may influence the agenda of the school and the awareness regarding school health promotion, they are not the ones deciding what staff is actually doing (Kolbe, 2005; Leurs, Schaalma et al., 2005).

St.Leger (St.Leger, 2004), followed by Apostolidou and Fontana (Apostolidou \& Fontana, 2003), advocates including a larger focus on school health promotion in initial teacher training programs. This is a more long-term strategy, preferably to be lobbied for and facilitated by national health promotion bodies and the Ministry of Health. At the regional level, we advocate training of pupil-care coordinators and school administrators. Attitude and more importantly behavior change of anyone who ought to be involved in school health promotion, including these professionals specifically can not be accomplished by educating knowledge only. Additionally, skills training, experiencing short-term successes and beneficial/pleasant collaborations between the education and health sectors are needed to enhance school health promotion at a local and regional level (Deschesnes et al., 2003; St.Leger, 1998; St.Leger \& Nutbeam, 1999).

Limitations of this study are that it is based upon a voluntary teacher survey, with a selfreport regarding the number of health issues addressed in class, only. The voluntary character of the survey enhances response rate bias. As it seems already that males are over-represented in the survey-sample, response rate bias is likely. With respect to the teacher self-report issue, that was found not a valid measure for school health promotion completeness by Resnicow and colleagues (Resnicow et al., 1998), it was not completeness we looked for. We looked for 
an indicator of effort put into classroom-based health promotion least likely to overestimate the input in classroom-based health promotion. By asking them per theme in what manner or with what materials they had addressed it, we tried to focus their memory and to limit socially desirable answers. With one of the outcomes of the study being the importance of support of school administration and other colleagues, the results ought to be complemented with the perceptions and actions of these professionals as well. Preferably, this should be based on structured interviews (Resnicow et al., 1998).

The survey includes one variable measured with one item (modeling) and three variables measured with two items (pupil and parent social norm and social support; and educationalroutine related SE), which correlated sufficiently. In future research more items should be employed for assessing these variables. Although the variables included in the survey were theory-based (Bandura, 1986; De Vries \& Mudde, 1998; De Vries et al., 2003; Fishbein \& Ajzen, 1975), this does not exclude the possibility that also other variables exert a direct or indirect influence on the number of health issues addressed per annum.

Another limitation is the possibility that the link between grade level and the number of health issues addressed is caused by the availability of specific health promotion programs only in certain grades. Most materials traced were aimed at grades 7 and 8 (Vlaardingerbroek et al., 2003). On the other hand, some materials available to lower grades in the Netherlands are more comprehensive and intense (Boot, Bessems et al., 2005). This may result in less health themes addressed in lower grades compared to grades 7 and 8 within the same time. It calls for future studies to develop more comprehensive measurement tools for classroombased health promotion further reducing the risk of overestimating the actual input provided.

As male teachers taught relatively more often in higher grades, compared to their female colleagues, it is very plausible that the near-significant gender-effect $(p=0.067)$ found in this study is caused by the grade-effect. This assumption is strengthened by the likelihood that male teachers were over-represented in the sample: less then $25 \%$ of teachers in Dutch primary education is male currently whereas $46 \%$ of the teachers participating in this study is male. Specific regional data regarding for the percentage of male/female teachers in grades 6,7 or 8 is not available. Therefore, based on these results, a gender-effect on school health promotion cannot be claimed.

This study indicates that a reduction of perceived barriers regarding school health promotion, especially misconceptions regarding school-based health promotion, the promotion of schoolbased knowledge and participation of pupils, staff and parents in school health promotion may be promising entry points for improvements in school health promotion in primary education. This implicates the important how-question for future research and the development of professional school health promotion: 'How to make optimal use of these entry points in health promotion practice to improve school health promotion in primary schools?'. 
For the promotion of school-based knowledge and raising whole-school participation we advocate a more participatory method: the schoolBeat priority workshop (Leurs, Jansen et al., 2005). In this workshop homogeneous groups of students, parents and staff are confronted with different health promotion priorities for their school and asked to select six priorities maximum. It is our experience that a lot of knowledge and perceptions are exchanged within the groups and between the groups leading to a sense of shared responsibility and the consensus looked for.

Overall, Intervention Mapping (Bartholomew et al., 2001) provides a sound and comprehensive planning strategy to go ahead from here. This implies that professionals map their interventions - step by step - based on sound analyses of the situation, including professional capacity. The focus points yielded by this study are the starting points. As school health promotion is a shared responsibility of the health sector and the education sector (Kolbe, 2005; St.Leger \& Nutbeam, 2000), we promote a collaborative action-research approach of health promotion professionals and school staff working through the Intervention Mapping planning matrix together. 


\section{Development of the schoolBeat quality checklist for healthy school interventions}

Published in Dutch as

Peters LWH, Leurs MTW, Jansen MWJ, Keijsers JFEM and Schaalma HP (2004). Ontwikkeling van the schoolBeat checklist voor kwaliteit van schoolgerichte interventies. TSG,82(I), 50-57. 
In the spring of 2002 the collaboration schoolBeat was established in the Maastricht-Mergelland region in the south of the Netherlands. This was an initiative of five local support organizations in the area of health promotion, welfare and safety: the Regional Health Service South Limburg (GGD Zuidelijk Zuid-Limburg), the Maastricht Mental Health Care Bureau (RIAGG Maastricht), CAD Limburg, Youth Care Bureau (Jeugdzorg) and the welfare foundation Trajekt (Leurs et al., 2002). The aim of SchoolBeat is to improve the collective health promotion and prevention programs in primary and secondary education. Additionally, it intends to meet the individual needs of students as part of an integrated health care approach (Kleijnen $\&$ Leurs, 2003). Using terminology common to mental health care, collective health promotion and prevention is largely the same as universal and selective prevention (Mrazek \& Haggerty, 1994). SchoolBeat aims to specifically improve collective health promotion and prevention using a demand-driven, plan-based approach and through the realisation of integrated, coordinated, high quality prevention programs. This article focuses on the quality of preventative interventions, with particular reference to measuring the quality of these interventions.

There are already a number of general quality models, such as the INK-model (Instituut Nederlandse Kwaliteitsprijs), the HKZ-model (Harmonization quality judgement in the care sector), ISO-norms (International Organization for Standardization) and the Balanced Score Card. There are also several quality instruments that are specifically designed for prevention program. In the Netherlands, for example, Preffi and Intervention Mapping (Bartholomew et al., 2001; Molleman et al., 1995; Molleman et al., 2003). Instruments such as Preffi meet a large need (Blokland et al., 2003), are viewed positively (Molleman et al., 2003) and can be used widely in the area of prevention. Because of their origin in and focus on the area of prevention, they are not always suited to measuring quality in other sectors. In specific sectors such as education an instrument is required that is, in terms of content and language, optimally tailored to this sector, particularly if the instrument is to be used by people active in this sector (such as teachers). Moreover, existing instruments are fairly extensive (Preffi 2.0 has 39 criteria and 108 questions), while schoolBeat sought a manageable and concise instrument. For that reason, SchoolBeat gave the NIGZ/Centrum for Review \& Implementation (CRIM) the task of developing just such an instrument. This article describes the background and development of that instrument: the schoolBeat checklist.

An important assumption in the development of this instrument was that it be useful in the identification and selection of good quality interventions and that it complements the schoolBeat network structure and demand-driven approach. The schoolBeat network structure is such that every school has a prevention team that comprises teachers, students, parents and a health promotion or prevention worker (the schoolBeat advisor). The school prevention team chooses one or more health-related themes, which will be the focus of interventions to be implemented at the school; this choice is made on the basis of a standard inventory of health care issues (objective needs) and the wishes and needs of personnel, students and parents (perceived needs). Following that, interventions are chosen from the programs being offered regionally and nationally that address the chosen area(s) identified by the prevention team. The aim of the schoolBeat quality checklist is to facilitate and systemize the intervention choice. 
Quality is an abstract term that requires further explanation. In the development of the checklist a process was followed common to quality assessment (Donabedian, 1980). In the context of a quality vision (for example what is the extent to which the wishes of customers and the norms of within a profession are taken into account?) quality criteria are formulated, which are then converted into indicators or measurable units. Norms are then established for each indicator in order to make it possible to see when a quality criterion is being met.

An important issue in relation to the quality vision is who determines the criteria to be used to assess quality. In accordance with current thinking in the area of quality, in which providers and users are important in determining quality, it was agreed within schoolBeat that the quality criteria should be relevant to both the collaborative regional support organizations (hereafter referred to as the project group) and schools and their prevention teams. The first step in developing the checklist was performing a review of commonly used quality criteria for interventions and quality testing instruments. Given the checklist was to be used by both schools and organizations offering programs, the focus of the review was the sector health / welfare / safety and the sector education. Additionally, the review also specifically looked at sources relating to the healthy school, also known as school health policy in the Netherlands. Generally, this means a school-wide analysis of the health and welfare of students and personnel, paying particular attention to the individual and the social and physical environment. Based on the results of the review, the project group and the schoolBeat Practical Advice Body (hereafter referred to as PAR) make choices with relation to the quality criteria for interventions to be used in schoolBeat. After this, these choices are used to identify the instruments, which may also be taken from existing quality instruments such as Preffi. In the article, the method and results of the review are discussed, after which the development process and the instrument are described.

\section{METHODOLOGY}

For the purpose of the review, information and literature on quality and assessing quality in the area of prevention, health promotion, welfare and safety was sought using various methods. Literature archives (NIGZ, Medline, Current Contents) were consulted using the following search terms and combinations thereof: quality, instrument, indicator, prevention, health promotion, education, healthy school and their equivalents in Dutch. In addition, other sources used included the Internet, relevant journals, experts in the area of quality were consulted and much information was obtained from literature lists from already identified publications.

The methodology used is the same as the standard methodology used by NIGZ/CRIM. Central to this approach is that information be obtained from written sources and through consultation, and from the perspective of policy, research and experience. Reviews of the 
NIGZ/CRIM should not be seen as exhaustive, but they do identify the most important information and insights.

The focus of the review was on information relevant to quality and/or quality assessment of interventions. Much of the current literature on quality focuses on the quality of organizations. Current thinking on quality, in keeping with Donabedian (1980), often differentiates between three dimensions: structure, process and results. The reason for this is that the quality of results (for example financial or health improvement, customer satisfaction) is determined by the quality of the processes that are implemented, and the quality of this is in turn determined by the structural aspects of the organization, such as leadership, human resources policy, and so on. For the purpose of the review, quality aspects were specifically targeted that fall under the dimensions process and results, given that these are seen as being the most directly relevant to the quality of interventions in schools.

\section{RESULTS OF THE REVIEW}

\section{Overview of commonly used quality criteria}

Firstly, looking at the results it can be seen that the literature on quality and quality assessment in general are not extraordinary in terms of clarity. Quality criteria are often not explicitly defined: sometimes they have to be deduced from the text or the elements of the instruments. Moreover, it isn't always clear whether what is talked being about is the quality of interventions or the quality of organizations or a specific approach, such as the healthy school approach.

In total, 15 useful publications were identified, ten in the area of prevention/care/welfare (Bering, 1997; Cameron et al., 2001; Claessens \& Braun, 1997; Eagle \& Davies, 1993; Nederland, 1999; Parish, 2001; Place \& Cazemier, 1998; Sluijs \& Wagner, 2000; Tones \& Tilford, 1994; Van Greenhuizen et al., 1997), two specifically in the area of the healthy school (European Network for Health Promoting Schools, 1998; Rivers et al., 2000) and three relating to the education sector (Ministerie van OCW, 2001; Paulussen, 1995; Zipper, 2002). In the original review the quality criteria named in each publication were identified. These were then classified, resulting in 11 (categories of) criteria (Peters \& Keijsers, 2002). These reflect the vast majority of criteria found in the publications; criteria that were only named in one publication or only vaguely referred to or were of no importance (for example 'performing specific activities') were not considered for inclusion. Table 6.1 lists the 11 criteria and the number of times they were named in publications in each of the three sectors. The table shows there are many similarities between the sectors, but also a number of differences.

In the sector prevention / care / welfare, the criteria effectiveness, efficiency and userorientation were identified most often. In addition, and particularly in World Health 


\begin{tabular}{lccc}
\hline & $\begin{array}{c}\text { Prevention / care } \\
\text { /welfare } \\
\text { Quality criterion }\end{array}$ & Healthy school & Education \\
\hline $\begin{array}{l}\text { Effectiveness, efficacy } \\
\text { Efficiency, suitability }\end{array}$ & 8 & & (2 publications) \\
$\begin{array}{l}\text { User orientation, user satisfaction } \\
\text { Consideration of individual and social and } \\
\text { physical surroundings }\end{array}$ & 8 & 2 & 2 \\
$\begin{array}{l}\text { Consideration of involvement of parents and } \\
\text { community }\end{array}$ & 10 & 3 & 1 \\
$\begin{array}{l}\text { Consideration of involvement of other } \\
\text { organisations (education, health, welfare) }\end{array}$ & 2 & 5 & 1 \\
$\begin{array}{l}\text { Quality of teachers, training, support } \\
\text { personnel }\end{array}$ & 2 & 1 & 1 \\
$\begin{array}{l}\text { Improving skills } \\
\text { Participation of all involved in planning, } \\
\text { development and implementation }\end{array}$ & 1 & 2 & 1 \\
$\begin{array}{l}\text { Ethical principles (such as fairness/justice/ } \\
\text { equality) }\end{array}$ & 2 & 3 & 1 \\
$\begin{array}{l}\text { Consideration of wishes of schools with } \\
\text { regard to implementation }\end{array}$ & 8 & 4 & 2 \\
\hline
\end{tabular}

footnote: Frequencies can be higher than the total number of publications in a sector because various criteria can come from the same publication in the same cell (for example fairness and equality in the category ethical principles).

Organization (WHO) publications, participation by those involved, consideration of the surroundings and ethical principles were also seen as important.

In publications relating to the healthy school, the most important aspects were principles in accordance with the European Network of Health Promoting Schools (ENHPS, 1998), criteria that the WHO had formulated for a healthy school, and quality standards that came out of an evaluation of healthy schools in Great Britain (European Network for Health Promoting Schools, 1998;

Rivers et al., 2000). In these sources the following aspects were identified as being important:

- cooperation between schools and health organizations;

- consideration of the individual and the social and physical school surroundings;

- attention for relationships with parents and the surrounding community of the school;

- participation of all involved in planning, development and implementation;

- ethical principles such as fairness and equality; and

- skills such as 'empowerment', critical thinking and self-confidence. 
In the educational sector, the focus of the review was on criteria identified in government policy in relation to quality care and in the area of curriculum innovation and implementation. From the perspective of government policy (Ministerie van OCW, 2001; Zipper, 2002) quality is put into operation in:

- an educational program that allows students to perform optimally;

- effective allocation of government resources;

- a safe school environment;

- involvement of parents and students in the school;

- cooperation with other organizations outside the school for the purpose of broad student care;

- maintaining the quality of teachers; and

- taking into account differences between students.

Important in the area of curriculum innovation and implementation are criteria which are used by teachers / schools to decide whether they will adopt interventions (Paulussen et al., 1995):

- instrumentality: is it clear what is expected of teachers?;

- relevance to prevailing circumstances; and

- investment/costs (financial, preparation time, implementation time, difficulty) and results (usefulness for students, appreciation by colleagues).

These eleven criteria were put to the project group and the PAR, who made appropriate comments and approved of them, as the basis for developing the checklist.

\section{Instruments for measuring quality}

After establishing the 11 criteria as the basis for the schoolBeat quality instrument, existing quality instruments were screened in terms of their relevance and usability for these criteria. For the sector prevention / care / welfare, five instruments were identified that are specifically focus on the quality of preventive interventions (Ader et al., 2001; Bartholomew et al., 2001; Cameron et al., 2001; Molleman et al., 1995; Molleman et al., 2003; Vandenbroucke et al., 1995). These instruments are, in terms of area of focus, fairly comparable and effectiveness appears to be the main quality criterion. However, this primarily concerns the expected effectiveness, which is determined by the degree of systematization of the development process of an intervention. In the instruments there are also criteria other than the 11 formulated criteria, primarily because they are seen as instrument for measuring effectiveness or a systematic approach: participation of those involved in the development, listening to the wishes of the user in terms of implementation and quality of the personnel. With the exception of the instrument of Vandenbroucke (Vandenbroucke et al., 1995), none of the instruments have been analyzed in terms of reliability and validity; this was to be done for Preffi, but the necessary results were not yet available (note a). It was concluded that these instruments are highly relevant for a large number of the criteria, but no single instrument covers the entire spectrum of the agreed 11 quality criteria. 
In the area of the healthy school, two instruments were identified. In terms of the ENHPS [20], goals, indicators and norms were formulated at the international, national and local levels. However, these goals have virtually nothing in common with the agreed criteria, but rather the structures, organizational characteristics, dissemination of the healthy school concept in the school and the eventual results of the entire healthy school approach (for example a reduction in the incidence of teasing). This instrument was therefore not seen as being relevant for the development of the checklist. The standards that have been formulated by the British National Healthy School Standard (Rivers et al., 2000) are certainly relevant for a number of criteria, such as involvement of school personnel in planning and ethical aspects.

In education, many instruments were developed in the 1980s that can be used for quality care (Leen, 2001). However, there is insufficient information available to determine the extent to which these instruments are relevant and usable for the checklist to be developed.

\section{DEVELOPMENT OF THE CHECKLIST}

Given that none of the identified instruments incorporated all of the 11 agreed quality criteria, the decision was made to develop a unique schoolBeat 'checklist for the quality of interventions in and around schools'. Extensive use was made of existing quality measuring instruments in the development process, especially the five instruments named in the prevention sector (Bartholomew et al., 2001; Cameron et al., 2001; Molleman et al., 1995; Molleman et al., 2003; Vandenbroucke et al., 1995) and the British National Healthy School Standard (Rivers et al., 2000). This was a creative and consultative process in which the ideas and priorities of those involved were considered, and particularly the PAR members. PAR highlighted the need for the checklist to be manageable and concise and of the need for it be able to be used by schoolBeat workers (local health promotion and prevention workers).

During the development process, two draft versions of the checklist were formulated. They were assessed and commented on by the PAR, the project group, two school health policy coordinators from regional public health services (GGDs) and a primary school teacher. The feedback, discussions and decisions largely addressed the following points.

\section{Splitting up criteria}

Based on the five instruments from the prevention sector and the ideas of the PAR members, the criterion 'effectiveness' was split into two criteria: proven effectiveness and planning. In the Netherlands, few health interventions in the education sector have been examined in terms of their effectiveness. Given that effectiveness is seen as being very important in the literature and by PAR, it was seen as necessary for the checklist at the very least to provide some indication as to the effectiveness of each intervention. It is generally assumed 
that a planned approach in the development of an intervention results in a greater chance of it being an effective intervention (Bartholomew et al., 2001; Kok, 1992). The original criterion 'efficiency' was split into 'efficiency for support organizations' and 'efficiency for the school'.

\section{Overlap between criteria}

Some of the original criteria displayed a large degree of overlap and for that reason were combined. In this way the criteria 'user orientation / user satisfaction' and 'consideration of the wishes of the school' were combined to create a new criterion 'education orientation'. In the first draft version some items were relevant to multiple criteria. In the final checklist there is no overlap, because overlapping criteria have been combined, or because items in calculating the various criteria have been given different emphasis.

\section{Doubts regarding the relevance of criteria for all interventions}

It was unclear from the literature whether the criteria 'consideration of the surroundings' and 'involvement of parents and community' should be applied to every individual intervention or only to the healthy school approach in its entirety. Even though most of those involved in the development phase did not think they should be considered for every intervention, these criteria were retained, primarily because they provide information on the scope of an intervention.

\section{Vagueness of criterion 'ethical principles'}

The criterion 'ethical principles' comprised abstract principles that were difficult to describe and measure, such as fairness, equality, and the like. For that reason this criterion was made more specific by looking at current themes that are important in the area of health promotion and education: consideration of disadvantaged groups and (multi)cultural issues. Additionally, an item specifically referring to treatment of the target group was added.

\section{Aiming to minimize the number of possible criteria}

In order to facilitate the usability of the checklist it was also desirable to have as few criteria as possible. Criteria that conceptually displayed any form of similarities with each other were combined as much as possible, especially where they consisted of few items. in this way the original criterion 'skills', which in the first draft version comprised a single item, was later included in the criterion 'planning': in reviews and meta-analyses it was observed that practicing skills increases the effectiveness (Bandura, 1997; Bartholomew et al., 2001; Jané-Llopis, 2002). The original criterion 'involvement of other organizations' was removed because it made no contribution to the process: schoolBeat is after all entirely oriented towards the relationships between schools and support organizations. 


\section{Aiming to minimize the number of items}

This aim came from the requirement of the PAR that the checklist be concise in order to encourage its use. Those involved realized that this aim is somewhat at odds with the need for specific and unambiguous indicators, which can have a detrimental effect on reliability. In terms of unambiguousness, each item has a short explanatory text using operational terms.

\section{Category and norm scores}

A three-point scale is used for scoring at the item level (no, a little, yes), to which the category 'unknown' was added for cases in which information is not available. The scores for the criteria are calculated and for the purpose of clarity reduced to three categories (good, average, poor). There is no overall assessment of the quality of an intervention because the criteria are so different from each other and cannot be combined. There is also no factor attached to the criteria indicating their relative importance. Further research is necessary to see how users feel about the absence of a single assessment score and how users might use such a quality assessment. If necessary, it is possible to formulate a factor for each of the criteria or a set of minimum criteria, which would be based on the wishes and experience of users.

The final checklist comprises 31 questions that are divided across nine criteria (see Table 6.2): effectiveness; planning; efficiency for support organizations; efficiency for the school; education orientation; participation; consideration of the surroundings; quality of support; ethical principles.

\section{PROPOSAL FOR USING THE CHECKLIST}

The aim of the checklist is to simplify and systemize the choices schools have to make when deciding which intervention(s) to introduce. It does this by providing an assessment of specific quality aspects relevant to both support organizations and schools. Such an instrument does not yet exist. The checklist is has not yet been applied to interventions. At this stage, it is to be used as follows. Using the checklist can be divided into two stages. Firstly, the filling in of the checklist based on information and secondly making a choice based on the checklist scores.

Primarily health promotion and/or prevention workers (the schoolBeat-advisors) will fill in the checklist. Given that the checklist also asks for an assessment from the school (teachers, students, parents), primarily for the criteria 'efficiency' and 'education orientation', it is recommended that (part of) the checklist be also completed by schools that have experience with the relevant intervention. In principle, the checklist should only have to be filled in once and the checklist scores for all those assessed interventions can be placed in a central database. It is also advisable to continuously consult with schools on their experience with a particular 
intervention, as more and more schools gain experience with that intervention. Assessments can differ per school or even per class. The checklist (or parts thereof) could also be used as a complementary evaluation-instrument by schools that have experience with the particular intervention in question: schools that have no prior experience with a particular intervention could then use this information.

Health promotion and/or prevention workers and school staff can all be involved in the process of choosing interventions. The proposed schoolBeat approach described in this article can also be adopted in other regions. Firstly, school staff, in this case the school prevention team, choose a health issue having compiled an inventory of the health issues, as well as the wishes and needs of the school. The schoolBeat advisor then identifies interventions relevant to the selected health issue, school type and age of students in question. The advisor then consults the checklist scores for those particular interventions and advises school staff on what the best interventions would be to precede to implementation. The school ultimately decides what interventions to adopt, a decision which is partly based on the advice of the advisor and the checklist scores. This choice may differ from the advice of the advisor if school staff have different priorities. The possibility of differing choices is an important element of this demand-driven approach inherent to schoolBeat in the area of school health policy.

\section{AREAS OF CONCERN IN USING THE CHECKLIST}

There are still a number of issues related to putting the checklist into use that warrant discussion. These issues have been analyzed in a number of pilot projects and will be discussed in further detail in a subsequent publication. However, below is a cursory examination of these issues and their possible implications for users of the checklist.

\section{Validity}

The checklist asserts that it can measure the quality of interventions for schools from the perspective of providers of such programs and the schools themselves. The approach used in the development of the checklist was designed to achieve just this, drawing on sources on quality and quality assessment in the prevention / care / welfare sectors and education. However, relatively few sources were used from the education sector, making it difficult to know whether education professionals think that the checklist measures all relevant aspects of the quality of interventions. This issue of validity also applies to the prevention sector, although a positive answer with regard to this sector is easier to obtain because much more literature was used and many more people were involved from this sector. This was also confirmed when the checklist was presented to a group of regional health care workers in a workshop (Peters et al., 2003). 


\section{Procuring sufficient available information}

A lot of information is required to complete the checklist, some of which has to be obtained from more than one organization, including national organizations, schoolBeat organizations and schools. Part of the required information is available from a recently compiled inventory of regional and national intervention programs, which identifies some 92 interventions in the education sector (Johansen, 2002). Obtaining all the information required to complete the checklist questions properly will not only take considerable time, but is also be fairly labor intensive. Moreover, monitoring on a continuous basis the assessments of schools, for example by using the checklist or parts thereof as an evaluation instrument in schools, requires good organization. The capacity to realize this at the regional level does not currently exist. However, given that the checklist can also be used at the national level, for example by linking it to the recently established web site www.gezondeschool.nl [the Dutch healthy school website], organizing the procurement of information for completing the checklist centrally and at the national level is advisable. To date, in current practice there has generally been little information on quality aspects of interventions available and, despite this, choices are still made. The checklist may facilitate and systemize the decision-making process, even in cases where not all the information is available.

\section{Reliability}

Once information is available, filling in the checklist requires this information to be assessed. However, this does not answer the question as to whether the information is reliable.

Reliability is determined by the unambiguity of items, the unambiguity of the information to be assessed and the comparability of the assessors. The unambiguity of items was an important aim in developing the checklist, but this was in conflict with need for conciseness. In this way 'a thorough analysis' (see item 2.3 in Table 6.2) can be performed in multiple items. However, the choice was made for an explanatory text with examples to accompany each item. In terms of the unambiguity of source information, it has been recently observed in Preffi that assessors react differently to missing or unclear information, which highlights the need for consultation and clear instructions (see note a).

In terms of the comparability of assessors, it is desirable that the checklist be completed by people with thorough knowledge of and experience with healthy school interventions. Recent experience with Preffi 2.0 shows that the assessment of different assessors can differ markedly, especially if the assessors have different backgrounds, come from different areas of expertise or have different professions. However, if these same assessors discuss their responses, greater consensus can be achieved (see note a). It therefore seems best to have more than one person complete the checklist (health promotion workers, prevention workers, welfare workers and teachers), who then discuss the responses in order to come to a consensus. 
Table 6.2 Overview of the quality criteria and items of the schoolBeat checklist

\section{Criterion I: Demonstrated effectiveness}

I.I Has the intervention achieved the desired results in the past?

I.2 Was there good quality evidence to support this?

\section{Criterion 2: Systematic approach}

2.1 Are the short-term goals clear and specific?

2.2 Has the target group been clearly identified?

2.3 Are the goals based on a thorough analysis van the problem?

2.4 Is the choice of target group based on a thorough analysis of the problem?

2.5 Is the intervention method suited to the goals?

2.6 Is the intervention method suited to the target group?

2.7 In the intervention are behavioral change principles used that have been proven effective? (such as active participation, feedback, etc)?

2.8 Does the intervention allow for the teaching or improvement of skills?

2.9 Was the target group involved in the planning/development of the intervention?

\section{Criterion 3: Efficiency for organization (schoolBeat partner)}

3.I Is the effort of personnel (in terms of training, preparations and support during implementation) from the organization reasonable for the type of intervention?

3.2 Are the costs (purchase of material, training personnel, etc.) for the organization reasonable for the type of intervention?

\section{Criterion 4: Efficiency for school}

4.I Is the effort of personnel (in terms of preparation and implementation) for the school/ teacher reasonable for the type of intervention?

4.2 Are the costs (purchase of material, training, etc.) for the school/docent reasonable for the type of intervention?

\section{Criterion 5: Suitability to education}

5.I Does the intervention make a contribution to one or more education goals?

5.2 Does the intervention improve the atmosphere in the class or the school?

5.3 In terms of practicality is the intervention easy to use in education?

5.4 Is the assessment of teachers with this intervention positive?

5.5 Is the assessment of students who have worked with the intervention positive?

5.6 Do parents see the benefits of the intervention?

\section{Criterion 6: Participation}

6.I Is the active participation of the target group (generally students) during the implementation of the intervention encouraged effectively?

6.2 Are parents or other persons, groups or organizations from the surrounding community effectively involved in the intervention?

\section{Criterion 7: Consideration of the surroundings}

7.I Does the intervention effectively take into account safety and supporting social environment with regard to the theme?

7.2 Does the intervention effectively take into account safety and supporting physical surroundings with regard to the theme? 


\section{Criterion 8: Quality of support}

8.I Is the required amount of instruction or training to prepare those people who will carry out the intervention in proportion to the intervention itself?

8.2 Is the support during implementation effective?

\section{Criterion 9: Ethical principles}

9.I Is the intervention suited to use in multicultural classes?

9.2 Does the intervention take the target group seriously (it isn't patronizing)?

9.3 Does the intervention make a contribution to reducing socio-economic health differences (for example by focusing on disadvantaged groups or on problems that are prevalent among these groups)?

\footnotetext{
Footnotes

I Possible answers for each item: Yes (2 points), Somewhat (I point), No (0 points), Unknown (0 points). For each criterion the item scores are totaled to reach a final assessment - Appears to be Good, Appears to be average, Appears poor. Because the number of items differs per criterion, the score that determines the final assessment can also differ.

2 The complete checklist is included in the original review [25] and in Appendix B of this thesis.
}

\section{CONCLUSIONS}

As part of the schoolBeat project, a quality checklist has been developed for interventions in the area of collective health promotion and prevention in education. While the schoolBeatchecklist still needs to be further tested in terms of validity, reliability and usability, it is possible to conclude that there is a real need for a tool such as this. A general literature review revealed that no existing measurement instruments encompass all those quality criteria considered relevant - in the areas of health promotion and prevention and education. Further analysis is necessary to examine the extent to which the checklist can be used to assist health promotion and prevention workers providing advice as well as school prevention teams themselves in choosing specific interventions.

The following questions relate specifically to this process: Do checklist assessments contribute to the advising and decision-making processes? Does it provide comparable advice/ choices? Upon which quality criteria are advice and subsequent choices based? Is it possible to attach factors to different criteria that reflect their importance? And can this factor be used to determine an overall quality assessment for a given intervention?

It is too early to know the extent to which a specific quality instrument for school interventions will actually play a role in the intervention choices of schools - whether or not complemented by pre-existing quality assessments. The ultimate goal of using the checklist is to make a contribution to improving the quality of school health policy. 


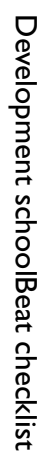




\section{Comprehensive quality assessment of healthy school interventions}

Published as:

Leurs MTW, Schaalma HP, Jansen MWJ, Mur-Veeman IM, Van Breukelen G, De Vries NK (2007). Comprehensive quality assessment of healthy school interventions. Preventive Medicine, 45(5), 366-372. 
Health promotion interventions in schools are some of the key strategies to enhance youth knowledge, attitudes and skills concerning healthy lifestyles (St.Leger, 1999). Specific interventions, combined with school policy, the school's infrastructure and links with health services and the local community, are central ingredients of comprehensive school health promotion (Allensworth \& Kolbe, 1987; WHO, 1996). Since worldwide interest in school health promotion rose in the 1980s, an ever-increasing number of school-based interventions have been developed and implemented. In some countries, this has now reached a level whereby schools feel overwhelmed by active marketing of many health promotion interventions of unknown quality (Lee et al., 2004; Leurs, Jansen et al., 2005).

Schools involved in the American Coordinated School Health Program and the European Health Promoting Schools Framework are urged to adopt good quality health promotion programs that best suit their needs (Kolbe, 1986; Noble \& Robson, 2005), analogous to the 'Communities that Care' approach used in community health promotion (Hawkins et al., 2002). In this article we elaborate on the question what is 'good quality' in school health promotion and how to assess this.

To increase the effectiveness of health promotion, it is widely accepted that effective interventions should be evidence-based and preferably based on systematic reviews (Mackenbach, 2003; Rychetnik \& Wise, 2004). Where evidence is absent, well-designed, theory-based interventions acknowledging the health promotion principles prescribed by the Ottawa Charter are advocated as a sound alternative (Bartholomew et al., 2001; Durlak \& Wells, 1997; Kolbe, 1986). However, in health promotion in general and school-based health promotion in particular, only a limited number of the available interventions have been subjected to some kind of evaluation, with varying quality (Gottfredson \& Wilson, 2003; Thomas, 2005). This makes it almost impossible for schools and support organizations to incorporate evidence into their selection process. Reports that the use of evidence-based school health promotion programs is not yet widespread among schools (Ringwalt et al., 2002) therefore come as no surprise. Transparency and accessibility of information describing the evidencebase of programs is needed. To this end we developed the tool described in this article.

Developing an assessment tool for a construct with a wide range of interpretations is always challenging. A number of general quality instruments for health promotion have been developed worldwide. SAMHSA's National Registry of Evidence-based Programs and Practices (NREPP), the Dutch 'PREFFI-instrument' and the Swedish 'Succeeding with Health Promotion - quality assurance' are some excellent examples (Ader et al., 2001; Bartholomew et al., 2001; Molleman et al., 2005). Proven effectiveness and a sound theoretical base are included in these tools as strong indicators for the quality of health promotion interventions. These instruments use solely the health promotion perspective and do not take the education perspective into account.

The challenge increases for constructs used in two distinct professional domains (Hudson, 2002). Principles of effectiveness and theory-based development are highly valued in the 
health promotion domain (Botvin, 2004; Dusenbury \& Hansen, 2004; Tones \& Green, 2004). However, schools seem to base their choices to adopt a health promotion intervention on other criteria (Leurs, Bessems et al., 2007). In this respect, schools are not so different from governments: getting 'evidence' into public health policy remains exigent (Nutbeam, 2003b; Rychetnik \& Wise, 2004). Quality tools in school health promotion are rare. In 1997, the American Centers for Disease Control and Prevention published a process evaluation manual for infrastructure development within the Coordinated School Health Program (CDC, 1997). The Hong Kong Healthy Schools Award Scheme takes evaluation of healthy schools a step further by looking at the school achievements and outcomes as well (Lee et al., 2005). However, neither focus on the quality of specific interventions included in school health promotion. The National Registry of evidence-based Programs and Practices (NREPP) in the United States does focus on specific interventions, also for schools, but limits this focus to their evidence-base ignoring possible other quality criteria used in education.

The aforementioned health promotion quality assessment tools do not reflect the perceptions of quality in the education sector. This makes them less useful for quality assessment of school-based interventions, necessary for school health promotion quality improvement. A quality assessment instrument integrating quality perspectives for both the educational and health promotion sectors was therefore developed: the 'schoolBeat-checklist'- the focus of this article. The developmental process of the checklist included a literature review, expert consultations, a minor validity study and a usability study providing promising results (Boot, Leurs et al., 2005; Peters et al., 2004). The checklist is part of the schoolBeat-project, which focused on developing and implementing coordinated, tailored school health promotion in the Netherlands (Leurs, Jansen et al., 2005).

\section{The schoolBeat-checklist}

The schoolBeat-checklist for quality assessment includes three criteria relevant to health promotion, two criteria considered specifically relevant to education and four criteria relevant to both sectors (see Appendix B). Only those professionals for whom the criterion is relevant assess that criterion: teachers assess six criteria and health promoters seven out of nine criteria. Each criterion consisted of three to 14 items for which an analytic scoring rubric was developed to reduce subjectivity due to differences in assessors' general interpretation of a construct (Mertler, 2001). Scoring is done on a three-point scale: 'no / insufficient' or 'unknown' (0), 'reasonable' (1), and 'good / definitely' (2). The average criterion scores, with a verbal quailification ('seems insufficient'; 'seems reasonable'; and 'seems good'), are the final outcome of the checklist. A manual (in Dutch) outlines explicit guidelines and checkpoints per item.

This study aims to fine-tune the content and application protocol of the schoolBeat-checklist. The outcomes of the quality assessments conducted in this study were also meant to be useful to the Dutch Healthy School Network. 


\section{METHODS}

The checklist evaluation included individual intervention assessments followed by a consensus meeting. To enable Dutch schools and health promoters to base school health promotion choices on quality assessment results, a wide range of promising school-based interventions were assessed. A group of three experts - an assistant professor of health promotion, the coordinator of the Dutch Healthy School Network and the schoolBeat coordinator - selected well described and widely available Dutch programs. An additional criterion of a maximum of 2 programs per developing or supporting organization limited the maximum number of health promotion programs available for assessment in the Netherlands in 2004 to 29. Projects ranged from the well documented and studied HIV/AIDS school prevention program 'Long Live Love' (Schaalma \& Kok, 2006) to non-evaluated teaching material on Biology and Cancer. Projects focused on strengthening social skills, the prevention of substance abuse, smoking prevention, promotion of healthy eating, and road safety. Publicly available information was collected on the selected programs, often including original intervention-materials. Twenty assessors (ten health promotion professionals and ten teachers, selected with the assistance of the national health promotion institute, with clear affinity to whole school health and the capacity to understand the complex issues associated with the assessment procedure) were randomly grouped in fours: two assessors from each domain. Each group was provided with the materials of a maximum of six interventions and members were asked to assess the quality of the interventions using the schoolBeat-checklist, before discussing their scores at a group consensus meeting. The meetings were facilitated by one of the experts mentioned before. Assessment took place in May/June 2004.

\section{Statistical analysis}

To test the added value of the consensus procedure, differences per criterion between average individual item-scores and consensus item-scores were tested with a paired sample t-test. Alpha was 0.05. Additionally, correlations of these individual scores and the consensus scores were calculated, and equality of the two standard deviations (of average individual and consensus score) was tested. (It can be shown mathematically that equality of the SDs of two paired observations, such as average individual score and consensus score implies a zero correlation between the difference and the mean of both scores. So we tested the latter correlation for significance.)

To evaluate the reliability of individual assessors and the mean across assessors, the generalisability of scores of individual assessors (denoted as $\rho$ ) was calculated for each criterion using the formula $\rho=\left(\mathrm{MS}_{\text {program }}-\mathrm{MS}_{\text {residual }}\right) /\left(\mathrm{MS}_{\text {program }}+(k-1) \mathrm{MS}_{\text {residual }}\right)$, with the number of assessors denoted as $k$. Here, $\mathrm{MS}_{\text {program }}$ and $\mathrm{MS}_{\text {residual }}$ are obtained from a two-way ANOVA per criterion, using program and assessor as crossed factors. $\mathrm{MS}_{\text {program }}$ is the observed variance between programs with respect to their average score across assessors. $\mathrm{MS}_{\text {residual }}$ is the 
unexplained score variance after adjusting for program and assessor effects, and is a mix of program by assessor interaction and measurement error (these two components cannot be distinguished with only one observation per program by assessor combination).

First, $\rho$ was calculated for each group of interventions sharing the same assessors. These $\rho$-values were then averaged across all groups of interventions to obtain one generalisability coefficient $\rho$ per criterion, reflecting generalisability of scores by individual assessors. This $\rho$-value was then used to calculate the generalisability coefficient (denoted as $\left.\rho^{\prime}\right)$ for the average of $k$ assessors with the Spearman-Brown formula: $\rho^{\prime}=k^{*} \rho /\left[1+(k-1)^{*} \rho\right]$, for each of the nine criteria (Crocker \& Algina, 1986). As the usual minimum reliability threshold for generalisability coefficients is 0.70 (Nunnally, 1967), the number of assessors needed per criterion to attain this minimum can also be derived from $\rho$ using the Spearman-Brown formula: $k=\rho^{\prime} *(1-\rho) / \rho^{*}\left(1-\rho^{\prime}\right)$ with $\rho^{\prime}=0.70$ (Crocker \& Algina, 1986).

\section{RESULTS}

Assessing 29 school-based health promotion interventions yielded an average individual score (i.e. the mean of the 2 or 4 assessors) and a consensus score per criterion for each intervention. Table 7.1 presents the mean and SD of both scores on each criterion for all 29 programs. The data yielded no significant differences for the mean individual and mean consensus scores for seven of the nine criteria - criteria 1, 2, 4, 5, 6, 8 and 9 -implying good agreement between the scoring procedures. The mean consensus scores for two criteria differed significantly from the mean individual scores: criterion 3, 'efficiency for support organization' (Mean difference $=0.19 ; \mathrm{t}=2.83$; $\mathrm{p}<0.05$ ) and criterion 7 , 'environmental awareness' (Mean difference $=0.24 ; \mathrm{t}=3.34 ; \mathrm{p}<0.05$ ). For these two criteria, the consensus scores were significantly lower than the average individual scores.

The correlation between the average individual and the consensus score (rl) is very high for all criteria, implying good agreement, except for the above-mentioned differences in means for criterion 3 (efficiency for support organizations) and 7 (environmental awareness). Furthermore, the average individual SD score is significantly lower than the consensus score for 8 criteria. This larger variability of the consensus score may be due to larger measurement error, which occurs if the consensus score was dominated by one assessor. 
Table 7.I Average individual scores versus consensus scores of the 2004 use of the schoolBeat checklist by 20 assessors for 29 school health interventions in the Netherlands

\begin{tabular}{|c|c|c|c|c|c|c|}
\hline Criterion & & Mean & $\mathrm{P}_{\mathrm{I}}$ & SD & $\mathrm{P}_{2}$ & $r$ \\
\hline \multirow{2}{*}{ I. Effectiveness proven (HP) } & Individual scores & 1.01 & \multirow{2}{*}{0.445} & .48 & \multirow{2}{*}{$0.76 \mathrm{I}$} & \multirow{2}{*}{$0.87^{* *}$} \\
\hline & Consensus score & 0.98 & & .50 & & \\
\hline \multirow{2}{*}{ 2. Well designed (HP) } & Individual scores & 1.40 & \multirow{2}{*}{0.418} & .34 & \multirow{2}{*}{0.027} & \multirow{2}{*}{$0.91 * *$} \\
\hline & Consensus score & 1.38 & & .41 & & \\
\hline \multirow{2}{*}{ 3. Efficiency for support organization (HP) } & Individual scores & 1.20 & \multirow{2}{*}{0.009} & .50 & \multirow{2}{*}{0.027} & \multirow{2}{*}{$0.82^{* *}$} \\
\hline & Consensus score & 1.01 & & .63 & & \\
\hline \multirow{2}{*}{ 4. Efficiency for school (EDU) } & Individual scores & 1.60 & \multirow{2}{*}{0.190} & .38 & \multirow{2}{*}{0.001} & \multirow{2}{*}{$0.88^{* *}$} \\
\hline & Consensus score & 1.53 & & .56 & & \\
\hline \multirow{2}{*}{ 5. Meeting educational needs (EDU) } & Individual scores & 1.33 & \multirow{2}{*}{$0.44 I$} & .30 & \multirow{2}{*}{0.029} & \multirow{2}{*}{$0.90 * *$} \\
\hline & Consensus score & 1.36 & & .37 & & \\
\hline \multirow{2}{*}{ 6. Participation of target groups (HP + EDU) } & Individual scores & 1.41 & \multirow{2}{*}{0.244} & .34 & \multirow{2}{*}{0.003} & \multirow{2}{*}{$0.76^{* *}$} \\
\hline & Consensus score & 1.33 & & .50 & & \\
\hline \multirow{2}{*}{ 7. Environmental awareness (HP + EDU) } & Individual scores & 1.33 & \multirow{2}{*}{0.002} & .51 & \multirow{2}{*}{0.000} & \multirow{2}{*}{$0.86 * *$} \\
\hline & Consensus score & 1.09 & & .72 & & \\
\hline \multirow{2}{*}{ 8. Quality of support (HP + EDU) } & Individual scores & 1.49 & \multirow{2}{*}{0.050} & .41 & \multirow{2}{*}{0.000} & \multirow{2}{*}{$0.90^{* *}$} \\
\hline & Consensus score & 1.40 & & .54 & & \\
\hline \multirow{2}{*}{ 9. Diversity (HP + EDU) } & Individual scores & 1.25 & \multirow{2}{*}{0.495} & .36 & \multirow{2}{*}{0.019} & \multirow{2}{*}{$0.87^{* *}$} \\
\hline & Consensus score & 1.23 & & .46 & & \\
\hline
\end{tabular}

\section{footnotes}

$\mathrm{P}_{\mathrm{I}}=$ two-tailed significance of the mean difference between mean individual and consensus scores (as tested with the paired $t$-test)

$\mathrm{P}_{2}=$ two-tailed significance of the difference between the standard deviations of mean individual and consensus scores (as tested by computing the average of, and the difference between, both scores, and then testing the correlation between average and difference, which is zero if and only if the two $S D$ s are equal).

$r=$ Pearson correlation between mean individual and consensus scores, with $* *=p<0.01$ 
Table 7.2 Generalisability coefficients per criterion and number of assessors needed to reach given generalisability levels - based on the 2004 use of the schoolBeat checklist by 20 assessors for 29 school health interventions in the Netherlands

\begin{tabular}{|c|c|c|c|c|c|c|}
\hline Criterion & e & ¿a & 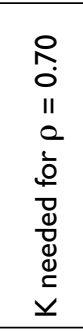 & 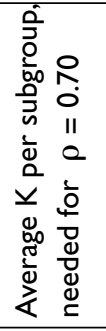 & 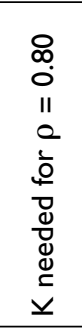 & 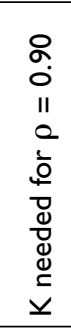 \\
\hline I. Effectiveness proven (HP) & 0.61 & 0.75 & 1.6 & & 2.7 & 6.0 \\
\hline 2. Well designed (HP) & 0.34 & 0.51 & 4.5 & 9.0 & 7.8 & 17.5 \\
\hline 3. Efficiency for support organization (HP) & 0.10 & 0.18 & 20.9 & $5.6 * 3$ & 35.8 & 80.5 \\
\hline 3. Efficiency for support organization (HP)*1 & 0.18 & 0.30 & 10.8 & & 18.5 & 41.7 \\
\hline 4. Efficiency for school (EDU) & 0.17 & 0.29 & 11.5 & 75 & 19.7 & 44.3 \\
\hline 4. Efficiency for school (EDU)*2 & 0.36 & 0.53 & 4.1 & 1.0 & 7.0 & 15.7 \\
\hline 5. Meeting educational needs (EDU) & 0.40 & 0.58 & 3.4 & & 5.9 & 13.2 \\
\hline 6. Participation of target groups (HP + EDU) & 0.37 & 0.70 & 4.0 & & 6.9 & 15.6 \\
\hline 6. Participation of target groups $(H P+E D U) * 1$ & 0.39 & 0.72 & 3.6 & 4.6 & 6.3 & 14.1 \\
\hline 7. Environmental awareness (HP + EDU) & 0.40 & 0.73 & 3.5 & & 6.0 & 13.4 \\
\hline 8. Quality of support (HP + EDU) & 0.22 & 0.53 & 8.2 & $4.5 * 3$ & 14.0 & 31.6 \\
\hline 9. Diversity $(\mathrm{HP}+\mathrm{EDU})$ & 0.47 & 0.78 & 2.6 & & 4.5 & 10.1 \\
\hline
\end{tabular}

*l One out of five sub-group g-coefficients was considered to be an outlier and recoded to zero in the calculation of the average $\rho$

*2 Two out of five sub-group g-coefficients were considered to be outliers and recoded to zero in the calculation of the average $\rho$

*3 Average $K$ per subgroup when using the $\rho$ corrected for outliers

footnotes

$\rho=\quad g$-coefficient for individual assessors,

$\rho^{\prime}=\quad$ g-coefficient for the average of the (two or four) assessors,

$K=\quad n r$ of assessors needed to obtain $a$ ' of 0.70 or 0.80 or 0.90 for their average

The Generalisability coefficient was used to calculate the number of assessors needed to reach desired levels of generalisability. For three criteria, the generalisability coefficient of one or two subgroups was considered to be a negative outlier and recoded to zero to produce a more realistic generalisability indicator for those criteria. The results in Table 7.2 indicate that eleven health promotion professionals and four teachers are needed if a minimum generalisability level of 0.70 is required for every criterion, or six HP professionals and four teachers if 
averaged across criteria (remember that HP professionals rated HP quality criteria, and teachers rated educational criteria). For the mixed criteria, eight to four assessors are needed using the same logic.

Four criteria yielded a group assessment generalisability coefficient above the minimum reliability threshold of 0.70 , namely criterion 1 (effectiveness); criterion 6 (participation of target groups); criterion 7 (environmental awareness) and criterion 9 (diversity).

The assessment results for each intervention have been reported previously (Boot, Bessems et al., 2005). In brief, four interventions scored positively (i.e. 'good / definitely') on the 'effectiveness proven' criterion and twelve scored positively on the 'well designed' criterion. Of these twelve interventions, only four scored positively on the 'meeting educational needs' criterion, together with 7 other interventions with lower scores on the 'well designed' criterion.

\section{DISCUSSION}

The schoolBeat-checklist is a promising quality assessment tool for healthy school interventions incorporating quality concepts as perceived by health promotion professionals and quality concepts as perceived by education professionals, acknowledging and respecting the differences between these perceptions. By providing nine different quality scores for each healthy school intervention, schools and health promotion support agencies are presented with a unique classification structure supporting a systematic selection of those interventions best suited to their needs in whole-school health.

Some improvements are advisable. The assessors' comments during the consensus meetings, especially for those items scoring low on generalisability, call for clarification in the checklist-manual. Besides this, the efficiency criteria three and four need further research as they yielded the most apparent outliers. As noted by St.Leger, school health promotion needs to be based on learning theories to raise levels of school-health effectiveness (St.Leger, 2001). Hence, this element should be made more explicit in the checklist.

Importantly, a large number of assessors are needed from the health promotion domain for reliable assessment. This is because of the high number of assessors required for the third criterion (efficiency for support organizations). If the median number of assessors for the health promotion criteria is used, five assessors are required. Given that training of assessors in the interpretation and use of rating-scales adds to inter-rater reliability (Stemler, 2004), the use of a lower number of health promoters in the assessment procedures is acceptable. Therefore we advocate four assessors per criterion. Criterion four (efficiency for schools) produced the largest numbers of outliers. The term 'efficiency' seems unclear in both assessor groups and reformulation of both efficiency criteria therefore is needed. Moreover, the lack of consensus within groups for the efficiency criteria may be caused by the present lack of consensus 
on efficiency in education and health promotion itself. When using the advocated number of assessors, we encourage comparative analyses of the assessments of health promoters and teachers. The difference between groups may have caused the lack of consensus for certain criteria. If significant differences between the groups cause the lack of consensus, it might be better to provide the groups' assessment results separately.

A limitation of the quality assessment results is that only program descriptions and materials were assessed instead of the actual program implementation and delivery in schools, or effects on health outcomes. For an intervention to be successful it needs an effective concept or theory and good delivery (Dusenbury et al., 2003; Rychetnik et al., 2002). The quality of delivery in schools (e.g., the percentage of a health education intervention that is actually delivered by the school above a minimum intensity level and within permitted boundaries for re-invention) varies greatly and is often poorly documented. Therefore, it is not easy to include program implementation and delivery in schools in assessment procedures. An American study (Gottfredson \& Gottfredson, 2002) indicated that the quality of implementation of school-based interventions is generally low when compared to implementation standards in prevention research. Studies have indicated that not everything in a curriculum is covered by teachers and that they are likely to teach increasingly less over time (Dusenbury et al., 2003). Therefore, even if a school decides to include only those programs with a positive assessment of the 'meeting educational needs' criterion, this is no guarantee of success. Implementation might be poor, the intervention may not be 'well designed' or the interventions chosen may have low scores on the 'effectiveness proven' scale.

This emphasizes the importance of discussing all criterion results with schools instead of providing an overall recommendation of 'good' versus 'not good'. By acknowledging the importance of the 'efficiency for schools' and the 'meeting educational needs' criterion for schools, we observed greater acceptance of the results of the effectiveness criteria by schools. Hence the aim of the checklist should not be to provide a success or failure verdict for interventions.

Given the solid development procedure, this first application study has yielded useful and unique quality assessments of popular and promising school health promotion interventions. However, the fact that not even half the criteria managed to pass the minimum reliability threshold for generalisability, with one producing a significant difference between average individual score and consensus score, and three criteria with considerable outliers, makes publication of these first results debatable. Yet, it is this debate among users from the education and health promotion domain and intervention developers regarding the assessments which may stimulate ongoing developments in whole-school health.

Although the schoolBeat-checklist was not developed from a quality assurance perspective, application of the checklist to school health promotion interventions and publication of the results is expected to have quality assurance spin-off effects. Development agencies will address the quality criteria of the schoolBeat-checklist more directly and more publicly once quality assessments based on the checklist are widely recognized and used in school health promotion. 


\section{CONCLUSIONS}

The schoolBeat checklist seems a valuable and reliable asset to school health promotion, when applied appropriately. This means involving at least four experienced health promoters and four experienced teachers in the assessment procedure, without aiming for consensus between assessors acknowledging their background differences. The checklist's efficiencycriteria require focusing.

The question remaining is: 'Do easily available quality assessments of healthy school interventions improve the quality of whole-school health promotion and its impact on the healthy development of youth?' With more research and experience, a system such as the one examined in this study should become both highly reliable and functional for schools that use it to identify effective programs that meet their needs. This enables schools to optimize their positive impact on the healthy life styles of youth. 


\section{Dlagnosis of Sustainable Collaboration}

in Health Promotion - a case study

Submitted by:

Leurs MTW, Mur-Veeman IM, Van der Sar

$R$, Schaalma HP, De Vries NK 
Collaborations and partnerships are elemental to health promotion in general and of school health promotion in particular, when dealing with multi-party problems (Andis et al., 2002; De Leeuw, 1989; Gray, 1989). Intersectoral collaboration where people from different domains, cultures and jargon are expected to work together is not without challenges (Allensworth, 1987; Padgett et al., 2004; Van Eyk \& Baum, 2002). Interest in the process and prerequisites of collaboration in organizing (school) health promotion, is rising (Deschesnes et al., 2003; El Ansari \& Weiss, 2006). Underlying theories and principles of organization change are widely available from other sectors (Cummings \& Worley, 2001; De Caluwé \& Vermaak, 1999, 2006; Van Raak, 1998). However, the scientific literature does not provide comprehensive monitoring instruments focusing on the specific pitfalls and opportunities in collaborative processes towards (school) health promotion.

In this chapter we delineate the DIagnoses of Sustainable Collaboration (DISC) model (Leurs, Mur-Veeman et al., 2003). The DISC-model is meant to describe the state of affairs of a health promotion oriented collaboration at a certain moment in time, aiming to reveal opportunities and impediments for change. A thorough analysis of the current status of the collaboration supports the selection of suitable change strategies to enhance the development of the collaboration(De Caluwé \& Vermaak, 2003).

To illustrate and assess the DISC-model, the 2003 application of the model to the Dutch schoolBeat collaboration is described. The schoolBeat-partners aimed to build a coordinated multi-organization strategy supporting tailored whole-school health promotion (Leurs, Jansen et al., 2005). This schoolBeat-strategy is based on sharing whole-school health promotion advisory tasks between organizations from the public health, welfare, mental health and addiction domains.

As it was the first time the DISC-model was used in its current form, exploring its usability for assessing intersectoral collaboration in general was the primary aim of this study. In this paper we will specifically address the differences indicated by DISC-based comparisons between the sectors participating in the schoolBeat-collaboration: schools, support organizations and governments.

\section{THE DISC-MODEL}

Effective health promotion alliances require management skilled in networking, knowledge-sharing and partnership creation and support (Barrett et al., 2005; Bracht, 1999; Umble et al., 2005). Assessment of a potential or existing health promotion collaboration, in addition to needs assessment in the health promotion setting, is required to enable systematic planning of strategies for program development, implementation and maintenance (Baldwin et al., 2005; Bartholomew et al., 2006). Hence, management skills regarding ongoing evaluation of the collaborative status of the alliance are needed as well (Cummings \& Worley, 2001; De Caluwé \& Vermaak, 2003). 


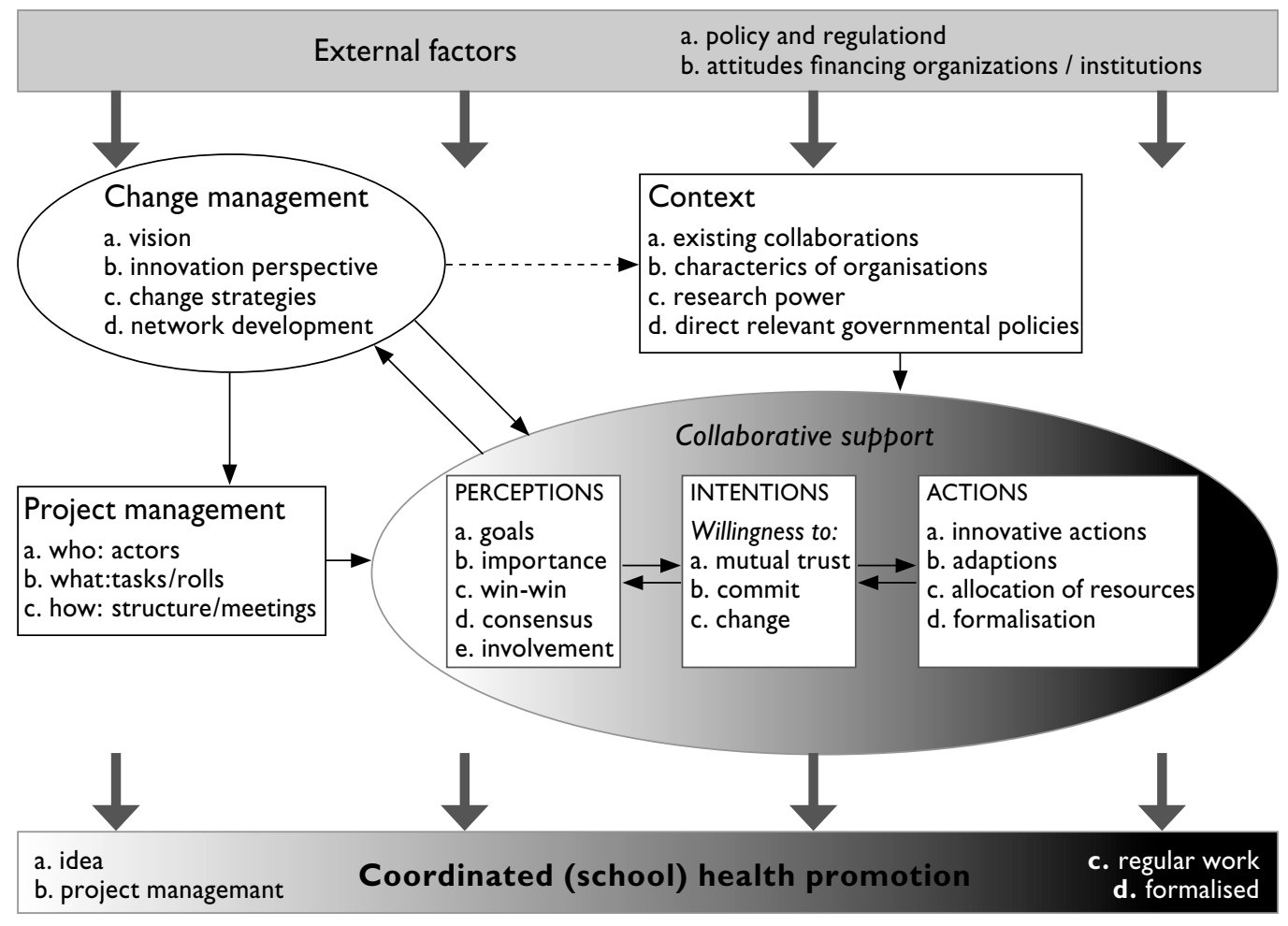

Figure 8.I The Dlagnosis of Sustainable Collaboration (DISC) model

The DISC model was developed to systematically support such evaluations. The model goes beyond the more traditional evaluation models used in health promotion, which focus primarily on the implementation and effects of single intervention programs. DISC describes factors affecting the evolution of collaboration. The model focuses on the interaction between the project management, the collaborating partners as a whole (i.e. the collaborative support), the project organization and factors in the wider context, and their impact on the subject of the collaborative process. At the level of the 'collaborative support' the model distinguishes between 'perceptions', 'intentions' and 'actions'. Each construct is assessed by a set of indicators. The term 'sustainable' refers to the aim of the collaboration to continue after the initial project phase has ended, without committing themselves to an ever lasting collaboration. If collaborations do not aim for continuation, DISC analysis is not appropriate. 
Table 8.I General description of constructs and indicators of the DISC-model (adapted from

(Ruland et al., 2002))

\begin{tabular}{lll} 
Construct & Indicators & General description per construct \\
\hline $\begin{array}{l}\text { External } \\
\text { factors }\end{array}$ & Policy and regulations & $\begin{array}{l}\text { The collaborative process is influenced by a number of factors } \\
\text { that are beyond the control or influence of the alliance itself: } \\
\text { Clear, preferably inter-sectoral policies, laws and regulations } \\
\text { providing challenging and sound goals for health promotion may } \\
\text { enhance the collaborative process. } \\
\text { Limiting factors may be diffuse borders between policy domains, } \\
\text { contradicting policies of different public sectors and policies fo- } \\
\text { cusing on the transformation of public organizations into private } \\
\text { enterprises. }\end{array}$
\end{tabular}

Attitudes of financing An encouraging and accommodating attitude of financing bodies bodies and commitment to provide the necessary funding over a longer period to prevent a brain drain from starting during the initial developmental phase, supports the collaborative process.

Context

a) Existing alliances

The collaborative process evolves in a context which can be

b) Characteristics of organizations

c) Research power influenced by the partners themselves

d) Direct relevant governmental policies

When parties have more positive experiences with each other in previous collaborative processes, need less energy for internal changes, have more research power and feel more supported by policies which they can influence as well, they are more open to sustainable collaborative process supporting inter-sectoral health promotion.

$\begin{array}{ll}\text { Change } & \text { a) Vision } \\ \text { Management } & \text { b) Innovation } \\ & \text { perspective } \\ & \text { c) Change strategies } \\ & \text { d) Network } \\ & \text { development }\end{array}$

The aspired change requires management by one or a small group of leaders.

In order to establish a successful collaboration individual and collective leadership skills are necessary to guide the developmental process. Change management strategies should fit the chosen innovation perspective and be supportive of the health promotion subject. The most relevant actors are included, and where missing, this will be accomplished by extending the network of the leaders of the collaborative process. 


\begin{tabular}{|c|c|c|}
\hline $\begin{array}{l}\text { Project - } \\
\text { management }\end{array}$ & $\begin{array}{l}\text { Whom: actors } \\
\text { What: tasks } \\
\text { How: structure }\end{array}$ & $\begin{array}{l}\text { During the development and initial implementation phase the } \\
\text { collaborative process is dealt with as a project in a project } \\
\text { management structure. } \\
\text { This includes deciding who are the actors in the project, what } \\
\text { do they need to do and how do they operate (planning, proce- } \\
\text { dures, evaluation, communication, etcetera). This project manage- } \\
\text { ment structure fades out when the subject of the collaborative } \\
\text { process is (close to) being integrated in regular work and the } \\
\text { alliance becomes self-supportive. }\end{array}$ \\
\hline
\end{tabular}

$\begin{array}{ll}\text { Support } & \text { Perceptions: } \\ \text { based on } & \text { a) Goals } \\ \text { intersectoral Importance } & \text { c) Win-win } \\ \text { collaboration } & \text { d) Consensus } \\ & \text { e) Involvement }\end{array}$

Intentions to:

a) Mutual trust

b) Commitment

c) Change

\section{Actions:}

a) Innovative actions

a) Adaptations

b) Reallocation of resources

d) Formalizations
Coordinated From idea and Health project management

Promotion to formalized regular work
The collaborative support can be assessed on the levels of perceptions, intentions and actions of the parties involved. Intersectoral collaboration evolves more smoothly when participating organizations share goals and interests, perceive positive outcomes supportive of their own goals, are able to reach consensus on the goal of the collaborative process and are of the opinion that the most relevant parties are involved in the collaborative process.

Parties involved should start with the intention to trust each other (if not present, this needs to be worked on first), the intention to commit themselves to the collaborative process and its subject and the intention to make changes within ones own organization, if needed, in favor of the collaborative process.

The collaborative process may induce a wide variety of actions, varying from the implementation to major innovations within ones own organizations to the inclusion of relatively minor adaptations of regular procedures. The actions may involve a reallocation of resources as well. Whatever actions result from a collaborative process, it is important that these are formalized in order to enhance sustainability. The level of formalization needed depends mainly on the type of action itself.

The collaborative process influences the development of the coordinated (school) health promotion and supports the move towards sustainability (goal):

Under continuous influence of the collaborative process, an idea is elaborated and develops into regular working routine being formalize. During this process the subject of the collaborative process evolves: it 'changes color' under influence of the collaborative process itself. 
Figure 8.1 presents the DISC-model; the DISC-constructs are delineated in Table 8.1. Generally, the DISC-model links assessments of the collaborative process directly to the reallife context in which the intervention or set of interventions is developed, implemented and, if successful, maintained. This makes the model appropriate for case study designs as described by Yin and advocated by others (Parsons \& Stears, 2002; Pluye et al., 2004; Yin, 2003).

The model is based on a literature review and initial experiences with an explorative research model introduced in the early 1990's. The initial model was used in multiple case studies in collaborative home care services in the Netherlands (Mur-Veeman \& Van Raak, 1994; Tijssen et al., 1992). The model proved to be valuable to case study research in home care and in shared care studies (Van Raak et al., 2003). It should be noted that the model focuses on elements important to interorganizational collaboration, organizational behavior and planned organizational change (Cummings \& Worley, 2001; Daft \& Noe, 2001; De Caluwé $\&$ Vermaak, 2003; Gray, 1989). The assumption is that the collaboration puts a strain on the participating organizations and requires them to change in a minor and in specific areas in a major way. This is based on the open systems school of thinking: organizations are social systems that interact with their environment aiming to meet internal needs as well as needs of the environment (Katz \& Kahn, 1966; Morgan, 1986).

Ruland and colleagues slightly modified the initial model to be applicable to organizations involved in health promotion alliances, with a strong focus on formalization (Ruland et al., 2003). However, true formalization of a sustainable alliance is a phase many health promotion alliances may never reach or wish to reach. Like Ruland and colleagues, often reviews and studies on collaborations seem to fail to recognize that the goal of their collaborative process (sustainable coordinated health promotion) may change under influence of the collaborative process itself. Gillies already recommended flexibility in project planning and working procedures, to enable the management of environmental changes at different levels (Gillies, 1998). This can be taken one step further by allowing for adaptations to the project or strategy itself as a result of the collaborative processes, influenced among other things by environmental changes. Hence, the focus of the collaboration may 'change color' during the transition period from idea to formalized activity. This is reflected in color change of the bar at the bottom of the DISC-model. We also added the indicator 'research power' in the context-construct. This was based on the finding that the absence or presence of scientific evaluation influences the level of successful implementation of care innovations in organizations (Fleuren et al., 2002).

In this article we describe the application of the model to the initial phase of the schoolBeat collaboration to delineate its possibilities and limitations in enhancing intersectoral collaborative processes in health promotion. The study was conducted in the 2003-2004 period, one year after the initiation of the collaborative process. 


\section{METHODS}

The study combined quantitative research (a cross-sectional survey), qualitative research (personal interviews) and document analysis. The primary aim of the study was to pilot the DISC-model as an instrument for diagnosing opportunities and impediments of collaborative processes. The practical aim of the pilot for those involved in the alliance diagnosed was to identify differences between groups of stakeholders (i.e. education, health / welfare and government) in school health promotion regarding the DISC-constructs (see Table 8.1), resulting in recommendations for improving the collaborative process itself.

\section{Sample}

A questionnaire was sent to fifty-five schoolBeat-stakeholders identified by the project management: 19 people from the education domain, 19 people from the support organizations and 17 from municipalities and provincial government. About half of the people from the education domain were active as pupil care coordinators in their schools for secondary education with responsibilities for school health, with the other half fulfilling management positions in primary or secondary educations responsible for preventive pupil care. From the support organizations CEO's, members of the schoolBeat-project group (management level) and schoolBeat advisors were identified as schoolBeat-stakeholders by the project management. Youth professionals participating in the regional youth meeting of public servants or the meeting of aldermen responsible for local and regional youth policy were included in the stakeholder group as well.

At random, eleven of the 55 stakeholders were invited to participate in a semi-structured interview. In addition, three influential stakeholders who did not participate in the survey and who were identified by the project management as stakeholders with a presumed negative attitude towards the schoolBeat-alliance, were approached to be interviewed as well. This included an alderman of one of the smaller municipalities, a school director and someone from the support organizations.

\section{Measurement}

The survey consisted of 22 scales operationalizing all the main concepts from the DISC model (see Table 8.1) with 3 to 8 items. Except for the dichotomous items in the existingcollaborations a five point scale was used ( 1 being 'totally disagree' and 5 being 'totally agree'). Table 8.2 reports the number of items and the Cronbach's alpha of each scale.

The interviews were semi-structured to address all constructs of the DISC-model. Where survey participants had presented the researchers with unexpected or unclear answers in the questionnaires, this was addressed in more detail in the interview. Additionally, documents such as minutes of meetings, project descriptions and correspondence with schools and local and regional governments were analyzed based on the DISC-model as well. 


\section{Statistical analyses}

Cronbach's alpha was calculated for the scales operationalizing the distinct DISC-constructs (Table 8.2). We accepted a reliability score of 0.40 or above because of the explorative nature of the case study and the relative low number of possible participants in the survey.

Analysis of variance was conducted to test whether stakeholders from the education sector, the public sector or the support sector responded differently to the DISC-constructs. Where differences among the means were significant $(p<0.05)$ or a trend was observed $(p<0.10)$, the Bonferroni test was used to test differences between groups. The transcribed interviews and retrieved documents were scored manually according to the definitions of the DISCconstructs (Table 8.1).

\section{Procedure}

For the quantitative part, a questionnaire was developed based on a self-evaluation survey for change managers of collaborative processes in primary health care using the original explorative research model (Van Raak et al., 1999). The questionnaire was adjusted to reflect the constructs of the DISC-model and to focus explicitly on the whole-school health collaboration studied. A collaboration expert and a healthy school expert tested face validity of the questionnaire regarding its fit with whole-school health collaboration and the DISC-constructs. The questionnaire was improved on the basis of their suggestions. This was followed by a pretest among four participants of a youth prevention alliance in a different region.

\section{RESULTS}

Of the 55 stakeholders invited to fill in the DISC-survey, 17 out of 19 people responded from the education sector (90\% response), 17 out of 19 from the support organizations (90\% response) and 8 out of 17 from the local and regional government (47\% response). Overall response amounted to $76 \%$. For the interviews, 12 persons of the 14 approached agreed to be interviewed. Of the interview group, four worked in the education sector, five for a support organization and three for a local or regional government.

Reliability analyses of the survey revealed that five scales were not sufficiently reliable with a Cronbach's alpha (or Pearson correlation for scales with only two items) below 0.60: the policy and regulations scale, the existing-collaborations scale, the willingness to change scale, the resources scale and the formalization scale. These scales and their items were not included in further analyses. The reliability coefficients, averages per construct and the results of the analyses of variance per construct are presented in Table 8.2. 
Table 8.2 Reliability, average and analyses of variance results per scale distinguishing sum-scores between public health, education and public service stakeholder-groups.

\begin{tabular}{lcccc}
\hline DISC-construct & $\begin{array}{c}\text { Number of } \\
\text { items }\end{array}$ & $\begin{array}{c}\text { Cronbach's } \\
\text { Alpha' }\end{array}$ & Mean (SD) & F \\
\hline External factors & & & & \\
- Policy and regulations & 4 & 0.48 & - & - \\
- Attitudes of financing organizations & & 0.74 & $2.68(0.89)$ & 0.16 \\
& & & & \\
Context & 3 & & & - \\
- Existing collaborations & 8 & 0.31 & - & $3.27^{\circ}$ \\
- Organizational characteristics & 3 & 0.61 & $3.71(0.50)$ & 0.63 \\
- Research power & 4 & 0.75 & $3.32(0.82)$ & 1.18 \\
- Relevant policies & & & & \\
Change management & 3 & 0.79 & $4.28(1.00)$ & 0.02 \\
- Vision & 6 & 0.60 & $3.89(0.42)$ & 1.13 \\
- Innovation perspective & 4 & 0.67 & $4.01(0.55)$ & $10.49 * *$ \\
- Change strategies & 4 & 0.65 & $4.07(0.55)$ & $4.94^{*}$ \\
- Network development & 5 & 0.87 & $3.29(0.81)$ & $4.69 *$ \\
Project management & & & &
\end{tabular}

\section{Collaborative support :}

- Perceptions

- Goals

- Importance / win-win

- Consensus

- Involvement

- Intentions

- Willingness to trust

- Willingness to commit

- Willingness to change

- Actions

- innovative actions \& adaptations

- resources

- formalization
9

4

5

5

3

4

4

5

2

2

Coordinated school health promotion
0.90

0.84

0.82

0.64

0.69

0.69

0.52

0.67

0.40

0.33

$4.39(0.59)$

0.33

$* *=p<0.01 ; *=p<0.05 ; \quad{ }^{o}=p<0.10$

1 For scales with two items, Pearson's correlation coefficient is presented. 
Table 8.2 shows relative low scores $(<3)$ for the perceived attitudes of financing organization scale (external factors- construct), relevant policies (context-construct) and innovative actions and adaptations (actions construct). The innovative actions and adaptations scale showed significant differences between the groups, with education stakeholders perceiving most innovative actions and adaptations (Mean 3.33; SD 0.37) and public service stakeholders perceiving least innovative actions and adaptations (Mean 2.11; SD 0.54).

Relative high scores ( $>4$ ) were found for three of the four scales in the change management construct with the change strategies and network development scales indicating significant differences between the groups (see Table 8.3). 'Goals' and 'willingness to trust' yielded also relative high scores without significant differences between groups.

Table 8.3 presents the constructs that revealed at least one significant difference between respondents of the three sectors: education, health and public service. Only for the first construct - organizational characteristics - differences found at item level are shown to illustrate the added value of further exploration in a DISC-study. The analyses revealed that stakeholders from the public sector indicated to be less committed to the schoolBeat initiative and to have incorporated fewer changes supporting whole-school health promotion compared to their school and support partners. Additionally, they reported to be least open to innovation and to experience the most financial problems now or in the near future. Health promotion staff reported the highest level of intention to commitment while education staff reported the highest level of innovative actions and adaptations. Participants from the education domain reported to be better staffed but also to experience more major organizational changes compared to the public service. The health promotion support staff involved experienced higher level of change strategies and project management compared to the education staff.

In this explorative phase, the interviews seemed to shed more light on specific opportunities and impediments of the collaboration studied. Project-related documentation, including goals and a project management structure, was combined with to the survey-results in preparation for the interviews. During the interviews it became apparent that stakeholders from the three sectors used different interpretations of the goals of the schoolBeat collaborative. Differences were related to the health promotion versus pupil care debate (i.e. 'Why talk about prevention when we have not enough support for our individual pupil care problems?'). From the educationstakeholders we learned that they were sceptical about yet another new approach, with mixed evaluations of previous attempts. Nonetheless, these education-stakeholders saw opportunities in linking the schoolBeat approach to a safe-school approach already operating in schools. They seemed keen on improvements in the whole-school pupil care continuum with policies changing towards full inclusive education. This means that children with special needs should be able to attend regular schools, like in the US and other Anglo-Saxon countries. This was somewhat contrary to what health promotion stakeholders' whished to achieve with the schoolBeat-approach focusing primarily for collaborative improvements in the health promotion end of the integral pupil care continuum. 


\begin{tabular}{|c|c|c|c|}
\hline DISC-construct & $\begin{array}{l}\text { Education } \\
\qquad(\mathrm{n}=\mathrm{I7}) \\
\text { mean (SD) }\end{array}$ & $\begin{array}{l}\text { Health Promotion } \\
\qquad(n=17) \\
\text { mean (SD) }\end{array}$ & $\begin{array}{l}\text { Public Service } \\
\qquad(\mathrm{n}=8) \\
\text { Mean (SD) }\end{array}$ \\
\hline \multicolumn{4}{|l|}{ Context } \\
\hline - Organizational characteristics: & $3.92(0.49)^{\mathrm{a}}$ & $3.68(0.46)$ & $3.40(0.45)^{b}$ \\
\hline - Open to innovation & $4.12(0.86)$ & $4.47(0.62)^{\mathrm{a}}$ & $3.50(0.93)^{b}$ \\
\hline - Fully staffed (no long-standing vacancies) & $4.53(0.62)^{\mathrm{a}}$ & $4.29(0.85)^{\mathrm{a}}$ & $3.43(0.73)^{\mathrm{b}}$ \\
\hline - Major organization change processes & $4.47(0.80)^{\mathrm{a}}$ & $4.24(0.83)$ & $3.38(1.30)^{\mathrm{b}}$ \\
\hline $\begin{array}{l}\text { - Financial problems now or expected in } \\
\text { the near future }\end{array}$ & $4.19(1.24)$ & $3.69(0.85)^{\mathrm{a}}$ & $4.75(0.46)^{\mathrm{b}}$ \\
\hline \multicolumn{4}{|l|}{ Change Management } \\
\hline - Change strategies & $3.72(0.39)^{\mathrm{a}}$ & $4.43(0.32)^{b}$ & $4.01(0.75)$ \\
\hline - Network development & $3.99(0.44)$ & $4.34(0.39)^{\mathrm{a}}$ & $3.69(0.80)^{b}$ \\
\hline Project Management & $2.91(0.78)^{\mathrm{a}}$ & $3.70(0.67)^{b}$ & $3.26(0.81)$ \\
\hline \multicolumn{4}{|l|}{ Collaborative Support } \\
\hline - Intentions: willingness to commit & $3.19(0.52)$ & $3.67(0.86)^{\mathrm{a}}$ & $2.83(0.60)^{\mathrm{b}}$ \\
\hline - Actions: Innovative actions \& adaptations & $3.33(0.37)^{\mathrm{a}}$ & $2.83(0.77)$ & $2.11(0.54)^{b}$ \\
\hline
\end{tabular}

Means with different superscripts are statistically different $(p<0.05)$

Regarding the DISC-constructs, the interviews and document analysis provided additional insights. For example, those interviewed found it difficult to distinguish innovative actions from adaptations within the 'action'-construct. The results of the interviews and the document analyses regarding the schoolBeat-alliance combined are summarized per DISCconstruct in Table 8.4.

Competitive feelings of one of the initial schoolBeat partners surfaced during the DISC-pilot. These feelings were a result of the decision by the municipalities to transfer their powers regarding the financing of certain types of school support to the schools (see Table 8.4). The employees of the partner providing the support involved, seemed to feel threatened by this decision. To those involved, it was not sure whether this was a temporary phenomenon that could be overcome with trust among the partners or that it would be a lasting complicating factor with possible destructive effects on the schoolBeat-alliance. Therefore, it was recommended to pay special attention to developments leading to a re-introduction of competition elements between collaborating partners. The competitive feelings should be recognized by all partners and discussed in the perspective of dealing with a complicating factor caused by external factors. 


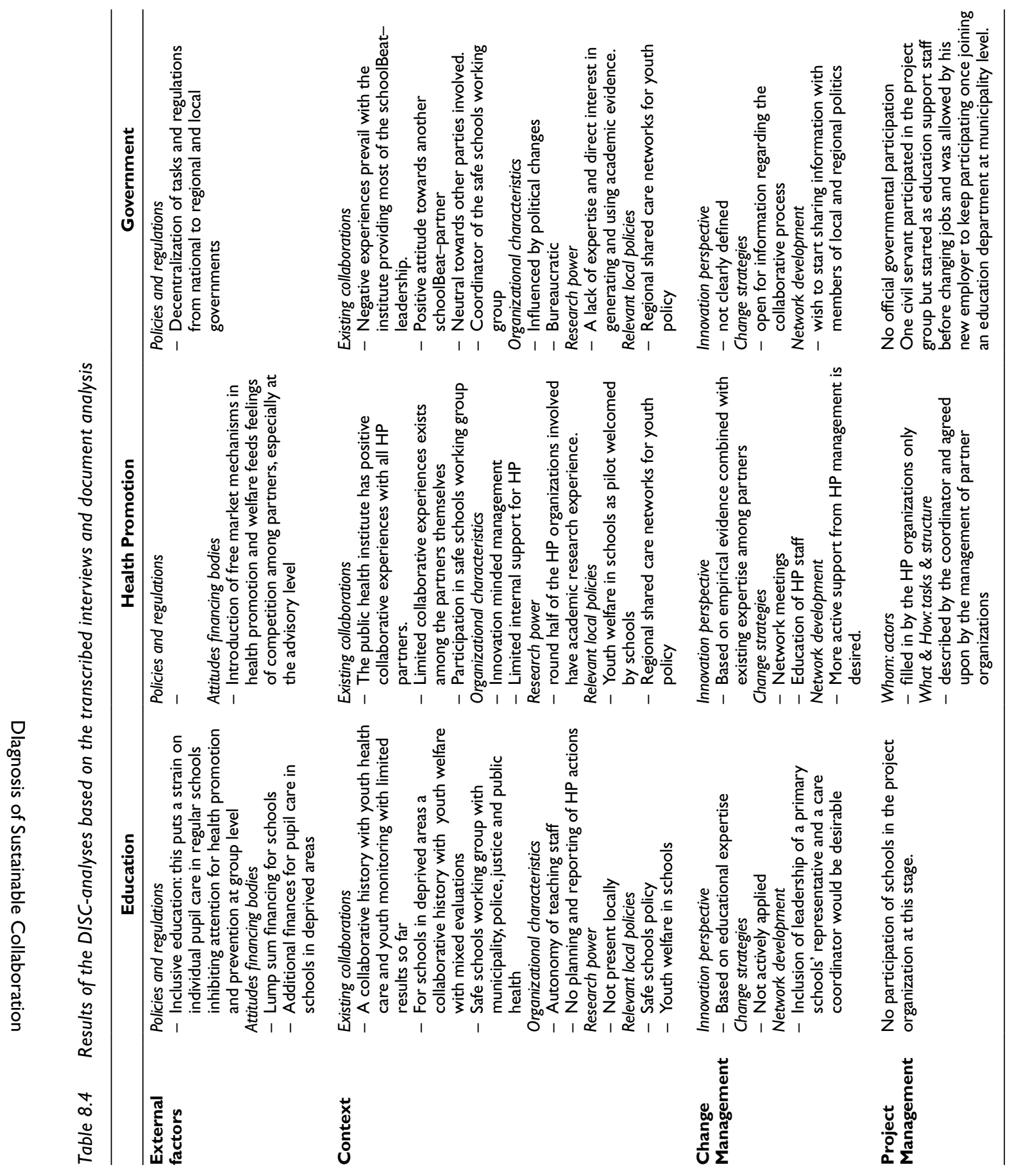




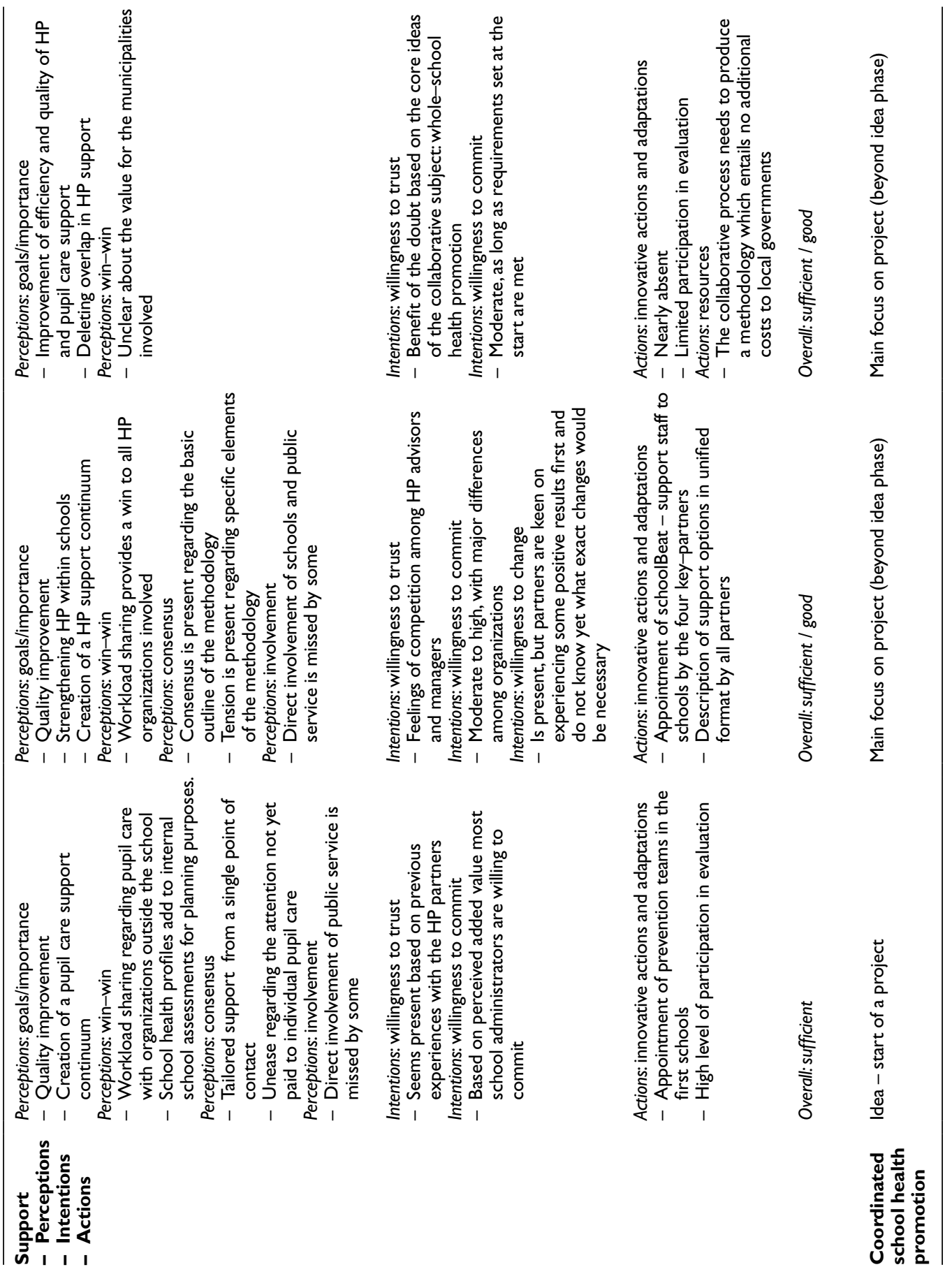


The interviews further suggest that education professionals were least positive about the schoolBeat-collaboration. Here it should be known that thee preparation of the schoolBeatalliance started in 2001 with representatives of support organizations and local communities. Discussions with the education sector started in 2002 at management level, followed by an introduction of the schoolBeat methodology late 2002, spring 2003 at the school level. Misconception regarding the schoolBeat-goals of the education stakeholders complicated this delayed start even more. As the education stakeholders were expecting an improvement on the whole pupil care continuum due to schoolBeat, they were in for a deception with the schoolBeat-methodology focusing on school health promotion and prevention only. Hence, this provides room for improvement when the schoolBeat-alliance continues to involve education-representatives and to work towards shared goals.

A summary of the combined results of the DISC-pilot, with recommendations for improvement of the collaborative schoolBeat-related processes was forwarded to the schoolBeat project team. The recommendations included extending the project management over a longer period of time; strengthening communication with policy-makers; providing a communication boost regarding the proposed methodology and the extra financial possibilities targeting stakeholders' colleagues; further development and clarification of the shared methodology itself; and intensifying information sharing among the key-stakeholders. Although not all recommendations could be carried out straight away due to a variety of constraints, they were all accepted as intermediate goals for the alliance by the schoolBeat-partners.

\section{DISCUSSION}

In this study we took up the challenge to learn from previous health-related collaborations (Mur-Veeman \& Van Raak, 1994; Ruland et al., 2002; Van Raak, 1998), and the diagnostic models used. Based on a literature review and practical experiences, we reshaped and extended the WIZDIZ-model into the DISC-model: diagnosis of sustainable collaboration. We explored the use of the DISC-model at an early stage in a collaborative and incremental process developing a comprehensive and tailored strategy for whole-school health promotion. Our aim was to provide a description of the current state of affairs regarding the collaboration in order to enable the selection and implementation of suitable change strategies.

The DISC-analysis provided us with a cross-sectional picture of a complex phenomenon: an inter-sectoral health promotion alliance. We found that involving stakeholders from the three groups involved and using multiple data sources complemented the picture created and seemed to increase validity of the findings.

The DISC-model provides a comprehensive overview of factors involved in inter-agency collaborations. Especially the qualitative strand of the study seemed to provide the most 
specific insights into the current status of the collaboration. This should not be limited to document analyses only as this may not provide insight into disquiet among partners or possible other - not formally reported - negative aspects of the current status of a collaborative process (Biglan, 2004; El Ansari \& Weiss, 2006; McMorris et al., 2005). For example, in the DISC-survey 'research power' did not reveal significant differences between groups based on survey-data, where document analysis did manage to provide useful information on this issue (see Table 8.4).

Our study clearly supports the value of using a systematic approach to monitoring the state of the art of interorganizational collaboration. Up-to-date information regarding windows of opportunity as well as impediments for collaborative change revealed by DISC-monitoring enhanced the selection of suitable strategies for collaborative problem solving.

To enable its use of DISC-monitoring in other alliances that lack support of a professional research team, a short DISC-checklist for the project management would be useful similar to the checklist developed for the WIZDIZ-model (Van Raak, Mur-Veeman et al., 2005). As the added value seemed to come from including different perspectives on the collaborative process, project managers using such a checklist should be encouraged to get stakeholderinput from all domains involved.

To test the DISC-model itself (for example by using structural equation modeling), more participants would need to be included. As the model focuses on collaborative processes, only those people can be asked to participate who are considered to be stakeholders in these processes. This limits the number of possible participants in such a study. To overcome this problem, it could be worthwhile to apply a more generalized survey to comparable alliances simultaneously. In our case it would be preferable to stay with whole-school health alliances in order to be able to work with comparable sets of stakeholders. Another option is turning the DISC-analyses into a longitudinal study, as suggested by Feinberg and colleagues regarding clarification of causal direction in network analysis (Feinberg et al., 2005). As the collaborative process evolves over time, DISC-analysis is expected to reveal a flow in the model from the idea phase toward organizational routine as the collaborative process matures. This is in line with the ideas of Plsek and colleagues regarding complexity science in which they advocate treating organizations as complex, adaptive systems (Plsek \& Greenhalgh, 2001; Plsek \& Wilson, 2001).

A weak aspect of the DISC-survey was the assessment of the existing collaborations construct and the formalization construct. Available literature in health promotion is unclear on these topics (Feinberg et al., 2005; St.Leger, 2005a; Weiss et al., 2001). For example is it closeness or number of relationships within the network that counts? And: what needs to be formalized as a requirement for sustainability? Or, what do participants actually mean when they talk about sustainability? A recent study by St.Leger indicated a wide variety of definitions of sustainability among participants in the same collaborations (St.Leger, 2005a). Further research in the area of sustainability is required. 
The DISC-model does not state how to advance and improve the collaborative process. Based on the systematically gathered evidence, informed decisions are possible for further action by those involved (Bartholomew et al., 2001; McMorris et al., 2005). In particular, those who are supposed to fulfill leadership tasks should be aware of the different DISC-constructs and current DISC-status of the alliance in order to do so. In our pilot, a literature search was conducted parallel to the DISC-analyses in order to provide evidence-based recommendations. For example the recommendation to extend the project management over a longer period of time was suggested by some of the interview participants but was also supported by recommendations of a support structure in current health promotion literature (Deschesnes et al., 2003; Tones \& Green, 2004). Additionally, as pointed out by Nutbeam policy makers do not make use of scientific evidence regularly (Nutbeam, 2004). Hence, it comes as no surprise that the DISC-analysis indicated that the 'research power' of the government is rather limited and that better communication with politicians is to be recommended here.

Tuckman's four-stage model of group development processes [In: (McMorris et al., 2005)] forming, storming, norming and performing - could add to the understanding of collaborative processes in health promotion. In the studied case, staff involved in the alliance from education, health promotion and government appeared to be in different developmental phases. The health promotion partners seemed to be in the storming phase in which some unease and conflict was present amongst each other. The education and governmental stakeholders were still in the forming phase of orientation and getting acquainted. Awareness of this aspect could help the leadership to prepare for the storming phase among these education and governmental stakeholders once they had moved through the initial getting-toknow-each-other-better phase. For the health promotion partners, time and effort needed to be spent on consensus seeking in order to advance their input in the collaborative process. Therefore, clarification of the developed methodology was one of the evidence-based recommendations as well.

Based on the first use of the DISC-model and additional literature searches, we modified the following elements of the model:

- the 'change-management' construct was changed into 'leadership' incorporating both individual leadership as well as collective leadership (Barrett et al., 2005; Daft \& Noe, 2001; Day, 2001). According to Weiss and colleagues this enables bridging diverse cultures and boundary-spanning functions as well as revealing and challenging assumptions that limit thinking and action (Weiss et al., 2001).

- Being a continuum, the concepts of 'innovative actions' and 'adaptation' were combined into the concept 'changes' within the 'action'-construct.

- The subject of the collaboration (represented by the bottom bar of the model) was simplified into a continuum starting as an 'idea' and leading to a 'routine' in its most pure form (Dusenbury \& Hansen, 2004; Pluye et al., 2004). This eliminates the term 'formalized' in the subject of the collaboration, being already included in the 'collaborative support - action' construct. 
- Additionally, based on the stakeholder theory, which includes the community's notion of social responsibility, and the institutional theory (Van Raak, Paulus et al., 2005), we introduce the concept of 'society values' as part of the external factors in the DISC-model.

\section{CONCLUSIONS}

The DISC-model is more than just the sum of the different parameters provided in the literature on interorganizational collaboration, organization change, networking and settingapproaches such as trust, relationships between partners and interpersonal connections, project management (including identification of roles and responsibilities), leadership, flexibility in working practices, institutionalization (Barrett et al., 2005; Daft \& Noe, 2001; Gillies, 1998; McMorris et al., 2005; Padgett et al., 2004). DISC-analysis provides indications regarding the links between these parameters and - potentially - enabling the detection of change in the combined collaborative parameters over time.

Linking a simplified DISC-analysis to the evaluation of single interventions in (school) health promotion based on a collaborative effort, may add to the explanation of the results of such an evaluation study. Context assessments have been advocated in several recent (school) health promotion studies (Biglan, 2004; El Ansari \& Weiss, 2006; St.Leger, 2004). The DISCanalysis provides insight into the organizational context of the intervention and indications for the sustainability of such an intervention as well as indications for the transferability of the evidence provided. This is almost all about the organizations who will have to support and implement the intervention structurally. Hence, DISC-analysis could help preventing type III errors from occurring in effectiveness studies: a health promotion intervention supposedly proves to be ineffective when it is actually the management and implementation which fails (Tones, 2000).

With collaborative processes inevitably linked to health promotion, thorough analysis of these processes should be part of any participatory action research approach to enhance health promotion via intersectoral collaboration. The DISC-analysis model offers a promising comprehensive evaluation framework looking at the status of the collaborative process and its impact on the goals of the health promotion initiative. Further exploration of the proposed DISC-constructs is warranted as well as simplifications of its use. 



\section{The schoolBeat strategy put into practice}

\section{Adapted from:}

Leurs MTW, Steenbakkers M, Janssen MWJ, et al. (2006). Het schoolSlagpraktijkboek: samen werken aan preventie op maat in het onderwijs [the schoolBeatmanual: working together towards tailored prevention in education]. Maastricht: GGD Zuid Limburg. 
During the schoolBeat development period (2002-2005) the schoolBeat-strategy was put into practice. This yielded new products and practice-based modifications of the schoolBeat-strategy as conceptualized and presented in chapter 2 . The present chapter summarizes parts of the schoolBeat manual not described previously to facilitate better understanding of the schoolBeat strategy and the processes involved in the successful implementation of the strategy. First, we look closely at the role of the schoolBeat advisors and the school prevention teams supported. Then we look at monitoring ('Quick scan shared care in whole-school health' and 'youth monitoring' including 'pupil reports') followed by the tools for planning whole-school health promotion (the healthy school model, the schoolBeat inventory and the schoolBeat matrix). We conclude this chapter with a description of the support received in developing the schoolBeat strategy.

\section{SCHOOLBEAT ADVISORS}

At the start of the schoolBeat development schools asked to have a single contact person, as they had become tired of all the different people and organizations 'banging on their door' promoting their interventions. In the schoolBeat strategy, this is the task of the schoolBeat advisor: a professional acting on behalf of the schoolBeat-partners. The schoolBeat advisor supports the school prevention team in priority setting based on monitoring and priority workshops and in systematic planning of a whole-school health promotion. For the specific interventions that are part of the whole-school health promotion plan, the advisor links the school with specific support partners, regardless of whether they are schoolBeat-partners or not. Because the advisor is the link between support partners and the school, the schoolBeat-advisor is able to build up a relationship with the school and also to enhance the relationship between the school and other support partners. After the introduction, schools expressed their satisfaction with a single schoolBeat advisor. The satisfaction of schools seemed to increase if they could work with the same advisor over a longer period of time.

The process evaluation of the Dutch Heart Health Community Intervention 'Hartslag Limburg' - which involved virtually the same organizations as those participating in the schoolBeat-collaborative (Steenbakkers et al., 2005) - indicated that expert training of the members of local health committees improved the actual functioning of the Health Committees (Ronda et al., 2004). Consequently, it was thought that training would be critical for schoolBeat advisors and that well-trained advisors are better able to implement the schoolBeat strategy through their contacts within schools. Additionally, they can more readily get in touch with partner organizations. Regional training was provided to the first eight schoolBeatadvisors. Professionals who took up schoolBeat-advisory tasks on a later date, were invited to participate in the national schoolBeat master class. In addition to training, the advisors participated in regular meetings, during which they exchanged their experiences with the schools. At these meetings, the schoolBeat coordinator discussed new developments in the schoolBeat project also. The advisors perceived the meetings to be very worthwhile and inspiring. 


\section{PREVENTION TEAMS}

Prevention teams were introduced to schools in the Netherlands by the safe school movement as well as by the healthy school and drugs project (Cuijpers et al., 2002; Prior, 1998). Within the schoolBeat approach, the prevention team complements the pupil care advisory team as part of an integral approach to whole-school health and safety (Leurs, Schaalma et al., 2005). Dutch law requires pupil care advisory teams in schools, not prevention teams. Nonetheless, almost all schools for secondary education in the Maastricht-Mergelland region did have some sort of prevention team at the start of the schoolBeat development.

The prevention team is supposed to be the central group implementing the schoolBeat strategy within a school. Taking into account the results presented in Chapter five of this thesis, commitment and support of school management is considered to be a prerequisite for the success of this team (Leurs, Bessems et al., 2007). Being able to apply the schoolBeat strategy requires a range of expertise and disciplines within any one prevention team, preferably with a member of school management as its chairperson to guarantee a link to school policy and sustainability. Secondly, a direct link to the pupil care advisory team is a prerequisite as well, that can be achieved by including the pupil care coordinator in the prevention team. The pupil care coordinator does not necessarily have to be the coordinator of the prevention team. Special attention should be paid to the inclusion of students in the prevention teams since they are central to health promotion in school (Barnekow et al., 2006; Clift et al., 2005). Other groups who should be represented in the prevention team are parents and education support staff. The representation of teaching staff largely depends on the internal organization of the school itself. From the teaching staff, it is advisable to have representatives of the physical education department as well the biology / personal care department. However, we learned that commitment and interest in healthy living is not limited to these departments. Therefore, it is better to have a maths teacher interested in healthy living in the prevention team than a biology teacher not at all interested in anything outside his/her classroom or exam requirements.

Communicating priorities and actions taken by the prevention teams appears to be important for effective whole-school health promotion. For example, there was a decline in interest in school health promotion within a school when the priority workshops with participating parents and pupils were not followed up within a few months. People seemed to be disappointed and less willing to become active again, when they did not see any action resulting from their contribution to the priority setting workshop. As generally most people - staff, parents and pupils - desire a good whole-school health promotion policy, the momentum for action created with monitoring results and a priority setting workshop should be acted upon. 


\section{QUICK SCAN SHARED CARE IN WHOLE-SCHOOL HEALTH}

Monitoring the status of whole-school health in schools and providing feedback regarding opportunities and challenges for improvement was the idea behind the Quick Scan Shared Care in Whole-School Health. Secondary schools in the Maastricht region initiated the development of the survey-based Quick Scan in 2002, focusing on the status of pupil care in their schools. They welcomed the offer by the schoolBeat partners to extend their survey with health promotion issues relevant to teachers, as well as the support by the schoolBeat partners in analyzing the surveys afterwards. The modified quick scan survey monitored the support in individual pupil care and support in whole-school health promotion. Additionally, the Quick Scan monitored health promotion priorities of school staff. In 2002 and 2005 the status of whole-school health in schools was monitored using the Quick Scan.

The regional pupil care coordinator together with the schoolBeat coordinator provided a school-specific feedback moment to all schools. They encouraged school managers to invite school staff involved with whole-school health to these meetings. Most managers did so. Even though response rates were low at some schools, it turned out that all school specific results provided ample topics for discussing possible improvements. We understood that the discussion of the school specific results of the Limburg youth monitor (see next section) combined with the Quick Scan results - as was the case in 2003 - added to the relevance of the Quick Scan for school staff. Therefore, schools and the Regional Public Health Service intended to repeat the Quick Scan in 2008/2009 parallel to the regional youth monitoring, enabling a combined discussion of results with the participating schools.

Appendix A provides an outline of the Quick Scan Shared Care in Whole-School Health, followed by the 2002 and 2005 results that could not be published in scientific journals due to low overall response rates. Nonetheless, they are included to illustrate the possibilities of the Quick Scan to schools and a school health collaboratives.

\section{YOUTH MONITOR - PUPIL REPORTS}

In Limburg youth health monitoring dates from 1996 (De Munter, 1998), with a cross-border Euregional follow-up in 2001 (Houben, 2002) and a provincial follow-up in 2005 (Houben, 2006). At the start, only regional results were presented, followed by school-specific reports in 2002. As adolescents do not always follow secondary education in their own municipality, this limits the value of reporting results at the municipality level. For this reason schoolspecific reports are preferred. However, we noticed that schools were not keen on making the school-specific results public. An incident in which negative reports on a school appeared in the press following the first safe-school survey in the Maastricht region contributed to this reluctance. 
Sharing results at the aggregated level with pupils was introduced in the 2005 youth monitor. The so called pupil reports were adapted from the reports used by the Rotterdam Public Health Services and piloted in the Maastricht region with the 2004 pupil safe school survey (Bessems \& Leurs, 2004b). The pupil report pilot indicated that parents assessed the reports to be useful for their discussions with their children regarding risky behaviors (Boot, 2005). Additionally, it seemed that a majority of teachers welcomed the pupil reports and positively valued their quality. Pupils reported being interested in the results of the survey in order to compare themselves with their peers. As a result, over 20000 secondary students in Limburg in 2 nd and 4th grade and their parents received a pupil report of the 2005 youth health monitor (Leurs et al., 2006).

Simultaneously, a teacher guide was distributed to provide additional discussion points, information and links for teachers interested in discussing the pupil reports within their class. We understood that it was often left to the individual teacher to decide whether he or she would discuss the pupil report with his or her class or not, leading to major differences in class time devoted to the pupil reports: from virtually none to more than a full lesson. Therefore, we recommend to study the implementation effects of including a feedback session in the contracts with schools regarding participation in the youth monitor as well as the effects of the feedback sessions themselves on pupils.

\section{THE SCHOOLBEAT PRIORITY WORKSHOP}

Part of the schoolBeat-strategy is the interpretation of data collected using the youth monitor and the Quick Scan Shared Care in Whole-School Health with the stakeholders of the school and translating this into priorities for whole-school health promotion. At the very least there needs to be a discussion of the results of both monitors with the school management and members of the prevention team. However, participation of pupils and parents in the planning stage of whole-school health promotion is recommended as well (Deschesnes et al., 2003; St.Leger, 2005b). We therefore introduced the schoolBeat priority workshop for secondary education. This workshop was adapted from a healthy school priority workshop for primary education (Boerma \& Hegger, 2001) and modified to fit the healthy school model (Wauters, 2004).

The workshop model was successfully used in the Maastricht region in all three locations of Porta Mosana College, OPDC St. Michaël and one location of Stella Maris College (Doijen \& Hardy, 2004; Leurs \& Hardy, 2005). At each school the workshop was tailored to the expressed needs and wishes of the school. For example, at the vocational departments of the schools mentioned, the workshop was conducted by teachers in each class as decided by the schools themselves. This was to encourage all pupils to contribute to the prevention policy of the school and to ensure that the school prevention policy would provide a good fit with the needs of its pupils. 
Although the original aim of the priority workshop was to set priorities based on epidemiological data, in practice it turned out not to be possible in one workshop session. We learned that presenting epidemiological data to teachers, parents and pupils requires a lot of explanation on the questions asked in the survey, on percentages which are still considered to be 'normal', and on the fit of the data with the own school population. This takes up too much time when the workshop has to be conducted in a single meeting. Another reason for leaving out the presentation of epidemiological data was because schools were more interested in the subjective priorities of those involved without influencing them with epidemiological data. The development of (easier to interpret) pupil reports of the youth monitor might change this idea. So although the inclusion of epidemiological data did not work in first instance, using pupil reports with school-based epidemiological data in the workshops is worth a second try.

Especially parents who participated in the workshops were very enthusiastic about the workshop. The workshop provided them with an instrument to discuss school policies related to their own expertise in child raising, and their desire to promote and support the healthy lifestyles of their children.

It turned out that the priority workshops were used as input workshops for priority setting for whole-school health promotion in the school prevention teams. Priorities set by the workshops were not always automatically incorporated in the school health plan. Interestingly, when the schoolBeat priority workshops were not followed-up with feedback on the workshop priorities adopted by the school prevention team resulting in action, they were perceived to be counter-productive by those involved. This was because the motivation for systematically improving whole-school health promotion changes and may lose momentum when not actively kept on the schools agenda. Timing of the priority-workshops in the planning cycle of the school combined with proper feedback to participants therefore is crucial to its added value in the schoolBeat strategy.

\section{THE HEALTHY SCHOOL MODEL}

The healthy school model used in the schoolBeat-strategy originates from the American comprehensive school health program (Marx \& Wooley, 1998). We translated and adapted the American model to fit the Dutch context (Leurs, Jansen et al., 2005). The model consists of eight strategies, all presented in Figure 9.1 and outlined in more detail and illustrated with specific examples for primary and secondary education in the schoolBeat manual (Leurs et al., 2006).

The idea behind the healthy school model is that an intervention mix is required over a longer period of time for school health promotion to be effective (Marx \& Wooley, 1998; St.Leger \& Nutbeam, 1999). Within the schoolBeat strategy the inclusion of a minimum of three elements of the healthy school model for a period of at least three years is recommended per health 


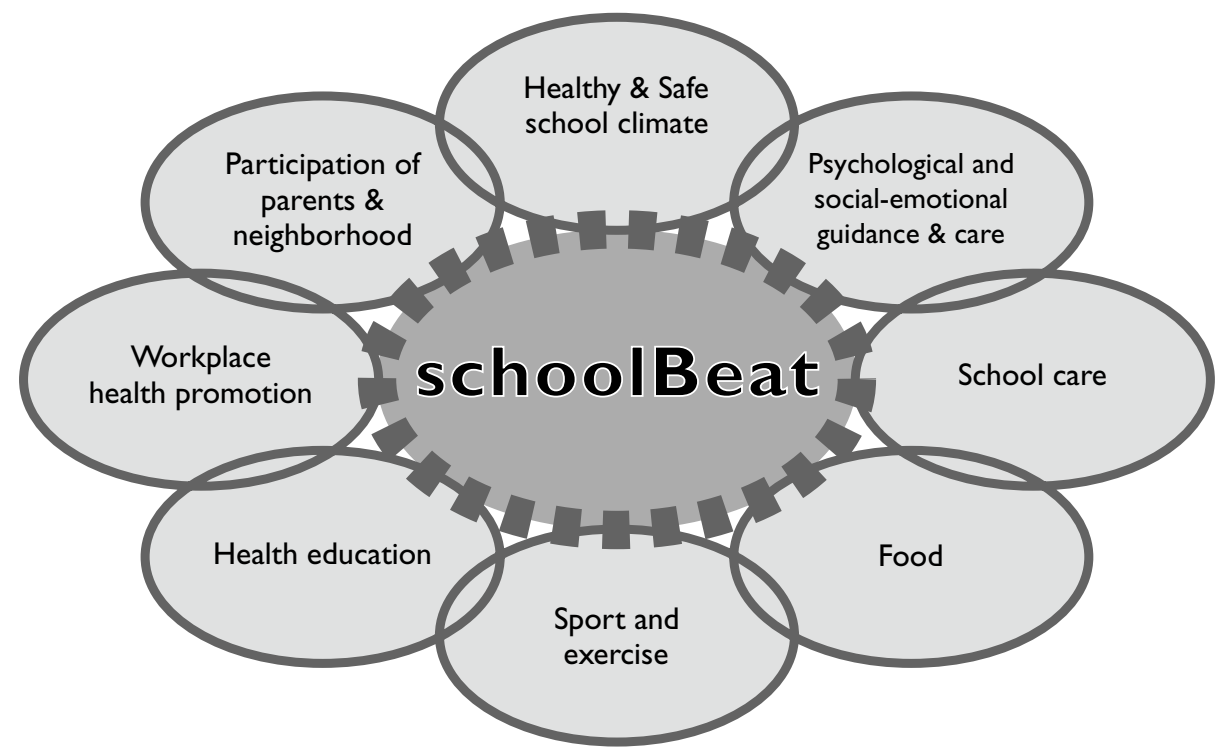

Figure 9.I The Dutch Healthy School Model, based on the American 'Healthy School Model' (Leurs \& De Vries, 2005)

promotion priority set by a school (Stewart-Brown, 2006; Valois \& Hoyle, 2000; Weare \& Markham, 2005). Some school health promotion programs in the Netherlands already meet this minimum within their intervention (Cuijpers et al., 2002; Jurg et al., 2006; Vermeer et al., 2005). With other interventions, the minimum number of elements for a specific priority set by the school needed to be reached by a combination of interventions.

The healthy school model is designed to support schoolBeat advisors and their prevention teams in the systematic planning of whole-school health promotion planning, together with the schoolBeat inventory, checklist and matrix. In practice, the schoolBeat advisors who used the model in their advice to schools stated that it assisted them in achieving the goal of working with a mix of interventions addressing each priority set by the school. The model also provided them with new directions to look at when planning to address these priorities.

\section{SCHOOLBEAT INVENTORY \& SCHOOLBEAT CHECKLIST}

When the schoolBeat partners started their exploration of the possibilities of creating a collaborative support structure for whole school health promotion, they started with an inven- 
tory of all school health promotion and prevention projects and programs available to schools in the Maastricht-Mergelland region (Johansen, 2002). The schoolBeat-project group developed a uniform grid for short project descriptions. This enhanced the usability by the partners of this inventory. The national healthy school working group and the regional youth prevention group in the neighboring region [Sittard-Geleen] were all consulted in this process to facilitate broader implementation of the inventory in later phases of development. The first regional inventory was presented in late 2002 (Johansen, 2002), followed by annual updates since then (Bessems \& Leurs, 2004a; Boot \& De Ruiter, 2006; Boot, Bessems et al., 2005; Gras et al., 2003; Schoolslag-team, 2007). Inventories were published in paper as well as on the Internet. The paper version allowed schoolBeat-advisors to provide schools with their own copy of the inventory. School-staff could then go through the inventory themselves at a time and place convenient to them. Since 2004, NIGZ prepared the inventory of nationally available interventions. A year later, NIGZ added the first results of the quality assessments using the schoolBeat checklist.

\section{SCHOOLBEAT MATRIX}

The schoolBeat matrix is very much a simplification of the intervention mapping methodology (Bartholomew et al., 2001). It is a matrix in which the target-groups of whole-school health and safety promotion are on one axis and the prevention priorities set by the school on the other (Leurs \& De Vries, 2005). For each combination of priority versus target group, the matrix shows the chosen intervention(s), who is responsible for realizing the intervention and - if necessary - which school health service provides the required support. The schoolBeat matrix is therefore a model for planning comprehensive whole-school health promotion.

The first step in using the schoolBeat matrix is to fill in the whole-school health interventions already in place. By doing this, the school has an overview of its current efforts and identifies prevailing lacunas. In secondary education, input turned out to be very limited for the higher grades. Using the matrix, it became evident that especially pupils in their final year were not targeted by whole-school health promotion.

The second step in using the schoolBeat matrix is to check which priorities are sufficiently addressed with the 3x3 rule introduced as part of the schoolBeat strategy as well (Leurs et al., 2006). The $3 \times 3$ rule states that each priority should be addressed using at least 3 elements of the healthy school model during a minimum period of three years. Priorities which seem to be addressed insufficiently could then be discussed further. It is the task of the schoolBeat advisor to present the interventions best suited to rectifying existing lacunas and strengthening the whole-school health promotion scheme. The schoolBeat-inventory with quality qualifications based on the schoolBeat checklist provides a good starting point for this search. An example of the schoolBeat matrix is presented in Table 9.2. 


\section{Table 9.I A page of the schoolBeat-inventory}

Name of the intervention:

Availability: the Netherlands or a specific region

Abstract of intervention description

\begin{tabular}{|c|c|c|c|c|}
\hline \multicolumn{5}{|c|}{ Specifications } \\
\hline Aim? & & & & \\
\hline \multicolumn{5}{|l|}{ Target group? } \\
\hline \multicolumn{5}{|l|}{$\begin{array}{l}\text { Costs for the school? } \\
\text { - extra funding options? }\end{array}$} \\
\hline \multicolumn{5}{|l|}{ Fits in with which lesson? } \\
\hline \multicolumn{5}{|l|}{ Teacher training required? } \\
\hline \multicolumn{5}{|l|}{$\begin{array}{l}\text { What modules or elements are included? } \\
\text { - is tailoring possible? }\end{array}$} \\
\hline \multicolumn{5}{|l|}{$\begin{array}{l}\text { Which persons are needed? } \\
\text { - how much preparation time is required? } \\
\text { - How much time does the intervention itself } \\
\text { take? }\end{array}$} \\
\hline \multicolumn{5}{|l|}{$\begin{array}{l}\text { Evaluated? (process / effect) } \\
\text { Results? }\end{array}$} \\
\hline \multicolumn{5}{|l|}{ schoolBeat checklist-score } \\
\hline I. effectiveness & 4. efficiency for school & 6000 & 7. surroundings & 00000 \\
\hline 2. systematic approach & 5. suitability to education & $\bullet \bullet 000$ & 8. quality of support & $\bullet \bullet \bullet 0$ \\
\hline 3. efficiency for support organization & 6. participation & 00000 & 9. ethics & $\bullet \bullet 000$ \\
\hline
\end{tabular}

Scale $\bigcirc ৩ ০ ০ ০$ week to strong

Contact details 
Table 9.2 The schoolBeat matrix for a hypothetical school for secondary vocational education [VMBO]

\begin{tabular}{|c|c|c|c|}
\hline Target groups & \multicolumn{3}{|c|}{ Priorities } \\
\hline & $\begin{array}{c}\text { bullying } \\
\text { \& social competencies }\end{array}$ & $\begin{array}{c}\text { obesity } \\
\text { (diet \& exercise) }\end{array}$ & $\begin{array}{c}\text { substance abuse } \\
\text { (smoking, alcohol, drugs) }\end{array}$ \\
\hline All grades & $\begin{array}{l}\text { - film ' Chatbox: who cares' } \\
\text { plus feedback session }\end{array}$ & $\begin{array}{l}\text { - intervention for over- } \\
\text { weight and obese pupils }\end{array}$ & \\
\hline Grade I & - bullying protocol & - daily PE-classes & $\begin{array}{l}\text { - I0 lessons - Healthy } \\
\text { School \& Drugs }\end{array}$ \\
\hline Grade 2 & $\begin{array}{l}\text { - renewed discussion of the } \\
\text { bullying protocol at the } \\
\text { start of the year }\end{array}$ & $\begin{array}{l}\text { - } 4 \text { times per week PE } \\
\text { - preparation of healthy } \\
\text { lunches for pupils and } \\
\text { school staff }\end{array}$ & $\begin{array}{l}\text { - I0 lessons - Healthy } \\
\text { School \& Drugs }\end{array}$ \\
\hline Grade 3 & $\begin{array}{l}\text { - renewed discussion of the } \\
\text { bullying protocol at the } \\
\text { start of the year }\end{array}$ & $\begin{array}{l}\text { - } 3 \text { times per week PE } \\
\text { - preparation of healthy } \\
\text { diners for school staff and } \\
\text { parents }\end{array}$ & $\begin{array}{l}\text { - I0 lessons - Healthy } \\
\text { School \& Drugs } \\
\text { - development of a website } \\
\text { on drug prevention for } \\
\text { teenagers }\end{array}$ \\
\hline $\begin{array}{l}\text { Grade } 4 \\
\text { (final exams) }\end{array}$ & $\begin{array}{l}\text { - renewed discussion of the } \\
\text { bullying protocol at the } \\
\text { start of the year }\end{array}$ & $\begin{array}{l}\text { - PE } 3 \text { times per week } \\
\text { - organization of PE } \\
\text { activities for children in } \\
\text { the neighborhood }\end{array}$ & $\begin{array}{l}\text { - feedback session on pupil } \\
\text { health report } \\
\text { - alcohol and drugs not } \\
\text { permitted on school } \\
\text { excursions }\end{array}$ \\
\hline Staff* & $\begin{array}{l}\text { - teacher training in the } \\
\text { early detection of bullying } \\
\text { problems in a class }\end{array}$ & $\begin{array}{l}\text { - free fruit in staff room } \\
\text { - cycling to school project } \\
\text { - healthy lunches prepared } \\
\text { by pupils }\end{array}$ & - identify training \\
\hline Parents/carers & $\begin{array}{l}\text { - information evening about } \\
\text { social interaction of pupils } \\
\text { and bullying } \\
\text { - presentation of movie on } \\
\text { bullying in cyberspace }\end{array}$ & $\begin{array}{l}\text { - healthy diners cooked by } \\
\text { pupils } \\
\text { - articles in the school } \\
\text { newspaper }\end{array}$ & $\begin{array}{l}\text { - article in school newspaper } \\
\text { - information evening }\end{array}$ \\
\hline Environment & & $\begin{array}{l}\text { - pupils run a healthy } \\
\text { canteen } \\
\text { - safe cycling routes to } \\
\text { school } \\
\text { - safe cycle-locks at schools } \\
\text { - after school activities in } \\
\text { the school neighborhood }\end{array}$ & $\begin{array}{l}\text { - smoke-free school } \\
\text { grounds for all pupils } \\
\text { - rules about leaving school } \\
\text { grounds during breaks }\end{array}$ \\
\hline
\end{tabular}

* School staff could be split into teaching staff and support staff. This is up to the school working with the schoolBeat matrix. 
The schoolBeat-matrix itself has been completed by four schools during the schoolBeat-development period. School representatives involved in the schoolBeat matrix warmly welcomed the overview the schoolBeat advisor was able to provide in using the matrix. It is recommended that schools update the schoolBeat prevention matrix annually as part of the school plan / whole-school health and pupil care plan, together with their healthy school advisor and their own school prevention team (Leurs et al., 2006).

\section{DEVELOPMENT SUPPORT}

The last part of this chapter describes the extra support received during the schoolBeat development period enabling the interventions described in this thesis to be developed and put into practice: the support of interns and volunteers, intellectual support, financial support and support of a national organization.

Developing and testing the schoolBeat strategy was an intense process. The assistance of public health students conducting their master thesis turned out to be very helpful. In total five masters students contributed to the schoolBeat development during the initial period (Bessems, 2003; Boot, 2003; Johansen, 2002; Van der Sar, 2004; Wauters, 2004). Additional support was received from two health promotion graduates who volunteered to support the schoolBeat-development in order to create some suitable work-experience (Vermeer et al., 2005). For both, this resulted in a job with one of the Limburg public health services.

Additionally, support in the form of inspiration and exchange beyond regional and national borders turned out to useful as well. The pupil reports are a good example of this, as they resulted from the national exchange which came out of the schoolBeat-masterclass. Of course, the Rotterdam pupil reports were already available on the Internet. However personal exchange made all the difference in this case. For this reason, the professionals involved in the schoolBeat-development were encouraged to present the schoolBeat-strategy at regional and national forums and to identify ideas for further improvement of the strategy (Bessems et al., 2004; Boot \& Bouts, 2005; Gelissen, 2003; Hardy-Pasmans, 2004; Peters et al., 2003; Prinsen \& Aan den Boom, 2002).

Although the effects of sharing ideas regarding the schoolBeat-strategy on a national level were not studied empirically, a few hypotheses may be deduced from the experiences of the schoolBeat-presenters. In general, audiences reacted positively to schoolBeat-ideas, which made the presenters more confident they were on the right track. Critical remarks were generally in the form of changes designed to improve the schoolBeat-strategy even further or to add new elements to the schoolBeat strategy. Additionally, having to present (elements of) the schoolBeatstrategy required presenters to become even more familiar with the strategy than before. The 
same applied to writing up one's experiences with schoolBeat in the schoolBeat manual and in a wide variety of professional journals.

The financial support of ZonMw was a critical factor in the schoolBeat development as this enabled the schoolBeat-partners to recruit a full time coordinator / researcher and to provide schools with some activity money if needed. Participating organizations financed the time invested by their employees in schoolBeat-advisory work and the participation in the schoolBeat project group and CEO-meetings. In 2003, the partners received an additional grant from the OGZ-foundation to trial the schoolBeat-checklist nationally. At the regional level, smaller grants were received from the city of Maastricht and the province of Limburg to conduct safeschool evaluations and to introduce pupil reports.

The National Institute for Health Promotion and Disease Prevention (NIGZ) supported the national implementation of the schoolBeat strategy. Regional public health organizations do not have the means to support national implementations: their output is meant to benefit the local public. An additional implementation grant by ZonMw facilitated the first national schoolBeat-masterclass in 2004 (co-hosted with NIGZ) and the production of the schoolBeatmanual in 2006. Since then a further two masterclasses have been organized by the NIGZ without the benefit of grants. The NIGZ invited all masterclass participants to join NIGZ's healthy school network afterwards. Additionally, the NIGZ continued to conduct national quality-assessments of healthy school interventions and to provide national input for healthy school inventories

Support of the schoolBeat development did not stop. A ZonMw-grant to establish an academic workplace for public health research and practice in the Maastricht-region and a ZonMwgrant to conduct DISC-based studies into whole-school health promotion collaboratives combined with the commitment of secondary schools in the whole of South Limburg provide ample opportunity to continue the schoolBeat-development. 


\section{General discussion}

With the schoolBeat project, we aimed to study wether "fragmented, uncoordinated, supply driven support of school health promotion can be transformed into a comprehensive, collaborative and demand oriented approach to effective whole-school health promotion" (see page 7). The data presented in this thesis clearly suggests that it is possible to develop and implement a comprehensive, collaborative and demand oriented schoolBeat-approach to whole-school health promotion within a timeframe of about four years. The schoolBeat strategy has become the national standard for school health promotion in the Netherlands.

In this general discussion, we will reflect upon the accomplished change, the successes and cautions we came across and the importance of the lessons we learned for future endeavors in public health. Special attention will be paid to the schoolBeat-checklist and the DISC-model. Additionally, we like to share some methodological considerations encountered as well. Recommendations for research topics and for the practice of school health promotion finish the discussion and leave room for some final conclusions. 


\section{CREATION AND INTRODUCTION}

In 2002, we started the schoolBeat project based on a grant for a regional collaborative approach to whole-school health promotion to be developed and put into practice within a period of four years, with five support organizations, in seven municipalities and over 70 schools for primary and secondary education (Leurs $\&$ Jansen, 2002). At first, we clarified what effective whole-school health promotion was and we outlined the requested approach in more detail with the regional partners involved: schools, health support agencies and municipalities (Leurs, 2003a). We consulted health promotion and planning literature and checked with the American approach to school health to outline the schoolBeat steps (Bartholomew et al., 2001; Bracht, 1999; Marx \& Wooley, 1998). Additionally, we looked into potential ingredients, such as a the Limburg Youth Monitor (De Munter, 1998; Houben, 2002), the priority setting workshop (Boerma \& Hegger, 2001), and the Preffi-instrument (Molleman et al., 1995; Molleman \& Hosman, 2003).

As time was a limited, we focused on possibilities for re-inventing existing tools to fit our needs rather than developing tools. We ended up developing only the schoolBeat quality checklist and the Quick Scan Shared Care from scratch (Kleijnen et al., 2003; Peters \& Keijsers, 2002) and modifying existing tools and models. If we had had more time in the preparatory phase, we could perhaps have explored experiences with whole-school health promotion in other regions and countries better by talking to the stakeholders involved directly and we might have come up with some other ideas. However, having contacted national and international experts on school health, we do feel that we have proceeded on the basis of a comprehensive understanding of the state of the art in whole-school health promotion.

Overall, we took an incremental approach to develop and implement the schoolBeat-strategy in the Maastricht-Mergelland region. Together with the regional school health support agencies, we looked for windows of opportunity to put the elements of the schoolBeat-strategy into practice. In line with Kingdon's multiple stream theory (Kingdon, 1995), we used agendasetting and advocacy to create policy windows for the introduction of the schoolBeat strategy. In this process, the schoolBeat coordinator - being the author of this thesis - acted as a social entrepreneur working with stakeholders from the three different streams: problem, policy and politics. As "social entrepreneurship is key to the success of health promotion and Healthy City development".[(De Leeuw, 1999) p261], it proofed to be an important factor for successful whole school health promotion as well. 


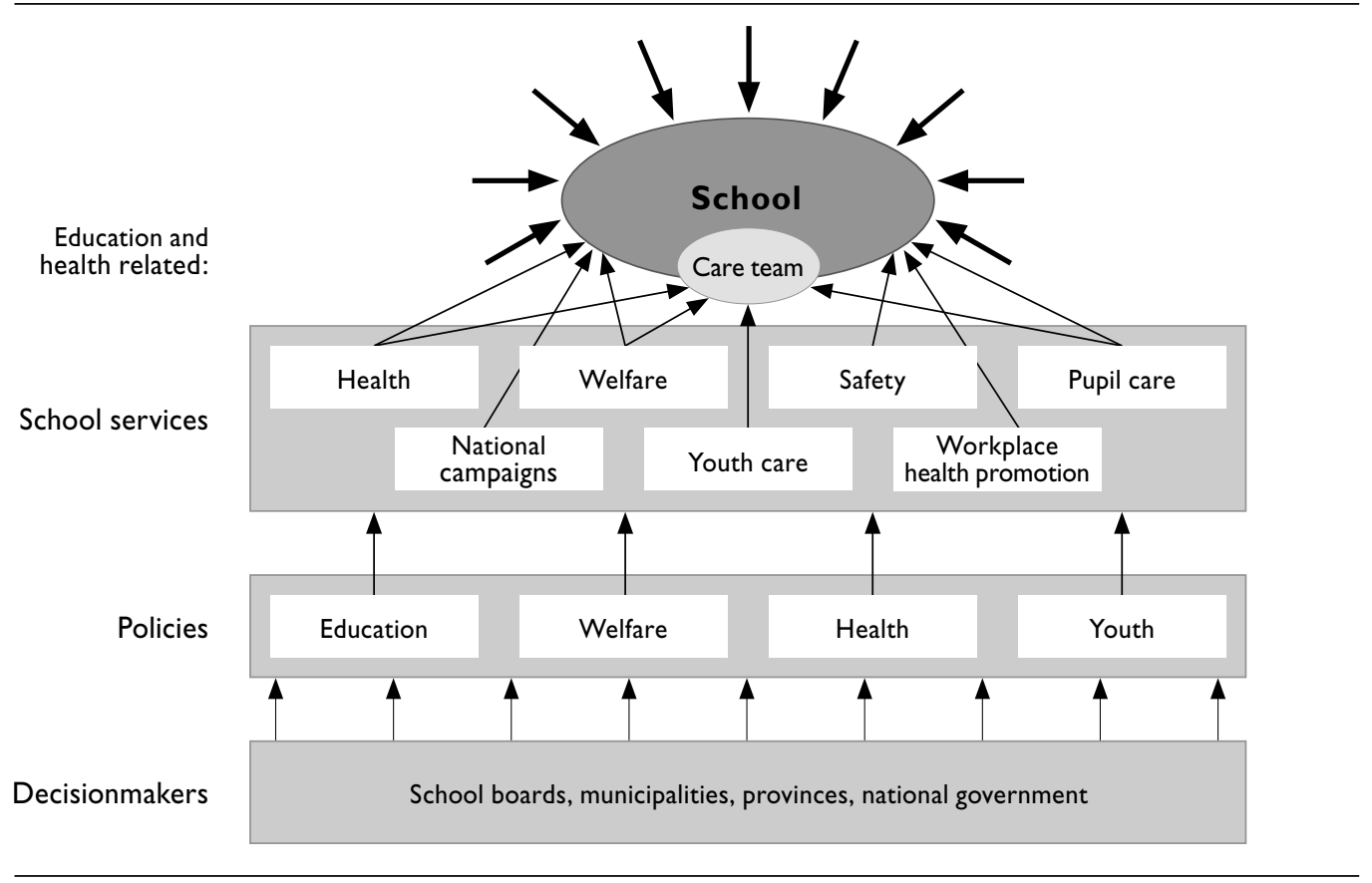

Figure 10.I Organizational structure of school-health at the start of the schoolBeat-development

\section{CHANGES IN THE ORGANIZATIONAL STRUCTURE}

The description of the organizational structure of school health at the start of the schoolBeat development in 2002 (see Figure 10.1) was based on the structures in place in the Maastricht region at the time. Schools complained that they were overwhelmed by requests from various organizations to start using their materials and programs. Health-support organizations were among these organizations, just like organizations focusing on culture or nature. Based on responses at the 2006 schoolBeat-masterclass in the Netherlands, we do understand that Figure 10.1 still accurately depicts the current situation in many Dutch regions.

The desired organizational school health support structure (see Figure 10.2) is the result of an iterative process with stakeholders in which the current organizational structure was adapted in over 10 steps. With integral youth policy and joint coordination by decision makers at school and governmental level beyond the direct influence of the schoolBeat partners, the schoolBeat project focused on improving the interaction between schools and school health support services in terms of health promotion in its broadest definition. 


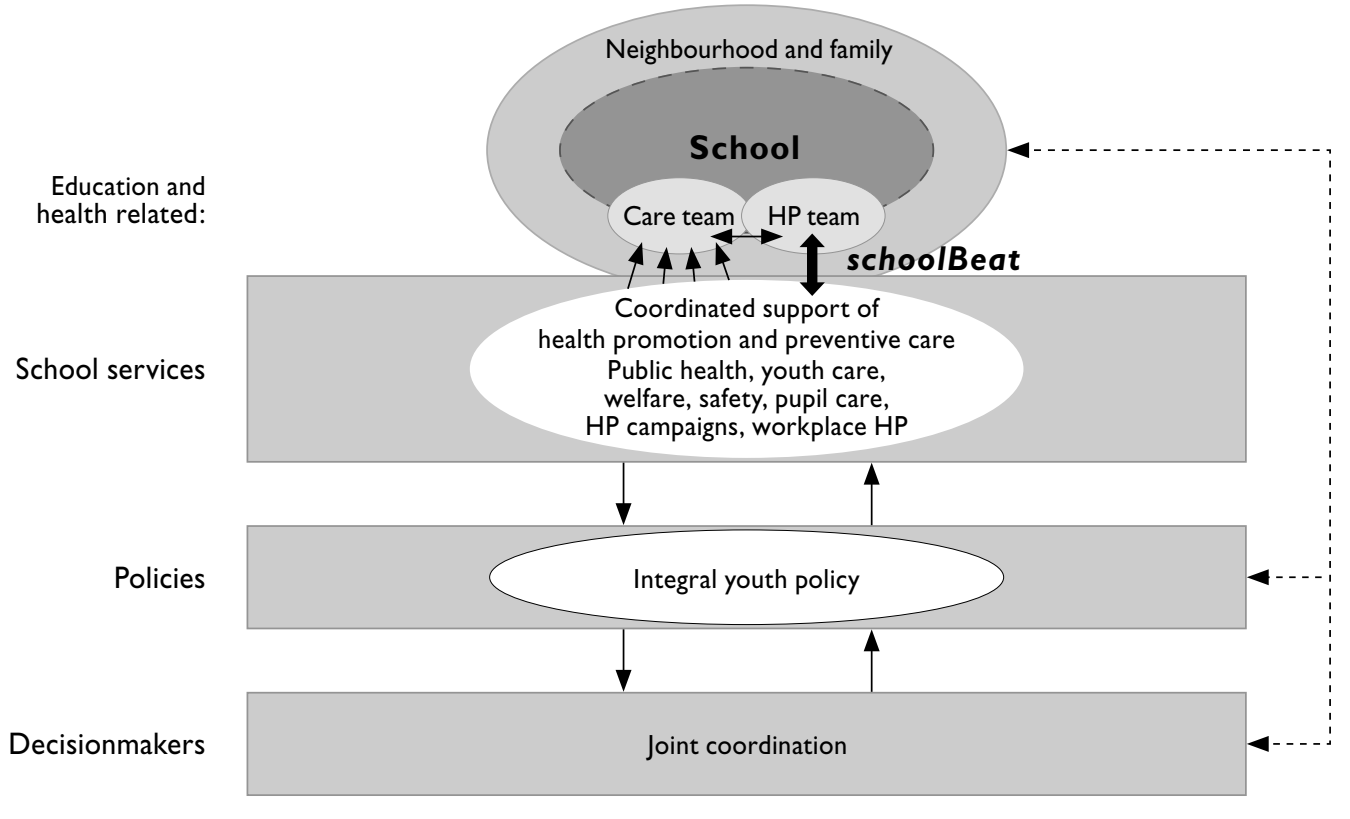

Figure 10.2 Desired organizational support structure of school-health.

During the schoolBeat-development period, the health and welfare organizations joined forces in their quest to provide more effective and efficient support for school health promotion in the region. The partners agreed on workload-sharing for the linkage between schools and school service providers via schoolBeat-advisors. The collaboration with safety-providers was strengthened via participation of the schoolBeat-coordinator in the safe-school working group. The schoolBeat-coordinator participated in regional pupil care meetings for primary and secondary education. Additionally, she was frequently invited to regional youth policy meetings. These regular contacts with whole-school health stakeholders enabled her to act as a 'bottomup' social entrepreneur for the development and implementation of schoolBeat.

The schoolBeat 'bottom up' strategy contrasts the more 'top-down' orientation of the social entrepreneur in the Heartbeat Limburg project, who started with the commitment of the national heart foundation and the regional majors in 1994 (Ruland et al., 2006). This was followed by four preparatory years involving top-level stakeholders. Changed windows of opportunity seem to account for the difference in focus of the Heartbeat and schoolBeat social entrepreneurs. With a local major in the board of governors of the Netherlands Heart Foundation and the impression that prevention of cardiovascular diseases needed a boost, a window of opportunity for the Heartbeat-strategy had opened to the regional public health service and the university hospital in 1994. However, eight years later when the Heartbeat program, 
financed by the Netherlands Heart Foundation, was well on its way, that window of opportunity changed as municipalities were asked to cover the cost of the Heartbeat program themselves. At the same time, the regional public health service presented the development of a similar strategy for whole-school health promotion, the schoolBeat strategy, also supported by a national grant. Municipalities, especially their public servants, were not pleased by the idea that this new strategy would be costing municipality's money in the future as well. This, together with the window of opportunity described in the previous chapter regarding the collaborative development of the Quick Scan Shared Care, lead to the adoption of a 'bottom up' social entrepreneur strategy for schoolBeat. That opportunities continue to change is shown by the recent 'top-down' introduction of the schoolBeat strategy in the Heerlen-region (Van den Brugge, 2006). Our study illustrates that the social entrepeneur should choose the approach best suited to the windows of opportunity for change detected and therefore be capable of working with a wide range of disparate individuals and organizations (Catford, 1997). As illustrated, at the start of the schoolBeat development, this was a more bottom-up oriented approach, chaning over the years when the first successes became visable to a more top-down approach. This was in line with detected windows of opportunities.

Due to national publicity on schoolBeat developments and the involvement of the National Institute for Health Promotion (NIGZ) in both the national healthy school collaborative and regional school-health developments, national health promotion campaigns took more notice of regional school health support structures. Youth related two-way interaction among policy and decision makers increased, as did the exchange between youth-related sectors at the policy level itself. It seemed that the Dutch society was just ready for an increase in youth-related interaction. At the national level developments towards comprehensive youth policy took of around the same time, led by the inter-ministerial organization Operation Young (Van der Spek, 2003). Together these developments opened the window for further exploration and implementation of comprehensive and tailored whole-school health approaches in the Netherlands.

Figure 10.3 illustrates that the 2005-situation in the Maastricht-Mergelland region was clearly different from the starting situation in 2002: health promotion / prevention teams had been installed by schools, two-way communication between school-services and youth policies was put into practice and the health and welfare organizations joined forces. Although the schoolBeat project did not aim for chances at the policy level, contacts at youth policy level between education, welfare, health and sports seemed to have increased as well. National campaigns were searching for how to proceed via the regional health and welfare organizations while continuing their direct approach to schools. Except for workplace health promotion, all school services had taken up or continued their role in whole-school health. This meant that some major steps towards the desired situation illustrated in Figure 10.2. had been taken in just four years. At the school level, the installation or revitalization of prevention teams linked with the individual pupil care teams at each secondary school in the Maastricht region was a step forward as well. Especially as all schools received support by a schoolBeat-advisor. In DISC-terms (see chapter 8), coordinated health and school health promotion moved beyond 


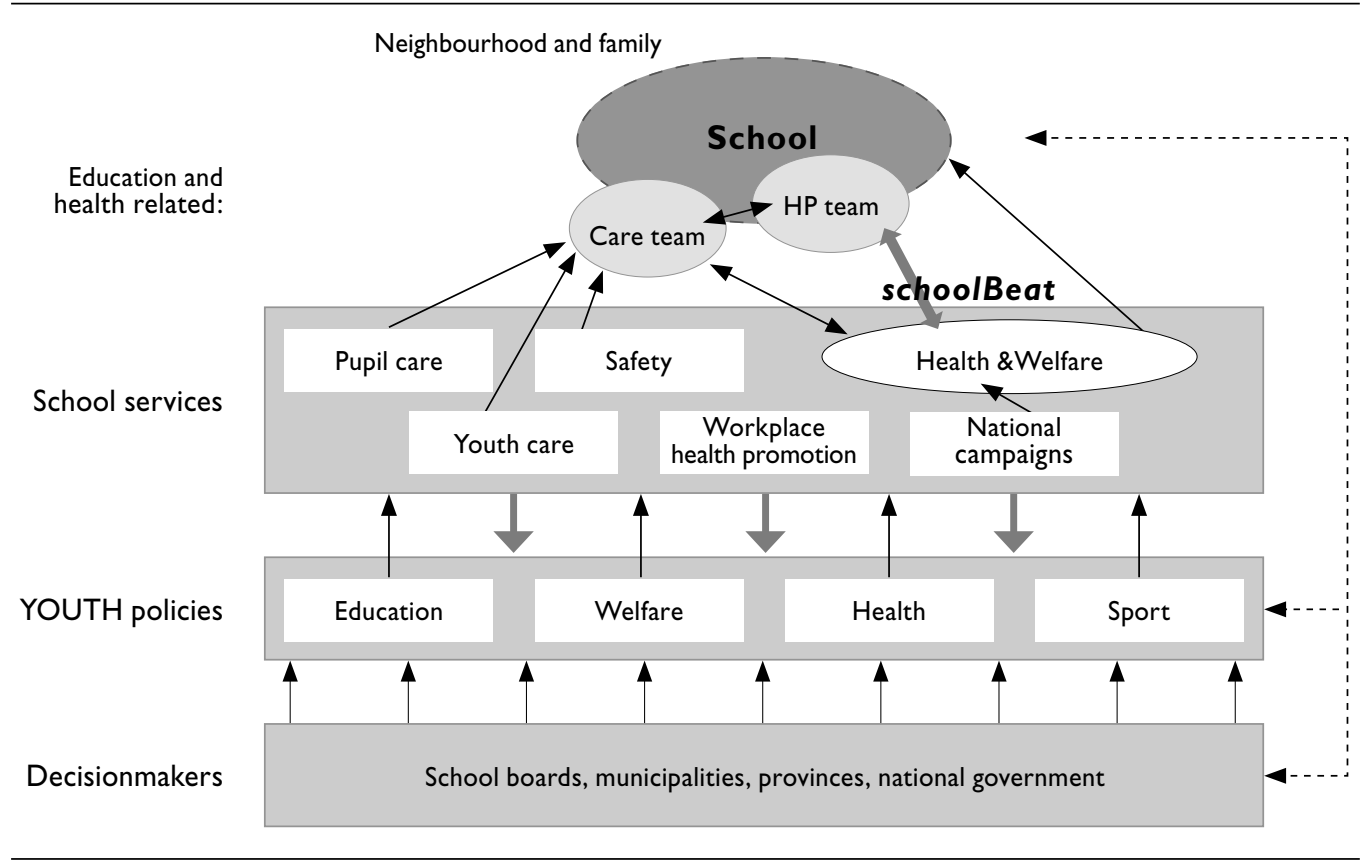

Figure 10.3 Organization of school-health support structure in the Maastricht-region in 2005.

the idea-phase resulting in several instruments, strategies and working groups all part of the schoolBeat steps, with differing levels of implementation.

Besides developing the schoolBeat strategy, piloting elements and monitoring the regional development closely, the social entrepreneur task turned out to be an intensive but essential task to detect windows of opportunities to put elements of the schoolBeat strategy into practice. The schoolBeat coordinator participated in a variety of regular meetings at different levels - such as meetings of pupil care coordinators, management meetings of health support organizations, safe-school meetings and regional youth meetings for civil servants - to understand the needs, barriers and rythms of those involved in whole-school health promotion. By becoming a member of these meetings, the schoolBeat coordinator was able to put wholeschool health promotion on the agenda, to introduce elements of the schoolBeat strategy and to create support for further developments and pilots. We managed to introduce the desired changes step by step, always within the boundaries of current practice. As current practice was continiously changing, the boundaries of what was possible and within reach to be changed was as well. Advancements and set backs regularly occurred. By 2005, we were still making progress towards realizing the desired organizational structure as presented in Figure 10.2. Therefore, we do not know yet, to what degree the desired organizational structure can be realized. 
Special attention is needed for workplace health promotion in schools, as this element of whole-school health is not linked yet. Although we did contact work-place health organizations, they were not interested in supporting school health promotion activities for staff. As workplace health organizations work on a contract-basis, they only provide services organizations, including schools, are willing to pay for. Only in one of the schools such activities were initiated. Here, the schoolBeat-coordinator interested the provincial sport council to adopt the school in supporting an exercise scheme for staff, coordinated by one of the staff members of the school. A work-place health organization was not involved.

At the national level, public health services who participated in the schoolBeat masterclass reported a more demand oriented approach to schools (Hekkink et al., 2006). In addition, public health services who did not participate in the masterclass, did report a more supply oriented approach to schools, comparable to the starting situation of the schoolBeat development in the Maastricht-Mergelland region (Hekkink et al., 2006). This indicates that the transformation from Figure 10.1 to Figure 10.2 is not limited to South Limburg.

National politics and policies are able to enhance the further development of the wholeschool health support structure, but may prove to become a major barrier as well. The ambition of the current Dutch government to develop centers for youth and families (Ministerie voor Jeugd en Gezin, 2007) should enhance coordinated support of health promotion and preventive care for schools. It will be up to social entrepreneurs to look for ways to create a proper fit of these centers with schools, national campaigns and organizations for work place health promotion at the local and regional level.

\section{THE IMPORTANCE OF THE SCHOOLBEAT PROJECT}

With the schoolBeat project, Public Health Services South Limburg, Maastricht University and NIGZ achieved in four years what national health support agencies had tried for decennia before. We managed to develope a well documented strategy for collaborative and tailored whole-school health promotion, we managed to put it into practice in one region with more to follow, and we raised it to the national standard for school health in the Netherlands. The documentation includes articles published in Dutch and English scientific journals but also a manual for professionals in Dutch and a national master class. This has not gone unnoticed. Recently public health services in the Netherlands indicated that they intend to start working with the schoolBeat-priority workshop, the schoolBeat quality assessments, the healthy school model and the national schoolBeat inventory (Dafesh et al., 2006). Even schoolBeat's email newsletter has drawn the interest of other public health services. They are interested in lowcost communication regarding their efforts and support offered in school health promotion with schools, municipalities and other health support partners in the region. 
In the following section the importance for public health is highlighted of the collaborative development, the documentation tools and the attention for pupil participation provided by the schoolBeat project.

\section{Collaborative development}

In the schoolBeat project, we overcame and acknowledged differences between the education domain and the health domain in favor of the mutual goal to improve the health and well-being of future citizens. This resulted in products understood and accepted by professionals from both domains and in a manual enabling adaptation and reinvention of the schoolBeat strategy to fit the needs of professionals in other regions and domains. A good example is the schoolBeat-checklist for quality assessment of healthy school interventions. Although the checklist has its roots in the Dutch Preffi-instrument (Molleman \& Hosman, 2003) developed and applied by public health experts and public health practitioners only, the checklist has taken a new direction in quality assessment. It included quality perspectives from two distinct professional domains and provided the assessment results to both domains as well (Leurs, Schaalma et al., 2007). The inclusion of both perspectives is important to take into account in the new intervention review schemes in the Netherlands such as the Dutch Review Committee on Youth Interventions [erkenningcommissie jeugdinterventies] (Van Yperen, 2007) and the Dutch Review Committee on Behavioral Interventions [Justitiële Erkenningscommissie Gedragsinterventies] (Van der Laan et al., 2006). The first committee mentioned has already included the schoolBeat checklist in their action plan for a broad youth intervention recognition scheme in the Netherlands (Van Yperen et al., 2006). Besides acknowledging different professional perspectives on quality, the schoolBeat checklist illustrates that quality is a broader concept than effectiveness: an intervention of good quality has to meet more criteria than the effectiveness criterion.

By including both domains from the very start of the development of the checklist, we intended to enhance its implementation as well (Grol et al., 2000; Rogers, 1995). The current interest of both domains for the schoolBeat checklist strengthens our impression that we are on the right track.

\section{Documentation tools}

Both the schoolBeat checklist and the DISC model are important tools for the systematic documentation of public health in the Netherlands (Leurs, Jansen et al., 2005; Leurs, Schaalma et al., 2007). Both tools encourage their users to describe more aspects of their intervention respectively their collaboration than professionals used to. The checklist requires information about the theoretical bases and the systematic development of an intervention, besides information on its effectiveness. Additionally, efficiency in time and money for support organizations and schools, ethical principles and levels of participation had to be accounted for amongst other issues as well. The application of the DISC model encourages its users to describe not only the processes between collaborating organizations, but also other issues like external fac- 
tors, context and the influence of leadership on the collaborative process. DISC supports the search for windows of opportunity for further change, and it provides directions for the most effective and efficient use of scare resources. Reviewing interventions and collaborations more systematically using the schoolBeat checklist and the DISC-model, provides the field of public health with more comprehensive opportunities for comparisons between interventions and collaboratives. Comparisons and the lessons learned based on the schoolBeat-checklist and DISCanalyses, add to the evidence base of public health. Both tools fit in with a recent pledge by Saan and De Haes for using health promotion reference schemes to enable comparisons and debate among researchers, practitioners and policy makers (Saan \& De Haes, 2005).

\section{Student participation}

Although the European Network for Health Promoting Schools has declared student participation to be the most important element of whole-school health promotion (Barnekow et al., 2006), in the Netherlands pupil involvement is limited. It was not even looked into at a recent scan of school health promotion support by the secretariat of the Dutch healthy schools network (Dafesh et al., 2006). Within the schoolBeat-development, pupil involvement was encouraged in piloting new developments (Boot, 2005; Vermeer et al., 2005) and in the priority setting workshops (Doijen \& Hardy, 2004; Leurs \& De Vries, 2005). As pupil involvement not only adds to the efficacy of whole school health but also to general school effectiveness (Barnekow et al., 2006), student participation in whole-school health offers a promising area for future research and development. Our study into the focus points for school health promotion improvements in primary schools support this recommendation (Leurs, Bessems et al., 2007).

\section{Limitations}

Definitely, 'the sky is the limit' does not apply to developing, testing, modifying, putting into practice and studying a collaborative strategy. It is an intensive process with limitations regarding ambition and research. We do not consider resources, time frame and levels of commitment and competencies as limitations. Constraints like these are part of the context in which the development is meant to take place and have to be addressed in the ongoing planning of the project.

\section{Ambition}

Our initial goal to develop and put into practice a school health strategy in 80 schools for primary and secondary education in a period of four years did turn out to be unrealistic. Especially primary schools were not yet ready for the intended changes. Therefore, using windows of opportunities (Kingdon, 1995), we focused mainly on the 10 schools for secondary education present in the Maastricht-Mergelland region, including a special needs school. In 2002, these schools had just started to meet regularly to improve the system of pupil care in their schools (Kleijnen \& Leurs, 2003). Extending pupil care with school health promotion was a minor step for them and a big opportunity for the schoolBeat team. Also the health sup- 
port organizations were not as ready to support comprehensive support for primary schools as they were for secondary schools. The public health services had already started with monitoring healthy behavior of secondary school pupils (De Munter, 1998; Houben, 2002).

Primary schools were still coming to grips with new pupil care policy in the Netherlands promoting inclusive education: providing care to pupils within regular schools instead of transferring pupils to special needs schools. Although we stayed in touch with the pupil care coordinating committee of the primary schools in the Maastricht-Mergelland region and although we conducted an explorative study among primary school staff (Leurs, Bessems et al., 2007), the application of the schoolBeat strategy in primary education was limited to incidental elements put into practice. Nonetheless, we ensured that every schoolBeat-newsmail included information on health promotion in primary schools and we encouraged schools to apply for some schoolBeat funding for minor health promotion interventions in their school. Several schoolBeat advisors assisted schools with the 1 page application form. By doing so, we understand that both the schools and the support agencies are now ready to proceed with wholeschool health promotion in primary education. Four years of the schoolBeat-project turned out to be necessary to create this window of opportunity.

\section{Level of evidence}

A newly developed comprehensive health promotion strategy is hard to evaluate with quantitative research approaches as randomized controlled trials and case-control or cohort studies. In the hierarchy of evidence, quantitative research is followed by more qualitative and interpretative research. Experts in school health promotion consider quantitative research of limited value for evaluating the health promoting school (Barnekow et al., 2006). They prefer qualitative and interpretative research with a focus on empowerment of participants and the implementation of change (Barnekow et al., 2006). With the DISC-model and the Quick Scan Shared Care we developed and applied instruments to conduct qualitative and interpretative research more systematically. The DISC-model has the extra advantage that it supports triangulation of quantitative and qualitative data. With a longer time frame and more resources, a higher level of evidence is possible as shown by Schuit and colleagues with the evaluation of the heartbeat program after five years of intervention (Schuit et al., 2006) The accompanying methodological considerations are discussed in the next section.

\section{METHODOLOGICAL CONSIDERATIONS}

We deduced four major methodological considerations from the study of the schoolBeat development: 1) conflicts of interest between research and development; 2) limited power of quantitative approaches to study whole-school health initiatives; 3) completion time \& timing; and 4) difference between professional groups. 


\section{Conflict of interest}

Developing new strategies, putting them into practice and studying them at the same time seems to imply a conflict of interest. Developers want their interventions to be a success whereas researchers want to test the null hypothesis in conditions that allow for falsification. Researchers and developers meet in the area of formative evaluation, which "aims to help develop and improve programs from an early stage, when opportunities for influence are likely to be greatest" [(Dehar et al., 1993) p.204]. Additionally, most researchers have a strong preference for reporting on successful effects of interventions as well. The number of publications on failed interventions is very limited. Being aware of this conflict of interest and the double bias towards the studied intervention resulting from it, may lead to unnecessary over-criticizing ones own work, like a teacher who is more critical towards his own child compared to other pupils in his class. Especially women should be aware of this caveat as they seem to have a stronger tendency to attribute success to external factors and failure to internal factors compared to men.

\section{Limited power}

The limited number of partners within any collaborative has consequences for quantitative research into collaboratives and for the evaluation of interventions introduced among the partners of any one collaborative. Even in the rare event of 100\% participation in such a study, the power of the study can only be sufficient when a very limited number of surveyitems is included. Things become even more complicated with a repeated measures design, as professionals change jobs, retire or have other reasons not to participate in all measures over time. Both the DISC-study as well as the Quick Scan Shared Care suffered from limited participation in repeated measures.

However, that does not imply that the measures taken with both instruments over time lost their importance. On the contrary, both instruments provided a clear picture of the status of the collaborative respective whole-school health at the time of the measurement. Participating schools and the schoolBeat team used the results to look for opportunities for further improvements and for barriers to tackle. For example, the results of the schoolBeat checklist assisted schools in selecting whole-school health interventions that fit their priorities as well as their corebusiness. Based on the results of the schoolBeat checklist, the schoolBeat team decided to develop a whole-school health intervention for the upper grades in secondary education as they located no suitable intervention (Vermeer et al., 2005). The results of the DISCmonitoring helped the understanding why organizations behaved in certain ways, and it helped adjusting social entrepreneurial tactics. For example the high expectations of schools towards improvements at the pupil care side of the school health continuum (Leurs, Kleijnen et al., 2003) were made explicit by the DISC-monitoring. This result encouraged the project management to target the misconception of schools regarding the aim of the schoolBeat development more actively than done before. 


\section{Completion time \& timing}

The schoolBeat study illustrated that developments have a rhythm; in this case dictated by schools. Especially between the autumn break and eastern the work has to be done. During the extended summer periods and the months preceding the summer break, school staff is not interested in participating in extra-curricular developments. If you do not tune into the rhythm of schools, and do not have for example your inventory ready at the time when schools plan their activities for next academic year, you will have to wait another year to try again. Therefore, one should time large surveys for school staff to the rhythm of schools. Timing of measurements also applies to other sectors were the workload peaks in certain months and is low in others.

Developments take time, often more time than expected. The mid-term aim to increase the number and quality of interventions suffered from this as we had to define and operationalize the term 'quality' first (Peters $\&$ Keijsers, 2002), then we had to transform the quality perspective into a checklist (Peters et al., 2004) and pilot it (Boot, 2003). A large-scale trial of the checklist was beyond the original study. Therefore, we applied for an additional grant with success and conducted the first national schoolBeat-checklist trial in 2004 (Leurs, Schaalma et al., 2007). The development process, grant application and national trial of the checklist left us with limited posibilities to increase the number and quality of whole-school health promotion interventions as well. This illustrates that planning activities based on interventions or instruments that still need to be developed, requires flexibility.

\section{Differences between professional groups}

Studying input from professionals from domains that differ in culture, jargon and values in the schoolBeat study, provided us with methodological challenges. For example, when studying prevention in schools, we had to clarify the concept of prevention first as the term prevention has many dissimilar definitions in different professional groups. This is not restricted to differences between education and health professionals. Even among the health professionals the use of different definitions of 'prevention' is common (Leurs et al., 2006). As a research methodology, interviews provide opportunities to take the differences into account when the interviewer is aware of differences in definition, jargon and culture. In surveys, one has to consider whether it is valid to use exactly the same survey for different professional groups: do they interpret the survey the same? To overcome this limitation, stakeholders from the different domains involved in the study object, should be involved in developing common indicators as advocated previously by St.Leger (St.Leger, 2000). By doing so in the development of the Quick Scan Shared Care and the schoolBeat checklist, we no longer ignored the school based stakeholders but got them involved and committed instead. 


\section{CONCLUSIONS}

The author of this thesis together with her schoolBeat-team developed, studied, modified, put into regional practice and established the schoolBeat strategy as the national standard for whole-school health promotion in the Netherlands in a period of four years time. The unique, well documented products yielded by this exceptional endeavor, such as the school-health support structure, the schoolBeat-checklist and the DISC-model, as well as the lessons learned during the collaborative development of the strategy are not limited to the field of school health. Their applicability extends potentially to all those areas were collaboration of people or organizations from different sectors is required, crossing boundaries of jargon, culture and regulations amongst others. Several organizations in different regions in the Netherlands are using elements of the schoolBeat-strategy already.

Now it is time to continue the learning curve regarding collaborative cross-sector approaches beyond the current schoolBeat phase. By putting the schoolBeat-evidence into practice on a larger scale and adapting it collaboratively to local and regional circumstances, more schools, more support organizations and more policymakers are able to optimize their impact on the health of tomorrow's citizens.

\section{RECOMMENDATIONS}

Based on the results presented in this thesis, I would like to conclude with a set of recommendations for future research and practice in whole-school health in the Netherlands.

\section{Priority topics for future research into whole-school health}

- The competency levels and expertise of those involved in whole-school health promotion. This includes professionals from the support organizations as well as from schools themselves.

- Analysis of the 2005, 2006 and 2007 schoolBeat-checklist results to refine the assessment procedure cost-effectively.

- The implementation of quality assessment scores for interventions in whole-school health.

- Triangulation of data sources for DISC-analysis, with special attention for the quantitative strand with its limited power by the very nature of the restricted number of partners in any collaborative.

- Interaction between national health promotion campaigns and regional school health services with respect to efficiency and effectiveness of whole-school health support.

- Strategies for enhancing active whole-school health promotion support by the school management and by pupils and parents. 


\section{Recommendations for the practice of whole-school health}

- Develop strategies and working methods for student participation in whole-school health promotion;

- Expand priorities set by the Netherlands government on intervention-effectiveness research and on the use of the most effective youth interventions in practice (Ministerie voor Jeugd en Gezin, 2007) with the quality criteria introduced with the schoolBeat checklist.

- Learn more about the language, core-business and rhythm of schools to enable tailoring of support services to the actual needs and opportunities of schools;

- Work towards multidisciplinary school-based prevention teams with representatives of school management, the pupil care advisory team, education staff, support staff, parents and pupils;

- Develop skills training for social entrepreneurs in school health promotion, preferably linked to the national schoolBeat masterclasses of the healthy schools network in order to enhance reflection on the new skills based on experiences with school health promotion in different regions.

- Use a four-year cycle of data collection and assessment, priority setting, planning, realization, and evaluation, preferably linked directly to the school calendar and taking into account the timing of local elections and expected policy changes as new windows of opportunity may arise from it;

- Link whole-school health monitoring based on the quick scan shared care with health behavior monitoring of pupils, both to be conducted at the start of a four-year planning cycle;

- Leave room in the annual planning for incidental activities that can be implemented quickly as a result of unexpected crises, innovative insights or new possibilities. However, ensure that those incidental activities support at least one of the prevention priorities set by the school and will be included in a broader approach incorporating a minimum of three healthy school strategies and spanning a contact-time of more than three years.

- Extend the annual schoolBeat inventory with information on elements of the healthy school model addressed by the described interventions. This enables the selection of a variety of strategies when planning to address a certain priority set by a school;

- Disregard those projects and programs with negative scores on the schoolBeat quality assessment, especially when they are proven to be ineffective. To high-light the projects this counts for, a 'black-list' is advocated to be included in the schoolBeat - inventory and in the database with youth interventions;

- Communicate the prevention priorities of the school and comprehensive actions taken to all groups involved, both inside and outside the school.

- Set a standard for the competency level of schoolBeat advisors and provide regular schooling, feedback sessions or supervision to maintain this.

- Listen to the ideas and perceived barriers of stakeholders, remodel evidence-based practices within professional standards accordingly, and leave enough room for evaluation.

- And last but not least: plan change-management strategies AND evaluation ahead collaboratively, without losing the required flexibility to tap into windows of opportunities as they arise. 


\section{REFERENCES}

Aarnio M, Winter T, Kujala U \& Kaprio J (2002). Associations of health related behaviour, social relationships, and health status with persistent physical activity and inactivity: a study of Finnish adolescent twins. British Journal of Sports Medicine, 36(5), 360-364.

Ader M, Berensson K, Carlsson P, Granath M \& Urwitz V (2001). Quality indicators for health promotion programmes. Health Promotion International, 16(2), 187-195.

Albertz N \& Ruiter M (1999). De gezonde school en psychosociale gezondheid - projectvoorstel 1999-2001 [The healthy school and psychosocial health - project proposal 1999-2001]. Maastricht: De Limburgse RIAGGs.

Allensworth D \& Kolbe L (1987). The comprehensive school health program: exploring an expanded concept. Journal of School Health, 57, 409-412.

Allensworth DD (1987). Building community support for quality school health programs. Health Education, 18, 32-38.

Andis P, Cashman J, Oglesby D, Praschil R, Adelman H, Taylor L \& Weist M (2002). A strategic and shared agenda to advance mental health in schools through family and system partnerships. International Journal of Mental Health Promotion, 4(4), 28-35.

Apostolidou M \& Fontana D (2003). Teacher attitudes towards health education in Greek-speaking Cyprus schools. Health Education, 103(2), 75-82.

Baldwin L, Abernethy P, Roberts L \& Egan H (2005). Forming, managing and sustaining alliances for health promotion. Health Promotion Journal of Australia, 16(2), 138-143.

Bandura A (1986). Social foundations of thought and action: a social cognitive theory. Englewood Cliffs, NJ: Prentice Hall.

Bandura A (1997). Self-efficacy: the exercise of control. New York: Freeman.

Barnekow V, Buijs G, Clift S, Bruun Jensen B, Paulus P, Rivett D \& Young I (2006). Health-promoting schools: a resource for developing indicators. Copenhagen: International Planning Committee of the European Network of Health Promoting Schools.

Barrett L, Plotnikoff RC, Raine K \& Anderson D (2005). Development of measures of organizational leadership for health promotion. Health Education \& Behavior, 32(2), 195-207.

Bartholomew LK, Parcel GS, Kok G \& Gottlieb NH (2001). Intervention mapping: designing theory- and evidence based health promotion programs. Mountain View, CA: Mayfield.

Bartholomew LK, Parcel GS, Kok G \& Gottlieb NH (2006). Planning health promotion programs; an Intervention Mapping approach. San Francisco, CA: Jossey-Bass.

Bering R (1997). Van beroep: kwaliteitsfunctionaris. Praktisch handleiding voor kwaliteitsfunctionarissen in de zorgsector. Utrecht: SWP/Nederlandse Vereniging voor Kwaliteit en Zorg.

Bessems K (2003). Behoefteonderzoek leerkrachten basisonderwijs: ASE-determinanten die samenhangen met gezondheidseducatie in de klas [Needs assesment in primary education: ASE-determinants related to health education]. Unpublished master thesis, Universiteit Maastricht, Maastricht.

Bessems K, Leurs M, Schaalma H, Ausems M \& De Vries H (2004, 14/15-04-2004). Behoefteonderzoek leerkrachten basisonderwijs: ASE-determinanten die samenhangen met gezondheidseducatie in de klas (poster). Paper presented at the Nederlands Congres Volksgezondheid [Dutch Public Health Conference].

Bessems K \& Leurs MTW (2004a). Het schoolSlag aanbod 2004-2005 [The schoolBeat supply 2004-2005]. Woerden/Maastricht: NIGZ/Maastricht Public Health Institute. 
Bessems KMHH \& Leurs MTW (2004b). Onderzoek Veilige School 2003 [Safe School Study 2003]. Maastricht: Maastricht Public Health Institute.

Biglan A (2004). Contextualism and the development of effective prevention practices. Prevention Science, 5(1), 15-21.

Blokland G, Prinsen B, Kok C \& Van Wijngaarden J (2003). De jeugd heeft de toekomst. Preventie van psychosociale problematiek bij jeugdigen, maatwerk van de GGD. Utrecht: NIZW/GGD Nederland.

Boerma L \& Hegger W (2001). Gezond op School - een methodiek om team en ouders samen te laten beslissen over prioriteiten op het gebied van gezondheid [Health at School - a method for team and parents to prioritize regarding health]. Nijmegen: ITS.

Boot N (2005). Evaluatie van de leerlingrapportages Veilige School [Evaluation pupil reports Safe School]. Maastricht: Maastricht Public Health Institute.

Boot N \& Bouts M (2005, 16-02-2005). Mogelijkheden in het VO E introductie genotmiddelen protocol. Paper presented at the Studiedag genotmidddelenpreventie [Drugprevention training], Maastricht.

Boot N \& De Ruiter S (2006). SchoolSlag inventarisatie 2006-2007; Mogelijkheden op het gebied van gezondheid en onderwijs in de regio Maastricht-Mergelland. Woerden/Geleen: NIGZ/GGD Zuid Limburg. Boot NMWM (2003). SchoolSlag-checklist 1.2 - Een onderzoek naar de validiteit, betrouwbaarheid en bruikbaarheid [The schoolBeat checklist 1.2 - A validity, reliability and usability study]. Unpublished master thesis, Maastricht University, Maastricht.

Boot NMWM, Bessems K \& Leurs MTW (2005). Het schoolSlag aanbod 2005-2006 [the schoolBeat inventory 2005-2006]. Woerden / Maastricht: NIGZ / Maastricht Public Health Institute.

Boot NMWM, Leurs MTW, Peters LWH, Keijsers JFEM, Schaalma HP \& De Vries NK (2005).

Evaluatie van de schoolSlag-checklist gericht op het beoordelen van de kwaliteit van schoolse interventies [Evaluation of the schoolBeat-checklist assessing the quality of school-based interventions]. Tijdschrift voor Gezondheidswetenschappen, 83(7), 405-411.

Bosdriesz M \& Berkenbosch W (2003). Jeugdzorgadviesteams voor het basisonderwijs. Methodiek voor de aansluiting van basisonderwijs en jeugdzorg [Youth care advisory teams for primary education. A method for linking primary education with youth care]. Utrecht: NIZW.

Botvin GJ (2004). Advancing prevention science and practice: challenges, critical issues, and future directions. Prevention Science, 5(1), 69-72.

Bracht N (1999). Health promotion at the community level: new advances (2nd ed.). Thousand Oaks: Sage Publications, Inc.

Brug J, Glanz K, Van Assema P, Kok G \& Van Breukelen GJ (1998). The impact of computer-tailored feedback and iterative feedback on fat, fruit, and vegetable intake. Health Education and Behavior, 25(4), 517-531.

Buijs G, Ausems M \& Leurs M (2004). De schoolSlag-prioriteitenworkshop Voortgezet Onderwijs [The schoolBeat priority workshop Secundary Education]. Woerden: NIGZ.

Buijs G, De Jong A, Paulussen T \& Wijngaarden J (2002). Landelijk actieprogramma schoolgezondheidsbeleid [National action plan school health promotion]. Woerden: NIGZ.

Buijs GJ (2005). Werkdocument De Gezonde School Methode Nederland [working paper The Health School Methodology the Netherlands]. Woerden: NIGZ.

Butte D (2005). Wij zijn niet meer 'hun' jongeren. Identiteitsbeleving en gedrag van de Molukse jongeren van de Molukkenbuurt in Capelle aan den IJssel. Rotterdam: GGD Rotterdam en omstreken. 
Cameron R, Jolin MA, Walker R, McDermott N \& Gough M (2001). Linking Science and Practice: Toward a System for Enabling Communities to Adopt Best Practices for Chronic Disease Prevention. Health Promotion Practice, 2(1), 35-42.

Campbell DT (1969). Reforms as experiments. American Psychologist, 24, 409-429.

Campbell DT (1984). Can we be scientific in applied social science? In: Conner RF (Ed.), Evaluation studies review annual (pp. 26-48). Thousand Oaks CA: Sage.

Campbell M, Fitzpatrick R, Haines A, Kinmonth AL, Sanderock P, Spiegelhalter D \& Tyrere P (2000). Framework for design and evaluation of complex interventions to improve health. BMJ, 321, 694-696.

Catford J (1997). Developing leadership for health: our biggest blindspot. Health Promotion International, 12(1), 1-4.

CDC (1997). Coordinated School Health Program Infrastructure Development: Process Evaluation Manual.

Atlanta: U.S. Department of Health and Human Services, Centers for Disease Control and Prevention.

Claessens M \& Braun J. (1997). GGD Klantentoets: standaard of maatwerk? GGD Nieuws, 19-22.

Clift S, Jensen BB \& (eds.) (2005). The health promoting school: international advances in theory, evaluation and practice. Copenhagen: Danish University of Education Press.

Costongs C \& Springett J (1997). Towards a framework for the evaluation of health-related policies in cities. Evaluation, 3(3), 345-362.

Crocker L \& Algina J (1986). Introduction to classical and modern test theory. Orlando (Florida): Harcourt, Brace, Javonich.

Cuijpers P, Jonkers R, De Weerd I \& De Jong A (2002). The effects of drug abuse prevention at school: "The Healthy School and Drugs" project. Addiction, 97, 67-73.

Cullen WK, Baranowski T, Baranowski J, Herbert D, DeMoor C, Hearn MD \& Resnicow K (1999). Influence of school organizational characteristics on the outcomes of a school health promotion program. Journal of School Health, 69, 376-380.

Cummings TG \& Worley CG (2001). Organization Development and Change (7th ed.). Mason, Ohio: South-Western College Publishing.

Dafesh ZJA, Buijs GJ, Hekkink K, Drossaert CHC \& Boer H (2006). Regioscan GGD en Gezondheid op scholen. Onderzoek naar de stand van zaken rond de ondersteuning van scholen door GGD'en op het terrein van gezondheid [Region scan of public health services and health at schools. Study into school health support by public health services]. Woerden / Enschede: NIGZ / Universiteit Twente.

Daft RL \& Noe RA (2001). Organizational behavior. Orlando: Hartcourt Inc.

Day D (2001). Leadership development: a review in context. Leadership Quarterly, 11, 581-613.

De Caluwé L \& Vermaak H (1999). Leren veranderen [Learning to change] (1st ed.). Alphen aan den Rijn: Samsom.

De Caluwé L \& Vermaak H (2003). Learning to change. Thousand Oaks: Sage Publications.

De Caluwé L \& Vermaak H (2006). Leren veranderen. Een handboek voor de veranderkundige. [Learning to change. A manual for change-experts] (2e revised ed.). Deventer: Kluwer.

De Kraker P (2004). Jeugdmonitor Zeeland + rapport = Kansen aan Zee [Youth Monitor Zeeland + report $=$ changes near the sea]. Middelburg: SCOOP.

De Leeuw E (1989). The Sane Revolution. Health Promotion: Background, Scope, Prospects. Assen/ Maastricht: Van Gorkum. 
De Leeuw E (1999). Healthy Cities: urban social entrepreneurship for health. Health Promotion International, 14(3), 261-270.

De Munter JPJM (1998). Jeugd en genotmiddelen - Resultaten van een onderzoek onder scholieren in Zuidelijk Zuid-Limburg [Youth and drugs - results of a pupil monitor in Southern South-Limbourg]. Maastricht: Maastricht Public Health Institute.

De Nooijer J, Veling M, De Vries H \& De Vries N (2006). Elektronische Monitoring en Voorlichting EMOVO. Evaluatie van het project [Electronic monitoring and education. Evaluation of the E-MOVO project]. Maastricht: University Maastricht.

De Ronne N (2004). Betere schoolprestaties dankzij een goed ontbijt [Better academic performances due to a good breakfast]. Tijdschrift Jeugdgezondheidszorg, 36(2), 34-37.

De Vries H, Backbier E, Kok G \& Dijkstra M (1995). The impact of social influences in the context of attitude, self-efficacy, intention and previous behavior as predictors of smoking onset. Journal of Applied Social Psychology, 25(3), 237-257.

De Vries H \& Mudde A (1998). Predicting stage transitions for smoking cessation applying the Attitude-Social influence-Efficacy Model. Psychology and Health, 13, 369-385.

De Vries H, Mudde A, Leijs I, Charlton A, Vartiainen E, Buijs G, Clemente MP, Storm H, Navarro AG, Nebot M, Prins T \& Kremers S (2003). The European Smoking prevention Framework Approach (EFSA): an example of integral prevention. Health Education Research, 18(5), 611-626.

Dehar M-A, Casswell S \& Duignan P (1993). Formative and Process Evaluation of Health Promotion and Disease Prevention Programs. Evaluation Review, 17(2), 204-220.

Deschesnes M, Martin C \& Jomphe Hill A (2003). Comprehensive approaches to school health promotion: how to achieve broader implementation? Health Promotion International, 18(4), 387-396.

Dietz WH (2001). The obesity epidemic in young children. BMJ, 322, 313-314.

Dijkstra A (2004). De schoolarts in Nederland. Tijdschrift Jeugdgezondheidszorg, 36(5), 89-92.

Dijkstra A (2005). Working mechanisms of computer-tailored health education: evidence from smoking cessation. Health Education Research, 20(5), 527-539.

Doijen G \& Hardy C (2004). De schoolSlag-prioriteitenworkshop. G, 2(6), 33.

Donabedian A (1980). Explorations in Quality Assessment and Monitoring. The Definition of Quality and Approaches to Its Assessment. Ann Arbor, MI: Health Administration Press.

Donkers A (2003). Integrale leerlingenzorg en de rol van de ouders [Integrated pupil care and the role of parents]. In: Van den Brand H (Ed.), Integrale leerlingenzorg in het voortgezet onderwijs [Integrated pupil care in secundary education] (pp. 45-54). Apeldoorn: Garant.

Doorduijn A, Fiddelaers-Jaspers R, Spee I \& Van Veen D (2002). Samenwerking in de uitvoering. Leerlingbegeleiding in het voortgezet onderwijs en externe instellingen [Collaboration in Practice. Pupil care in secundary education and external institutions]. Leuven-Apeldoorn: Garant.

Dooris M (2006). Healthy settings: challenges to generating evidence of effectiveness. Health Promotion International, 21(1), 55-65.

Durlak JA \& Wells AM (1997). Primary prevention mental health programs for children and adolescents: a meta-analytic review. American Journal of Community Psychology, 25(2), 115-152.

Dusenbury L, Brannigan R, Falco M \& Hansen WB (2003). A review of research on fidelity of implementation: implications for drug abuse prevention in school settings. Health Education Research, 18(2), 237-256. 
Dusenbury L \& Hansen WB (2004). Pursuing the course from research to practice. Prevention Science, 5(1), 55-60.

Eagle CJ \& Davies JM (1993). Current models of 'quality' - an introduction for anaesthetists. Canadian Journal of Anaesthesia, 40, 851-862.

El Ansari W \& Weiss ES (2006). Quality of research on community partnerships: developing the evidence base. Health Education Research, 21(2), 175-180.

Ellenbroek E \& Reijmerink W (2003). Haal meer uit kennis [make more use of knowledge]. TSG, 81(4), 216-217.

European Network for Health Promoting Schools (1998). The ENHPS indicators for a healthy school. Copenhagen: ENHPS.

Feinberg ME, Riggs NR \& Greenberg MT (2005). Social networks and community prevention coalitions. The Journal of Primary Prevention, 26(4), 279-298.

Fillekes-Brand P \& Bron M (2000). De gezonde school en genotmiddelen [The healthy school and drugs]. In: Rosier JJ \& Walraven G (Eds.), De Veilige School (pp. 1-12). Alphen aan den Rijn: Samsom H.D. Tjeenk Willink.

Fishbein M \& Ajzen I (1975). Belief, attitude, intention and behavior: an introducation to theory and research. Reading MA: Addison-Wesley.

Fleuren MAH, Wiefferink CH \& Paulussen TGWM (2002). Belemmerende en bevorderende factoren bij de implementatie van zorgvernieuwingen in organisaties [Inhibiting and enhancing factors for the implementation of care innovations in organizations]. Leiden: TNO Preventie en Gezondheid.

Geelen H, Veen Dv \& Walraven G (1998). Supporting Service Integration through professional training in the Netherlands. Multi-Service Schools. Leuven/Apeldoorn: Garant Publishers.

Gelissen (2003). Introductie in de schoolSlag-werkwijze (lezing). Maastricht: LSP-preventie congres: preventie X politiek werkt!

Gillies P (1998). Effectiveness of alliances and partnerships. Health Promotion International, 13(2), 99-120.

Gilsing R (1999). Lokaal jeugdbeleid. Onderzoek lokaal sociaal beleid [Local youth policy. A local social policy study]. The Hague: Social Cultural Planning Bureau.

Goffin A, Fleming C, Grove J, Thompson R, Flentje J, Smith M, Alvaro R, Lock C, Philips J \& Taylor J (2004). Successful inter-agency collaboration: health agencies working together to better promote health in schools. Paper presented at the World Conference on Health Promotion and Health education, Melbourne.

Goldschmeding J \& Van de Looij-Jansen P (2003). De Rotterdamse Jeugdmonitor - Resultaten 14-15 jarigen per deelgemeente (2000/2002) [The Rotterdam Youth-monitor - results 14-15 year olds per sub-municipality (2000/2002)]. Rotterdam: GGD Rotterdam en omstreken.

Goodman RM (1998). Principles and tools for evaluation community-based prevention and health promotion programs. Journal of Public Health Management and Practice, 4(2), 37-47.

Gorissen WHM (2001). Kennis als hulpbron. Het gebruik van wetenschappelijke kennis bij beleidsvorming in de jeugdgezondheidszorg voor 4-19 jarigen [The use of scientific knowledge in policy development in youth health care for 4 to 19 year olds]. Utrecht University, Utrecht.

Görts C \& Jonker R (2001). Gezondheid op school. Een inventariserend onderzoek naar schoolgezondheidsbeleid in Nederland [Health at school. An inventory of school health policy in the Netherlands]. Haarlem: Rescon Research \& Consultancy. 
Gosin MN, Dustman PA, Drapeau AE \& Harthun ML (2003). Participatory Action Research: creating an effective curriculum for adolescents in the Southwestern US. Health Education Research, 18(3), 363-379.

Gottfredson DC \& Gottfredson GD (2002). Quality of School-Based Prevention Programs: Results from a National Survey. Journal of Research in Crime and Delinquency, 39(1), 3-35.

Gottfredson DS \& Wilson DB (2003). Characteristics of effective school-based substance abuse prevention. Prevention Science, 4(1), 27-38.

Gras A, Johansen S \& Leurs MTW (2003). Het schoolSlag aanbod 2003 [the schoolBeat supply 2003]. Maastricht: GGD Zuidelijk Zuid-Limburg en partners.

Gray B (1989). Collaborating: Finding common ground for multi-party problems. San Francisco: Jossey Bass.

Green LW \& Kreuter MW (1999). Health Promotion and Planning: an educational and ecological approach.

Mountain View: Mayfield Publishing Company.

Green LW \& Lewis FM (1986). Measurement and evaluation in health education and health promotion. Palo Alto, CA: Mayfield.

Greenberg MT (2004). Current and future challenges in school-based prevention: the researcher perspective. Prevention Science, 5, 5-13.

Grol R, Van Everdingen J \& Casparie A (2000). Invoering van richtlijnen en veranderingen - een handleiding voor de medische, paramedische en verpleegkundige praktijk [Implementation of guidelines and changes - a manual for the medical, para-medical and nursing practice]. Maarssen: Elsevier/De Tijdstroom.

Grunbaum JA, Kann L, Kinchen S, Ross J, Hawkins J, Lowry R, Harris WA, McManus T, Chyen D \& Collins J (2004). Youth Risk Behavior Surveillance - United States, 2003. Morbidity and Mortality Weekly Report, 53, SS2.

Guldbrandsson K \& Bremberg S (2006). Two approaches to school health promotion--a focus on health-related behaviours and general competencies. An ecological study of 25 Swedish municipalities. Health Promotion International, 21(1), 37-44.

Hardy-Pasmans C (2004). SchoolSlag, preventie op maat in het onderwijs [schoolBeat-workshop at the Best practice-day OGGZ]. Utrecht.

Hawkins JD, Catalano RF \& Arthur MW (2002). Promoting science-based prevention in communities. Addictive behaviors, 27, 951-976.

Hekkink C, Buijs G \& Dafesh ZJA (2006). Research on the regional implementation of health promoing schools in the Netherlands. In: Barnekow V, Buijs G, Clift S, et al. (Eds.), Health-promoting schools: a resource for developing indicators. Copenhagen: International Planning Committee of the European Network of Health Promoting Schools.

Hirasing RA, Frederiks AM, Van Buuren S, Verloove-Vanhorick SP \& Wit JM (2001). Toegenomen prevalentie van overgewicht en obesitas bij Nederlandse kinderen en signalering daarvan aan de hand van internationale normen en nieuwe referentiediagrammen [Increase of the prevalence of overweight and obesity among Dutch children and detection based on international norms and new diagrams of reference]. Nederlands Tijdschrift voor Geneeskunde, 145, 1303-1308.

Hornby G \& Atkinson M (2003). A framework for promotion mental health in school. Pastoral Care in Education, 21(2), 3-9.

Houben T (2002). Jongeren in Limburg - onderzoek in 2001 naar genotmiddelengebruik en (riskant) gedrag by scholieren in het Voortgezet Onderwijs [Youth in Limburg - 2001 study into drug use and (risky) behavior by high school students]. Geleen/Heerlen/Maastricht/Venlo: Limburgse GGD'en. 
Houben T (2006). Jongeren onderzoek 2005 - onderzoek door GGD'en naar het middelengebruik en (riskant) gedrag bij Limburgse scholieren in het voortgezet onderwijs [Youth study 2005 - study into drug use and (risky behavior of high school pupils in Limbourg by Public Health Institutes]. Geleen/Heerlen/Maastricht/Venlo: Limburgse GGD'en.

Hudson B (2002). Interprofessionality in health and social care: the Achilles' heel of partnership? Journal of Interprofessional Care, 16(1), 7-17.

Jané-Llopis E (2002). What makes the ounce of prevention effective? A meta-analysis of mental health promotion and mental disorder prevention. Dissertation. Nijmegen: Quickprint.

Jensen B \& Simovska V (2005). Involving students in learning and health promoting processes clarifying "why?" "what?" and "how?". Promotion E Education, 12(3-4), 150-157.

Johansen S (2002). Het aanbod van preventieprojecten op scholen - een inventarisatie vanuit het perspectief van het Coordinated School Health Program en het Nederlandse Schoolgezondheidsbeleid the suppy of school prevention projects - an inventory from the Comprehensive School Health Program and Dutch Healthy School Policy]. Unpublished master thesis, Maastricht University, Maastricht.

Jones J, Scanlon K, Raphael B, Hillin A, McAlpine R, Critchley A, Stonehouse R, McKie D, KerrRoubicek H \& Meerman G (2002). Health and Education Working Together: The New South Wales School-Link Initiative. International Journal of Mental Health Promotion, 4(4), 36043.

Judd J, Frankish C \& Moulton G (2001). Setting standards in the evaluation of community based health promotion programmes - a unifying approach. Health Promotion International, 16(4), 367-380. Jurg ME, Kremers SPJ, Candel MJJM, Van der Wal MF \& De Meij JSB (2006). A controlled trial of a school-based environmental intervention to improve physical activity in Dutch children: JUMP-in, kids in motion. Health Promotion International, 21(4), 320-330.

Katz D \& Kahn R (1966). The Social Psychology of Organizations. New York: John Wiley \& Sons.

Kautiainen S, Rimpelä AH, Vikat A \& Virtanen SM (2002). Secular trends in overweight and obesity among Finnish adolescents in 1977-1999. International Journal of Obesity Related Metabolic Disorders, 26(4), 544-552.

Kerkhoff T \& Wagenaar-Fisher M (2005). Jeugdgezondheidszorg in historisch perspectief [A historical perspective of youth health care]. In: Boudewijnse HB, Van Lokven EM \& Oskam E (Eds.), Nederlands Leerboek Jeugdgezondheidszorg - Deel A Organisatie [Dutch textbook Youth Health Care] (pp. 21-43). Assen: Koninklijke Van Gorkum.

Kervezee C (2003). Onderwijsverslag over het jaar 2002 [Education report 2002]. The Hague: Inspectie van onderwijs.

Kingdon JW (1995). Agendas, Alternatives and Public Policies (2nd ed.). New York: Harper Collins College Publishers.

Kleijnen R \& Leurs M (2003). VORMing \& REC Slaan een (school)Slag - Integrale Ketenzorg in het Voortgezet Onderwijs Maastricht e.o. [Integral Shared Care in Secundary Education in the Maastricht area]. Maastricht: Stichting VORMming.

Kleijnen R, Van Mulken T \& Leurs M (2003). Regionale trends: Quickscan Preventie en Zorg VO [Regional trends: Quickscan Prevention and Care in Secundary education]. In: Kleijnen R \& Leurs M (Eds.), Een klasse apart. Gids Integrale Leerlingenzorg. Maastricht: stichting VORMing.

Kok G (1992). Quality of planning as a decisive determinant of health education effectiveness. Hygiene, $11,5-8$. 
Kok G, Schaalma H, Ruiter RAC, Van Empelen P \& Brug J (2004). Intervention mapping: protocol for applying health psychology theory to prevention programmes. Journal of Health Psychology, 9(1), 85-98.

Kolbe LJ (1986). Increasing the impact of school health promotion programs: emerging research perspectives. Health Education, 17, 47-52.

Kolbe LJ (2005). A framework for school health programs in the 21st century. Journal of School Health, 75(6), 226-228.

Konu A \& Lintonen T (2006). Theory-based survey analysis of well-being in secondary schools in Finland. Health Promotion International, 21(1), 27-36.

Lazarus R, Wake M, Hesketh K \& Waters E (2000). Change in body mass index in Australian primary school children, 1985-1997. International Journal of Obesity, 24(6), 679-684.

Lee A, Cheng FFK \& St.Leger L (2005). Evaluating health promoting schools in Hong Kong: development of a framework. Health Promotion International, 20(2), 177-186.

Lee A, Keung MW \& Tsang CKK (2004). Difficulties faced by health educators in Hong Kong: from barriers to strategies. Journal of Primary Care and Health Promotion, 1(1), 17-22.

Lee A, Tsang C \& Lee SH (2003). A comprehensive "healthy schools programme" to promote school health: the Hong Kong experience in joining the efforts of health and education sectors. Journal of Epidemiology and Community Health, 57, 174-177.

Leen E (2001). Instrumenten voor kwaliteitszorg. Alphen aan de Rijn: Kluwer.

Leurs M \& Jansen M (2002). Schoolbeat - the new Challenge. Network News of the European Network of Health Promoting Schools, 7, 26-28.

Leurs MTW (2003a). $1^{e}$ voortgangsverslag schoolSlag februari 2002- januari 2003 [1 ${ }^{\text {st }}$ schoolBeat progress report 2002-2003]. Maastricht: BJZ/CAD/GGD/RIAGG/Trajekt.

Leurs MTW (2003b). Gezondheidsbevordering in het onderwijs: de schoolSlag-uitdaging [Health promotion in education: the schoolBeat-challenge]. Remediaal, 4(1), 3-8.

Leurs MTW (2004). Gezondheidsbevordering en preventie op school - verslag van de World Conference on Health Promotion \& Health Education [School health promotion - report of the World conference on Health Promotion \& Health Education]. TSG, 82(7), 467-468.

Leurs MTW (2005). Het Gezonde School Model - onderdeel van de schoolSlag-werkwijze [The Healthy School Model - part of the schoolBeat-methodology]. In: Boot N, Bessems K \& Leurs MTW (Eds.), Het schoolSlag-aanbod 2005-2006 (pp. 242). Maastricht-Woerden: NIGZ/GGD Zuidelijk Zuid-Limburg.

Leurs MTW, Bessems K, Schaalma HP \& De Vries H (2007). Focus points for school health promotion improvements in Dutch primary schools. Health Education Research, 22(1), 58-69.

Leurs MTW \& De Vries NK (2005). Samen planmatig aan de slag met preventie [working systematically together in prevention]. Zorgbreed [Journal of Whole School Health], 2(8), 32-40.

Leurs MTW \& Hardy C (2005). Een planmatige aanpak van gezondheidsbevordering en preventie in het onderwijs als onderdeel van integrale ketenzorg: ervaringen van het OPDC St.Michaël [Planned health promotion and prevention as part of shared care in education: experiences at the OPDC St.Michaël]. In: Kleijnen R \& Van den Broek G (Eds.), Grensoverschrijdende Integrale Leerlingenzorg een [pro]actief proces (pp. 377-392). Antwerpen-Apeldoorn: Garant.

Leurs MTW, Jansen M \& Ruiter M (2002). Coordinated School Health Program: het 'Gezonde School Model' van de toekomst? [CSHP: the Healthy School Model of the future?]. TSG, 80(7), 471-473. 
Leurs MTW, Jansen MWJ, Schaalma HP, Mur-Veeman IM \& De Vries NK (2005). The Tailored Schoolbeat-Approach: New Concepts for Health Promotion in Schools in The Netherlands. In: Clift $S$ \& Jensen BB (Eds.), The Health Promoting School: International Advances in Theory, Evaluation and Practice (1st ed., pp. 89-107). Copenhagen: Danish University of Education Press.

Leurs MTW, Kleijnen R, Consten K, Pennartz A \& Feron F (2003). Integrale ketenzorg binnen het onderwijscontinuum van zorg [Integrated shared care as part of the education continuum of care]. Remediaal, 4(2), 16-22.

Leurs MTW, Mur-Veeman IM, Schaalma HP \& De Vries NK (2003). Integrale samenwerking gaat verder dan de samenwerking tussen professionals: introductie van het DISC-model [Integrated collaboration continues beyond professional collaboration: introduction of the DISC-model]. TSG, 81(6), 369-372.

Leurs MTW, Schaalma HP, Jansen MWJ, Mur-Veeman IM, St.Leger LH \& De Vries NK (2005). Development of a collaborative model to improve school health promotion in the Netherlands. Health Promotion International, 20(3), 296-305.

Leurs MTW, Schaalma HP, Jansen MWJ, Mur-Veeman IM, Van Breukelen G \& De Vries NK (2007). Comprehensive Quality Assessment of Healthy School Interventions. Preventive Medicine, 45(5), 366-372.

Leurs MTW, Steenbakkers M \& Jansen MWJ (2006). Het schoolSlag-praktijkboek: samen werken aan preventie op maat in het onderwijs [the schoolBeat-manual: working together towards tailored prevention in education]. Maastricht: GGD Zuid Limburg.

Lister-Sharp D, Chapman S, Stewart-Brown S \& Sowden A (1999). Health promoting schools and health promotion in schools: two systematic reviews. Health Technology Asssessment, 3, 22.

Mackenbach J (2003). Tackling inequalities in health: the need for building a systematic evidence base. Journal of Epidemiology and Community Health, 57, 162.

Maes L \& Lievens J (2003). Can the school make a difference? A multilevel analysis of adolescent risk and health behaviour. Social Science \& Medicine, 56, 517-529.

Maes L, Stevens V, De Coninck C \& Hoelebrandt P (2001). Gezondheidspromotie op school [Health promotion at school]. In: Stevens V \& Vandenbroucke S (Eds.), Gezondheidspromotie 2001 - 10 jaar gezondheidspromotie in Vlaanderen [Health Promotion 2001 - 10 year health promotion in Flandres] (pp. 248-258). Leuven/Apeldoorn: Garant.

Marshall BJ, Sheehan MM, Northfield JR, Maher S, Carlisle R \& St.Leger LH (2000). School-based health promotion across Australia. Journal of School Health, 6, 251-252.

Marx E \& Wooley SF (1998). Health is Academic - A Guide to Coordinated School Health Programs. New York: Teachers College Press.

McDonald B (2002). A partnership approach to health promotion in post-primary schools. Paper presented at the ENHPS-conference Education \& Health in Partnership, Egmond aan Zee.

McLeod J (2003). The Partnership Analysis Tool: for partners in health promotion. Melbourne: VicHealth. McLeroy K, Norton BL, Kegler MC, Burdine JN \& Sumaya C (2003). Community-based interventions. American Journal of Public Health, 93(4), 529-533.

McMorris LE, Gottlieb NH \& Sneden GG (2005). Developmental states in public health partnerships: a practical perspective. Health Promotion Practice, 6(2), 219-226.

Mertler CA (2001). Designing scoring rubrics for your classroom. Practical Assessment, Research \& Evaluation, 7(25), Retrieved August 18, 2005 from http://PAREonline.net/getvn. asp? $\mathrm{v}=2007 \& \mathrm{n}=2025$. 
Merzel C \& D’Afflitti J (2003). Reconsidering Community-Based Health Promotion: Promise, Performance, and Potential. American Journal of Public Health, 93(4), 557-574.

Ministerie van OCW (2001). Nota Kwaliteit aan de basis [Policy Quality at the basics]. Den Haag: SDU.

Ministerie voor Jeugd en Gezin (2007). Alle kansen voor alle kinderen - programma voor jeugd en gezin [All choices for all children - program for youth and family]. The Hague: Ministerie voor Jeugd en Gezin.

Molleman G, Van Driel W \& Keijsers J (1995). Preventie effectiviteits instrument Preffi 1.0. Ontwikkelig van een effectiviteitsinstrument voor de GVO/preventiepraktijk. Utrecht: Landelijk Centrum GVO.

Molleman GRM \& Hosman CMH (2003). Ontwikkeling van een kwaliteitsinstrument voor de effectiviteit van gvo/preventie-programma's - De Preffi 1.0; ontwikkeling, ervaringen en uitgangspunten voor een Preffi 2.0 [Development of a quality instrument for the effectiveness of health promotion programs the Preffi 1.0; development, experiences and guidelines for a Preffi 2.0]. TSG, 81(5), 238-246.

Molleman GRM, Peters LWH, Hosman CMH, Hommels LM, Ploeg MA, Kok HH \& Llopis E (2003). De Preffi 2.0: systematische ontwikkeling van een kwaliteitsinstrument voor gezondheidsbevordering [The Preffi 2.0: systematic development of a quality instrument for health promotion]. TSG, 81(5), 247-255.

Molleman GRM, Peters LWH, Hosman CMH \& Kok GJ (2005). Implementation of a quality assurance instrument (Preffi 1.0) to improve the effectiveness of health promotion in the Netherlands. Health Education Research, 20(4), 410-422.

Morgan G (1986). Images of organization. Beverly Hills: SAGE Publications, Inc.

Mrazek PJ \& Haggerty RJ (1994). Reducing risks for mental disorders: frontiers for preventive intervention research. Washinton: National Academy Press.

Mukoma W \& Flisher AJ (2004). Evaluations of health promoting schools: a review of nine studies. Health Promotion International, 19(3), 357-368.

Mur-Veeman I \& Van Raak A (1994). Interorganisational networks on the Dutch home health care market. International Journal of Health Planning and Policy, 9, 245-258.

Nadar P, Stone E, Lytle L, Perry C, Osganian S, Kelder S, Webber L, Elder J, Montgomery D, Feldman H, Wu M, Johnson C, Parcel G \& Luepker R (1999). Three-year maintenance of improved diet and physical activity. Archives of Pediatric E Adolescent Medicine, 153, 695-704.

Nederland G (1999). Kwaliteitstoetsing in de GGZ. Utrecht: GGZ Nederland.

Noble C \& Robson C (2005). Just how far can healthy schools go? Health Education, 105(3), 161-163.

Nunnally JC (1967). Psychometric theory. New York: McGrawHill.

Nutbeam D (1992). The health promoting school: closing the gap between theory and practice. Health Promotion International, 7(3), 151-153.

Nutbeam D (2003a). Getting 'evidence' into public health policy, and 'policy' into public health research. TSG, 81, 155-159.

Nutbeam D (2003b). How does evidence influence public policy - tackling health inequalities in England. Health Promotion Journal of Australia, 14, 154-158.

Nutbeam D (2004). Getting evidence into policy and practice to address health inequalities. Health Promotion International, 19(2), 137-140.

Nutbeam D, Aar L \& Catford J (1989). Understanding childrens's health behaviour: the implications for health promotion for young people. Social Sciences and Medicine, 29(3), 317-325. 
Padgett S, Bekemeier B \& Berkowitz B (2004). Collaborative Partnerships at the State Level: Promoting Systems Changes in Public Health Infrastructure. Journal of Public Health Management \& Practice, 10(3), 251-257.

Parish R (2001). Health promotion: towards a quality assurance framework. WHO Regional Publications European Series, 92, 171-184.

Parsons C \& Stears D (2002). Evaluating health-promoting schools: steps to success. Health Education, 102(1), 7-15.

Paulussen T (2002). Voeren scholen een gezondheidsbeleid? [Do schools execute a health policy?]. In: Jansen J, Schuit AJ \& Van der Lucht F (Eds.), Tijd voor gezond gedrag - bevordering van gezond gedrag bij specifieke groepen [Time for healthy behavior - promotion of healthy behavior among specific groups] (pp. 134-141). Bilthoven: RIVM/Bohn Stafleu Van Loghum.

Paulussen T, Kok G, Schaalma H \& Parcel GS (1995). Diffusion of AIDS curricula among Dutch secondary school teachers. Health Education Quarterly, 22(2), 227-243.

Paulussen T, Panis R, Peters L, Buijs G \& Wijnsma P (1998). Stand van zaken schoolgezondheidsbeleid in Nederland [State of the art of school health policy in the Netherlands]. Woerden: NIGZ.

Paulussen T \& Wiefferink K (2002). Implementatie is geen vanzelfsprekendheid [Implemention does not happen naturally]. Tijdschrift voor Jeugdgezondheidszorg, 34(4), 68-71.

Paulussen TGW (1995). Adoption and implementation of AIDS education in Dutch secondary schools. Landelijk Centrum GVO, Utrecht.

Peters L (2001). De Netwerkbenadering - review [The network appraoch - review]. Woerden: NIGZ - Centre for Review and Implementation.

Peters L, Leurs M \& Snijders D (2003). Meten van kwaliteit van interventies voor het onderwijs [Measuring the quality of school interventions]. Paper presented at the NIGZ-congres, Arnhem.

Peters LWH \& Keijsers FEM (2002). Kwaliteitscriteria voor gezondheidsbevorderende interventies in en rondom scholen: review en checklistontwikkeling [Quality criteria for school health promotion interventions: review and checklist development]. Woerden: NIGZ - Centre for Review and Implementation.

Peters LWH, Leurs MTW, Jansen MWJ, Keijsers JFEM \& Schaalma HP (2004). Ontwikkeling van de schoolSlag checklist voor kwaliteit van schoolgerichte interventies [Development of the schoolBeat checklist for quality of school-based interventions]. TSG, 82(1), 50-57 [online in English: http:// www.schoolslag.nl/pool/55/documents/schoolBeat_quality_checklist.pdf ].

Peters LWH \& Paulussen TGWM (1994). School health - a review of the effectiveness of health education and health promotion. Utrecht: Dutch Centre for Health Promotion and Health Education and IUPHE/EURO.

Pijpers FIM (1990). Schoolgezondheidsbeleid [School Health Policy]. In: Bonnet-Breusers AJM, Rensen HBH \& Wassenaar J (Eds.), Handboek Jeugdgezondheidszorg (pp. 1-9). Maarssen: Elsevier/Bunge.

Pijpers FIM (1999). Schoolgezondheidsbeleid in het basisonderwijs [School health policy in primary education]. Leiden University, Leiden.

Place M \& Cazemier G (1998). Goed, beter, kwaliteit. Werkboek voor kwaliteitsverbetering van sociaal pedagogische diensten. Utrecht: Vereniging Somma \& Trimbos Instituut.

Plsek P \& Greenhalgh TT (2001). The challenge of complexity in health care. BMJ, 323, 625.

Plsek P \& Wilson T (2001). Complexity, leadership, and management in healthcare organisations. BMJ, 323, 746-749. 
Pluye P, Potvin L, Denis JL \& Pelletier J (2004). Program sustainability: focus on organizational routines. Health Promotion International, 19(4), 489-500.

Pratt J, Pampling D \& Gordon P (1998). Partnerships fit for pupose? London: King's Fund.

Prinsen S \& Aan den Boom K (2002). Studiedag 'Van Hagelslag naar Chocola' [Seminar 'From Chocolate Sprinkles to Chocolate], Maastricht.

Prior F (1998). Elk geval van onveiligheid is er één te veel! Richting, ruimte en resultaten bii veiligheidsbeleid in scholen. [Each case of unsafety is one too many! Guidelines, space and results in safe school policies]. In: Rosier JJ \& Walraven G (Eds.), De Veilige School (pp. 1-24). Alphen aan den Rijn: Samsom. Ravensbergen J (2003). ZON, ZonMW en Effectieve Implementatie [Zon, ZonMW and effective implementation]. In: Ravensbergen J, Friele R, Keijsers J, et al. (Eds.), In zicht - nieuwe wegen voor implementatie. Assen: Koninklijke Van Gorkum.

Resnicow K, Davis M, Smith M, Lazarus-Yaroch A, Baranowski T, Baranowski J, Doyle C \& Wang Dt (1998). How to best measure implementation of school health curricula: a comparison of three measures. Health Education Research, 13(2), 239-250.

Reubsaet A, Reinaerts EBM, Brug J, Van Hooff JPv \& Van den Borne HW (2004). Process evaluation of a school-based education program about organ donation and registration, and the intention for continuance. Health Education Research, 19(6), 720-729.

Ringwalt CL, Ennett S, Vincus A, Thorne J, Rohrbach LA \& Simmons-Rudolhp A (2002). The prevalence of effective substance use prevention curricula in U.S. middle schools. Prevention Science, 3(4), 257-265.

Rissel C \& Bracht N (1999). Assessing Community Needs, Resources, and Readiness - Building on Strengths. Bracht, $N(e d)$. Health promotion at the community level $2^{\text {nd }} e d$. Sage Publications, Inc.: Thousand Oaks, California.

Rivers K, Aggleton P, Chase E, Downie A, Mulvihill C, Sinkler P, Tyrer P \& Warwick I (2000). Setting the standard: research linked to the development of the National Healthy School Standard (NHSS). London: University of London/Department of Health.

Rogers E, Moon AM, Mullee MA, Speller VM \& Roderick PJ (1998). Developing the 'health promoting school' - a national survey of healthy school awards. Public Health, 112, 37-40.

Rogers EM (1995). Diffusions of Innovations (4th ed.). New York: The Free Press.

Ronda G (2003). The Dutch Heart Health Community Intervention 'Hartslag Limburg' An evaluation. Maastricht University, Maastricht.

Ronda G, Van Assema P, Ruland E, Steenbakkers M \& Brug J (2004). The Dutch Heart Health Community Intervention 'Hartslag Limburg': design and results of a process study. Health Education Research, 19(5), 596-607.

Rowling L (1996). The adaptability of the health promoting schools concept: a case study from Australia. Health Education Research, 11(4), 519-526.

Rowling L (2002). School mental health promotion: perspectives, problems and possibilities. International Journal of Mental Health Promotion, 4(4), 8-13.

Ruland E, Van Assema P, Ament A, Gorgels T \& Van Ree J (2006). Hartslag Limburg : integrale gezondheidsbevordering in buurten, gemeenten, bij huisartsen en in het ziekenhuis : de opbouw : bundeling van praktijk, onderzoek en beleid [Heartbeat Limburg: comprehensive health promotion in communities, by general practitioners and in the hospital - the start - combining practice, research and policy]. TSG, 84(2), 83-89. 
Ruland E, Van Raak A, De Vries NK \& Van Ree J (2002). Lessen van Hartslag Limburg: samenwerking in de openbare gezondheidszorg moet gestructureerd en gemanaged worden. In: Jansen J, Schuit A \& Van der Lucht F (Eds.), Tijd voor gezond gedrag. Bevorderen van gezond gedrag bij specifieke groepen [Time for healthy behavior. Promotion of healthy behavior among specific groups]. Bilthoven: RIVM.

Ruland E, Van Raak A, Spreeuwenberg C \& Van Ree J (2003). Managing New Public Health: hoe zijn blijvende preventieve samenwerkingsverbanden te realiseren? Een agenda voor actie en onderzoek [How can preventive collaborations be realised? An agenda for action and research]. TSG, 81(1), 52-55.

Rychetnik L, Frommer M, Hawe P \& Shiell A (2002). Criteria for evaluating evidence on public health interventions. Journal of Epidemiology and Community Health, 56, 119-127.

Rychetnik L \& Wise M (2004). Advocating evidence-based health promotion: reflections and a way forward. Health. Health Promotion International, 19(2), 247-257.

Saan H \& De Haes W (2005). Gezond effect bevorderen. Het organiseren van effectieve gezondheidsbevordering [Promoting health effects. Organization effective health promotion]. Woerden: NIGZ.

Schaalma HP \& Kok G (2006). A School HIV-Prevention Program in the Netherlands. In: Bartholomew L, Parcel G, Kok G, et al. (Eds.), Planning Health Promotion Programs: An Intervention Mapping Approach (pp. 511-544). San Francisco, CA: Jossey-Bas.

Schaalma HP, Kok G, Bosker RJ, Parcel GS, Peters L, Poelman J \& Reinders J (1996). Planned development and evaluation of AIDS/STD education for secondary school students in The Netherlands: short-term effects. Health Education Quarterly, 23(4), 469-487.

Schleicher A, Charbonnier E, Davidson M, Heller JL, Kadar-Fulop J \& Shewbridge C (2003). Education at a Glance 2003. OECD.

Schoolslag-team (2007). De schoolslag inventarisatie 2007 - 2008. Overzicht onderwijsprojecten en lesmaterialen over gezondheid in de regio Maastricht-Mergelland [the schoolbeat inventory 2007-2008]. Geleen/Woerden: GGD Zuid Limburg / NIGZ.

Schuil PB, Bolscher DJA, Brouwers-de Jong EA, Hengeveld H, Van Lokven EM, Menu TMA \& Norg AGH (1987). Nederlands leerboek voor de jeugdgezondheidszorg. Assen/Maastricht: Van Gorkum.

Schuit AJ, Wendel-Vos GCW, Verschuren WMM, Ronckers ET, Ament A, Van Assema P, Van Ree J \& Ruland EC (2006). Effect of 5-Year Community Intervention Hartslag Limburg on Cardiovascular Risk Factors. American Journal of Preventive Medicine, 30(3), 237-242.

Sluijs EM \& Wagner C (2000). Kwaliteitssystemen in zorginstellingen; de stand van zaken in 2000 [Quality systems in care organizations; state of the art in 2000]. Utrecht: NIVEL.

Smit A \& Braat H (2006). Themarapport Primair Onderwijs [theme report Primary Education]. Middelburg: SCOOP.

Somers M \& Vandenbroucke S (2001). Implementatie van gezondheidsbevordering in het basisonderwijs en de eerste graad van het secundair onderwijs [Implementation of school health promotion in primary and secondary education]. Leuven: KU Leuven.

St.Leger L (1998). Australian teachers' understandings of the health promotion schools concept and the implications for the development of school health. Health Promotion International, 13, 223-235.

St.Leger L (2000). Developing indicators to enhance school health. Health Education Research, 15(6), 719-728.

St.Leger L (2001). Schools, health literacy and public health: possibilities and challenges. Health Promotion International, 16(2), 197-205. 
St.Leger L (2004). What's the place of schools in promoting health? Are we too optimistic? Health Promotion International, 19(4), 405-408.

St.Leger L (2005a). Capacity building and sustainability in the youth intersect project by Brimbank-Melton PCP - an evaluation: Unpublished manuscript.

St.Leger L (2005b). Protocols and guidelines for health promoting schools. Promotion E Education, XII(3-4), 145-147.

St.Leger L \& Nutbeam D (1999). Evidence of effective health promotion in schools. In: Boddy D (Ed.), The evidence of health promotion effectiveness. Shaping public health in a new Europe (pp. 110-122). Brussels: European Union.

St.Leger L \& Nutbeam D (2000). A model for mapping linkages between health and education agencies to improve school health. Journal of School Health, 70(2), 45-50.

St.Leger LH (1999). The opportunities and effectiveness of the health promoting primary school in improving child health - a review of claims and evidence. Health Education Research, 14(1), 51-69.

Steckler A, Goodman RM \& Kegler MC (2002). Mobilizing organizations for health enhancement. Theories of organizational change. In: Glanz K, Rimer BK \& Lewis FM (Eds.), Health behavior and health education. Theory, research and practice (pp. 335-360). San Francisco: Jossey-Bass.

Steenbakkers M, Bastiaens C, Leurs M, Ruland E \& Jansen M (2005). Vijf jaar community-based werken in Hartslag Limburg (1998-2003). Ervaringen uit de praktijk. [Experiences with five year community-based practice in Heartbeat Limburg (1998-2003)]. TSG, 83(2), 108-112.

Stemler SE (2004). A comparison of consensus, consistency, and measurement approaches to estimating interrater reliability. Practical Assessment, Research \& Evaluation, 9(4), Retrieved August 18, 2005 from http://PAREonline.net/getvn.asp?v=2009\&n=2004.

Stewart Burgher MS, Barnekow Rasmussen V \& Rivett D (1999). The European network of health promoting schools - the alliance of education and health. Denmark: ENHPS.

Stewart-Brown S (2001). Evaluating health promotion in schools: reflections. In: Rootman I, Goodstadt, M., Hyndman B, et al (Eds). Evaluation in health promotion - principles and perspectives (pp. 272-284). Copenhagen: WHO Regional Office for Europe.

Stewart-Brown S (2006). What is the evidence on school health promotion in improving health or preventing disease and, specifically, what is the effectiveness of the health promoting schools approach? Copenhagen: WHO Regional Office for Europe.

Taras H (2005). Obesity and Student Performance at School. Journal of School Health, 75(6), 199-213.

Thomas R (2005). School-based programmes for preventing smoking (Cochrane Methodology Review). The Cochrane Library(2), retrieved from http://www.cochrane.org/cochrane/revabstr/AB001293.htm on 001292 September 002005.

Tijssen IMJG, Van Raak AJA, Mur-Veeman IM \& Maarse JAM (1992). Multiple-case studies. Enkele problemen bij de praktijk van het onderzoek naar zorgvernieuwingsprojecten [Multiple case studys. Some problems in the practise of care innovation research]. TSG, 70(6), 337-344.

Tjalsma-Smit A (2007). Personel communicaton regarding school dental health services. Woerden: NIGZ. Tones K (2000). Evaluating health promotion: a tale of three errors. Patient Education and Guidance, 39, 227-236.

Tones K (2005). Health promotion in schools: the radical imperative. In: Clift S \& Jensen BB (Eds.), The health promoting school: international advances in theory, evaluation and practice (pp. 23-40). Copenhagen: Danish University of Education Press. 
Tones K \& Green J (2004). Health Promotion - Planning and Strategies. London: SAGE publications. Tones K \& Tilford S (1994). Health education: effectiveness, efficiency and equity ( $2^{\text {nd }}$ ed.). London: Chapman \& Hall.

Umble K, Steffen D, Porter JHG, Miller D, Hummer-McLaughlin K, Lowman A \& Zelt S (2005). The national Public Health Leadership Institute: evaluation of a team-based approach to developing collaborative public health leaders. American Journal of Public Health, 95(4), 641-644.

Valois RF \& Hoyle TB (2000). Formative Evaluation Results from the Mariner Project: A Coordinated School Health Pilot Program. Journal of School Health, 70(3), 95-103.

Van den Brugge GW (2006, 27 September 2006). Heeft de jeugd een gezonde toekomst? Paper presented at the Aftrap Gezonde School - Parkstad Limburg [Kick off healthy school - Heerlen region].

Van der Laan P, Krooi H, Van der Voort P \& Wijkman M (2006). Toetsing en certificering van preventieve, curatieve an repressieve interventies in de jeugdzorg. Een international orientatie [Assessment of preventive, curative and repressive interventions in youth care - an international scan]. Leiden/Woerden: NSCR/ Adviesburea Van Montfoort.

Van der Meeren WBJM (1981). Rapport gezondheidseducatie en jeugdgezondheidszorg [Report health education and youth health care]. TSG, 59, 830-836.

Van der Sar R (2004). Samen aan de (school)Slag! Een onderzoek naar de samenwerking en vraaggestuurd integraal schoolgezondheidsbeleid in de regio Maastricht-Mergelland. [Working together in schoolBeat a study into collaboration and tailored whole-school health policy in the Maastricht-Mergelland region]. Unpublished master thesis, Universiteit Maastricht, Maastricht.

Van der Spek N (2003). Operatie Jong Samen werken aan integraal jeugdbeleid [Operation Young - developing integrated yougth policy]. The Hague: Ministeries of Foreign Affairs, Justice, Education, Social Welfare and Health.

Van Eyk H \& Baum F (2002). Learning about interagency collaboration: trialling collaborative projects between hospitals and community health services. Health $\&$ Social Care in the Community, 10(4), 262-269.

Van Gorp K \& Mooij R (2004). 'Langer gezond leven' en de rol van de jeugdgezondheidszorg ['Healthy living longer' and the role of youth health care]. Tijdschrif voor Jeugdgezondheidszorg, 36(3), 56-57.

Van Greenhuizen YM, Burgmeijer RFJ, Filedt Kok-Weimar T \& De Jager AM (1997). Op weg naar volwassenheid. Evaluatie jeugdgezondheidszorg 1996. Maarssen/Leiden: KPMG/TNO-PG.

Van Lier P, Muthén B, Van der Sar R \& Crijnen A (2002). Preventing disruptive behavior in elementary schoolchildren: I impact of a universal classroom-based intervention. In: Van Lier PAC (Ed.), Preventing disruptive behavior in early elementary schoolchildren (dissertation). Rotterdam: Erasmus University.

Van Oers JAM (2002). Gezondheid op koers? Volksgezondheid Toekomst Verkenning 2002 [Health on track? Future Perspectives on Population Health]. Bilthoven: RIVM.

Van Raak A, Mur-Veeman I, Hardy B, Steenbergen M \& Paulus A (2003). Integrated Care in Europe. Description and comparison of integrated care in six EU countries ( $1^{\text {st }}$ ed.). Maarssen: Elsevier.

Van Raak A, Paulus A \& Mur-Veeman I (2005). Why do health and social care providers co-operate? Health Policy, 74, 13-23.

Van Raak AJA (1998). Zorgvernieuwing: een kwestie van routine. Een studie naar de vorming van interorganisationele netwerken en naar systeemveranderingen in de thuiszorg vanuit interactionistisch perspectief. [Innovations in care: a matter of routine. A study into the development of inter-organizational networks and system changes in home care from an interactionistic perspective](dissertation). Maastricht University, Maastricht. 
Van Raak AJA, Mur-Veeman IM, Paulus ATG \& Van Merode GG (1999). WIZDIZ-99 diagnoseinstrument integrale zorg [WIZDIZ-99. A shared-care diagnostic instrument]. Maastricht: Maastricht University - BEOZ.

Van Raak AJA, Mur-Veeman IM, Paulus ATG \& Van Merode GG (2005). WIZDIZ-2005. In: Bohlmeijer E, Ruland E, Van Raak A, et al. (Eds.), Procesmanagement in public health - ontwerp, analyse $E$ verandering. Utrecht: Trimbos-instituut.

Van Veen D \& Day C (1998). Multi-Service Schools. Integrated services supporting vulnerable children, youth and families. In: Van Veen D, Day C \& Walraven G (Eds.), Multi Service Schools (pp. 7-16). Leuven/Apeldoorn: Garant Publishers.

Van Veen D, Day C \& Walraven G (1998). Multi-Service Schools. Leuven/Apeldoorn: Garant Publishers.

Van Yperen T (2007). Ondersteuning van professionalisering van de sector. Jeugd \& Co - Kennis, 1(2), 48-49.

Van Yperen T, Bouwens J, Molleman G, Beckers M \& Zwikker M (2006). Concept: Werkdocument Erkenning Jeugdinterventies. Utrecht: NIZW/NIGZ/RIVM.

Vandenbroucke S, Lenders F \& Vinck J (1995). De kwaliteit van de planning van gezondheidspromotieprojecten in Vlaanderen [The quality of the planning of health promotion projectects in Flanders/Belgium]. Tijdschrift Gezondheidsbevordering, 16, 150-162.

Vandenbroucke S \& Stevens V (2003). Gezondheidspromotie voor jongeren in Vlaanderen: beleid en praktijk [Health promotion for adolescents in Flanders/Belgium: policy and practice]. Tijdschrijft voor Jeugdgezondheidszorg, 35(4), 72-76.

Verdurmen J, Van Oort M, Meeuwissen J, Ketelaars T, Graaf Id, Cuijpers P, De Ruiter C \& Vollebergh $\mathrm{W}$ (2003). Effectiviteit van preventieve interventies gericht op jeugdigen: de stand van zaken [Effectivenes of preventive activities targetting youth: state of the art]. Utrecht: Trimbos-instituut.

Vermeer A, Steenbakkers M, De Munter H \& Leurs M (2005). Op weg naar een gezonde school! Nieuw leefstijlprogramma voor bovenbouw havo/vwo: de Heartbeat Survival Day [Towards a healthy school! New lifestyle program for the highest grades in secundary education: the Heartbeat Survival Day]. Niche - bulletin voor het onderwijs in de biologie, 36(2), 13-16.

Veugelders PJ \& Fitzgerald AL (2005). Effectiveness of school programs in preventing childhood obesity: a multilevel comparison. American Journal of Public Health, 95(3), 432-435.

Vlaardingerbroek N, Schulten I \& Sannen A (2003). Handboek Implementatie. Leidraad voor preventiewerkers bij het invoeren van het project 'Gezonde School en Genotmiddelen' in het basisonderwijs [Implementation Manual. Guidance for prevention workers regarding the implementation of the 'Healthy School and Drugs' project in primary education]. Utrecht: Trimbos Institute.

Wafelbakker F (1983). Jeugdgezondheidszorg in beweging. Lichamelijke, sociale en milieu-aspecten [Youth Health Care on the move. Physical, social and environmental aspects]. Groningen: Wolters-Noordhof.

Walker R (2000). Collaboration and alliances: a review for VicHealth. Melbourne: VicHealth.

Wallerstein N, Polascek M \& Multrud K (2002). Participatory evaluation model for coalitions: the development of system indicators. Health Promotion Practice, 3(3), 351-373.

Wauters SA (2004). Gezond kiezen?! Onderzoek naar de schoolSlag Prioriteiten Workshop Voortgezet Onderwijs [Healthy choices? Evaluation of the schoolBeat priority workshop for secundary education]. Unpublished master thesis, Maastricht University, Maastricht.

Weare K \& Markham W (2005). What do we know about promoting mental health through schools. Promotion E Education, XII(3-4), 118-122. 
Weiss ES, Miller R \& Lasker R (2001). Findings from the national study of partnership functioning: report to the partnerships that participated. New York: The Center for the Advancement of Collaborative Strategies in Health.

Wells JH, Barlow J \& Stewart-Brown S (2003). A systematic review of universal approaches to mental health promotion in schools. Health Education, 103(4), 197-220.

WHO (1986). Ottawa Charter for Health Promotion. Copenhagen: WHO Regional Office for Europe.

WHO (1996). The status of school health. Geneva: WHO.

Yin RK (1994). Case study research. Design and Methods (2 ${ }^{\text {th }}$ ed.). Thousand Oaks: Sage Publications.

Yin RK (2003). Case study research. Design and methods ( $3^{\text {rd }}$ ed.). Thousand Oaks: Sage Publications.

Young I (2002). Conference Report: Education \& Health in Partnership - A European Conference linking education with the promotion of health in schools. Woerden: NIGZ.

Zipper TMG (2002). Werken aan kwaliteit: naar een bruikbaar systeem van kwaliteitszorg voor het onderwijs [Working on quality: towards a useful system for quality care in education]. De Thij: Carmel Management Academy. 


\section{SUMMARY}

Healthy children, healthy employees, healthy families, healthy neighborhoods, healthy schools... Health promotion in the school-setting requires more than just a single lesson on healthy eating or not smoking. Health promotion in schools targets the promotion of the healthy development of children. This is primarily the responsibility of parents. However, children grow and develop 24 hours a day. As schooling is compulsory between the ages of 5 and 18 in the Netherlands, children grow up at school too. It is the task of schools to prepare children for nationally established competency-levels, mostly operationalized in terms of knowledge. Impacting on a healthy lifestyle and the healthy development of children comes second in this process. Due to compulsory education and the presence of professional staff many national and regional organizations perceive schools as the ideal setting to promote a healthy lifestyle and the development of children. They call upon schools regularly to participate or implement their health promoting projects and campaigns. They compete with each other for the attention of schools. Schools become overwhelmed and even irritated in this confusing market. And knowing that whole-school health comprises also workplace health promotion and health promotion for the school at large, something had to be done.

This is just what schoolBeat is about: how can schools contribute to the healthy development of pupils and staff without compromising on their own core-business: education. Schoolbeat aims to optimize the support of whole-school health by external organizations, especially from the health and welfare sector. The accompanying schoolBeat-study, as described in this PhD-thesis, is based on the following problemstatement:

Can a fragmented, uncoordinated, supply driven support of school health promotion be transformed into a comprehensive, collaborative and demand oriented approach to effective whole-school health promotion?

A roadmap: Chapter 1 describes the history, Chapter 2 the starting situation; Chapter 3 the opportunities for collaboration; Chapter 4 the link with individual pupil care; Chapter 5 the important factors in primary education; Chapter 6 the development of a quality checklist for healthy school interventions; Chapter 7 the first application of this checklist; Chapter 8: a model supporting sustainable collaborations; Chapter 9 continues by discussing further aspects of schoolBeat not covered in earlier chapters and Chapter 10 finally reflects on the schoolBeat project as a model for school health promotion. But first a short summary per chapter.

Chapter 1 of this thesis starts with a historical perspective of health promotion in schools, starting in Roman times. The development of school health became more serious about 150 years ago, and evolved into school health promotion in the middle of the 20th century. At the start of the 21st century, school health promotion in the Netherlands was characterized by fragmentation and supply-orientated support with several regional and national organizations competing for the interest of schools. The introduction finishes with a description of the goals of the schoolBeat-study and a reading guide for this thesis. 
In Chapter 2 the status of school health promotion in the Netherlands is outlined in more detail. The schoolBeat-strategy is introduced, including the schoolBeat-steps towards a healthy school and the intended evaluation of the schoolBeat-collaboration.

The schoolBeat process comprises of six steps: (1) determining the needs of the school; (2) setting health promotion priorities; (3) assessing important and changeable determinants'; (4) formulating a school health plan (5) realizing the school health plan; and (6) performing a school-based evaluation. In step 4, the schoolBeat-interpretation of the American Healthy School Model, includes eight strategies that can be combined in setting priorities and the schoolBeat-checklist to assess the quality of healthy school interventions (see chapter 6 and 7). The diagnosis of sustainable collaboration model DISC (see chapter 8) was developed to monitor the collaboration between schools, organizations, and governments involved in school health promotion.

Chapter 3 focuses on the processes and initial results of developing a collaborative model tailored to whole-school health in the Netherlands, named schoolBeat. A literature review, observations, and stakeholder consultation provided a clear picture of the current situation in school health promotion, and factors limiting a comprehensive and needs-based approach to school health. This revealed that the establishment of a health promotion team within a school is fundamental to an effective approach to tailored school health promotion. A respected (senior) school staff member should chair this team. To strengthen the link with the school care team, the school care coordinator should be a member of both teams. To provide coordinated support to all schools in a region, the participating health promotion and welfare organizations decided to share advisory tasks which are included in the regular health promotion work of their staff. This was operationalized as working with one advisor for each school, representing all school-health organizations, and using a comprehensive overview of all possible support and projects promoting health. Empowering schools in needs assessments and comprehensive school health promotion is an important element of the developed approach. This chapter concludes with an examination of emerging issues in evaluating collaborative school health support during the first 18 months of development, and implementation and future perspectives regarding sustainable collaboration and quality improvement.

In Chapter 4 the schoolBeat-strategy is discussed from the perspective of youth health care, an important factor in the care structure of schools. As is the case with public health services, care and health promotion services in schools are working together more and more closely. Both play important roles in integrated shared care in schools. In the Maastricht-region, this shared care perspective is described in six levels. The care-continuum starts at the ground level, incorporating the whole school, and via the class-level finishes at sub-groups in each class. It stresses pupil support outside the school in specialized centers of expertise. The youth health care supports this continuum at several levels. It facilitates schools in outlining their needs and supports strengthening the care power of schools. Systematic and

1 This step changed over the years into 'selection of activities and strategies' (Leurs et al., 2006). 
effective promotion of the healthy development of children should by the starting point. The chapter concludes with a short description of the schoolBeat-strategy facilitating this starting point, and a reflection on international and national developments in whole-school health promotion.

To enable improvements in school health promotion, Chapter 5 examines possible determinants of the number of health promotion issues addressed by primary school teachers in the Netherlands. The main factors examined are context characteristics and constructs of attitude, social influence, self-efficacy and perceived barriers. A total of 180 primary school teachers teaching 9 to 12 year olds (grades 6,7 and 8) participated in a cross-sectional survey. The results show that it is possible to differentiate between teachers addressing three or more health issues per year versus those who address fewer based on grade level (more health issues are addressed at higher grades), perceived disadvantages, self-efficacy and staff support. The latter seems to exert the greatest influence and may be one of the most promising focus points for improvements of school health promotion in the Netherlands.

Chapter 6 describes the background and the development process of a checklist for assessing quality of school health promotion interventions. The checklist was developed as part of the innovative regionally developed schoolBeat-strategy but can also be used nationally. It aims to facilitate and systematize the process of selecting interventions by providing an assessment of quality aspects of interventions. The checklist contains quality criteria which are perceived to be relevant by either supporting organizations, schools or both. The checklist is based on a review of quality criteria and quality assessment instruments in the areas of health promotion, prevention, welfare, safety, the healthy school and education. Based on the results of the review a common set of quality criteria was established. In the subsequent operationalization process, existing quality assessment instruments were used and brevity was considered important, for reasons of practicality. The initial idea behind the checklist was that local health promotion officers could apply the checklist to interventions themselves.

Chapter 7 describes the first national application of the schoolBeat-checklist in 2004. Twenty-nine healthy school interventions were assessed in the Netherlands, each by two health promoters and two teachers - individually and at a consensus meeting. Generalisability coefficients were calculated for the nine specific quality criteria. The mean consensus score differed from the mean average individual score for two out of nine criteria. To obtain a threshold Generalisability coefficient of 0.70 , the number of assessors required per criterion ranges from 1.6 to 10.8, with an average of 4.7. Based on this study, we concluded that quality assessment procedures pertaining to healthy school interventions using the schoolBeat checklist require about four experienced assessors from each professional domain (health and education) to create reliable quality scores based on individual assessment only. Publicly available quality scores enable the inclusion of high quality interventions in school policies in order to increase the impact of school health. 
Chapter 8 describes the DIagnosis of Sustainable Collaboration (DISC) model, developed to facilitate comprehensive monitoring of public health collaboratives. The model focuses on opportunities for and impediments to collaborative change based on evidence from interorganizational collaboration, organizational behavior and planned organizational change. A description of the 2003/2004 application of the model to the Dutch whole-school health promotion collaboration is used to illustrate the practical relevance and to provide an assessment of the DISC-model.

The study combined quantitative and qualitative research. A DISC-based survey was sent to 55 stakeholders in whole-school health promotion in one Dutch region. The analysis provided for comparisons between stakeholders from education, public service and public health. This was followed by 11 semi-structured DISC-based interviews and a DISC-based document analysis. The results revealed significant differences between respondents from different domains for a number of the constructs. The interviews provided a more detailed picture of the situation surrounding the collaboration studied with regard to the DISC-constructs.

It was concluded that the DISC-model is more than just the sum of the different parameters provided in the literature on interorganizational collaboration, organization change, networking and setting-approaches. Monitoring a collaboration based on the DISC-model yields insight into windows of opportunity and current impediments for collaborative change. DISC-based monitoring is a promising strategy enabling project managers and social entrepreneurs to plan change management strategies systematically.

Chapter 9 is a primarily a summary of those parts of the schoolBeat manual (Leurs et al., 2006) that were not addressed in previous chapters of this thesis to facilitate better understanding of the schoolBeat strategy and the processes involved in the successful implementation of the strategy. It begins with a examination of the role of the schoolBeat advisors and the school prevention teams. This is followed by a description of the monitoring at the school level (using the Quick scan shared care in whole-school health and youth monitoring including pupil reports) and the tools for planning whole-school health promotion (the healthy school model, the schoolBeat inventory and the schoolBeat matrix). This chapter ends with a discussion of the support used to develop the schoolBeat-strategy, to implement it and to evaluate it. In retrospect, this turned out to be an intensive process.

The thesis is completed in Chapter 10 with a general discussion about the significance of the development of the schoolBeat-strategy, the most important results of this developmental process and experience gained in both the facilitating and limiting factors. Based on this discussion and on the previous chapters, it is reasonable to conclude that the project group succeeded in transforming fragmented, uncoordinated, supply-driven support of school health promotion into a comprehensive, collaborative and demand oriented approach in the Maastricht region. Helped by active knowledge transfer, the schoolBeat strategy - renamed the Healthy School Model - is now the national standard for health promotion in education. The effectiveness of schools as settings for health promotion is shown to be promising. Finally, this chapter and the thesis ends with a number of recommendations relating to the practice of healthy schools, as well as recommendations for future research in this area. 


\section{SAMENVATTING}

Gezonde kinderen, gezonde werknemers, gezonde gezinnen, gezonde buurten, gezonde scholen... Bij gezondheidsbevordering in het onderwijs komt meer kijken dan enkel een lesje over gezonde voeding of niet roken. Gezondheidsbevordering in het onderwijs is gericht op het bevorderen van een gezonde ontwikkeling van kinderen. Primair ligt de verantwoordelijkheid voor een gezonde ontwikkeling van kinderen bij hun ouders. Zij hebben ook de grootste impact op deze ontwikkeling. Maar kinderen groeien 24 uur per dag op. Sinds de invoering van de leerplicht wet, inmiddels ruim twee eeuwen geleden, groeien kinderen een deel van de tijd op in scholen. Scholen hebben daarbij als taak gekregen om kinderen voor te bereiden op landelijk vastgestelde eindtermen, veelal geoperationaliseerd in kennistermen. Het beïnvloeden van een gezonde leefstijl en gezonde ontwikkeling van kinderen lijkt daaraan ondergeschikt. Vanwege de leerplicht en de professionaliteit van scholen zien een groot aantal organisaties lokaal, regionaal en landelijk in scholen de ideale setting om de gezonde leefstijl en ontwikkeling van kinderen positief te beïnvloeden. Zij doen daarom veelvuldig een beroep op scholen om mee te werken aan speciale lesmodules, projecten en campagnes gericht op een of meer gezonde leefstijlgedragingen. Hierbij lopen ze soms elkaar in de weg. Scholen zien door de bomen het bos niet meer. En dat terwijl schoolgezondheidsbeleid zich ook zou moeten richten op gezondheidsbevordering op de werkplek en op de school als geheel. Iets moet er daarom gebeuren.

Dit is nu precies waar het bij schoolSlag om draait: hoe kunnen scholen een bijdrage leveren aan de gezonde ontwikkeling van leerlingen en medewerkers zonder concessies te hoeven doen aan hun eigen kerntaak: onderwijs. SchoolSlag streeft naar optimale ondersteuning van schoolgezondheidsbeleid door externe organisaties, met name uit de gezondheids- en welzijnssector (inclusief verslavingspreventie, ggz en sport $\&$ bewegen). Het bijbehorende schoolSlag-onderzoek, zoals verwoord in dit proefschrift, is gebaseerd op de volgende probleemstelling:

\section{Kan een gefragmenteerd, aanbodgerichte ondersteuning van schoolgezondheidsbeleid worden getransformeerd naar een integrale, gezamenlijke en vraaggerichte ondersteuning van effectieve gezonde scholen?}

Een routekaart: Hoofdstuk 1 beschrijft de historie, Hoofdstuk 2 de startsituatie, Hoofdstuk 3 de mogelijkheden voor samenwerking, Hoofdstuk 4 de relatie met leerlingezorg, Hoofdstuk 5 determinanten van bereidheid onder leraren, Hoofdstuk 6 de ontwikkeling van een instrument om de kwaliteit van schoolse interventies te bepalen, Hoofdstuk 7 beschrijft ervaringen met de eerste toepassing van dit instrument, Hoofdstuk 8 beschrijft een model dat de ontwikkeling van duurzame samenwerking kan ondersteunen, Hoofdstuk 9 vervolgt met een reflectie op de onderdelen van het schoolSlag die niet in voorgaande hoofdstukken zijn behandeld; en Hoofdstuk 10 besluit met een discussie over schoolSlag als model voor gezondheidsbevordering in het onderwijs. Nu eerst een nadere toelichting op de verschillende hoofdstukken. 
Dit proefschrift begint in Hoofdstuk 1 met het historisch perspectief van gezondheidsbevordering in het onderwijs, startend bij de Romeinen. Via de leerplichtwet van 1806 en de ontwikkeling van de schoolgezondheidszorg een halve eeuw later, tot de nationale en international ontwikkelingen rondom schoolgezondheidsbeleid in de tweede helft van de vorige eeuw om uit te komen bij de situatie aan het begin van de 2le eeuw: gefragmenteerde en aanbodgerichte ondersteuning van tal van organisaties die met elkaar concurreren om de aandacht en inzet van scholen. De introductie wordt afgerond met een toelichting op de doelen van de schoolSlag-studie en een leeswijzer voor dit proefschrift.

In Hoofdstuk 2 wordt voor een internationaal lezerspubliek toegelicht hoe gezondheidsbevordering in het onderwijs in Nederland is georganiseerd. Accent in dit hoofdstuk ligt bij de uitleg over de schoolSlag-werkwijze, waaronder het schoolSlag-stappenplan, en de wijze waarop de schoolslag-samenwerking wordt geëvalueerd.

Het schoolSlag-stappenplan omvat de volgende zes stappen: (1) bepaling van de zorgbehoefte van de school; (2) bepaling van prioriteiten voor gezondheidsbevordering; (3) bepaling van belangrijke en veranderbare determinanten ${ }^{2}$; (4) opstellen van het schoolgezondheidsplan; (5) uitvoering van het schoolgezondheidsplan; en (6) evaluatie op schoolniveau. Bij stap vier wordt gebruik gemaakt van de schoolSlag-interpretatie van het Amerikaanse Gezonde School Model, bestaande uit acht verschillende strategieën die gecombineerd ingezet kunnen worden om invulling te geven aan de vastgestelde prioriteiten, en de schoolSlag-checklist om bestaande interventies te toetsen op kwaliteit (zie hoofdstuk 6 en 7). Om de samenwerking tussen scholen, instellingen en overheden betrokken bij schoolgezondheidsbeleid te kunnen monitoren, is het duurzame samenwerkingsmodel DISC (zie hoofdstuk 8) ontwikkeld.

In Hoofdstuk 3 staan de initiële ideeën over de schoolslag-werkwijze nogmaals toegelicht in combinatie met een reflectie op de eerste resultaten van het samenwerkingsproces. Op basis van literatuuronderzoek, observaties en gesprekken met betrokkenen ontstaat een helder inzicht in de Nederlandse situatie bij aanvang van het schoolSlag-project. Tevens werden factoren in beeld gebracht die een samenhangende, vraaggerichte ondersteuning belemmeren. Op basis hiervan ontstond het inzicht dat het instellen van een schoolpreventieteam belangrijk is om effectief schoolgezondheidsbeleid op maatwerk te maken, waarbij het team voorgezeten zou moeten worden door iemand uit de schoolleiding. Om de verbinding met het zorgadviesteam van de school te versterken, ligt een personele unie via deelname van de zorgcoördinator aan beide teams voor de hand.

Om de ondersteuning van scholen gecoördineerd te laten verlopen, besloten de betrokken regionale gezondheids- en welzijnsorganisaties om hun adviestaken gezamenlijk in te vullen. Het gaat hierbij om adviestaken die tot de reguliere werkzaamheden behoren van gezondheidsbevorderaars en welzijnswerkers. De instellingen hebben dit vormgegeven door te gaan werken een gezamenlijke schoolSlag-adviseur per school, die gebruik maakt van een overzicht

2 Deze stap is in de loop van het schoolSlag-project geëvolueerd in 'bepaling van activiteiten en strategieën' (Leurs et al., 2006). 
van het aanbod van alle betrokken instellingen. Het toerusten van scholen om te werken met een behoefte-inventarisatie en preventieplannen schoolbreed op te stellen, hoort hierbij. Het hoofdstuk besluit met een reflectie op de ontwikkelingen in de eerste 18 maanden, implementatiemogelijkheden en mogelijkheden voor duurzame samenwerking en kwaliteitsverbetering.

In Hoofdstuk 4 wordt de schoolSlag-werkwijze besproken vanuit het perspectief van de jeugd-gezondheidszorg, een belangrijke actor in het zorgbeleid van scholen. Net als bij GGDen, groeien in het onderwijs collectieve gezondheidsbevordering en preventie enerzijds, en individuele leerlingenzorg anderzijds, namelijk naar elkaar toe. Ze vormen een keten binnen het onderwijscontinuüm van zorg. Deze keten is in de regio Maastricht in samenwerking met het onderwijsveld uitgewerkt in zes niveaus van zorg onder de noemer 'integrale ketenzorg'. De keten start met een basisniveau, dat de gehele school omvat, en loopt via het niveau van de klas en van subgroepen in de klas tot het niveau van individuele hulpverlening via externe voorzieningen. De jeugdgezondheidszorg (JGZ) vervult op de verschillende niveaus van zorg een versterkende en ondersteunende rol in deze innovatieve benadering van zorg in het onderwijs. Het gaat daarbij onder meer om het mee in kaart brengen van de zorgbehoefte van de school én het bijdragen aan de versterking van de zorgkracht van de school. Uitgangspunt zou hierbij het systematisch en effectief bevorderen van een gezonde ontwikkeling van leerlingen moeten zijn. Dit hoofdstuk besluit met een beknopte omschrijving van de schoolBeatwerkwijze waarmee dit uitgangspunt vormgegeven kan worden en een reflectie op internationale en nationale ontwikkelingen op het terrein van de gezonde school.

Aanknopingspunten voor verbeteringen in het schoolgezondheidsbeleid van basisscholen staan beschreven in Hoofdstuk 5. Via aan breed uitgezette vragenlijst onder leerkrachten van groepen 6, 7 en 8 in de regio Maastricht-Mergelland in 2003 is gekeken naar factoren die van invloed zijn op het aantal verschillende gezondheidsthema's waar leerkrachten zich voor inzetten. De resultaten laten een verschil zien tussen leerkrachten die jaarlijks met drie of meer gezondheidsonderwerpen aan de slag gaan en leerkrachten die dat aantal niet halen. Het gaat hierbij om verschillen in groepen (meer onderwerpen worden aangesneden in de hogere groepen) en verschillen in verwachtingen ten aanzien van nadelen, van de eigen effectiviteit en van de ondersteuning door de schoolleiding. De schoolleiding lijkt de meeste invloed te hebben op de inzet van leerkrachten ten aanzien van gezondheidsbevordering in het onderwijs en is daarom een van de veelbelovende aangrijpingspunten voor versterking van schoolgezondheidsbeleid in het onderwijs.

Hoofdstuk 6 beschrijft de achtergrond en ontwikkeling van een checklist voor de kwaliteit van collectieve preventie voor het onderwijs: de schoolSlag-checklist. Hoewel deze speciaal is opgesteld als onderdeel van de regionaal ontwikkelde schoolSlag-werkwijze, is deze ook landelijk inzetbaar. Het doel van de checklist is het faciliteren en systematiseren van de keuze van interventies die op scholen kunnen worden uitgevoerd - stap 4 van de schoolSlag-werkwijze. De checklist bevat kwaliteitscriteria die door ondersteuningsinstellingen, het onderwijs of beide belangrijk worden geacht. De checklist is gebaseerd op een review naar kwaliteitscriteria en kwaliteitsmeetinstrumenten op de terreinen preventie, welzijn, veiligheid, de gezonde 
school én het onderwijs. Op basis van de reviewresultaten is een gezamenlijke set criteria vastgesteld, die vervolgens is geoperationaliseerd in items. Het gaat hierbij om criteria als 'effectiviteit aangetoond', 'planmatigheid', 'efficiëntie voor school' en 'onderwijsgerichtheid'. Bij het operationaliseringproces is geput uit bestaande kwaliteitsmeetinstrumenten en is gelet op beknoptheid. Het oorspronkelijke idee achter de checklist was dat lokale gezondheidsbevorderaars de checklist zelf zouden gaan toepassen.

In Hoofdstuk 7 worden kwaliteitsbeoordelingen van schoolse interventies in internationaal perspectief geplaatst. Tevens worden de resultaten van de eerste nationale toepassing van de schoolSlag-checklist beschreven. Internationaal gezien is de toetsing van schoolse interventies beperkt tot algemenere evaluaties vanuit een gezondheidsperspectief. Het perspectief van het onderwijs wordt daarin niet meegenomen. De schoolSlag-checklist combineert juist beide inzichten. Om de waarde van de schoolSlag-checklist te evalueren, is de checklist in 2004 toegepast op 29 landelijk beschikbare schoolse interventies. Elke interventie is zowel individueel als gezamenlijk gescoord door vier professionals: twee docenten en twee gezondheidsbevorderaars. Bij twee van de negen criteria werd een significant verschil gevonden tussen het gemiddelde van de individuele oordelen en het gezamenlijke oordeel.

Geconcludeerd wordt dat er voor kwaliteitsbeoordelingen van schoolse interventies met behulp van de schoolSlag-checklist ongeveer vier ervaren beoordelaars per professioneel domein nodig zijn. Deze kunnen individueel hun oordeel geven. De meerwaarde van een consensusbijeenkomst is met deze studie niet aangetoond. Het is de verwachting dat openbare kwaliteitsoordelen de opname van kwalitatief goede interventies in het schoolbeleid bevorderen om zodoende meer impact te hebben op schoolgezondheid.

In Hoofdstuk 8 wordt het duurzame samenwerkingsmodel DISC nader toegelicht en worden de resultaten gepresenteerd van de eerste toepassing van het model op de samenwerking tussen scholen, instellingen en gemeenten en provincie in het kader van schoolSlag. Het model focust op bevorderende en belemmerende factoren ten aanzien van samenwerking in de openbare gezondheidszorg. Het model is gebaseerd op bewijzen uit studies naar interorganisationele samenwerkingsverbanden, gedrag van organisaties en planmatige organisatieverandering. Het DISC-model is in 2003/2004 toegepast via een vragenlijstonderzoek onder 55 betrokkenen bij de schoolSlag-werkwijze in Maastricht-Mergelland, aangevuld met 14 semi-gestructureerde interviews en een documentenanalyse. In de analyse van de resultaten is vooral gekeken naar verschillen tussen betrokkenen uit het onderwijs, van de overheid en uit de gezondheids- en welzijnssector. De hierbij gevonden verschillen boden bruikbare aanknopingspunten voor het bijstellen van strategieën om de beoogde samenwerking te bevorderen en gesignaleerde belemmeringen hiervoor systematisch weg te nemen.

Hoofdstuk 9 is vooral een samenvatting van die onderdelen van het in het voorjaar 2006 verschenen schoolSlag-praktijkboek, die in eerdere hoofdstukken van dit proefschrift nog niet zijn uitgewerkt. Het gaat hierbij om de unieke rol van de schoolSlag-adviseur en het schoolSlag-team c.q. het schoolpreventieteam. Maar ook om de verschillende manieren om schoolgezondheid te monitoren. Zo worden de quickscan integrale ketenzorg, de Limburgse 
Jeugdmonitor en de leerlingrapportage besproken behorend bij stap 1 van de schoolSlagwerkwijze. Dit wordt gevolgd door de schoolSlag-prioriteitenworkshop (onderdeel van stap 2), de schoolSlag-inventarisatie (onderdeel van stap 3) en de schoolSlag-matrix (onderdeel stap van 4) toegelicht. Leerlingen, ouders en personeel stellen prioriteiten voor ten behoeve van het gezondheidsbeleid van de eigen school via de schoolSlag-prioriteitenworkshop. In schoolSlag-inventarisatie staat het beschikbare landelijke én regionale aanbod op uniforme wijze beschreven. Deze inventarisatie is te gebruiken bij het invullen van de schoolspecifieke schoolSlag-matrix. De matrix is een integraal planningsmodel voor scholen gericht op verschillende doelgroepen en gebruik makend van een op maat samen te stellen set van activiteiten per vastgestelde prioriteit. Zie www.schoolSlag.nl voor meer informatie.

Tot slot vindt een reflectie plaats op de inzet om de schoolSlag-werkwijze te ontwikkelen, te implementeren en te evalueren. Dit bleek een intensief proces te zijn.

Het proefschrift wordt afgesloten in Hoofdstuk 10 met een algemene discussie over het belang van de ontwikkeling van de schoolSlag-werkwijze, de belangrijkste resultaten van dit ontwikkelingsproces en de hierbij ervaren bevorderende factoren en beperkingen. Op basis van deze discussie en de voorafgaande hoofdstukken is de conclusie gerechtvaardigd dat het gelukt is om in vier jaar tijd een gefragmenteerde, aanbodgerichte ondersteuning van schoolgezondheidsbeleid te transformeren in een integrale, gezamenlijke en vraaggerichte ondersteuning van gezonde scholen in de regio Maastricht-Mergelland. Mede door actieve kennisoverdracht, geldt de schoolSlag-werkwijze - als 'gezonde school methode' - inmiddels als de nationale standaard voor gezondheidsbevordering in het onderwijs. Dat hierdoor de effectiviteit van scholen als setting voor gezondheidsbevordering toeneemt, is daarbij aannemelijk gemaakt.

Dit hoofdstuk en daarmee ook het schoolSlag-proefschrift wordt afgesloten met aanbevelingen voor zowel de praktijk van gezondheidsbevordering in het onderwijs als het onderzoek hiernaar. 


\section{Thank YOU}

To all those contributing to a healthy development of children in Maastricht-Mergelland and beyond!

\section{Thank YOU}

And to all of you who made the endeavour called 'promoveren in de praktijk' a worth while experience!

\section{DANK U}

Free time is now dedicated to Justin, Pia, Celine, Ben, friends and relatives - who all had to put up with the investment in this thesis!

Dank jullie allen voor jullie steun en vooral jullie inspiratie! 


\section{CURRICULUM VITAE}

Mariken Leurs was born in Grave (Noord-Brabant) on 16 April 1970. She grew up in Epe (Veluwe) where she attended the St.Bernardus-school (primary school) and RSG de Springborn (high school). After completing her International Baccalaureate at the United World College of South East Asia in Singapore, she studied Health Sciences at the University of Limburg (later renamed Maastricht University). She graduated in 1995 in Health Education and Promotion and in Human Movement Sciences. This was followed by consultancy work for the World Health Organization in Geneva, working on the World Atlas on Tobacco or Health.

Her combined studies proved to be excellent preparation for her career in the promotion of health-enhancing physical activity at the Netherlands Olympic Committee * Netherlands Sports Federation (NOC*NSF), where she started in 1996. Here she prepared and supported regional 55-plus on the Move! campaigns and ran the Europe on the Move! network in close collaboration with the Finnish UKK Institute. In 1999, Mariken became the coordinator of the national health-enhancing physical activity campaign 'The Netherlands on the Move!'. It included launching a morning-gymnastics television-programme in 2000 as a joint production with the public broadcasting organization AVRO. This was followed by a period as acting manager of the Innovation and Development Department responsible for Sport for All / Local Sport Strategies. In the spring of 2002 she left NOC*NSF to commence a job as co-ordinator / researcher in school health promotion at the Maastricht Public Health Institute as she wanted to understand processes of horizontal and vertical collaboration, implementation and invention at the local level better. Four yours in Maastricht resulted in this thesis and previously described products and activities in the area of whole-school health.

Along the way, she has also held a number of advisory tasks including membership of the ZonMW-Committee on Healthy Living Campaigns and the Sport Advisory Committee of the VSG -Union for Sports Municipalities. Furthermore, she lectured on school health promotion and planned behaviour change in sport and exercise.

In spring 2006 Mariken became the coordinator of a new and ambitious youth program Zorg voor Jeugd- with the Netherlands Organization for Health Research and Development (ZonMw) in The Hague. Enabling the generation of evidence to improve the care for youth is her goal these days. As improved care for youth benefits whole-school health promotion as well, her schoolBeat challenge continues. 


\section{PUBLICATIONS}

\section{7}

Leurs MTW (2007). Weet u wat echt werkt?. Tijdschrift Jeugdbeleid, 1(3), 189-193.

Leurs MTW, Bessems K, Schaalma HP, De Vries H (2007). Focus points for school health promotion improvements in Dutch primary schools. Health Education Research, 22(1), 58-69.

Leurs MTW, Schaalma HP, Janssen MWJ, Mur-Veeman IM, Van Breukelen G, De Vries NK (2007) Comprehensive Quality Assessment of Healthy School Interventions. Preventive Medicine, 45(5), 366-372.

Van Lieshout M, Leurs M (2007). Maatschappelijke opgaven Jeugd. ZonMw: Den Haag. ZonMw (2007). Programma Zorg voor Jeugd - weten wat werkt. Den Haag: ZonMw.

\section{6}

Leurs MTW, Steenbakkers M \& Jansen MWJ (2006). Het schoolSlag-praktijkboek: samen werken aan preventie op maat in het onderwijs. Maastricht: GGD Zuid Limburg

Mur I, Leurs M (2006). Developing youth care: the challenge of integrated school health promotion. International Journal of Integrated Care, 6, published online 6 December 2006, www.ijic.org

ZonMw (2006). Programma Ouders van tegendraadse Jeugd. Den Haag: ZonMw.

ZonMw (2006). Innovatieprogramma Multi System Therapy en Functional Family Therapy -fase 1. Den Haag: ZonMw.

\section{5}

Bessems K, Buijs G, M Leurs M (2005). Gezondheidsprogramma's in de klas - welke zijn slecht en goed? Jeugd in School en Wereld - vakblad voor het basisonderwijs, 89(9), 30-32.

Bessems K, Buijs G, Leurs M (2005). Gezondheidsprogramma's nader bekeken. Docenten en preventiefunctionarissen beoordelen de kwaliteit. Jongleren - tijdschrift voor docenten verzorging in het voortgezet onderwijs, 11 (lente), 10-12.

Boot N, Bessems K \& Leurs M (2005). Het schoolSlag aanbod 2005-2006. Woerden / Maastricht: NIGZ / GGD ZZL.

Boot NMWM, Leurs MTW, Peters LWH, Keijsers JFEM, Schaalma HP, De Vries NK (2005). Evaluatie van de schoolSlag-checklist gericht op het beoordelen van de kwaliteit van schoolse interventies. TSG, 83(7), 405-411.

Hopman-Rock M, Borghouts JAJ, Leurs MTW (2005), Determinants of participation in a health education and exercise program on television. Preventive Medicine, 41(1):232-9.

Leurs MTW \& Hardy C (2005). Een planmatige aanpak van gezondheidsbevordering en preventie in het onderwijs als onderdeel van integrale ketenzorg: ervaringen van het OPDC St.Michaël. In: R. Kleijnen \& G. Van den Broek (Eds.), Grensoverschrijdende Integrale Leerlingenzorg - een [pro]actief proces (pp. 377392). Antwerpen-Apeldoorn: Garant.

Leurs MTW, Jansen MWJ, Schaalma HP, Mur-Veeman IM, NK de Vries (2005). The tailored schoolBeat-approach: new concepts for health promotion in schools in the Netherlands. In: Clift $S$, en BB Jensen. The Health Promoting School: International Advances in Theory, Evaluation and Practice. Copenhagen: Danish University of Education Press in association with WHO 
Leurs MTW, Mur-Veeman IM, Schaalma HP, Feron FJM, De Vries NK (2005). Integrale ketenzorg biedt mogelijkheden om de zorgkracht in het onderwijs te versterken. Tijdschrift Jeugdgezondheidszorg, 37(4), 71-76.

Leurs MTW, Schaalma HP, Jansen MWJ, Mur-Veeman IM, St.Leger LH, De Vries NK (2005).

Development of a collaborative model to improve school health promotion in the Netherlands. Health Promotion International, 20(3), 296-305.

Rademaker CW, De Vreede JJM, Kraaykamp G, Leurs MTW (2005). De invloed van ouders, school en vrienden op het cannabisgebruik van jongeren. TSG, 83(7), 398-404.

Steenbakkers M, Bastiaens C, Leurs M, Ruland E, Jansen M (2005). Vijf jaar community-based werken in Hartslag Limburg (1998-2003). TSG, 83(2), 108-112.

Vermeer A, Steenbakkers M, De Munter H, Leurs M (2005). Op weg naar een gezonde school! Nieuw leefstijlprogramma voor bovenbouw havo/vwo: de Heartbeat Survival Day. Niche - bulletin voor het onderwijs in de biologie, 36(2), 13-16.

\section{4}

Bessems K, Buijs G, Leurs M (2004). Kwaliteit van onderwijsprojecten bepaald. Een toepassing van de schoolSlag-checklist 1.2. Woerden/Maastricht: NIGZ/GGD ZZL.

Bessems K, Leurs M (2004). Het schoolSlag aanbod 2004-2005. Woerden/Maastricht: NIGZ/GGD ZZL.

Bessems K, Leurs M (2004). Onderzoek Veilige School 2003. Maastricht: GGD ZZL.

Kleijnen R, Leurs M, Pennartz A (2004). Integrale ketenzorg. Nadere positionering, landelijke trends en praktische uitwerking binnen schoolzorgbeleidsplannen in de regio. Remediaal, 4(4), 8-14.

Leurs M (2004). Gezondheidsbevordering en preventie op school - verslag van de World Conference on Health Promotion \& Health Education. TSG, 82(7), 467-468.

Leurs M, Jansen M, Feron F (2004). From school health promotion to integrated school health care schoolBeat in the Netherlands. Network News of the European Network of Health Promoting Schools, 8 , 22.

Leurs M, Kleijnen R, Consten K, Pennartz A, Feron F (2003). Integrale ketenzorg binnen het onderwijscontinuüm van zorg. Remediaal, 4(2), 16-22.

Leurs M, Peters L, Schaalma H (2004): Kiezen voor beter leren. Hoe zorg je voor effectieve gezondheidsbevordering op school? G, 2(6), 24-25.

Peters LWH, Leurs MTW, Jansen MWJ, Keijsers JFEM, Schaalma HP (2004). Ontwikkeling van de schoolSlag checklist voor kwaliteit van schoolgerichte interventies. TSG,82(1), 50-57.

Sniekers J, Buijs G \& Leurs M (2004). Op weg naar een gezonde school. Woerden: NIGZ.

\section{3}

Kleijen R, Leurs M (2003). Gids Integrale Ketenzorg VO. Maastricht: VORMing.

Leurs M (2003). Gezondheidsbevordering in het onderwijs: de schoolSlag-uitdaging. Remediaal 4(1), 3-8.

Leurs M, Mur-Veeman I, Schaalma H, De Vries N (2003). Integrale samenwerking gaat verder dan de samenwerking tussen professionals: introductie van het DISC-model. TSG 81(6), 369-372. 


\section{2}

Leurs M. Het schoolSlag-perspectief. Maastricht: Bureau Jeugdzorg Maastricht \& Heuvelland, CAD Limburg, GGD Zuidelijk Zuid-Limburg, RIAGG Maastricht en Stichting Trajekt.

Leurs M, Jansen M (2002), Schoolbeat - the new Challenge. Network News - the European Network of Health Promoting Schools, 7, 26-28.

Leurs M, Jansen M, Ruiter M (2002), Coordinated School Health Program: het 'Gezonde School Model' van de toekomst? TSG, 80(7), 471-473.

\section{1 and before}

Coumans B, Leurs M (2000). Gezond bewegingsadvies voor mensen met een chronische ziekte. Huisarts Geneeskunde, 17(5), 178-185.

Coumans B, Leurs MTW (1999). Gezondheid en sport - ziekte en sport. Cumulatief Geneeskundig Nascholingsstysteem 15(10), 27-36.

Jenniskens DMAL, Leurs MTW (1998). Inventarisatie handvest Nederland in beweging!: wat doen ondertekenaars op het gebied van beweging(sstimulering)? Arnhem: NOC*NSF.

Leurs M (2000). Update 55-plus in Beweging!. Oudfit (2), 20-21.

Leurs M (1999). Nederland komt in beweging: bewegingsnormen en projecten van 'Nederland in beweging'. GGD nieuws. (5), 25-27

Leurs M (1999). GVO Transtheoretisch. AGM Bulletin.

Leurs MTW (1995). Achievement attributions E emotional responses in sport for athletes with disabilities. Unpublished master thesis, Maastricht University, Maastricht.

Leurs MTW (1993). Voorlichting en besluitvorming voorafgaand aan sterilisatie van de vrouw [Education and decision making prior to sterilization of the woman]. Unpublished master thesis, Maastricht University, Maastricht.

Leurs MTW, Boonekamp GMM, Van der Staak TS (1999). Nieuw bewegingsadvies voor de jeugd actieprogramma 'Nederland in Beweging!'. Lichamelijke Opvoeding 87(10), 580-581.

Leurs M, Coumans B(1995), Handboek Nederland in Beweging! Gezondheidsbevordering door een Actieve Leefstijl, NOC*NSF: Arnhem (laatste supplement gereed in 1998).

Leurs M, Coumans B, Wolfhagen PJJM (2000). Bewegingsstimulering vereist maatwerk. Geneeskunde en Sport, 33(3), 33-37.

Leurs MTW, Land JA, Damoiseaux V (1994). Voorlichting voorafgaand aan sterilisatie bij de vrouw, Nederlands Tijdschrift voor Obstetrie en Gyneacologie, 107(8), 295-299.

Leurs M, Ooijendijk WTM (1999). De nieuwe Nederlandse Norm Bewegen, TSG, 77(3).

Leurs MTW, Van Nierop J (2001). Health Enhancing physical activity and active living for you and your community. TSG, 79(3), 184-185.

Mulder G, Leurs M (1999). Sportief Wandelen: en Arthur slaapt weer als een roos. GGD Nieuws, (2), $5-7$. 


\section{APPENDIX A}

\section{THE QUICK SCAN SHARED CARE IN WHOLE-SCHOOL HEALTH 2002 AND 2005}

The Quick Scan Share Care in Whole-School Health is a survey for school staff and focuses on their perceptions and whishes regarding the whole-school health continuum of services, structures and activities. The survey was developed in 2002 by a group of school care administrators, a temporary regional pupil care coordinator and a temporary whole-school health promotion coordinator [the schoolBeat coordinator] in the Maastricht region. The survey was pre-tested among a small group of teaching staff. Participating schools were provided with one copy of the survey and asked to duplicate and disseminate it among teaching staff themselves. The survey was only marginally adjusted for the second measurement in order to shorten it in response to general criticism about the length of the survey in 2002. The layout was made more user friendly. Instead of asking what means were used for each health promotion topic addressed, in 2005 this was done overall with regard to any of the health promotion topics addressed. However, accommodation for longitudinal analysis and addition of some retrospective evaluation items did not shorten the survey by much.

On both occasions, schools received a confidential school report and a publicly available regional report. In 2005, a comparison with the results of the measurements in 2002 were included. The reports were limited to a presentation of frequencies of the different items included. Presentation of the report was followed by a meeting of the research staff and the school administration, often accompanied by those involved in whole school health in that particular school, with major differences per school. The discussions that followed added to the interpretation of the results per school. This was boosted when the school-specific results of the Limburg Youth Monitor became available to schools in early 2006.

Three hundred and forty-four surveys were returned by the ten participating schools in 2002 and two hundred in 2005. Response rates were 38\% and 23\% respectively. This drop in the number of participants was mainly accounted for by two of the ten participating schools: together they provided 171 respondents in 2002 and 35 respondents in 2005. The merger process of the schools seem to have caused the drop in response rates. The response percentage per school varied from over $90 \%$ for a special education school with a teaching staff of 13 to a response rate of $17 \%$ for two high schools offering pre-university education with a teaching staff of more than over 100.

The major differences in response percentages between schools and the overall drop in response over time imply that the results of this study should be examined very critically as they have very little to no scientific significance whatsoever. Nonetheless, this section is included in the appendix as an illustration of what type of information the quick scan might yield when response rates are improved. 
The composition of the samples regarding the tasks of staff that participated in this study did not differ significantly, with the exception of the mentor-task. In 2002, 52\% of the school staff participating reported performing mentor-tasks. In 2005, 63\% reported performing such tasks $(\mathrm{t}=-2.46, \mathrm{p}=0.01)$.

The Quickscan Shared Care survey consisted mainly of items using a 5-point scale varying from "stongly disagree" (=1) to "strongly agree" (=5). Additionally, yes-no items were included and some evaluative constructs were given a 5-point scale varying from "much worse' ( $=-2)$ to 'much better' $(=+2)$.

The reported levels of personal observation skills were measured with a six-item observation scale focusing on personal problems: fear of failure, concentration weakness, socialemotion problems, psychological problems, learning problems and physical health problems (Cronbach's $\alpha=0.81$ ); and a six-item observation scale focusing on risk behavior: alcohol and drug misuse, bullying, child abuse, sexual intimidation and domestic violence (Cronbach's $\alpha=0.91$ ).

The contribution of teacher to pupil care was measured using two scales: an individual care input scale consisting of five items (Cronbach's $\alpha=0.75$ ) and a health promotion input scale consisting of three items (Cronbach's $\alpha=0.58$ ).

Items pertaining to mentor tasks in shared care were divided into three scales based on factor analysis. This yielded a mentor-centered care scale consisting of four items (Cronbach's $\alpha=$ 0.71 ), a mentor-pupil communication scale with three items (Cronbach's $\alpha=0.74$ ) and a mentor care competency scale with three items (Cronbach's $\alpha=0.78$ ).

A specialized pupil care scale consisting of 7 items (Cronbach's $\alpha=0.88$ ) was constructed. This scale focused on the individual pupil care provided by specialists. A separate scale was constructed consisting of three items addressing the functioning of the pupil care team: the care team scale (Cronbach's $\alpha=0.67$ ). Based on factor analysis, two scales were constructed based on the pupil care organization items: a teacher-support scale and a pupil-care policy scale both consisting of three items (respectively Cronbach's $\alpha=0.81$ and Cronbach's $\alpha=0.80$ ).

Based on factor analysis, the items pertaining to whole-school health promotion and prevention were split in a health promotion responsibility scale comprising two items (Spearman correlation $=0.62, \mathrm{p}<0.01$ ) and a health promotion practice scale comprising six items (Cronbach's $\alpha=0.78$ ).

The perceived status of the internal organization of integral shared care was measured using two items pertaining to individual pupil care and health promotion (Spearman correlation = $0.58, \mathrm{p}<0.01$ ). This was complemented in 2005 by an item pertaining to attention to staffwellbeing, yielding a reliable internal shared care scale (Cronbach's $\alpha=0.71$ ). 
Perceived changes in the internal organization of integral shared care over the last three years was measured in 2005 only. This was done using three distinct items regarding individual pupil care, health promotion and attention to staff well-being (Cronbach's $\alpha=0.60$ ).

In the 2005 survey, a separate set of two items focused on the perceived status of health promotion support for schools and perceived changes in this support over the last three years. The level of response to these items was around $70 \%$ of the response to the items regarding individual pupil care.

\section{Statistical analyses}

Independent sample t-tests were performed to test whether the perceived status of the internal organization of individual pupil care and health promotion changed significantly between 2002 and 2005. For the evaluative constructs only measured in 2005, one-sample t-tests were performed testing whether the mean would significantly differ from 0 .

Due to the anonymous nature of the survey and the major differences in group-size between $\mathrm{T}^{0}$ (2002) and $\mathrm{T}^{1}$ (2005) paired t-tests and non-parametric tests could not be applied. The analyses were conducted for the whole group as well as per school and per type of school (regular versus special).

Analysis of variance procedures were used to detect significant differences between the staff of participating schools. One school was excluded in the analyses of the 2002 results as only one school staff member from this school had participated in the survey. This meant analysis of variance was applied to the 2002-results of nine schools and the 2005-results of ten schools. The Bonferonni-test was applied post-hoc to identify between which schools significant differences existed.

NB. Reliability analyses were conducted using 2002 data only.

\section{Results}

Comparisons between the overall 2002 and 2005 data indicated that the self-reported mentorship skills had improved, especially the perception of pupil care responsibility of the mentor and the communication skills with pupils in individual pupil care (see Table A.1). Assessment of the internal organization of individual pupil care improved significantly as well. This was contrary to the assessment of the internal organization of whole-school health promotion which changed in the opposite direction.

Comparisons of scale means for $\mathrm{T}^{0}$ (2002) and $\mathrm{T}^{1}$ (2005) per school-type indicated significant differences for schools providing regular education for the mentor-centered scale $(t=-3.70, p<0.01)$, the assessment of the internal organization of individual pupil care $(\mathrm{t}=-3.25, \mathrm{p}<0.01)$ and the assessment of the internal organization of health promotion and prevention $(\mathrm{t}=6.25, \mathrm{p}<0.01)$. The mentor-pupil communication scale $(\mathrm{t}=-1.69, \mathrm{p}=0.09)$ 
tended towards significance. In the case of schools providing special education, significant differences could only be revealed for the observation of risk behavior scale $(t=2.46, p=0.02)$ and the assessment of the internal organization of individual pupil care $(t=-9.04, p<0.01)$. Three other scales revealed a tendency towards significance: the mentor-centered scale $(\mathrm{t}=1.73, \mathrm{p}=0.09)$; the mentor-pupil communication scale $(\mathrm{t}=-1.87, \mathrm{p}=0.07)$; and the pupil-care policy scale $(\mathrm{t}=1.76, \mathrm{p}=0.08)$.

Comparisons of scale means for $\mathrm{T}^{0}$ (2002) and $\mathrm{T}^{1}$ (2005) per school yielded a diverse picture. For example, results from one school indicated a significant decrease in the internal status of individual pupil care organization whereas five others from the sample group of nine revealed a significant increase in this construct. For all scales and constructs, the results of at least one school indicated a tendency to a significant difference between the 2002 data and the 2005 data.

Using one-way analysis of variance for the care scales and constructs, we tested the hypothesis that the means of these scales and constructs do not differ significantly between schools. For the 2002 data, this hypothesis was rejected for all scales and constructs. Based on the 2005 data, the hypothesis was not rejected for three scales: the mentor-pupil communication scale $\left(\mathrm{F}_{11,112}=1,47, \mathrm{p}=0.15\right)$; the specialized pupil-care scale $(\mathrm{F} 11,67=1,75, \mathrm{p}=0.08)$; and the health promotion responsibility scale $\left(\mathrm{F}_{11,172}=1,23, \mathrm{p}=0.26\right)$.

The average number of health promotion topics addressed by school staff increased significantly from an average of 4.37 topics in 2002 ( $S D=4.03$ ) to 7.36 topics in 2005 (SD = 3.44). In this comparison, the average was based on the topics that were included in both surveys. In 2005, the most popular topics were 'norms and values' (93\%), 'general social skills' (88\%), 'study skills' (86\%) and 'bullying' (85\%). 'General social skills' and 'bullying' were in the 2002 top-three as well, while the other two were not included in the 2002 survey. 'Prevention of depression' received the lowest percentage from staff members in both surveys.

Please note once again: due to the low response rates, these results are virtually meaningless. The reason for presenting them in this appendix is to illustrate what type of information the quick scan could yield, if response rates are higher. 
Table A.I Comparisons of 2002 and 2005 scale and construct means regarding organization and practice of whole-school.

\begin{tabular}{|c|c|c|c|c|c|}
\hline & $\begin{array}{c}\text { T0 }=2002 \\
\text { Mean (SD) } \\
N\end{array}$ & $\begin{array}{c}\mathrm{TI}=2005 \\
\text { Mean (SD) } \\
N\end{array}$ & $\mathrm{t}$ & \multicolumn{2}{|c|}{$\begin{array}{c}95 \% \text { confi- } \\
\text { dence interval } \\
\text { of difference } \\
\text { between } \\
\text { T0 and TI }\end{array}$} \\
\hline \multicolumn{6}{|l|}{ Teaching } \\
\hline $\begin{array}{l}\text { - Observation competence regarding } \\
\text { personal problems with students }\end{array}$ & $\begin{array}{c}3.76(.61) \\
302\end{array}$ & $\begin{array}{c}3.80(.57) \\
183\end{array}$ & -.73 & -.15 to & .07 \\
\hline $\begin{array}{l}\text { - Observation competence regarding risk } \\
\text { behavior by students }\end{array}$ & $\begin{array}{l}3.01(.80) \\
306\end{array}$ & $\begin{array}{l}2.98(.69) \\
156\end{array}$ & .41 & -.12 to & .18 \\
\hline $\begin{array}{l}\text { - Teacher's contribution to individual pupil } \\
\text { care }\end{array}$ & $\begin{array}{l}4.05(.58) \\
218\end{array}$ & $\begin{array}{c}4.03(.53) \\
183\end{array}$ & .35 & -.09 to & .13 \\
\hline $\begin{array}{l}\text { - Teacher's contribution to health promotion } \\
\text { and prevention }\end{array}$ & $\begin{array}{c}3.95(.65) \\
306\end{array}$ & $\begin{array}{c}3.95(.60) \\
185\end{array}$ & -.01 & -.12 to & .12 \\
\hline \multicolumn{6}{|l|}{ Mentorship } \\
\hline - Central role of the mentor in pupil care & $\begin{array}{c}3.48(.85) \\
185\end{array}$ & $\begin{array}{c}3.76(.79) \\
122\end{array}$ & $-2.90 * *$ & -.47 to - & -.09 \\
\hline - Care-communication skills with pupils & $\begin{array}{c}3.80(.83) \\
184\end{array}$ & $\begin{array}{c}4.04(.83) \\
124\end{array}$ & $-2.54 *$ & -.43 to - & -.06 \\
\hline - Care skills related to mentorship & $\begin{array}{l}3.91(.70) \\
191\end{array}$ & $\begin{array}{l}3.97(.77) \\
125\end{array}$ & -.72 & -.23 to & .10 \\
\hline \multicolumn{6}{|l|}{ Individual pupil care } \\
\hline - Care team & $\begin{array}{c}4.00(.83) \\
230\end{array}$ & $\begin{array}{l}4.11(.85) \\
156\end{array}$ & -1.40 & -.29 to & .05 \\
\hline - Specialized pupil care & $\begin{array}{l}3.64(.75) \\
210\end{array}$ & $\begin{array}{l}3.76(.74) \\
79\end{array}$ & -1.26 & -.32 to & .07 \\
\hline $\begin{array}{l}\text { - Teacher support regarding individual pupil } \\
\text { care }\end{array}$ & $\begin{array}{c}3.01(.92) \\
286\end{array}$ & $\begin{array}{c}3.17(.98) \\
188\end{array}$ & $-\mathrm{I} .74^{\mathrm{H}}$ & -.33 to & .02 \\
\hline - Policy regarding individual pupil care & $\begin{array}{c}3.55(.93) \\
236\end{array}$ & $\begin{array}{c}3.58(.87) \\
138\end{array}$ & -.36 & -.23 to & 16 \\
\hline Whole-school health promotion \& prevention & & & & & \\
\hline $\begin{array}{l}\text { - Health promotion responsibility of the } \\
\text { school }\end{array}$ & $\begin{array}{c}3.89(.87) \\
328\end{array}$ & $\begin{array}{l}3.85(.86) \\
\quad 184\end{array}$ & .47 & -.12 to & .19 \\
\hline - Health promotion practice & $\begin{array}{c}3.34(.66) \\
223\end{array}$ & $\begin{array}{c}3.30(.64) \\
126\end{array}$ & .53 & -.10 to & .18 \\
\hline
\end{tabular}


Overall organizational status

- Status of internal organization of individual pupil care

$2.88(.93)$

323

- Status of internal organization of health promotion and prevention

Perceived changes in previous three years'

- Internal organization of individual pupil care

- Internal organization of health promotion and prevention

- Attention for well-being of staff

- External support for health promotion and prevention
$3.28(.85)$

310

$-$

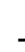

$-$

$\begin{array}{ccc}3.35(.85) & -5.7 I * * & -0.64 \text { to }-0.31 \\ I 89 & & \\ 2.8 I(.8 I) & 6.00 * * & 0.32 \text { to } 0.63 \\ I 73 & & \end{array}$

$\begin{array}{cccc}0.81(.74) & 13.74 * * & .69 \text { to } .93 \\ 158 & & & \\ 0.37(.72) & 5.97^{* *} & .25 \text { to } & .49 \\ 136 & & & \\ -0.14(.98 & -1.84^{\mathrm{H}} & -.29 \text { to } & .01 \\ 164 & & & \\ 0.28(.67) & 4.57^{* *} & .16 \text { to } & .41 \\ 116 & & & \end{array}$

$\mathrm{H}=p<0.10 ; *=p<0.05 ; * *=p<0.01$

1 For these items, $a$ one-sample $t$-test was applied, testing whether the mean would significantly differ from 0 as these items were measured on a 5 -point scale from "much worse" $(=-2)$ to "much better" $(=+2)$. 


\section{APPENDIX B}

THE SCHOOLBEAT CHECKLIST AS USED IN THE 2004 TRIAL (see chapter 7)

\section{Criterion Effectiviness (HP)}

Fill in: No $=0$ points ; Unknown or perhaps/possibly $=I$ point $;$ Yes $=2$ points

I.I Has the intervention achieved the desired results in the past?

I.2 Has the interventions achieved the desired process-changes in the past?

I.3 Is the evidence based on sound scientific research?

Fill in: total number of points for criterion I
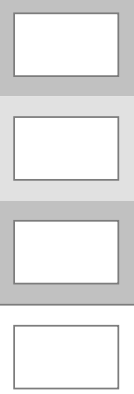

\section{Assessment criterion I: Effectiveness}

Circle the final score for this criterion that corresponds to the total point score

\begin{tabular}{|c|c|c|}
\hline Total & Assessment & Final score \\
\hline $5-6$ & Seems evidence based & 2 \\
\hline $3-4$ & Evidence is limited & 1 \\
\hline $0-2$ & No evidence / proven to be not effective & 0 \\
\hline
\end{tabular}

Fill in the final score for criterion I on page 185

Possible remarks pertaining to criterion I 


\section{Criterion Systematic approach (HP)}

Fill in: No $=0$ points ; Unknown or perhaps/possibly $=I$ point $;$ Yes $=2$ points

2.I Are the goals theory-based?

2.2 Are the short-term goals clear and specific?

2.3 Is the target group clearly identified?

2.4 Are the goals based on a problem-analysis?

2.5 Is the target group - choice based on a thorough analysis of the problem?

2.6 Are the intervention strategies suited to the goals?

2.7 Are the intervention strategies suited to the target group?

2.8 Is the intervention content suited to the goals?

2.9 Is the intervention content suited to the target group?

2.10 Does the intervention include evidence-based behavioral change principles?

2.II Does the intervention allow for the teaching or improvement of skills?

2.12 Was the target group involved in the planning/development of the intervention?

2.13 Are the minimal requirements for program integrity specified in an implementation plan?

2.14 Were representatives of the professionals who are supposed to carry out the intervention, involved with the development and planning of the intervention?

Fill in: total number of points for criterion 2 
Assessment criterion 2: Systematic approach

Circle the final score for criterion 2 that corresponds to the total point score

\begin{tabular}{|c|l|c|}
\hline Total & Assessment & Final score \\
\hline $17-24$ & \multirow{2}{*}{ Seems to be good } & 2 \\
\hline $9-16$ & \multirow{2}{*}{\begin{tabular}{l} 
Seems to be limited / poor or limited information \\
\hline $0-8$
\end{tabular}} & $\begin{array}{l}\text { Doesn't seem to be good / unable to be assessed due } \\
\text { to lack of information }\end{array}$ \\
\hline
\end{tabular}

Fill in the final score for criterion 2 on page 185

Possible remarks pertaining to criterion 2 


\section{Criterion Efficiency for support organization (HP)}

Fill in: No $=0$ points ; Unknown or perhaps/possibly $=I$ point $;$ Yes $=2$ points

3.I Is the effort of personnel (in terms of training, preparations and support during implementation) from the organization reasonable for the type of intervention?

3.2 Are the costs (purchase of material, training personnel, etc.) for the organization reasonable for the type of intervention?

3.3 Is realization of the intervention reasonable within the maximum available time and financial possibilities?

Fill in: total number of points for criterion 3

\section{Assessment criterion 3: Efficiency for support organization}

Circle the final score for criterion 3 that corresponds to the total point score

\begin{tabular}{|c|c|c|}
\hline Total & Assessment & Final score \\
\hline $6-8$ & Seems to be efficient for support organization & 2 \\
\hline $3-5$ & $\begin{array}{l}\text { Seems to have limited efficiency / poor or limited } \\
\text { information }\end{array}$ & 1 \\
\hline $0-2$ & $\begin{array}{l}\text { Seems to be not efficient / unable to be assessed due } \\
\text { to lack of information }\end{array}$ & 0 \\
\hline
\end{tabular}

Fill in the final score for criterion 3 on page 185

Possible remarks pertaining to criterion 3 


\section{Criterion Efficiency for school (EDU)}

Fill in: No $=0$ points ; Unknown or perhaps/possibly $=I$ point $;$ Yes $=2$ points

4.I Is the effort of personnel (in terms of preparation and implementation) for the school/teacher reasonable for the type of intervention?

4.2 Are the costs (purchase of material, training, etc.) for the school/docent reasonable for the type of intervention?

4.3 Is the intervention suitable to be implemented in more years or more levels within schools?

Fill in: total number of points for criterion 4

\section{Assessment criterion 4: Efficiency for school}

Circle the final score for criterion 4 that corresponds to the total point score

\begin{tabular}{|c|l|c|}
\hline \multicolumn{1}{|c|}{ Total } & Assessment & Final score \\
\hline $6-8$ & Seems to be efficient for school & 2 \\
\hline $3-5$ & $\begin{array}{l}\text { Seems to have limited efficiency / poor or limited } \\
\text { information }\end{array}$ & 1 \\
\hline $0-2$ & $\begin{array}{l}\text { Seems to be not efficient / unable to be assessed due } \\
\text { to lack of information }\end{array}$ & 0 \\
\hline
\end{tabular}

Fill in the final score for criterion 4 on page 185

Possible remarks pertaining to criterion 4 


\section{Criterion Suitability to education (EDU)}

Fill in: No $=0$ points ; Unknown or perhaps/possibly $=I$ point $;$ Yes $=2$ points

5.I Does the intervention make a contribution to one or more education goals?

5.2 Does the intervention improve the atmosphere in the class or the school?

5.3 Does the intervention fit in with the regular teaching methods?

5.4 Does the intervention offers opportunities for a personal touch by teachers?

5.5 Is the assessment of teachers with this intervention positive?

5.6 Is the assessment of students who have worked with the intervention positive?

5.7 Is the lay-out attractive and suitable for pupils?

5.8 Does the intervention fit in with desires of teachers?

5.9 Does the intervention fit in with the world pupils live in?

5.10 Does the intervention facilitates differentiation within a class / group?

5.II Does the intervention incorporate more than one theme or subjects?
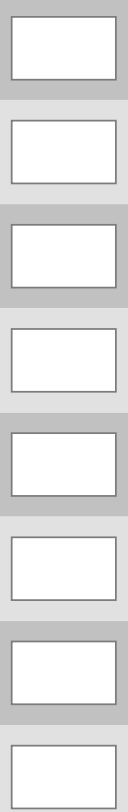

5.12 Does the intervention fit in with the school rules

Fill in: total number of points for criterion 5 
Assessment criterion 5: Suitability for education

Circle the final score for criterion 5 that corresponds to the total point score

\begin{tabular}{|c|l|c|}
\hline Total & Assessment & Final score \\
\hline $15-22$ & Seems suitable & 2 \\
\hline $7-14$ & \multirow{2}{|c|}{\begin{tabular}{l} 
Seems to be limited / poor or limited information \\
\hline $0-6$
\end{tabular}} & $\begin{array}{l}\text { Seems to be inadequate / unable to be assessed due } \\
\text { to lack of information }\end{array}$ \\
\hline
\end{tabular}

Fill in the final score for criterion 5 on page 185

Possible remarks pertaining to criterion 5 


\section{Criterion Participation (HP + EDU)}

Fill in: No $=0$ points ; Unknown or perhaps/possibly $=I$ point $;$ Yes $=2$ points

6.I Is the active participation of the target group (generally students) during the implementation of the intervention actively encouraged?

6.2 Will parents or other persons, groups or organizations from the surrounding community be actively involved in the intervention?

6.3 Will parents or other persons, groups or organizations from the surrounding community be passively involved in the intervention?

Fill in: total number of points for criterion 6

\section{Assessment criterion 6: Participation}

Circle the final score for criterion 6 that corresponds to the total point score

\begin{tabular}{|c|l|c|}
\hline \multicolumn{1}{|c|}{ Total } & Assessment & Final score \\
\hline $5-6$ & \multirow{2}{|c|}{ Seems adequate } & 2 \\
\hline $3-4$ & \multirow{2}{|c|}{\begin{tabular}{l} 
Seems to be limited / poor or limited information \\
\hline $0-2$
\end{tabular}} & $\begin{array}{l}\text { Seems to be inadequate / unable to be assessed due } \\
\text { to lack of information }\end{array}$ \\
\hline
\end{tabular}

Fill in the final score for criterion 6 on page 185

Possible remarks pertaining to criterion 6 


\section{Criterion Consideration of the surroundings (HP + EDU)}

Fill in: No $=0$ points ; Unknown or perhaps/possibly $=I$ point $;$ Yes $=2$ points

7.I Does the intervention pay attention to a safe and supporting social environment with regard to the theme?

7.2 Does the intervention pay attention to safe and supporting physical surroundings with regard to the theme?

Fill in: total number of points for criterion 7

\section{Assessment criterion 7: Relevance to surrounding area}

Circle the final score for criterion 7 that corresponds to the total point score

\begin{tabular}{|c|c|c|}
\hline Total & Assessment & Final score \\
\hline $5-6$ & Seems to be relevant & 2 \\
\hline $3-4$ & Seems to be limited / poor or limited information & I \\
\hline $0-2$ & $\begin{array}{l}\text { Seems to be inadequate / unable to be assessed due } \\
\text { to lack of information }\end{array}$ & 0 \\
\hline
\end{tabular}

Fill in the final score for criterion 7 on page 185

Possible remarks pertaining to criterion 7 


\section{Criterion Quality of support (HP + EDU)}

Fill in: No $=0$ points ; Unknown or perhaps/possibly $=I$ point $;$ Yes $=2$ points

8.I Is the required amount of instruction or training to prepare those people who will carry out the intervention adequate?

8.2 Is the implementation supported by a trustworthy organization?

Fill in: total number of points for criterion 8

\section{Assessment criterion 8: Quality of support}

Circle the final score for criterion 8 that corresponds to the total point score

\begin{tabular}{|c|c|c|}
\hline Total & Assessment & Final score \\
\hline $5-6$ & Seems to be adequate & 2 \\
\hline $3-4$ & Seems to be limited / poor or limited information & 1 \\
\hline $0-2$ & $\begin{array}{l}\text { Seems to be inadequate / unable to be assessed due } \\
\text { to lack of information }\end{array}$ & 0 \\
\hline
\end{tabular}

Fill in the final score for criterion 8 on page 185

Possible remarks pertaining to criterion 8 


\section{Criterion Diversity (HP + EDU)}

Fill in: No $=0$ points ; Unknown or perhaps/possibly $=I$ point $;$ Yes $=2$ points

9.I Is the intervention suited to use in multicultural classes?

9.2 Does the intervention take the target group seriously? (it isn't patronising)

9.3 Does the intervention make a contribution to reducing socio-economic health differences? (for example by focusing on disadvantaged groups or on problems that are prevalent among these groups)

9.4 Does the intervention pay respect to diversity in norms and values?

Fill in: total number of points for criterion 9
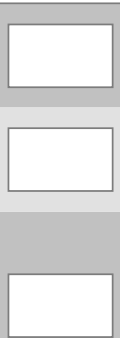

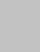




\section{Overall Quality of the program}

Write down your final-score for each criterion in the table below. This table provides an overview of your quality assessment.

$0=$ poor $;=$ moderate; 2 = good

I. Demonstrated effectiveness

2. Systematic approach

3. Efficiency for support organization

4. Efficiency for school
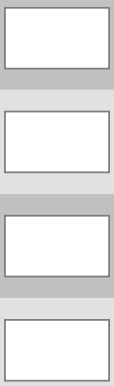

5. Suitability for education

6. Participation
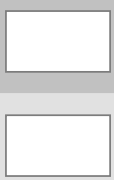

7. Relevance to the surroundings

8. Quality of support
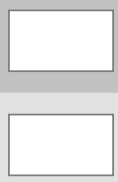

9. Diversity

Quality assessments results have been published in Dutch on www.gezondeschool.nI.

This schoolBeat-checklist 2.0 was developed by GGD Zuid-Limburg, NIGZ and Maastricht University and received financial support from ZonMw-Gezond Leven and Fonds OGZ. 